From Icon to Metaphor: Studies in the Semiotics of the Hieroglyphs

Goldwasser, Orly

Posted at the Zurich Open Repository and Archive, University of Zurich ZORA URL: https://doi.org/10.5167/uzh-157995

Monograph

Published Version

Originally published at:

Goldwasser, Orly (1995). From Icon to Metaphor: Studies in the Semiotics of the Hieroglyphs. Fribourg, Switzerland / Göttingen, Germany: University Press / Vandenhoeck Ruprecht. 
Orly Goldwasser From Icon to Metaphor 


\section{ORBIS BIBLICUS ET ORIENTALIS}

Published by Othmar Keel and Christoph Uehlinger on behalf of the Biblical Institute of the University of Fribourg Switzerland, the Egyptological Seminar of the University of Basel, the Institute for Ancient Near Eastern Archaeology and Languages of the University of Berne, and the Swiss Society for Ancient Near Eastern Studies

The Author:

Orly Goldwasser was born in Tel-Aviv, Israel. She studied Egyptology and Archaeology at Tel-Aviv University and Egyptology at the Hebrew University in Jerusalem. Her Ph. D. thesis was entitled "The Verbal System in Literary Letters of the 19th Dynasty" and was completed in 1987. She has published articles on Late-Egyptian grammar and on the study of registers of language in literary Late Egyptian. In addition, she has published hieratic ostraca and other Egyptian artifacts that were found in Israel. She is currently a lecturer in the Department of Egyptology at the Hebrew University, Jerusalem. 


\section{Orbis Biblicus et Orientalis $\quad 142$}

Orly Goldwasser

\section{From Icon \\ to Metaphor}

Studies in the Semiotics of the Hieroglyphs

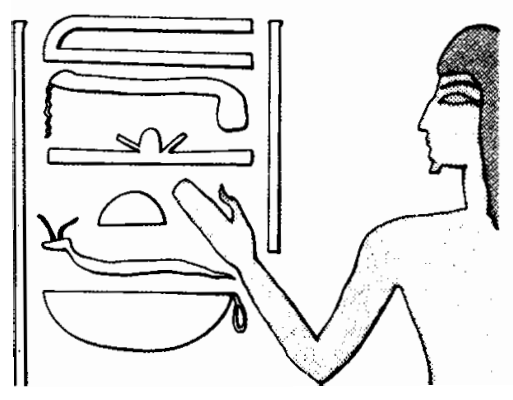

University Press Fribourg Switzerland Vandenhoedk \& Rupredht Göttingen 
Die Deutsche Bibliothek - CIP-Einheitsaufnahme

\section{Goldwasser, Orly:}

From Icon to Metaphor: studies in the semiotics of the hieroglyphs / Orly Goldwasser. Fribourg, Switzerland: Univ. Press; Göttingen: Vandenhoeck und Ruprecht, 1995

(Orbis biblicus et orientalis; 142 )

ISBN 3-7278-1015-7 (Univ.-Verl.)

ISBN 3-525-53777-8 (Vandenhoeck \& Ruprecht)

NE: GT

Publication subsidized by the Swiss Academy of Humanities and Social Sciences

Die Druckvorlagen wurden von der Verfasserin als reprofertige Dokumente zur Verfügung gestellt

C 1995 by University Press Fribourg Switzerland Vandenhoeck \& Ruprecht Göttingen

Paulusdruckerei Freiburg Schweiz

ISBN 3-7278-1015-7 (University Press)

ISBN 3-525-53777-8 (Vandenhoeck \& Ruprecht)

Digitalisat erstellt durch Florian Lippke, Departement

für Biblische Studien, Universität Freiburg Schweiz 
To Yoni 



\section{CONTENTS}

\section{ACKNOWLEDGMENTS}

Chapter 1 - THE TAMING OF METAPHOR - A STUDY ON SOME SCENES OF THE NARMER PALETTE

1.0 The First Question

1.1 The Initiatory Taming of Metaphor and the Birth of the Hieroglyphic Script

1.1.1 "The Theatre of the New Scene"

- The Narmer Palette

1.2 The Codification System

1.3 "Creatures of the Mind's Eyes" - The Metaphoric Level

1.4 The Emergence of the "Phonetic Metaphor"

1.5 The Hieroglyphic Script System - The Playing Fields of the Icons

1.6 The Hieroglyphic Script System as a Complex Metaphorical Construct

1.7 Cognition and Size - the Pawns of the Linguistic Play

1.8 Concluding Remarks

Chapter 2 - THE HIEROGLYPHIC "SIGN" IN THE LIGHT OF SOME TWENTIETH-CENTURY THEORIES OF SIGN

2.0 Introduction

2.1 Notes on the Theories of Sign

2.2 The "Signified Elect"

2.3 Jacques Derrida and the Hieroglyphs 
viii

2.4 "Entering the Writings" 38

2.4.1 A Few Examples $\quad 40$

2.5 Concluding Remarks 51

Chapter 3 - THE HIEROGLYPHIC WORD AS A COMPLEX METAPHORICAL CONSTRUCT

3.0 Introduction $\quad 54$

3.1 Metonymic versus Metaphorical Axis 55

3.2 A Description of the System - From Icon to Metaphor

3.2.1 The Iconic Reading 56

3.2.1.1. The Animation of Dead Metaphors

3.2.1.2 Visual Poetics - The Case of the Animalistic Metaphors

3.3 Metonymic Relationship 63

3.3.1 On the Pictorial Representation of the Root 63

3.3.2 The Tool Stands as Signifier for the Owner of the Tool

3.3.3 A Location is Part of a Signifier for Someone Associated with that Location

3.3.4 The Part of the Body Responsible for a Certain Sense Is Part of the Signifier of the Sense

3.3.5 A Coloured Entity Represents the Colour 69

3.4 The "Phonetic Metaphor" 71

3.4.1 New "Puncepts" of the Script? 75

3.4.2 The Case of Monoconsonantal Signs $\quad 77$ 
3.5 On the Border of the Illusionary 79

3.6 The Determinatives 80

3.6.1 A Few Introductory Words on

Categorization and Conceptual Domains $\quad 80$

3.6.1.1 Ad Hoc Categories 83

3.6.1.2 Domain 84

3.6.2 A Glimpse into the Landscape of the Egyptian Mind - The Status of the Determinatives

3.6.2.1 The Metaphoric Axis 85

3.6.2.2 The Metonymic Axis 90

3.6.2.3 Ad Hoc Categories 94

3.6.2.4 Rage, Sickness, and Dangerous Behaviour - The "Myth and Belief Principle"

3.7 A Few Concluding Words

Appendix A - $\quad$ ANOTHER FORM OF FOCUSSING

Appendix B - THE INTERACTION PROCESSES AND

IMAGE SCHEMA OF THE "TREE GODDESS" METAPHOR IN THE NEW KINGDOM

FIGURES

LIST OF FIGURES

LIST OF ABBREVIATIONS

BIBLIOGRAPHY

GENERAL INDEX 


\section{ACKNOWLEDGMENTS}

My first expression of gratitude must go to my English editor, Hilit Blum, who brilliantly tamed so many signifiers and thus enabled us to reach the searched-for signifieds. Her contribution to the spirit of the book is invaluable.

Special thanks go to Sarah Groll for her continued support throughout the years, and to Nathaniel Laor for introducing me to the idea that hieroglyphs find their origins in metaphor.

I am grateful to Antonio Loprieno for many valuable discussions, and to Irene Shirun-Grumach for her comments.

Chapter 2 of the book was the subject of my lecture in Crossroad III, held at Yale University in May 1994. I benefited greatly from my colleagues' remarks, for which I owe them my gratitude.

I would also like to thank Yeshayahu Shen, David Brezis, Adi Ofir and Gabi Motzkin for reading parts of chapters 2 and 3.

My thanks to Guy Hivroni who molded the hieroglyphs and figures on the computer with great patience and efficiency, and prepared the cameraready manuscript.

Anthony Berris invested a great deal of care and insight in the preparation of the index. Nicolay Tarkhanov and Pavel Shrago did the enhancement work on figures 4 and 14. Rodika Penchas drew the cover illustration.

Last but not least, I would like to thank Professor Othmar Keel most warmly for the hospitality of his OBO series.

The Hebrew University, Jerusalem

May 1995 


\section{INTRODUCTION}

This book presents the theory that the renowned allure of hieroglyphs lies beyond mere visual merits, and that its sources should be sought in the realms of metaphor, semiotics and cognitive studies. Primarily, I shall attempt to show that the appeal of the hieroglyphic sign emanates from, or indeed is, the very appeal of metaphor in its numerous incarnations.

It is my belief that hieroglyphs provide a historical test-case of unparalleled interest to the modern scholar of language and cognition. On the assumption that the same currents and tensions that underlie and shape every language exist also in Ancient Egyptian, one obvious important difference cracks open the private sphere of the language and exposes its conception and its growth generations after its actual expiry - namely, its pictorial quality. As the products and elements of picture-language, hieroglyphs are in fact the visible fossils of historical thought processes, without which they would have lain uncovered or unaccounted for and remained within the realm of mere hypothesis or inductive guesswork. In their litmus-like action, hieroglyphs detect and colour for our examination the secretive machinations and furtive roles played by various metaphorical transpositions in the cognitive processes underlying all linguistic discourse. In this respect this study belongs to the modern tradition which regards metaphor as a central cognitive tool, and not a mere embellishment or "seducer of reason."

Hieroglyphs are the crossroads par excellence of word and picture; ${ }^{1}$ words which do not describe pictures, but are made of pictures. The reader is carried relentlessly from literal meanings to various transposed meanings, and back to the literal. The final meaning of a word might be entangled with associations conjured up by the pictorial during the process, while echoes of ambiguities hover above. As in verbal metaphor, "graphic rhetoric" may conceive and create new beings and may represent something that does not have a "name."

The icon within the Egyptian script system describes a full circle. Starting from the initial status of "representative of object," it moves into the sphere of language as the representative of the signified. Then, through various metaphorical transpositions, it slowly distances itself from the object, until it reaches the final phase of the "phonetic metaphor," where the iconicity of the sign should be neutralized. Yet, in funerary contexts, the converted icons - the linguistic signs - may suddenly be mutilated. The voided icon,

1. For an introduction to the hieroglyphic script, see Davies 1987. 
in its status as "phonetic metaphor," may be again treated as the "thing itself." Thus, through the dark alley of magic, the object makes its return.

However, within the hieroglyphic system, some pictures may describe words. The determinatives are pictures which very often stand outside the phonetic information structure of the word. Their iconic meanings create a rich fabric of relations with the original word.

Modern descriptions of the metaphoric qualities of the hieroglyphs should be kept separate from Horapollian ${ }^{2}$ or Renaissance-like views of the script as well as from cryptography. Although "Horapollian" reasoning is not foreign to "hieroglyphic thinking" even before the Ptolomaic period, it is not the central metaphorical mechanism of the script.

I hope that this work will be the articulate expression of a feeling which has been with me for as long as I have loved hieroglyphs. What began as a wish to investigate and explain to myself anew the special magic of hieroglyphs using tools hitherto unknown to me, has grown into a rather daring attempt to provide the reader with what I consider to be a missing link in the history of semiotics.

2. See Iversen 1993; David 1965. 


\section{THE TAMING OF METAPHOR ${ }^{1}$-A STUDY ON SOME SCENES OF THE NARMER PALETTE}

\subsection{The First Question}

In his book The Birth of Civilization in the Near East, Henry Frankfort relates the history of the search for what he describes as "the moment in which the 'form' of civilization came into being" (1956:3). To me these words seem of crucial importance and to my mind they have not received sufficient attention during recent decades. I would therefore like to quote them here almost in their entirety:

A question which we have left unanswered is that of origins. The reader will find that in trimming the ramifications of historical beginnings we have exposed the trunks rather than the roots of Egyptian and Mesopotamian civilization. To what extent can their roots be known; what were the forces that brought them into being? ... for time and again such changes as an increase in food-production or technological advances (both, truly enough, coincidental with the rise of civilization) have been supposed to explain how civilization became possible. This misconception bars the road to a deeper understanding (Frankfort 1956:VI).

What was the "new intellectual order" that made possible the sudden emergence of the Egyptian civilization on the stage of history about five thousand years ago, already crowned with the invention of the hieroglyphic script? Studies in recent decades have offered us little by way of new reconstructions which do not fall into the fields of socio-anthropology, economics and the like, perhaps for fear of being accused of "pseudo-scientific quasi-philosophical speculations" (Frankfort 1956:VI). ${ }^{2}$

At the risk of meeting with such a fate, I would like to try in the following pages to uncover some of the "roots" of the Egyptian "form" of

1. An earlier, shorter version of this chapter appeared in LingAeg 2 (1992): 67-85.

2. Thirty years later, in his book The Origin of Writing, Roy Harris writes about the various descriptions of the supposedly evolutionary path taken by writing systems: "None of these evolutionary accounts can satisfactorily identify the transition from pre-writing to writing, because they do not squarely face the issue of what basic conceptual advance underlay the first attempts to produce written records" (Harris 1986:74). 
civilization, which present themselves at the beginning of the dynastic period as a new form of thought.

\subsection{The Initiatory Taming of Metaphor and the Birth of the Hieroglyphic Script}

\subsection{1 "The Theatre of the New Scene" ${ }^{* 3}$ - The Narmer Palette}

Doctrines must start from the point where the matters of which they treat first began to take shape.

Giambattista Vico, The New Science, 314

In her search for an explanation of the great "intellectual leap" of the early dynastic period, Emma Brunner-Traut, in her highly influential "Aspective"- the Epilogue to Heinrich Schäfer's Principles of Egyptian $A r t,{ }^{4}$ states that ". . . in the construction of their state at the turning-point of prehistory and history. . . the Egyptians released themselves from their attachment to the 'object'." In her essay, however, she makes no attempt to reconstruct or specify this procedure, nor does she define the new status of the "object" or answer the question of whether this "release" was complete and to what degree. In this book I would like to offer, as a working hypothesis, a possible reconstruction of the cognitive processes and semiotic structuring efforts which may have been involved in the creation of the "new intellectual order." My data base in this chapter is the normative material of the period, the so-called "ceremonial slate palettes," centering on the famous "Narmer palette" (figs. 1-2). ${ }^{5}$

Historiography is created when people begin to write. The locus classicus of this event on the evolutionary path of Egyptian civilization is

3. This metaphor was coined by Davis, see below.

4. Brunner-Traut in Schäfer 1986:439; she also speaks of "a new intellectual order" in which "clear boundary lines and firmly established values are the characteristic signs of a new mental order," op. cit. 430-431. Recently see also Kemp 1989.

5. My interest in this chapter does not lie in the definition of "writing" versus "symbols" etc. (for a recent contribution to this subject, see Vernus 1993). I try to describe the cognitive faculties that made the invention of the hieroglyphic system possible. 
the monument today called the Narmer palette, dated around 3000 B.C. Of all the finds of the Early Dynastic period, the Narmer palette stands out as the most normative text; in the sense that its proportions, its subject matters, and the particular manner in which these subjects are realized became in time the hallmark of Egyptian decorum. Although other royal monuments are known (the Narmer mace-head, the Scorpion mace-head [fig.8], see Millet 1990), it is this particular monument which is almost invariably selected as a convenient reference mark, indicating the "turning point" from pre-state to state, from proto-history to history, from pre-canonical to canonical art (Gardiner 1961:403-404). ${ }^{6}$

The reason for this choice is by no means accidental. The palette, and especially its recto, partitioned into three sections, immediately catches the eye with its sense of order. ${ }^{7}$ In comparison with other monuments of the period (and even with its own verso), the organization of the scene is exceptionally spacious, showing no traces of horror vacui. ${ }^{8}$ The recto of the palette (fig.l) relates the victory of King Narmer over certain Asiatics, probably from the Delta area, and possibly also from the Sinai Peninsula or Canaan. ' In its central register, the king, followed by a sandal-bearer, smites an Asiatic foe; above the enemy's head, still in the same register, the scene is oddly repeated, the king now appearing as a falcon subduing human-headed papyri stems. Beneath the central register, below the king's legs, appear two dead enemies in "floating" position - the typical representation of the dead in the proto-dynastic period - with hieroglyphs probably indicating their origin. Hieroglyphic signs also appear above the sandal-bearer and the smitten enemy, most probably indicating names and titles. The monument is crowned with a top register bearing the name of the king - N'r mr (The Cleaving Catfish) - written in hieroglyphic pictograms, within a building, probably the royal palace (sereh), on both sides of which appear the emblems of the woman-cow goddess.

Many studies surround this quaint mixture of picture and word. Art historians have long perceived it to be the first example of what is called in Egyptology "the canon of proportions and subjects" - that strict set of

6. This is a commonly held view in Egyptology, as can be deduced from the following list of citations, which is by no means complete - GroenewegenFrankfort 1951: 20-23; Hayes 1953:31; Frankfort 1956; Davis 1989: 159-164; Kemp 1989:39,42; Baines 1989,1991; Fairservis 1991; Hornung 1992:150.

7. For the "sense of order," see Gombrich 1979:3 and passim.

8. Here compare the earlier proto-dynastic palettes in figs.3-5.

9. For the activities of Narmer (or his administration) in Canaan, see Oren 1989. 
rules to which the main body of dynastic art adheres. In the recent words of art historian Whitney Davis, "The Narmer palette is the very site of the appearance of the new image; it is the very theatre in which the new scene of representation is being staged" (Davis 1992:201). ${ }^{10}$ Scholars of religion, on the other hand, have emphasized the triumph of personified powers over those animalistic powers which dominated the pre-historical monuments such as the Two-dog palette or the Hunter's palette ${ }^{11}$ (figs. 3,4; Hornung 1982:100,107). ${ }^{12}$ Finally, as a major historical testament, the palette has usually been taken to mark the unification of Egypt and the subduing of the Asiatic threat. ${ }^{13}$ So far, however, to the best of my knowledge, it has never been treated as a purposeful linguistic construct.

Traditional mapping of the proto-dynastic cultural history has tended to chart a rather conveniently cleft landscape; first, it is said, come the predictable scenic descriptions of rulers relating their triumphs or major events in the life of the people, such as the counting of the herds, or bark processions (figs 5,6 ). This is followed by a somewhat murky emblematic phase, for all intents and purposes better considered a transitory one. And then come hieroglyphs.

Yet, in my opinion, the recto of the Narmer palette shows not so much a transitional stage of healthy adolescence as a permanent one of split adulthood. In other words, I view this side of the palette as a cluster of different linguistic components ${ }^{14}$ whose novel composition represents the birth of a semiotic system, in which a constant point of balance and tension is maintained through the triadic support of picture, emblem, and phonetic sign; a triple coexistence that will not cease to be until the very final phases

10. Davis calls the Narmer palette the "locus classicus of canonical Egyptian art" (1989:159). See also Schäfer 1974:10; Meyer 1974; Baines 1991.

11. See also Petrie 1953.

12. Assmann writes about the canon - "Die Regeln des Kanons verweisen auf die Ewigkeit der Erscheinungssituation. Sie sichern dem Bild die Merkmale des Heiligen und Vollkommenen, die die Vorbedingung unwandelbarer Fortdauer sind" 1990:7.

13. See Yadin 1955; Ward 1963; Oren 1989. For a different interpretation, see Millet 1990.

14. On the understanding of the Egyptian "image" and "scene" in general as a semiotic "text," see Tefnin 1984:59: "'scènes', unités syntagmatiques constituées au minimum d'une 'figure' et d'une 'action', analogues à la phrase des langues naturelles." 
of Egyptian civilization. ${ }^{15}$

In this sense, the Narmer palette offers no less than a whole new codification system, crystallizing the monumental intellectual effort of a rather long period. Here, for the first time (in the monuments known to us), the semiotic system is revealed as a poly-system whose existence perpetually demands the development and acceptance of multiple and simultaneous options for presentation and attention by the "thinker" who created it, as well as by the reader who attempts to decipher it. But it is not exclusively its inaugural nature (at least in historiographical evidence, if not in history) that makes this part of the palette unequaled and epoch-making. What truly singles it out as a rare testimonial in historiography is its capture, and subsequent immortalization, of a "freeze" image in a film we would otherwise, perhaps, never have seen. As a photographic moment of a language still in swaddling clothes, a document of mental processes, it may serve, not merely the Egyptologist, but those who inquire into language in general, as well as those who investigate the abilities of the human mind to conceive and comprehend it.

In the following part of the chapter, I shall therefore attempt to define this achievement from a cognitive point of view, and to show that once mastered by the early Egyptians, it immediately acquired the power to create new options for confronting complex realities, and may indeed have generated such realities itself.

\subsection{The Codification System}

"It is therefore with something like regret that one leaves behind the last illusionistic topographical curve . . . for one and a half millennia and with it practically the last appeal to spatial imagination. From now on a tyrannical and rigid groundline is the rule . . . within the span of a few generations the bold efforts to depict coherent scenes in space and local setting are sacrificed for the sake of a rendering in which depth is destroyed and unity restricted to a mere sequence of figures or of actions . . . The numinous strength of the bull-king trampling on his enemy, the human dignity of King Scorpion, ${ }^{16}$ standing in homely proximity between his fan-bearer and his reverent acolyte, have been superseded by a hieratic figure performing a symbolical act. . . This is not an act performed at a

15. See also Melzer 1980.

16. See our fig .8. 
certain place, witnessed from a certain angle. . But from the Narmer Palette coincidence and contiguity are barred and the king's more violent gesture has therefore the peculiar static quality of a symbol. King Narmer's is a timeless act" (H.A. Groenewegen-Frankfort, in her book Arrest and Movement, when discussing the Narmer palette [1951:19-21]). ${ }^{17}$

The introduction of Saussurean terms may, perhaps, be helpful here. Once we begin to regard the recto of the Narmer palette as one of the earliest records of a classification system of word vs. icon or signifier vs. signified, the abandonment by the "thinker"18 of the attempt to convey relatively realistic scenes in favor of a new form of representation makes a new kind of sense, what Itamar Even-Zohar would define as the active modeling of the world: "The 'real world', meaning in this context conditions which are inter-subjectively observable and experienceable, is replaced, so to speak, by possible worlds, i.e., prefabricated selections from the ready-made repertoire available to the culture" (1990:208; also Davis 1989:4). ${ }^{19}$ Now, if we accept picture-script like the Egyptian as having not one but two equally important signifiers for every signified - one phonetic and one pictorial, it follows that in the Narmer palette, the anonymous writer completes a linking process which at that time had already been crudely realized in a few preceding palettes. From the innumerable visual options that were hitherto open to him, he selected only one as a "mental image," 20 to be permanently fixed henceforward to a certain linguistic

17. Also many others, e.g., Davis 1989:159-163; Schäfer 1986:10; Millet 1990.

18. On the supposed existence of an "inventor" or "thinker," see Ray 1986; Kemp 1989; Kaplony 1966; and Harris 1986. This is, of course, an oversimplification of the process. On the existence of a proto-hieroglyphic tradition, see Arnett 1982; and recently Helck 1985; Baines 1988; Vercoutter 1991; Vernus 1993. In a recent article Kaiser suggests (after Dreyer) a much earlier tradition of writing (Kaiser 1990::288,n.15;Vernus 1993:86).

19. This point of view coheres with the notion of "scheme" as defined by Brown and Yule 1983: 247; both views relate to the "relativistic" stream. The term "form," as suggested by Frankfort, is more general, being the sum of schemata of a certain civilization; in his words -"a certain coherence among its various manifestations, a certain consistency in its orientation, a certain cultural 'style' which shapes its political and its judical institutions, its art as well as its literature, its religion as well as its morals" (Frankfort 1956:3).

20. This term is used here in its commonplace sense. The "mental image" is defined differently in different disciplines, sometimes also overlapping with "visual code" and "anticipatory schemata," see Niesser 1976:145-146. Here compare Lakoff's definition of mental images - "Imagine a basketball. Imagine 
concept; in other words, he has nailed a particular picture to a particular word. The concept "king" would from now on forever be identified with a rather sombre looking individual wearing a mini-skirt, an oblong hat and an artificial tail. A rival king, differently attired, will henceforward be excluded as a signified. A similar process establishes the iconic identity of the enemy par excellence. Thus the gestalts ${ }^{21}$ and schemata ${ }^{22}$ of decorum are established in order to serve the needs of the reigning ideology (see also Tefnin 1979). As Roland Barthes has sharply phrased it in his Rhetoric of the Image : ". . . in every society various techniques are developed intended to fix the floating chain of signifieds in such a way as to counter the terror of uncertain signs" (1977:39).

If, following the Saussurean tradition ${ }^{23}$ (Saussure 1966:65-70), the sign is made up of a concept (signified) and a "sound-image" (signifier), then in the Narmer palette a linkage is created between a sound image and a restricted concept. ${ }^{24}$ That is to say, a select concept, represented visually as a "mental image," is linked with a linguistic object, a signifier, a linkage that will henceforward remain fixed.

a trunk. Imagine the basketball inside the trunk. Our real eyes cannot see through the trunk to the basketball, but our mind's eye can" (Lakoff 1987:446-7). This ability to "see through" is one of the central features of Egyptian art, see Schäfer 1986.

21. "For the ideogram is an inclusive gestalt, not an analytic dissociation of senses and functions like phonetic writing" (McLuhan 1964:94).

22. Davis uses the term Urgestalt (1989:63). For gestalt in general see Gombrich 1979:4-5. We follow Johnson's definition of image schemata as existing "at a level of generality and abstraction that allows them to serve repeatedly as identifying patterns in an indefinitely large number of experiences, perceptions, and image formations for objects or events that are similarly structured in the relevant ways" (1987:28). Nevertheless, the term "schema" has many different definitions, from Kant to Neisser; see Johnson 1987:19ff, and a detailed discussion in Neisser 1976.

23. I have chosen to work at this stage with the original Saussurean terminology due to its distilled clarity so vital to this phase of the study, a clarity which contrasts with the Byzantine complexity of some of the other theories; as Umberto Eco says about what constitutes communication theory, "sign-function is nothing more than the correspondance between a signifier and a signified, or between a sign-vehicle and a meaning" (1979:52-53). On the "sign," see below chapter 2 .

24. For an extensive discussion of "concept" in the hieroglyphic script, see Mrsich 1978, 1979. 
Needless to say, this process was not detached from social and cultural realities. ${ }^{25}$ During the turbulent formation period of the Egyptian state, when political and religious parties were vigorously striving for dominance, the signified may have still been floating, the identity of "Egyptian," "king" and "enemy," to give but few examples, still uncertain. Images appearing in texts earlier than the Narmer palette, cannot now be positively identified, as not one but a number of signifiers (now extraneous to the canon) were used to denote them. ${ }^{26}$ During this "signmaking" process, the whole semiotic system consolidated to create a long-lasting unification between the signifier and a preferred signified. These new restricted visual concepts, in their turn, reflected back on the concepts themselves and transformed them into the national trust of images.

The principal scene in the Narmer palette is iconic; from this point onwards, the system veers strongly towards the definition of the linguistic signifier, e. g., what might be defined as "the quest for the word, 27 rather than the presentation of scenic descriptions with "realistic" landmarks. ${ }^{28}$ This, in my opinion, is also the origin of the phenomenon which Davis terms the "sameness" of Egyptian art, whereby "one work is more or less like another" (I agree with him, of course, that "invariance is not just an inevitable but an intentional ${ }^{29}$ property of Egyptian art" 1989:4). For once a signifier is established it remains the same, although signified and sign change ad infinitum. As Jacques Derrida puts it, "A signifier is from the very beginning the possibility of its own repetition, of its own image or

25. See Kemp 1989, and recent contributions from the point of view of social anthropology, Endrödi 1991, Baines 1988.

26. E.g., who is the man fighting the lions on the Gebel el- 'arak knife-handle (Gardiner 1961, p1.XX)? What is the meaning of the scene in Hierakonpolis Tomb 100 (Fig. 6)? This sort of question can be asked about almost every monument antecedent to the Narmer palette and the "King Scorpion" mace-head (Millet 1990). For a recent discussion see Williams and Logan 1987.

27. Assmann regards the "pictorial" representations as referring to the world and not to the word "Die kleinen Bildzeichen beziehen sich also auf Sprache (Namen), die grossen auf Welt (Handlungen)" (Assmann 1991:80). See below chapter 3.

28. Kent Weeks describes this phenomenon as the creation of "categories": "Egyptian reliefs thus contain what the Egyptian artist and his culture considered the most readily perceptible and most essentially complete representations of the categories of objects and events" (1979:69 and passim).

29. My italics. 
resemblance. It is the condition of its ideality, what identifies it as signifier, and makes its function as such, relating it to a signified, which, for the same reasons, could never be a 'unique and singular reality.' From the moment that the sign appears, that is to say from the very beginning, there is no chance of encountering anywhere the purity of the 'reality, 'unicity,' 'singularity'" (Derrida 1974:91). ${ }^{30}$

The verbal act "the king subdues the enemy" created in the palette, thus withdrawn from its contextual time and place, settles in the "nowhereness" of the repetitive, condensed verbal act ${ }^{31}$ which GroenewegenFrankfort rightly identifies, but wrongly condemns, as "a timeless act."

My hypothesis will offer a paradigmatic explanation for this "mixed" state of affairs, expressed in such conclusive statements as "C'est pourquoi on peut affirmer que l'art égyptien est tout entier 'hiéroglyphique';. . . il faut ajouter que les hiéroglyphes eux-mêmes font partie de l'art égyptien" (Fischer 1986:25).

\section{3 "Creatures of the Mind's Eyes" - The Metaphoric Level}

Above the subdued enemy, a falcon with a human hand holds a human-headed land-strip with papyri growing from it. This is a composition

30. "Un signifiat est d'entrée de jeu la possibilité de sa propre répétition, de sa propre image ou ressemblance. C'est la condition de son idéalité, ce qui le fait reconnaître comme signifiat et le fait fonctionner comme tel, le rapportant à un signifié qui, pour les mêmes raisons, ne saurait jamais être une 'realité unique et singulière'. Dès que le signe apparaît, c'est-à-dire depuis toujours, il n'y a aucune chance de rencontrer quelque part la pureté de la 'réalité', de l' 'unicité', de la 'singularité'."

31. "To repeat something undoubtedly means: to be able to represent it. The possibility of producing a sign or an utterance repeatedly as this unity idealizes it, i.e., bestows upon it the unity of its signifying" (Frank 1989:415).

32. The fact that the Egyptians always regarded large-scale iconic representations as an inseparable part of the representation of language is demonstrated in numerous and varied examples where a large-scale representation plays the role of determinative. Excellent examples are provided by Fischer 1986; 1977:4. Vernus (1986:65) exemplifies the "iconization" of the hieroglyphic signs in the midst of the hieroglyphic word. The most common examples are in two-dimensional stelae where the pictorial large-scale iconic representation of the deceased acts as a determinative of his name, or where a seated statue acts as a determinative of its owner's name. 
which could be said to "portray an impossible representation of objects in the known world" (Zeidel and Kasher 1989:619), and accordingly could be described as surrealistic. And, if surrealistic images are taken as the pictorial equivalents of metaphors since they are "anything but literal or commonplace descriptions of the real world" (Zeidel and Kasher 1989:618; Jakobson 1971), the Narmer picture is also metaphoric. The second level of signmaking, therefore, is the pictorial representation of a metaphor, the latter probably already existing on the verbal or conceptual level.

The complex metaphor presented in the case before us can actually be separated into two metaphors: the "Falcon-King"33 (1) subdues the "Papyri-Man"(2) ${ }^{34}$ The deep structure of the first metaphor is "the king is a Horus-falcon. ${ }^{135}$ It seems that the king is playing the part of the tenor to

33. Religious beliefs and cognitive processes are in no way mutually exclusive. When the king was taken through the religious or "historical" situations to be the god Horus, e.g., the "Sacred Falcon," the identity King-Falcon could be conceived cognitively through a metaphorical extension initiating the movement from the "fetish-incarnation" level (Frankfort 1948:167). Metaphor is used here as the conceptual tool through which the religious concept is materialized (Lévi-Strauss 1966). This new "child of the mind" is now located in the religious sphere as a "godly manifestation." The proof that this cognitive tool was available to the Egyptians lies in the many pictorial representations of non-religious metaphors, in script and iconography. See examples: Baines 1985:41-63, and chapter 3 below.

34. Probably representing a nisbe; see EG:62. This metaphor falls within the category of the "genitive link," see Brooke-Rose in Hawkes 1972:69.

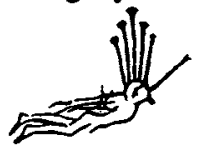

is a somewhat different variation of this metaphor, see Davis

1992:128 fig.36 (dynasty 2). For another possible variation see Baines 1985:245 fig. 144 (Compare here the variation in interaction [category IV] and in the hair-dress [category Ia] of the "'tree-goddess" in Appendix B below).

35. Unlike Gardiner who reads the palette as "The falcon-god Horus (i.e. the king) leads captive the inhabitants of the papyrus-land ( $T_{3}-m h w$ ' the Delta')" (EG:7), most scholars have understood the personified representation of Horus here as the god performing the act on behalf of the king (Schulman [19911992]80 n.7 and bibliography there, also Goedicke 1988; Othmar Keel also believes the falcon to be a falcon deity who offers the king his enemies [personal communication]). Nevertheless, personification is involved here, as the act of "subduing the enemy" is well within the scope of the bird's ability as it can easily (and maybe even more forcefully) be described by means of 
the falcon's vehicle; the human hand defines the nature of the act as human, although curiously enough it comes well within the scope of the particular bird's ability. This suggestive combination meets all definitions of metaphors from Samuel Johnson's "two ideas in one" ${ }^{36}$ to Lakoff and Johnson's "conceiving of one thing in terms of another" (1980:36). It is an incarnation in the pictorial of the "interaction" theories: "the co-presence of the vehicle and tenor results in a meaning (to be clearly distinguished from the tenor) which is not attainable without interaction" (Richards 1936:100; Black 1962). ${ }^{37}$ This meaning may not be represented on the surface level by a verbal equivalent, yet it still represents a complex state of relations on the conceptual level of the being, Horus-King, which materializes itself through the elaborate pictorial avenue.

Looking back on earlier material of the same genre, i.e., the earlier palettes, we soon observe the absence of such advanced metaphoric combinations. These exquisite pieces of art (Petrie 1953) are rich in symbols, but almost entirely innocent of pictorial metaphors. The pictorial metaphor makes its first appearance to date in the so-called "Libyan palette" and the

the claw. However, the identification of King-Horus seems to be rooted in the earliest records and was accepted as such by most scholars (see the article by Schenkel 1980:15-19). This identification was recently questioned by Hans Goedicke 1988, and followed since then by Erika Endesfelder 1994 (I thank Prof. Irene Shirun-Grumach for this reference). This subject cannot be elaborated here, yet I would like to suggest that the kings did not stand in danger of schizophrenia (as feared by Goedicke [p.127]) if they carry more then one metaphoric allusion. In later times kings were metaphorized as Horus falcons (Gardiner 1915:65), strong bulls, and lions all at the same time. However, King Narmer is named after the catfish. Helck (1985) regards the "catfish" as a pure rebus since he believes that a Nagada king would not name himself after a fish as they hated fish. Would the king then allow himself to appear in the pictorial (even if in a rebus) as a catfish? Could the association be eliminated and the signified discarded completely? However, if not a simple rebus, the reason may lie in the endurance qualities of this fish; it has the ability to survive many hours outside the water. If this is indeed the case, Narmer is probably "The Aggressive Survivor."

36. Quoted in Richards 1936:93

37. Davidson's theory of the metaphor is challenged by this explanation of the Egyptian experience, which stands firmly in the way of the "pragmatic" theory. The unveiled "cognitive picture" represents new gestalts, and thus the assertion "metaphor is not meaning but use - in this it is like assertion, hinting, lying, promising" has to be questioned (Davidson 1978:41). 
"Battlefield palette" (figs.7,9), which, judging by their style, should be dated in proximity to the Narmer palette, though slightly earlier (Davis 1989:149-152). In the Libyan palette (fig.7) a falcon, a lion, a scorpion, and two falcon-standards are engaged in an attack on various walled cities. ${ }^{38}$ Each of the attacking icons is known to be a symbol or emblem connected with royalty and deities, and the appearance of the scorpion may allude to the actual king "Scorpion," known from his famous mace-head (fig.8) and from other monuments (Millet 1990). This king is usually placed shortly before King Narmer, in dynasty 0 (von Beckerath 1984:45). A similar procedure is carried further in the Battlefield palette, where personified standards lead two prisoners (fig.9). ${ }^{39}$

In his Fecundity Figures, John Baines chose to interpret the pictorial representation demonstrated in the "Libyan palette" (fig.7) as no more than that of symbols or emblems expanded into metaphors through the personification process. ${ }^{40}$ The picture on the upper right-hand corner, for instance, may thus be read as "the Falcon-King breaks the town wall." Admittedly, the would-be pictorial construct "Falcon-King" is dramatically weakened by the fact that only the vehicle (the falcon) of the deep structure "the king is a falcon" is represented ${ }^{41}$ (vehicle metaphor). It may even be argued that this slight crudity of representation places the palette back into the animalistic-emblematic realm of religion rather than in the more advanced stage of metaphor. I believe, however, that when examined in the retrospective light of the Narmer palette, the Libyan palette may be revealed as a budding form of more complex metaphorical thought, in that a metaphorical cognitive process is already being activated in it, if only by means of the relatively simple violation - "the falcon breaks the town wall," which can hardly be taken literally. Evidently, however, if the strength of metaphor lies in the violation of categorical rules of interaction by crossing categorical boundaries (Kittay 1987:19), this phenomenon is

38. For the identification of those enclosures and new architectural data of the period, see O'Connor 1989.

39. The "personified standards" motif seems to appear also on a fragmentary piece known as the Bull palette. This palette is likewise dated on stylistic grounds to the Narmer era; see Davis 1989:78, fig.4.1.

40. Baines 1985. For the personification metaphor in general, see Lakoff and Johnson 1980:33-35.

41. In this case it will be categorized as a "replacement" metaphor. See Brooke-Rose in Hawkes 1972:69. Baines sees it as "the most "primitive' form" of personification, 1985:42. 
only mildly visually performed in the Libyan palette case of the alleged "Falcon-King" where a new reality is not fully realized. Nor can the standards on the Battlefield palette be considered full-blooded metaphors due to the essentially metonymic combination underlying them - men carrying standards represented only by the standards (compare Turner 1987:21). ${ }^{42}$ My perception of the personification process in these cases is therefore not far from Baines'. Yet, in my view it is a beginning of what is to become the kernel of a whole thought system, rather than a mere "bridging form" (Baines 1989:474).

The process of personification, which has ripened in the Narmer palette, is a simple and accurate reflection of both parts of the Greek compound word metaphora (meta meaning 'over,' and pherein - 'to carry'). In it the literal meaning of pictorial icons is carried into a different meaning, the latter an elaborate product of interaction, combination and selection. During the activities giving birth to the particular metaphor "Falcon-King," the deep structure of the conceptual metaphor "Rulers Are Birds of Prey"43 (compare Turner 1987) has sired the interlacement of two separate domains: qualities such as speed, grace, sharp sight and predatory nature (and the like [Goedicke 1988:126]) have been borrowed from the falcon, whereas the human king has supplemented those sophisticated gestures feasible only for a human being. The fact that the Egyptians recognized and appreciated the abilities of the falcon can be deduced from the incarnation of the personificated $h w / s i 3$ in a falcon form ("The falcon shows the regal aspects of command and perception of king or god" [Baines 1985:65-6 with fig.65]). ${ }^{44}$ However, only the relevant characteristics of both sides

42. Indeed, the visual power of the personified standards also cannot be fully appreciated because of the fragmentary state of the palette. Yet their metonymic essence, or their positions as symbols, e.g., "dead metaphors" that have undergone a personification process, seems to dramatically weaken their metaphorical effect; no genuine interaction process is taking place, no veritable "new being" is created. The human proportions are retained; the "conceptual dimension" is not activated. Theoretically the standards might also be understood as the budding form of the modern conceptual metaphor "A District is a Person" on the same grounds as "A Nation is a Person" (see Turner 1987:19).

43. On myth as a set of conceptual metaphors, created within the cognitive system, to enable man to tackle his surroundings, see Lévi-Strauss 1966. Is John Baines pointing in this direction, when he says that "metaphor and metonymy stand at the beginning of the formation of deities" (1985:23)?

44. Is Baines close to our point of view when he writes "They [the bird forms] 
have been taken into account; the fact that the falcon has feathers has been neglected, as have his nesting habits and some other features. ${ }^{45}$ The human king, on his part, has been pictured through that part of him most relevant for the required semantic value of the metaphor - his hand - while other parts and abilities remain latent in the background. The new pictorial entity of the Narmer palette depicts a falcon with a human hand. Yet, it is not a falcon with a human hand, but the Aristotelian "something fresh" (Rhetoric III,1410b [Hawkes 1972:10]). ${ }^{46}$ The falcon is no longer a literal falcon, nor is the king a literal king. The final meaning is the result of a "transposition" ${ }^{47}$ process, blending both into a creature beyond them.

Two overall moves were needed, on the whole, for the emergence of the metaphorical pictorial phrase. First came the fixing of the iconic picture to the signifier, i.e., the word, releasing the Egyptian "thinker" from

should be understood as hypostases, not figures of their own right. The texts give them no explicit names, and their explanations are heavily allegorical" (1985:65). Is there a possibility to regard this case as an ad hoc "birdification" process?

45. See "highest level of attribute" in Turner 1991:168; "feature-cancellation" in Tsur 1992:209-213 and also Shen 1991. The question whether the highest level attributes of the Ancients were the same as ours still remains to be studied. In the modern metaphor "He is an eagle," the characteristics taken from the eagle are his graceful flight, sharp sight (each of these qualities in isolation should also be understood metaphorically), possibly his alleged status as a "kingly bird," etc. The conventional processing of the metaphor will put aside the feathers, the beak, the legs equipped with long curved talons, and the fact that the eagle sleeps all night. The predatory, raptorial skill of the bird might be conjured up in certain contexts (the Nazi eagle?).

46. Kittay wonders in her recent book whether "the Homeric phrase the rosy fingered dawn' is metaphorical ... for the ancient Greek who believed the dawn to be a goddess, human-like in form, do we say that the expression was figurative or literal?" (1987:19). If we accept this point of view, we should assume that in our case the thinker actually believed that a certain falcon, or several possible falcons, may literally be the king. This view might indeed find support in the Late Period beliefs in Egypt; but did the very sophisticated writer of the Sinuhe Tale actually believe that King Senwosret I of the 12th dynasty literally turned into a falcon, when he writes: bik ' $h . f h n^{\prime}$ 'smsw.f " The falcon, he flew with his followers" (Blackman 1972, R21). Have the followers turned into birds as well?

47. Compare Polotsky's syntactical "transpositions" (1976). For the suggested process of "transformation" in the creative process and in metaphor, see Miall 1987. 
the bond of realism into an imaginative space. Then freed from realism, in the sphere of thought and language, metaphor released (even if ad hoc) the bond of signifier and signified, thus creating a new sign. Once metaphoric energy had been infused into the system, it became the very element generating and sustaining the triangularity of the whole semiotic structure.

\subsection{The Emergence of the "Phonetic Metaphor"}

Once the "object" had been freed, the road lay open to the search for possible representations of the abstract units of speech. Motley and multitudinous as these possibilities proved to be, the search inevitably extended beyond the frontiers of language. "Falcon-King" became a new abstract reality obtained by the combination of two concrete representations - the falcon and the human hand. Henceforth, every word could be delineated either by a single, concrete icon, or by combinations of two or even more "transposed icons," i. e., metaphors. The icon, in its turn, might represent itself or something else; that is, it could be literal or metaphorical.

But Egyptian script did not halt at the level of meaning, as metaphoric choice and tension arose even from the very building blocks of verbal utterance, phonetic particles. Here, a new kind of metaphoric move, putting into play new tools only recently mastered, ${ }^{48}$ appears on the stage of language. Vexatiously to the modern reader, trained to take his alphabet for granted, this kind of metaphoric processing arises not from semantic relations, but from a phonetic resemblance of two icons. What is extracted from an icon (e.g., the $s 3$ duck) is not any of its semantic properties, but its phonetic property $(s ;)$ resembling that of another, ${ }^{49}$ yet a different (and usually more abstract) verbal icon ( $s$ - son). In Saussurean terms, if the icon is read phonetically, a duck-signifier is dislodged from its original setting in a signified and assigned to a different signified (son). The new, though always unwelded reality, is formally created in a son-duck combination, compounded of the semantic qualities of the son, and the

48. The fact that the "pun" or "rebus" belongs to metaphoric cognitive abilities was already realized by Vico, see Haskell 1987: 74.

49. The phonetic resemblance of the pintail duck and the word "son" is somewhat obscure (EG: 471). 
phonetic properties of the duck ${ }^{50}$ (For a detailed discussion on this process see below chapter 3 ).

Needless to say, such a hazardous and intricate situation would not have been possible unless the visible, written signifier within the hieroglyphic system had been motivated rather than arbitrary (Tefnin 1984). In any case, the bond between the phonetic signifier and a certain signified is as arbitrary in Egyptian as in any other language.

More clearly still, the new multifunctional cognitive space, orchestrating various "thought-sections" polyphonically, would require altogether different rules of processing from those operating in a strictly arbitrary system. From now on, the mind is being challenged to deal not merely with pictures to be processed into linguistic information, ${ }^{51}$ but also with some pictures which are semantically "false," whose semantic information is misleading and sometimes even intrusive. Here, sometimes, feelings of ambiguity and incongruence may disturb the mental match between the pictorial icon, voided of its semantic referent, and the new sign. $^{52}$

In a way, phonetic metaphor can be said to have been the medium through which the language of new abstraction has freed itself from the difficulties presented by those abstractions, utilizing phonetic metaphor for the representation of specifications such as proper names - the name of the king Narmer in his palace, the name of his sandal-bearer, and the name of his vanquished enemy.

The recto of the Narmer palette ultimately evolves in the tense field lying between two forceful semiotic systems, each pulling its own way. The one, making full use of the sensual power of the image, is the more or less concrete pictorial system, a representation rich in implications, connotations and cultural references. Opposite it, stands the relatively new effort to meticulously convey verbal messages, to describe "words" and

50. ". . . a sign is not a fixed semiotic entity but rather the meeting ground for independent elements (coming from two different systems of two different planes and meeting on the basis of a coding correlation)" (Eco 1976:49). In contrast to the first impression, it seems that the icon (in this case the "duck") does not disappear from the cognitive space, but becomes "dormant." For the creative power of the "phonetic metaphor" see below chapter 3.

51. On the "intrusion" of the image see Neisser 1976. For the different processes required for the processing of pictures versus letters, i.e., phonetic signs, see below chapter 2 .

52. See also Goldwasser and Laor 1991:45-48. 
phrases, probably stemming from the growing demands of economic or even legal systems for an unequivocal medium of communication, as well as from the pharaohs' desire for the "eternalization of the name."

\subsection{The Hieroglyphic Script System - The Playing Fields of the Icons}

Since it is the representation of a word, a certain icon in a certain position is fated to be fossilized as the representation of each word in the lexicon (Sethe 1935). ${ }^{54}$ For example, the common royal attribute "the strong bull" position (EG, E1), and the "strong hand" signifying metaphorically the notion "strong" (EG, D40). This way of writing will designate a theoretical "small bull" with the same "bull" but with a different sign for the adjective "small" instead of the "strong hand." As in the verbal act, the word "bull" remains unaltered, and the change in the semantic message is achieved by the attribution of the different adjectives.

As they are images, the icons nevertheless always retain the ability to return to their raw iconic phase. ${ }^{55}$ The above-mentioned combination $k 3$ nht -"strong bull" - might also be written pictorially as an attacking bull, with the strong hand
redundant, yet strengthened message. ${ }^{57}$

53. For a summary of this subject, see Schenkel 1983. For a possible parallel with the beginning of the Chinese script, see Cooper 1987.

54. Also Bloomfield, see Harris 1986:74.

Manfred Frank, describing the "minimal accord" between Derrida, Searle and Husserl, writes: "[The] point of consensus is that the iterability, and thus the idealizability of its elements, is a necessary prerequisite for every symbolic order" (Frank 1989:417).

55. See Vernus 1993:97-101.

56. For other examples, see Vernus 1986.

57. Here belongs the enchanting example brought forward by Vernus of $f$ sn.i "my brother." He writes in connection to this example:"Cette utilisation 
In an account of Winifred Blackman, sister of the famous Egyptologist A. M. Blackman, we find an even more striking example of the vitality of icons. "Many years ago, my brother. . . recorded a custom of hanging skins of foxes over the doors of houses in Lower Nubia. On inquiry he found that they were believed to be charms 'to protect the women of the household, preventing miscarriages, and helping them in labor'. In some parts of Egypt if a mother wants another child she will attach a small piece of fox's skin to the head of her last-born living child" $(1968: 107){ }^{58}$ In this case some language detective work may meet with curious results indeed.

In Egyptian, the word $m s$, "to give birth," may be written with the simple enough pictogram of a woman giving birth to a child however, also be written with a "phonetic metaphor" $\#=m s$, (fig. 10) identified by Egyptologists, after a rather tiresome search, as an object (chasse=mouche?) made of the skins of three small fennec foxes, ${ }^{59}$ tied

together. ${ }^{60}$ At times, the word is written with both signs, $\frac{2}{\pi}$, the woman hieroglyph followed by the a sign representing the phonetic value of the pictogram, here the three fennec foxes, which may seem to be rather redundant, a common phenomenon (as we have already seen) in Egyptian script. In some examples, however, the woman is suddenly giving birth to the tied foxes (fig. 11), ${ }^{61}$ the "chasse=mouche" taking the place of the child, which probably conjures up a pictorial metaphor of "a blessed childbirth."

des potentialités iconiques des signes hiéroglyphiques peut transgresser la séparation entre registre d'écriture et registre de représentations" (1987:62).

58. I would like to thank Galit Dayan for this reference.

59. For the fox and its possible religious and erotic connotations, see Hornung and Staehelin 1976:113-114; Störk 1977:348; Janssen 1990.

60. Lacau 1954:45-46.

61. One may also wonder whether the version of the word hnms "friend" (FCD:193=pPrisse, 9,9), creates the meaning of "childhood friend," as the birth sign may retain its iconic as well as its phonetic signified. 
Plainly, the more motivated the sign, the more open it becomes to departure from convention. The motivated hieroglyphic sign will always inspire new signs, new combinations and consequently new meanings. The attraction of the pictorial and the variegated options for conveying reality and speech will maintain the Egyptian writing system as very much an "open work," and the reader as an active participant in the communication act. This may seem a very obvious statement since only such forms initially possessing meaning can change that meaning. However, bearing in mind that we are mostly the citizens of arbitrary language domains, it seems to me important to stress the metamorphic potential inherent in a non-arbitrary system (see Vernus 1986, 1987).

It seems that the Egyptians achieved a fascinating juggler's command of all processes activated by metaphor. As they shifted the icon from the concrete to the abstract, they were equally free to move the "creatures of the mind" back into a new concrete existence. ${ }^{62}$ An outstanding example of the concretization of metaphor is the "legged bowl" $\$ (EG, W24). This pictogram, standing for the verb "to bring" is the result of an early fusion between two hieroglyphs which may have occurred in the following way: phonetically the word "bring" was pronounced in; the "phonetic metaphor" process was activated in this case on an icon with a close phonetic value, the in (or $n w$ ) $O$ bowl. The next step was the attribution of another sign, in this case the "walking legs" usually representing actions that involve movement $\Lambda$. Presumably written separately at the beginning $\Lambda^{*},{ }^{63}$ these two icons were soon attracted to each other, as the alluring option of a "new being" presented itself on the threshold $\$. The attractive "coming bowl" possibly signified "something coming to you," probably "something good coming to you," suggested by the likely cultural connotation of the offering-bearers. The materialization of the pictogram (fig.12) enabled a person to signify concretely not only the material gift, but the abstract notion of "bringing." ${ }^{64}$ The Ptolemaic version $/ \mathrm{Wb} 1: 90$ ) reconstructs

62. ". . l'art en deux dimensions peut créer des objets dans l'art en trois dimensions. Les figures emblématiques animées d'hiéroglyphes en sont un exemple" (Baines 1991:11).

63. The "legged" signs already appear in the "combined" form in the material from the Archaic period, see Germon-Riley 1985:257. A $n w$ vessel is mentioned in LRL 18,2; see also Wb 2:213; see also Sethe 1935:13.

64. Given the new early date for the invention of the script (e.g., Kaiser 1990; 
the whole from the part, thus ending the existence of the enchanting surrealistic being.

Whether the initial attachment between the bowl and the verb "to bring" had an associative motivation behind it or not remains a matter of conjecture. In any case, none of these linguistic events should be assumed to have happened "by the book."

\subsection{The Hieroglyphic Script System as a Complex Metaphorical Construct}

The suggestion that hieroglyphs were spawned by the activation of different metaphorical processes should also be examined on the evidence of later material. The mature script zealously guards the properties I have mentioned. For example, let us take a rather incidental and very partial example from a $5^{\text {th }}$ Dynasty tomb of the nobleman Wernu (Davies et al. 1984, pl.28) which makes up part of his official curriculum:

The translation runs:

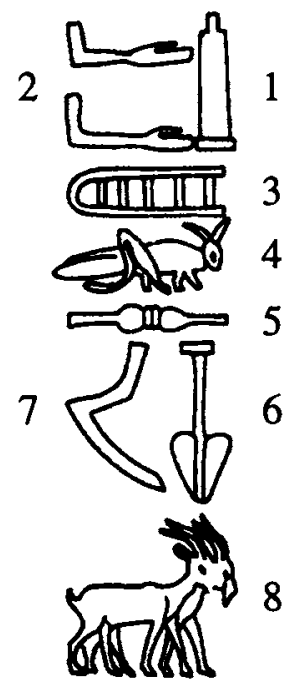

"Support of the arms of the one who captures (in the net) the locust (enemy), the uniter of the two noblemen."

Vernus 1993:86), it seems possible that a "puncept" might have gained a life of its own, moving outside the sphere of the script into reality. On the term "puncept," see below Chapter 3. For more on this hieroglyph, see Goldwasser and Laor 1991:42. 
No. 1, the iwn pillar, should be read iconically but understood through the prism of an added metaphorical movement, which presents some version of the metaphor "The Supporter Is a Pillar" ${ }^{\text {"65 }}$ (the English idiom "pillar of society" naturally comes to mind) probably reflecting on the conceptual metaphor "SOCIETY IS A BUILDING." The fact that the iwn pillar is shown iconically strongly reflects on the vehicle of the metaphor, probably slowing or even preventing the unavoidable "death" of the metaphor. ${ }^{66}$ iconically.

No. 2, 'wy - the two hands, should be read iconically and understood

No. 3, the net, is read iconically but could also become meaningful through a synecdochic process as the "net-man" (probably a nisbe).

No. 4, snhm - the locust, is the vehicle of the metaphor "The Enemy is a Locust" (Grapow 1924:98). The metaphorical nature of the locust now carries the metonymic "net-man" into a further metaphorical movement as the net becomes a figurative entity (on the locust metaphor, see below chapter 3 ).

No. 5, the $s$-"door bolt." The iconic signified should be completely discarded here due to the "phonetic metaphor" process. A metonymic process puts forward the phoneme $s$ alone.

No. 6, sm 3-"lung and windpipe" and "unite" (EG, F36). This is one of those numerous cases where it is hard for us to decide which metaphorical process came first; it may be that a search for some pictorial representation of the abstract concept "to unite" led to "lung and windpipe," two vital organs whose separation would cause immediate termination of life. The icon thus acquired the phonetic value of the abstract entity "to unite." On the other hand, it may be that an a priori phonetic resemblance between the name of the joint organs and that of the abstract concept led to the choice of the organs-icon as the representative of the abstract verb.

No. 7, $m_{3}$ - "Sickle" (EG, U1). Here again, as in the case of the $s$ "door bolt," the iconic meaning of the signifier should be discarded, giving way to the phonetic part of the word alone.

No. 8, s'hwy - "the two dignitaries" (EG, E31). This is clearly the representation of a metaphor. The goats carrying cylinder-seals were some

65. For this metaphor in the Egyptian literature, see Fischer 1963:40, n. 2 and bibliography there.

66. On the power of the concrete, see recently Paivio 1991. Advertising strategy often makes use of this phenomenon. On the conceptual metaphor in general see, Lakoff and Johnson 1980 and Appendix B, note 1 below. 
kind of "favorite goats." (In our inscription the goats bear no seals). ${ }^{67}$ Gardiner mentions in this context the Arabic word saraha, which means "to pasture freely." In this case, the iconic representation of the vehicle has a strong counter-effect, striving against the possible "death" of the metaphor.

Chapters 2 and 3 will be devoted to a systematic description of the metaphorical movements that are involved in the reading of every hieroglyphic inscription.

\subsection{Cognition and Size - the Pawns of the Linguistic Play}

On their way from the representation of the concrete to the representation of the ultimate abstract - the written word ${ }^{68}$ - the icons undergo several changes. Being "children of the mind," they represent the situation of the word and word-parts in discourse, thus assuming equal graphic proportions. As in the exquisite inscription of Wernu, the locust, the fish, the different birds and the goats are all placed in the same grid (fig. 13), a process made available to the culture by the activation of the concrete icons as pictorial metaphors. When accepted as metaphors, these mental images, let loose in a wonderland where a house is the same size as a snake, a child and a locust, they are primarily connected not by touch, movement or mutual recognition, but by the unseen strings of linguistic rules. $^{69}$

67. A common phenomenon; see many examples in the Coffin Texts.

68. The fact that the Egyptians determine the words that are close to our notion "abstract," by a papyrus-roll following the words as a determinative, suggests that the Egyptians might have already understood what semiotics has emphasized in the last century: that words, even the most concrete ones, are abstractizations, as they refer to a collective existence that does not exist in the real world (Eco 1976:66; Sinha 1988:35,n.2). Yet, another possible explanation might connect this choice to the hieratic script typical of the papyrus, which may be regarded as a kind of "abstractisation" of the hieroglyphic script. See discussion below, Chapter 3.

69. It seems that the pictorial input of the hieroglyphs is being assimilated to the verbal-linguistic information. Results of recent studies, like that of Allan Paivio (1991), strongly suggest that our pictorial knowledge of the world is represented mentally in terms of fine-grained analog structures that are distinct from linguistic representations, although interfaced with them. Usual systems of language and picture provide many crossovers of information from one side to another; hieroglyphs may allow more. 


\subsection{Concluding Remarks}

The Narmer palette is a poetic accomplishment. One theme "kingship and foes" - is represented twice in a cyclical combination in the central register. The same combination, which is contained by the central register, also envelops it. The king is mounted in his palace-sereh above (an upward heavenly direction) while the dead foes (a downward direction, realm of the dead) are trodden under his feet. ${ }^{70}$

The seeming redundancy of the repeated message creates a poignant communication act which encourages the initiate observer to pay more attention to the tools and vehicles serving the "message," than to the message itself. The newly invented tools of thought, which we have named icons, pictorial metaphors, and phonetic metaphors are clearly represented and exemplified. Metaphor reigns over reality: from the icons to phonetic metaphors via other forms of metaphor, the world is represented as a conceptual cosmos, and reality is subject to human cognitive faculties. The great "intellectual leap" has been masterfully accomplished.

Indeed, it is my belief that only once we pass the magic "wand of metaphor" over the hieroglyphs, do redundancy and surfeit reveal to us those qualities we most treasure in a text - richness, even opulence, and a multiplicity of options at every stratum of the linguistic system.

In the following parts of the book I shall seek the definition of this "opulence" and "multiplicity of options," and try to define the rules and constraints they obey.

70. For the application of literary-criticism methods to Egyptian wall-scenes, see Assmann 1989. 


\title{
2. THE HIEROGLYPHIC ${ }^{1}$ "SIGN" IN THE LIGHT OF SOME TWENTIETH-CENTURY THEORIES OF SIGN.
}

\begin{abstract}
Spoken words are the signs of the affections of the soul, and written words are the signs of spoken words. Just as all men have not the same writing, so all men have not the same speech sounds, but the affections of the soul which these signify are the same for all, as also are those things of which our experiences are images.
\end{abstract}

Aristotle, De Interpretatione ${ }^{2}$

Unlike the Greeks, the ancient Egyptians did not address themselves directly to the definition of the "sign," as we now know it. They were not concerned with any such questions. This absence of commentative material is, however, what may be called a speaking absence, for in light of the actual script in which reference to what we today call the "sign" is self-evident and abundant, it is the very lack of extraneous material which may indicate how deeply the concept of sign had been internalized and processed in Egyptian thinking. This would seem a piece of argumentative solipsism, were it not for another case of notorious documentary silence, that surrounding the pyramids of Giza. Without any plans or detailed studies of this aweinspiring project ever having been discovered in Egypt, pyramids stand as indisputable evidence of their builders' far-reaching knowledge of what we call today geometry, architecture and physics. The hieroglyphic sign system, a no meaner sum of different totals, relations or "kinds of differences," similarly proves, beyond any commentative theoretical text, its makers' admirable command of word, phone, object, "object of thought" and image - all of which find their place and role within the oneness of the hieroglyph. It is my object to show that the creation of the hieroglyphic sign in its present form would have been impossible without a profound awareness of the processes involved.

1. Conventional hieroglyphic examples from the inscriptions of the Old Kingdom to the end of the New Kingdom, except for cryptography, will be used. This chapter is based on a lecture in Crossroad III (Yale University), April 1994.

2. Sinha 1988:4. 
In this context, one may be reminded of the Greek perception of Egyptian anxiety about the translation of Egyptian texts into Greek, found in the XVIth Hermetic tractate:

Expressed in the original language, the tractate clearly preserves the sense of the words - for also the very character of the sound and the. ... of Egyptian words has in itself the power meaning (energeia) of what is said. In as far as it is possible for you king - and everything is - preserve this tractate untranslated, lest such mysteries get into the hands of the Greeks, and lest the presumptuous and rambling and, one might say, ostentatious idiom of the Greeks dispose of the holiness and the strength and the efficacious (energetikos) speech of the words. For the Greeks, $O$ king, have empty arguments fit for proofs, and that is what the philosophy of the Greeks is: a noise of arguments. We, however, use no arguments, but sounds full of efficacy ${ }^{3}$ (Podemann Sorrensen 1987:42).

\subsection{Notes on the Theories of Sign}

Written language, or written signs, stand for other things; that is, they signify. Most written languages today use arbitrary signs which stand for phonetic entities, which in their turn signify something given different names, in different disciplines - "concept," "signified" or "interpretant," and "object" or "significatum" (Lyons 1977:95-119). Most scholars of signification agree that the connection between the sign and the significatum is not direct, but that the word signifies [the thing] by means of mediating concepts (Lyons 1977:96). This triadic relationship is often represented by different versions of what is called "the triangle of signification": 5

3. My italics.

4. "The interpretant is not the interpreter. ... The interpretant is that which guarantees the validity of the sign, even in the absence of the interpreter" (Eco 1976:68).

5. "The semiotic study of content is often complicated by recourse to an over-simplified diagram which has rigidified the problem in an unfortunate way. The diagram in question is the well-known triangle, diffused in its most common form by Ogdan and Richards" (Eco 1976:59). 
B concept, (signified), interpretant

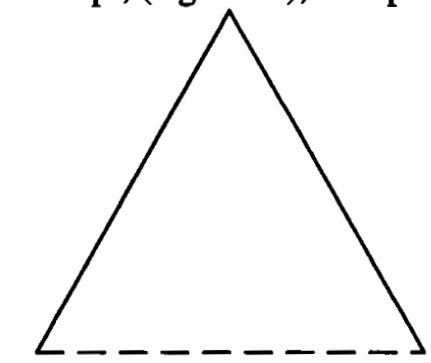

sign A C referent (significatum)

(The broken line represents the indirect relation of the sign and significatum.)

In his "Cours de linguistique général," Ferdinand de Saussure suggested a different presentation of the sign. He assumed that the sign is actually made up of what he called the "sound image" and a concept, or signifier (signifiant), and signified (signifié). He uses a different sort of graphic representation of the sign:
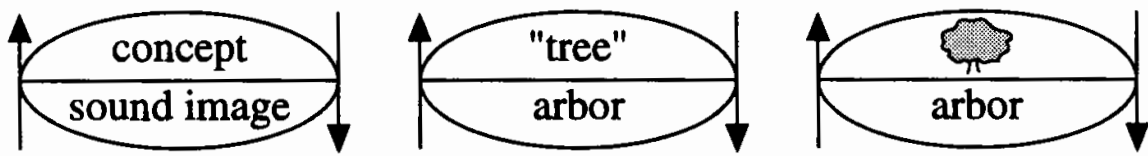

In Saussure's diagram, the whole represents the sign, made up of signifier and signified. It should be noted that the actual referent or object is absent from the Saussurean classification: "Objects are not considered within Saussure's linguistics . . from the point of view of the functioning of a code. . . the referent must be excluded as an intrusive and jeopardizing presence" (Eco 1976:60-61, cf. Lyons 1977:101). Another important point to be kept in mind is that for Saussure "a sign is not a fixed semiotic entity but rather the meeting ground for independent elements (coming from two different planes and meeting on the basis of coding correlation)"(Eco 1976:49). ${ }^{6}$

6. In his article "A Semiotic Approach to Semantics," Umberto Eco also suggests that meaning is created without the actual referent, through what he calls 
I have chosen to work basically within the Saussurean tradition,? but with the important addition of the "written signifier" that refers to the "phonetic signifier," which in alphabetic scripts is the one that refers to the signified. Thus, in English, the written sign cat refers to the phonetic kat which in its turn sends the reader to its signified. Nevertheless, approachable (in written language) only by way of the written signifier, the phonetic signifier in mid-way plays a double role of signifier/signified and may be regarded as a signifier of the signified or looked upon differently as the signified of the written signifier. This relationship becomes much more complicated in pictorial script as we shall see below.

Operating in a non-arbitrary system, the written signifiers of ancient Egyptian are images. The motivated image then becomes a "built-in" property of the script. This makes the much debated question of thought and image and their relations irrelevant; since we do not have to wonder whether or not pictures play a part in the way we understand language, pictures in this case are a given fact. We are therefore called upon to ask how the script represents the ideology of its inventors and what part the given pictures of the script play in the reader's mind, as well as to ponder the impact of the pictorial entities on the relation of signifier-signified.

The question here is actually a two-fold one. First, we have to ask ourselves how the pictorial script represents the a priori existing conceptual system of the inventors of the script; the second part of the question would be how the given pictorial system might reflect on the conceptual system of the reader or the literate.

I believe (as I have shown in detail in chapter 1), that the great intellectual progress of the Egyptians on the threshold of history became possible only when they were able to relocate their descriptive efforts from the one specific object, from the unique occurrence, to the word. ${ }^{8}$ Saussurean

"cultural units," which correspond to linguistic terms, leaving aside the actual referent. He claims that "the notion of referent, undoubtedly useful to physicists and logicians, is useless and damaging to semiotics" (1971:24 and passim).

7. For a discussion on the hieroglyph as "sign" in the Saussurean sense and on the terminology ideogram vs. logogram, see Depuydt 1994; also Mrsich 1979. For an extensive discussions on terminology, see Haas 1976 and Pulgram 1976.

8. In his Stein und Zeit Assmann expresses the opinion that the hieroglyphic system refers to the language and not to what he calls the "world" "'Weltreferenz' ist in diesem Schema nicht vorgesehen. Alle Funktionen, auch die Ideogramme und Determinative, beziehen sich auf die Sprache." His "world-reference" is put in what he calls "Materialität der Zeichen" which he 
tradition, too, locates the concrete object outside the word-sign. Thus, even though they make use of what might be hastily understood as objects, the Egyptians are really handling select prototypical repetitive objects, as has already been noted by Sethe - "In der ägyptischen Hieroglyphenschrift herrscht, wo wir sie kennen lernen, d.h. zu Beginn der geschichtlichen Zeit, schon ganz allgemein die festgeprägte Form des Begriffszeichens, die das Kennzeichen einer wirklichen Bildschrift im Unterschied zu der primitiven Bildverwendung der schriftlosen Völker bildet. Jedes einzelne Element der Rede wird durch ein isoliert dastehendes Bild ausgedrückt, das seine Form, seinen Tapus [sic! read:Typus], unter allen Umständen, ohne jede Rücksicht auf den Zusammenhang behält" (1935:12; also Schott 1951:74-75). ${ }^{9}$

Many hieroglyphic signs actually play the double role of a written signifier and a signified (see Vernus 1986; Depuydt 1994). But, while the Saussurean "signified" is the end of a repetitive action of individual choice from a code, the represented hieroglyphic sign is the image of a "select concept" actually forcing itself (consciously or unconsciously) on the individual. This pictograph becomes the only canonical representation of all the occurrences and manifestations of the word in visible language - a sum of things. ${ }^{10}$ This conceptual entity, to be sharply differentiated from referent, together with the signifier creates the Saussurean sign. In an $\mathrm{X}$-ray-like process of our cognitive activities, we encounter the "figure of thought" which can only be postulated on theoretical grounds in linguistics and philosophy. The hieroglyphic script unveils, on many occasions, what

leaves out of the semantic level of the word. It seems that the "Materialität" operates within the semantic system through the process of the "signified elect" and does not stand outside the system. Where exactly is this "outside"? In the context of the Narmer palette he states that "Die kleinen Bildzeichen beziehen sich also auf Sprache (Namen), die grossen auf Welt (Handlungen)." I believe, as I stated above in chapter 1, that the Narmer palette describes "words" on three levels of description, and not the "world." Later in his text Assmann claims that the big signs become a part of the word, when playing the role of the determinative, which means that they have moved on from their function of "world" delineation into the language ("Ein neues Stadium ist erreicht, wenn die 'grossen' Zeichen in das Repertoire der 'kleinen' integriert werden. Genau dies ist der Ursprung der Determinative. Das Determinativ ist ursprünglich nichts anderes als das auf Schriftformat verkleinerte 'Bild', das zu den ihm vorausgehenden Phonogrammen als der ursprünglichen Beischrift hinzutritt.") See Assmann 1991:77-80.

9. See above chapter 1 .

10. In a way, of course, a signifier of many signifieds. 
has become the deep-structure element of the bipartite sign - the signified.

\subsection{The "Signified Elect"}

The question that naturally arises here is how the choice of pictorial signifier was made, whether consciously or unconsciously. The question of how is, in this case, inseparable from the question of by whom, the answer traceable to the motivated fields of ideology ${ }^{11}$ as well as the pristine fields of cognitive studies.

In order to reconstruct the possible ideological policies involved in the institutional shaping of the beholder's conceptual space (e.g., Baines 1991:45 and passim) we must first be fully aware of the political interest which the dominant circles had in shaping the repertoire of signs: making the king a certain chosen king, the enemy a certain select enemy. The word 邹

$s$ "man" (EG, A1), translated by the Wörterbuch as "Mann," "männliche Person," "jemand" (Wb 3:404), probably represents an Egyptian seated male, thus presenting the "best example" or prototype (Lakoff 1987:41) of the category "man" for the Egyptian ${ }^{12}$ (or should the translation be restricted to "Egyptian human being" in this case, at least at the beginning?). It also stands as the prototypical representation of the whole category "human beings" when activated as a determinative to other members of the category. This situation may reflect back on the conceptual system of the reader, as a prototypical choice of the signified "human being" is forced by the system on the literate beholder. This indoctrination probably materializes itself later also in the literary sphere, as when the writer of the Admonitions says: (his)tyw hpr $m$ rmt $m$ st $n b$ - "Foreigners have become people everywhere."13 The word used, "people" $r m t \leftrightharpoons 4$, is represented by an Egyptian male and female (the male always comes first!). The signs $\perp$ never lost their full iconic value, as is well demonstrated in numerous variegated examples of the first person suffix of $s \underline{d m}$. $f$ forms that are written iconically in accordance with the gender and status of the writer (EG:39).

11. "Ideology involves a systematically organized presentation of reality." It also involves selection procedures, see Hodge and Kress 1979:15 and passim.

12. One should perhaps wonder why a seated position seems to be the prototypical choice in the case of the human being.

13. Gardiner 1909 pl.1, 1.9; Lichtheim 1973:161; Loprieno 1988:29. 
The word $t p$ "head " (EG, D1), with all its usual metaphorical transferences (e.g., chief, first), is always represented by the head of an Egyptian. Of all the standards of gods available from the early period, it was always the standard bearing the Horus falcon that was chosen to determine the notion "god."

Yet this is not the only selection process involved. There must have been another parallel intervening process, evolving from sources beyond institutional and political decisions.

The most important word ib $\nabla$ "heart" - described by Hellmut Brunner as "Im Leben wie im Jenseits ist das Herz für den Ägypter Zentrum des Menschen, für den Körper wie für den Geist" (1977:1159) - is represented by an animal heart (also EG, F34). So are other inner organs like the stomach, the lungs, and tongue (EG, F32,36,20). Most of the "exterior" parts of the body like the face, nose, eyes, legs, and phallus are written with the pictograph of the human part. ${ }^{14}$ Surprisingly enough (perhaps due to better hearing faculties or a predisposition to obedience?), the act of "hearing," $s d m$, is written with the help of an animal signifier $\mathscr{D}$ probably an ear of an ox, ${ }^{15}$ while the human ear 8 may stand as a pictograph usually only for the noun "ear" (EG, F21, D18). ${ }^{16}$ All the above pictographs obey the linguistic rules of words and are activated freely in reference to human as well as animal activities regardless of their pictorial value. ${ }^{17}$

A certain type of Nile riverboat (one out of many) was chosen as the pictograph for $d p t$ "a boat" (EG, P1). The word $s d r$ "spends the night" (EG, A55) had to be written with the pictograph of a man lying on a typical Egyptian bed, probably never available to many Egyptians as well as to other people: "He who did not sleep on a box owns a bed." ${ }^{18}$ In words like tsm

14. See Schott 1951: 74-75; also Westendorf 1975:261.

15. Known also to Horapollo, see Iversen 1993:48.

16. The word $m s d r$ " ear" can be written with the human signifier $\mathcal{P}$ or the animal signifier $\mathscr{O}$. Nevertheless, the human ear as a signifier is very limited in use. Almost all words concerned with ears and hearing make use of the animal signifier (EG, D18, F21). For further discussion on this subject, see below chapter 3 .

17. The word "eye" Verbs like "to see," as well as "to look" and "blind" always accept the determinative of the human eye, although many animals are much more sharp-sighted than man.

18. Gardiner 1909 rt. 7,10; Lichtheim 1975:156. 
the prototypical member of the class of hunting dogs in ancient Egypt - a kind of saluki greyhound. ${ }^{19}$

These choices and many others seem to emanate from conscious or unconscious choices of what is defined today in cognitive studies terminology as "prototypical members" of a category (for the elaboration of this topic see below chapter 3). The knowledge of what the Egyptians regarded as prototypical members of their categories in language and culture would have been lost forever, if not for the hieroglyphic system that conserved them and exposed them in the "laboratory of the script." It seems that categoric definitions and differentiations play a most important cognitive role within the script system, as well as in the maintaining of control by the leading groups over the conceptual system of the reader and, to a certain extent, also that of the non-literate beholder, as at least parts of the script were probably comprehensible even to the uninitiated. ${ }^{20}$ Names of kings, gods, and iconic signs were probably easily identified. This position is very different from that of any non-iconic script, in which the script presents itself as a completlely "sealed system" to the uninitiated. The aggregate of images available to the culture, which George Lakoff calls "conventional images," will probably be strongly influenced by the iconic script (1987:446-7). As part of the "official culture," the script on many occasions will mirror the social status, the canonical concepts and prototypical choices of the elite group responsible for the invention of script. Nevertheless, due to the "open" character of the script (it having no strict repertoire of spellings, and thus remaining a dynamic aggregate of signs), non-canonical pressures may sometimes surface within the system.

The hieroglyphic signs are therefore a ready-made collection of

19. "Although the determinative remained term, ( $t s m$, my remark) refers to a distinct breed, but rather means "hound," i.e., "hunting dog" (Fischer 1980:77). For a recent contribution on the dog, see Baines 1993. For pictorial representations of non-prototypical dogs (very short-legged), see Boessneck 1988,pls.91-93; also the cute little New Kingdom ivory dog holding a fish in its mouth in the British Museum collection (unpublished BM EA13596 ; I would like to thank Dr. Richard Parkinson for his help in this matter).

20. Due to its iconic nature it is very plausible that parts of the hieroglyphic inscriptions were understandable even to the illiterate. In the name $M n h p r R^{\prime}$ for example, the hieroglyphs $h p r$ and $R^{\prime}$ can be read iconically. Names of kings and repetitive formulae are easily recognized even today by many tourists after a few days in Egypt. See also Schott 1951:63. 
"signifieds-elect" forged to control many mental representations of the reader and partially also of the illiterate beholder - able to infiltrate the most intimate mental processes which are almost inaccessible in other cultures and scripts. ${ }^{21}$

This point of view stands in contrast to views like the one presented by Aleida Assmann in her article "Die Sprache der Dinge. Der lange Blick und die wilde Semiose." Assmann describes pictorial script as prone to what she calls "wilde Semiose" which threatens every use of "the language of the thing" :22

Es gibt ein einfaches semiotisches Gesetz, das ist die inverse Relation von Anwesenheit und Abwesenheit. Damit ist gemeint, dass ein Zeichen, um semantisch erscheinen zu können, materiell verschwinden muss. . . .Vor dem Standard dieser Zeichenlogik, die auf den Pfeilern der Immaterialisierung und der Weltdistanz aufruht, sollen im folgenden Zeichenprozesse beschrieben werden, die diesen Spielregeln nicht folgen. Von der semiotischen Normalitätserwartung aus gesehen handelt es sich um exotische, obsolete, pathologische Verfahren, die deshalb unter dem Sammelbegriff der wilden Semiose zusammengefasst werden. Wilde Semiose bringt die Grundpfeiler der etablierten Zeichenordnung zum Einsturz, indem sie auf die Materialität des Zeichens adaptiert und die Präsenz der Welt

21. This aspect of the hieroglyphic sign is the one responsible for the characteristics which, according to Marshall McLuhan, are attributable to emotion and experience. He describes the movement of man from the pictorial script to the alphabet as a movement concomitant with crisis: "Nearly all the emotional and corporate family feeling is eliminated from his relationship with his social group. He is emotionally free to separate from the tribe and to become a civilized individual, a man of visual organization who has uniform attitudes, habits, and rights with all other civilized individuals." Hieroglyphs are "culturally richer forms of writing" which "offered men no means of sudden transfer from the magically discontinuous and traditional world of the tribal word into the cool and uniform visual medium"( McLuhan 1964:92). Nevertheless, McLuhan does not offer an explanation of the mechanism of the visual organization that ensnares his "tribal man." Jan Assmann, recognizing the visual powers of the hieroglyphic script, assigns them to what he calls "Materialität' der Zeichen," namely - "Dem Drang zur verflüssigenden Spiritualisierung tritt die Materialisierung des Texts als ein Veto entgegen" (Assmann 1991:78,86). See also Aleida Assmann 1988. On the "Sinnfälligkeit" of the script, see Schott 1951:61.

22. My italics. 
wiederherstellt. In jedem Fall erzeugt sie Unordnung im bestehenden Beziehungssystem der Konventionen und Assoziationen, sie stellt neue, unmittelbare Bedeutung her, sie verzerrt, vervielfältigt, sprengt bestehenden Sinn (Assmann 1988: 238-239).

These kinds of theories, so well presented by Aleida Assmann, postulate that the ideal signifier should be encouraged to disappear easily from the reader's mind, in order to aid him to reach the sought-for signified, or meaning. Otherwise the reader stands in danger of being seduced by the signifier, instead of by the message. (Here compare also Derrida's discussion of Hegel in his essay "The Pit and the Pyramid." $)^{23}$

It seems that alongside the powerful "destructive" dangers of "wilde Semiose" - which do exist as the other facet of poetic achievement - there is the process of the "signified-elect" which presents a completely different option, working in sharp contrast to the disordering powers. Hieroglyphs may, on different occasions, lead the reader more directly to the select meaning, which is in this case restricted by the system. This is, of course, made possible because hieroglyphs do not denote simple "things" but "repeatedly selected things," codified things, i.e., signifieds.

\subsection{Jacques Derrida and the Hieroglyphs}

The importance of hieroglyphs to the history of ideas and to semiotics was accentuated in the last decade by Jacques Derrida, who of all modern semioticians comes nearest to an understanding of the hieroglyphic sign. In his Of Grammatology, he describes the birth of what I have termed the phonetic metaphor, in his own terms "rébus à transfert": "As pictogram, a presentation of the thing may find itself endowed with a phonetic value. This does not efface the 'pictographic' reference which, moreover, has never been simply 'realistic.' The signifier is broken or constellated into a system: it refers at once, and at least, to a thing and a sound. The thing is itself a collection of things or a chain of differences 'in space'; the sound, which is also inscribed within a chain, may be a word; the inscription is then ideogrammatical or synthetic, it cannot be decomposed; but the sound may

23. "It follows, as concerns the sign, that the content of the sensory intuition (the signifier) must erase itself, must vanish before Bedeutung, before the signified ideality, all the while conserving itself and conserving Bedeutung" (Derrida 1982: 89). 
also be an atomic element itself entering into the composition: we are dealing then with a script apparently pictographic and in fact phoneticoanalytical in the same way as the alphabet" (1976:90).

Derrida regards the hieroglyphic sign as "never being simply realistic," i.e., not as the object itself. Elsewhere he postulates that "Is it not evident that no signifier, whatever its substance and form, has a 'unique and singular reality?' A signifier is from the very beginning the possibility of its own repetition, of its own image or resemblance. It is the condition of its ideality, what identifies it as a signifier, and makes it function as such, relating it to a signified which, for the same reasons, could never be a 'unique and singular reality'" (Derrida 1976:91; see chapter $1 \mathrm{n} .54$ above).

The coupling of the theory of the hieroglyphic sign and Derrida's deconstructive approaches is by no means accidental. Derrida is a theoretician of script and language who questions and challenges the Greek-based concepts of Western thought leading in the direction of pre-Greek as well as "Greek-free" conceptualizing efforts. ${ }^{24}$ It is well known that any critical current seeks the most comfortable medium through which to represent itself, and Deconstruction is no exception. Hence what better medium than a script system built on the interplay of separately recognizable signs for a movement aiming at: " . . the taking apart of hierarchial systems of thoughts which can then be reinscribed within a different order of textual signification $^{25}$... the vigilant seeking-out of those 'aporias,' blindspots or moments of self-contradiction where a text involuntarily betrays the tension between rhetoric and logic. . To 'deconstruct' a piece of writing is therefore to operate a kind of strategic reversal, seizing on precisely those unguarded details. . ." (Norris' description of deconstruction [1987:19]). It is not surprising, therefore, that hieroglyphs should hold such an attraction for the deconstructive mind.

Derrida's attraction to the hieroglyphic script fits well within his search for a writing that is more fundamental to signifying practices than phonetic writing. In his view, hieroglyphs are the realization of the process of writing rather than a static script. In this he follows Freud who regarded hieroglyphs as the "archaeology of the psyche" (on no account does he place them on the echelon of writing as a less mature or primitive state of écriture; on Freud and the hieroglyphic system, see Vernus 1983).

Derrida's understanding of the mechanism of the pictorial is deep

24. See also Kammerzell 1993.

25. For excellent examples of these phenomena in hieroglyphic texts, see Fischer 1977 and Vernus 1986. 
and comprehensive. As Geoffrey Bennington once poignantly put it, "Derrida is neither Jew nor Greek, but 'Egyptian,' in a non-biographical sense to be explored" (Bennington 1992:99). He may not, however, be fully aware of the extent to which the hieroglyphic system operates around two of his central assumptions; namely, that the sign is the abode of two main powers: the "différance" and the "break from within."

"Différance" denotes the everlasting gap (already partially recognized by Saussure, who regarded meaning not as a relation of identity between signifier and signified but as a product of differences) between the signifier and its alleged signified. Unlike Saussure and his followers, Derrida modifies the definition of the sign as a construct of an ever-lasting cleavage between signifier and signified. The relationship of these two components is by no means given or definable. The sign marks only "a place of difference." A sign always leads to another sign.

Another topic that is raised by Derrida is the "break from within," suggested in his more recent works (and also in Glas) ${ }^{26}$ It delineates a simultaneous process of revelation and concealment also built on ongoing phonetic associations within parts of individual words, to the extent that one of his adversaries, Richard Rorty, writes: "The most shocking thing about Derrida's work is his use of multilingual puns, joke etymologies, allusions from anywhere, and phonic and typographical gimmicks" (cited by Culler 1982:144). Recently, Culler himself has turned forcefully to the discussion of "another level and mechanism of signification" provoked by Saussure's unpublished study of anagrams. It seems that Saussure himself was somehow haunted by the possibility of other signifying processes working beneath or alongside the apparent signs of the text. Most of the new insights suggested by Culler can be easily understood as describing mechanisms of the hieroglyphic script, e.g., "language seems not so much a system of signs, each joining a signifier with a signified, as an infinite pattern of echoes and repetitions, where readers are confronted with a

26. "the patient, stealthy, quasi-animal or vegetable, tireless, monumetal, derisory transformation of one's name, a rebus, into a thing or name of a thing." See also on Hegel and eagle, Derrida 1974 and Ulmer 1988. Puns also play an important role in magic. Borghouts defines magic as "a creative act where a certain signifiant will bring about a signifie with an often complicated range of underlying reasons for the mutual, imputed, contiguity; similarity is often explained on the level of myth" (1980:1137). From this perspective, magical thought is a more "open" system that may create new relations between signifiers and signifieds. 
problem of determining which of the numerous possible patterns to pursue, which to treat as endowed with significance. Signs are not simply given to perception: to perceive the signifier at all is to confer on some patterns and not on others the status of meaningful expressions"; or "Once one begins to think of letters or of phonetic qualities as possible constituents of other patterns, one is approaching language in a new way;" or that "the words of a work are rooted in other words"(1987:180,183). We shall see that this "array of potential patterns" rises to the surface in the iconic hieroglyphic script system obliging the reader to confront "hidden significances." Another important insight brought forward by Culler is the suggestion that addressees may not always be aware of these processes of selection, as in the case of advertisements and poetry. Culler concludes that "relations between signifiers and or between signifiers and signifieds can always produce effects, whether conscious or unconscious, and this cannot be set aside as irrelevant to language" (1987:181).

The hieroglyphic sign system on the whole operates in two main directions in a multi-dimensional space. Primarily, instantly opposing meanings surface within almost every word, generating strong deconstructive dissolving forces, threatening to break the word from within. At the same time, metaphorical processes of all kinds operate strongly in the opposite direction, trying to tame the elusive signified, searching to embed a certain signifier in a certain signified. The latter inclination emphatically reduces the "freedom of difference" 27 while intensifying the cognitive network surrounding almost every word.

Derrida significantly remarks that the "ideo-phonograph already represents a mixture of signifier and signified." For a detailed understanding of this phenomenon we will have to "enter the sign."

\section{4

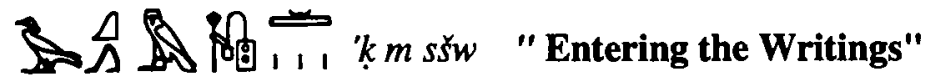

Written language is made up of two signifiers, one written, and one phonetic; writing is "le signifiant du signifiant." This analysis attributes the rightful importance to the written word, an importance which has been denied from Plato to Saussure. However, as I said above, another signifier should be added to Saussure's simple model consisting of signifier/signified,

27. This term was coined by Derrida to describe the many obstacles on the way from signifier to signified. Derrida suggests that the signified can never actually be reached. 
at least where written language is concerned: the final SIGN constituting two signifiers and a signified. In alphabetic scripts (with represented vowels), very few words will have two different signifieds (homonyms like race; race), whereas in hieroglyphics many words will refer (at least at some stage of the cognitive processing) to two signifieds, if not more. ${ }^{28}$ Thus almost every hieroglyphic word will contain two different signifiers, and usually also two (or more) signifieds. Moreover, the "double" signifier hosts two different components: the one motivated or "isomorphic" (the pictorial), the other based on cultural code.

Yet by virtue of the very fact that it is being sent by another signifier, the second signifier - i.e., the phonetic signifier (the Saussurean "sound image") - may also be regarded as a signified. (Perhaps it is to this phenomenon that Derrida's "ideo-phonogram" refers?) In order to clarify this situation within the script we should consider in detail a few examples, through a process which could metaphorically be called "Entering the Writing" after the Egyptian expression ' $k m s \breve{w},{ }^{29}$ which will aim at the atomic decomposing and definition of the "word molecule." Through this procedure, I propose to demonstrate that the hieroglyphic sign shares with modern semiotics the concept "word" as the abode of both signifier and signified, and that highly complicated relationships among what we have termed signifiers, signifieds, image, concept and context prevail in each and every word.

28. Haas is obviously of a different opinion as he writes that "to the extent to which a grapheme has ceased to fulfil its original motivating function, its pictorial character has lost its relevance. Whatever significance continues to attach to it is then quite independent of its being a pictogram; its survival may be due entirely to that natural institutional conservatism which attaches to the use of any kind of grapheme. Its relation to extralingual objects may become as irrelevant as is the similarity between our S-grapheme and a snake. It follows that the occurence (sic) of pictures, in itself, is of no special interest for the characterisation of writing systems (my italics)" (1976:140).

29. See Mrsich 1978:112. Also Wb 3, Beleg.,477,20; Urk. IV:415,14. 

to reach a signified and not to remain "on the way" or, in Derrida's terms, on the everlasting "path" to the signified, never reaching his goal.

\section{Ex. a.2 (phonetic reading)}

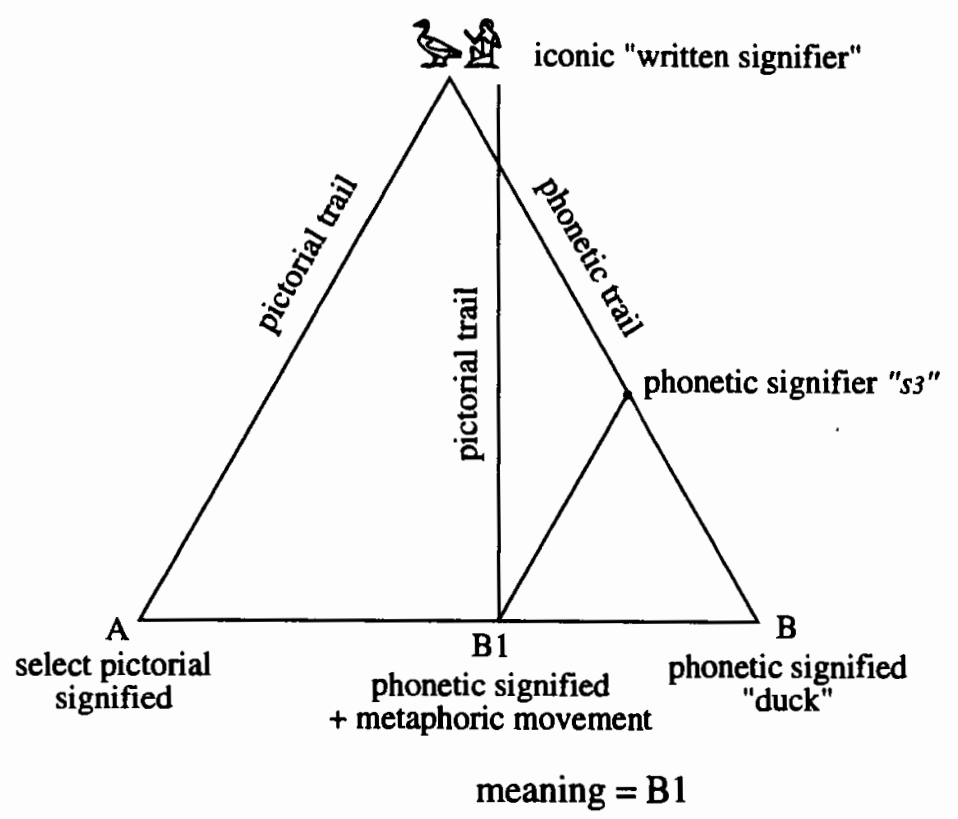

The difference between this example and the previous one is that here a contextual consideration (i.e., the determinative) leads the reader to activate other possibilities on the phonetic trail. The determinative also plays the additional role of "ambiguity dispeller, ${ }^{30}$ cancelling other phonetic

30. No simplistic view concerning the reading process involved can be adopted. Modern research has shown the reading process to be a complex procedure involving both "letters recognition" and "word recognition levels" (Matlin 1994:37-40, and bibliography there; see especially the work of Rumelhart and McClelland). Since no psychological experiments were carried out in ancient Egypt we will have to assume that reading hieroglyphs involves the same procedures involved in alphabetic or modern ideographic (e.g., Chinese, Japanese) reading processes. Nevertheless, the hieroglyphic script differs from every other script known to date, on the grounds of its strong iconicity. One can only suggest that this strong iconicity might stand in the way of "word superiority effect" as it may create stronger attention centers within 
possibilities. The final meaning is B1; A and B should be discarded.

This is an Egyptian example of Derrida's "rébus à transfert." The cognitive quality which, in my opinion, enables the transference from one signified to another is metaphor, channeled into the novel use of the "phonetic metaphor" (see detailed discussion in chapter 3). Although Derrida apparently recognizes the fact that the pictographic entity is not fully annulled at this point, he does not relate this process directly to the strong deconstructive powers activated from within. In fact, the iconic signified is not so easily put aside. We shall see later that the "discarded" iconic signified may continually intervene; developments as the $s$ duck and its egg and the evolvement of the hieroglyph $b$, soul are similarly evidence of "unsuccessful" banishments of the iconic signifiers-signifieds. To define this signified as deprived of all meaning is incompatible with the hieroglyphic thought system. However, this subject will be elaborated in the next chapter.

b. The š̆n

lotus flower (EG, M7)

Ex.b.1

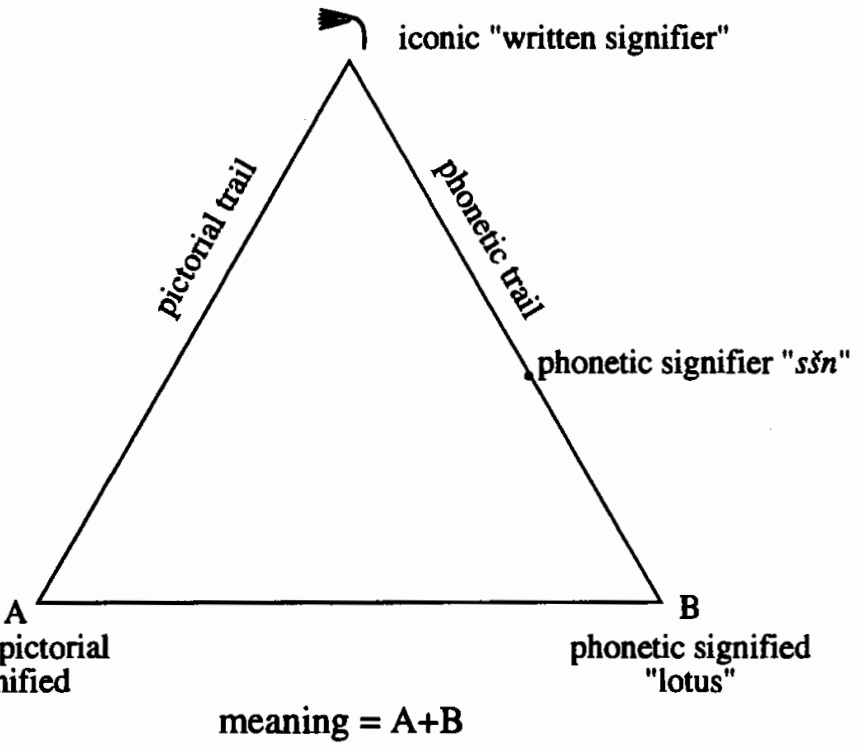

the word, which may compete with "the whole" (on this subject see Appendix A below). This phenomenon does not exist in alphabetic scripts where the "non-iconicity" of the alphabetic signs deprives them of the ability to become variegated "attention centers." Even in scripts like Chinese, the "open" iconicity is much reduced, and the signs must be processed by the reader in order to return them to their original iconicity. 
This example is parallel to the $s$ - duck example. The iconic signified is easily reached; the name of the flower - the phonetic signifier - can be reached only through the pictorial trail. There is no representation of the phonetic signifier.

Ex.b.2

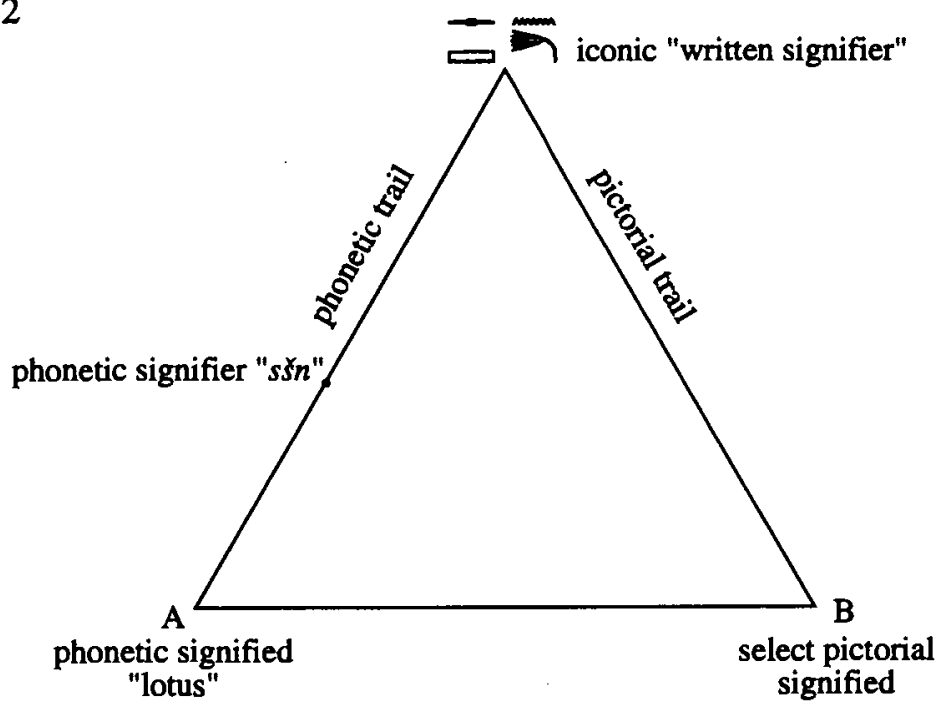

meaning $=A+B$

This writing of the word is a typical version which exhibits a phenomenon shared by most written Egyptian words. As there is no one "correct" writing of a word, but a plethora of many normative possibilities, ${ }^{31}$ a word may be written iconically, phonetically, or phonetically and iconically.

In the second example of the sšn, the reader is initially drawn directly to the phonetic signifier by a set of the most "non-motivated" written signifiers within the script - the uniliteral pictographs. Due to their

31. The writing cannot be described as "rule-free." There are words that resist certain signs, although these signs are phonetically suitable, at least theoretically. The explanation of this phenomenon is usually sought in the realms of decorum (Schenkel 1974; Meltzer 1980) or phonetics (Schenkel 1984). I believe that in some cases at least, the reason should also be sought in a putative "cognitive clash" between the signified and the possible signifier (Goldwasser and Laor 1991:47). 
highly repetitive quality, it seems that the uniliteral signs are usually to be taken as the most conventionalized signifiers, as "dead metaphors," virtually void of their iconic identity. A few later Ptolemaic examples point in other directions, enhanced by legends such as the one from papyrus Jumilhac about the name Inp - Anubis. ${ }^{32}$ Examples such as the 18th Dynasty writing of the word nini ("greeting", see FCD:126) which pictures a man offering two $n$ signs $\| " N$, are probably a play on their phonetic value as well as their iconic presence as "water," as understood also by the Wörterbuch. ${ }^{33}$ However, in our š̌n example the reader is led primarily on the phonetic trail, in a process which probably very much resembles reading in an alphabetic script. Then, the following pictorial diverts the reader's attention onto the parallel trail of the pictorial signifier towards the pictorial signified. The final meaning will emerge as the combination between the specified phonetic signifier and the select iconic signified. Thus we are facing a double representation of the word, by two separate written signifiers, the one leading to the phonetic signifier (and from there to the phonetic signified), the other aiming directly at the "select" iconic signified. The reader may reach the sought-for semantic value without the phonetic signifier (as in the first šn example), but this leaves him at the mercy of his memory alone, and he runs the risk of reaching a different, erroneous signified (e.g., a different flower). Here we encounter for the first time the "double written signifier" where the "covert" phonetic signifier (as in examples $1-3$ above) is brought to the surface of the script. The reader is led to the sought-for signified twice, once phonetically and once visually. ${ }^{34}$ During this procedure the reader acquires what might be defined as "maximum information" through both channels, and the outcome is a double bond of the signifier and the signified. In the two examples of the š̌n, metaphoric processes were not activated.

32. Vandier 1962, pl.VI, p.155, 117. Vandier tries to explain the Egyptian legend through an acrophonic explanation; it seems highly unnecessary. The 4 may stand as a pictograph for "wind" (a metonymy, see below chapter 3, the discussion on the sail determinative), nmm for "water" and $\square$ as the "stone of the mountain." See also Jacq 1988:106-107.

33. Wb 2:203,10 "die Begrüssung durch Wassersprengen." See Westendorf 1991.

34. A prominent example of this phenomenon from the Archaic Period is the inscription of Neit-hotep from Helwan. The three monoconsonants that make up the $h t p$, are scattered around the triliteral sign (Bard 1992:299, fig.3). 


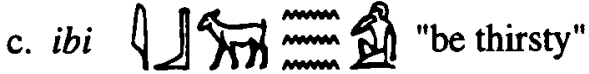

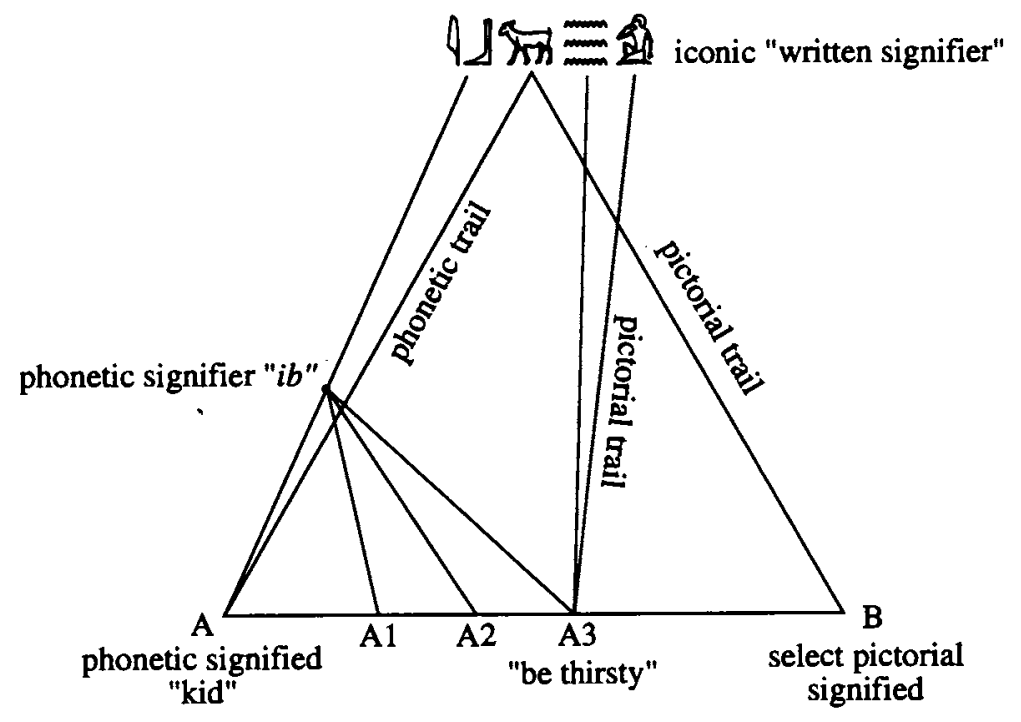

meaning $=\mathrm{A} 3$

This spelling of the word $i b i$ gives us a very different relation between the phonetic and the pictorial signifiers. The beginning of the word, which provides the reader with full information of the phonetic signifier, leaves him free to search for the signified. This search is immediately anchored in the presented redundant iconic kid (its iconicity stressed by its full redundancy, which also makes the "phonetic metaphor" process superfluous here), leading the reader to a choice of the signified "kid" (the fact that the kid is semantically "alive" is made clear by 19th Dynasty and later examples like 3 [EG, E8; the kid may also appear as determinative in 'wt "cattle," see Lesko Dic. I:71]). But the untrained reader will soon find himself in conflict with the information produced on the parallel iconic path. The water signifier and the man with his hand in his mouth will transfer him instantly to the beginning of the procedure, where the phonetic information was presented, before the choice of a signified. The kid should be forcefully discarded, and the search for the signified should commence again, in the realms of water and human "senses." The chosen phonetic signified this time is the $i b i$ which refers to "thirsty," enhanced semantically on the iconic trail by the determinatives. After the "break from within," 
there is a strong effort to tie the signifier to the correct signified. This intricate contrasting procedure is of course not activated in uniliteral examples like $1 \mathrm{D}$ or $41 \mathrm{~mm}$ (FCD:15; it is almost certain that for the experienced reader these processes take place very rapidly).

d. The pr $\square$ house (EG, O1)

This is one of the most schematic prototypes represented in the script. The multiplicity of iconic signifieds in this case might be the reason that led to the choice of a "summarized gestalt" (see Hornung 1992:25-26).

Ex.d.1 pr $\square$ "house"

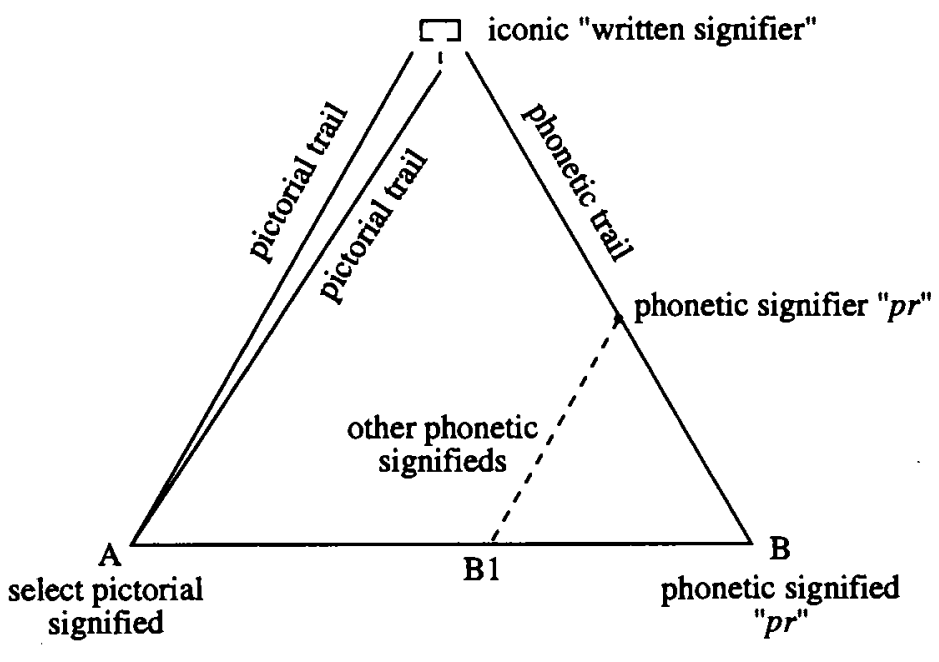

$$
\text { meaning }=\mathrm{A}+\mathrm{B}
$$

The $p r$ "house" represents the situation already encountered by us in the iconic examples of $s 3$ and sšn. 


\section{Ex.d.2 pri $\square \wedge$ "go out"}

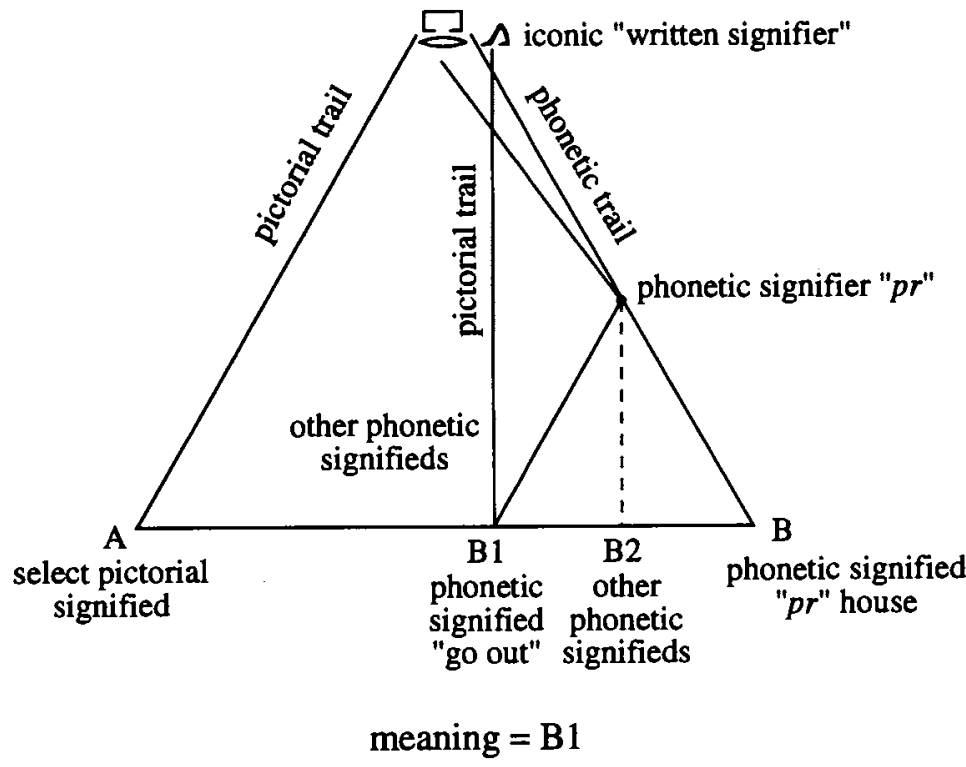

This is a different case. The $p r \square$ pictograph sends the reader on a "false trail" to the pictorial signified "house." The second sign, the $r$ $\boldsymbol{O}$, is an "unmotivated" uniliteral sign, which consists of the final phone of the phonetic cluster $\mathrm{pr}$. The sudden appearance of the "redundant" phonetic information forces the reader to make his way through to the phonetic signifier, ${ }^{35}$ which is still free of a signified. There he may well search for the preferred signified, being led by the guiding clue of the phonetic $r$, indicating that the sought-for signified should be looked for in the phonetic domain, not in the pictorial one; the processing will involve the transference via the phonetic metaphor into an altogether new semantic signified - the word pri "to go out." Thus two different signifieds will be activated here, phonetic and pictorial, with the pictorial signified being necessarily discarded in order to complete the reading process successfully. The final pictograph $\Lambda$, the "walking legs," is phonetically extraneous to the word. It brings along extra-semantic information to the scene of the signified which is already found as expected, accenting the choice in the new semantic information. It also involves a categorization effect (or effort?); the extra non-phonetic information is that pr is done "leggily" or "by legs," which is

35. See Kaplony 1966. 
a synecdochical representation of the "walking human." The added semantic information will take part in the non-deconstructive movement within the script, which will help create a stronger bond between a signifier and a certain signified acting against the deconstructive powers embedded ipso facto in the discarded pictorial signified. ${ }^{36}$

e. hpr 贯留 $\circlearrowright$ "to become"

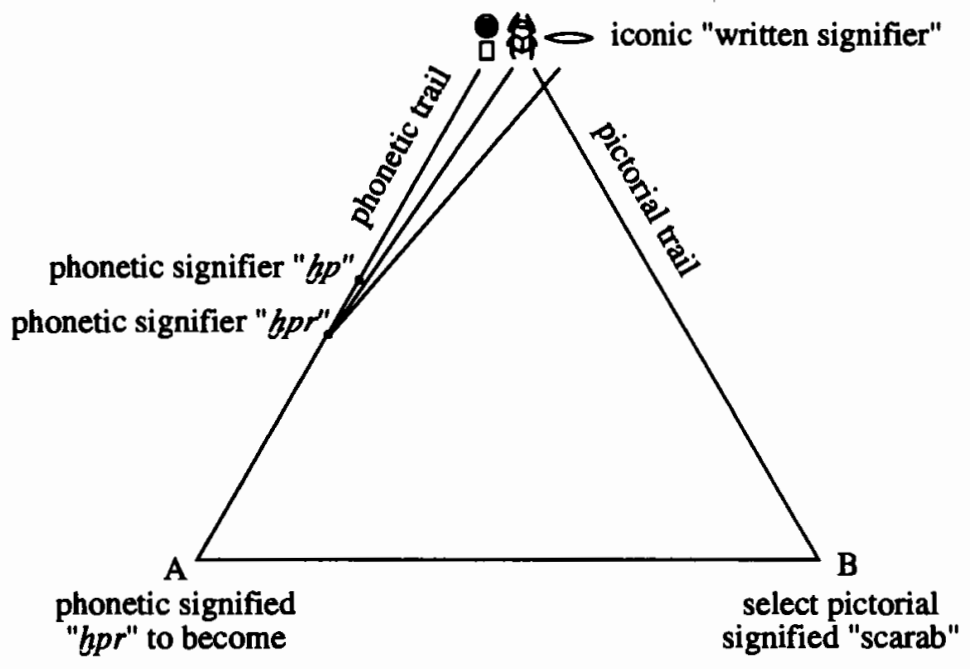

$$
\text { meaning }=\mathrm{A}(+\mathrm{B})
$$

Initial information appears on the phonetic trail. It is immediately intensified and completed by the addition of the pictorial hpr, which determines the phonetic information, and at the same time suggests itself as a signified. The information is summed up by the uniliteral $r$ sign, which sends the reader back to the phonetic trail to search for the signified. The

36. The reduced iconicity of the two signs $p r$ and $r$ might cause the reader to feel that he is facing a pictorial gestalt that signifies "to come out." It is indeed a possibility that words built of signs which are iconically "weak," would lend themselves more easily to be processed as "a whole." Yet, semiotically the word is made up of three iconic signs, of which two at least still carry their full iconic meaning. The parallel "legged" variation presents a different semiotic identity, and should be dealt with separately. 


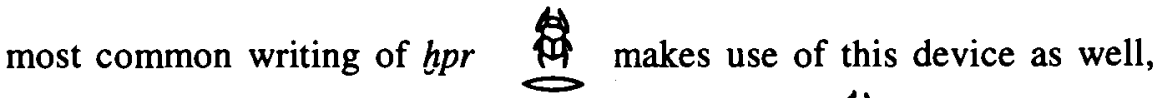
without the initial reference to the phonetic signifier. above example of $\square \triangle$, the difference being that the determinative is probably felt to be superfluous in the case of $h p r$ (Wb $3: 261-265$ ), as the meaning of the word is a fascinating interaction process between the vehicle of the metaphor and the meaning of the metaphorized notion "to become," 37 through the appearance of the concrete vehicle. The pictorial entity is not discarded, but the final meaning is a combination of the phonetic and pictorial information.

We rarely find examples that renounce the vehicle of the metaphor, though they do exist, mostly in funerary texts. One may even encounter an alphabetic writing of the word may permit the "death" of the metaphor, avoiding the confrontation with the strong vehicle. ${ }^{38}$ Indeed, the connotation may also exist on the phonetic level, but in this case it remains optional, and is related to the general question of whether the speech community felt the metaphor to be "dead" or "alive," on the phonetic basis alone (for a continuation of this discussion see below chapter 3). Other examples are and $[$ (e.g., Sethe1922:4*,6*). The last example comes from a funerary text that deliberately avoids any pictorial representation of signifiers that might be connected to divine beings. From the semiotic point of view, might be regarded as an abnormal representation breaking the coherence of this special word. Into the double processing of the scarab and the verb "to become," a foreign icon is introduced, but its pictorial value has to be completely discarded before the right signified can be reached, an intrusion which breaks the rare harmony that exists in this word between the phonetic and iconic information.

37. It may be translated into a Semitic language, e. g., Hebrew, as "להתחרפש"*; see below chapter 3 .

38. Lacau writes about the hpr: "L'insecte est considéré comme sacré même dans son emploi comme lettre. On l'aurait coupé en deux si on ne l'avait pas regardé comme un dieu. Or je ne connais pas l'example de cette coupure" (1914:50). 
f. $\operatorname{srt} \| \bullet\}$

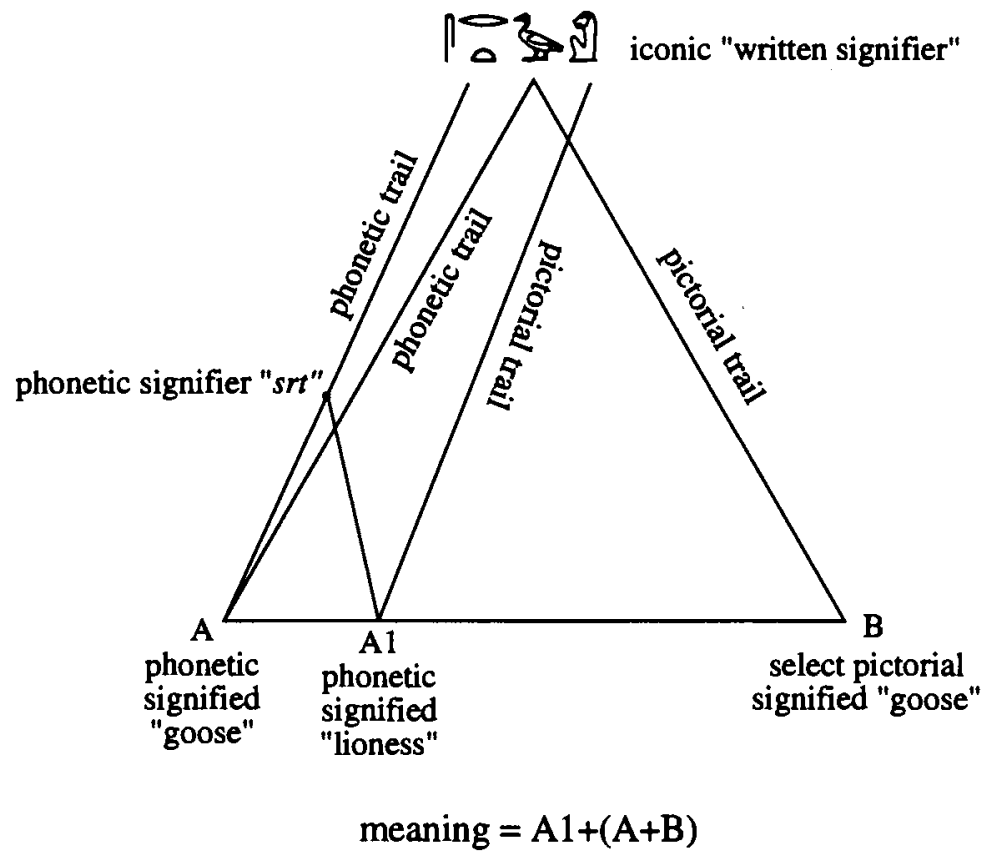

The goose creates strong deconstructive powers within the word, and is indeed called by Brovarski (1984a:879) "incongruous." Its "gooseness" stands strongly against the sought-for representation of the lioness signified. The female determinative strengthens the signified, but not enough. The "discarded" signified (a "phonetic metaphor") is strong, facing no rival animal signified. The outcome is a lion goddess which is called "a goose goddess." Hence the "false" duck signified is not discarded and finds its way into the semantic whole. 


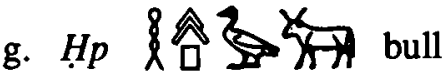

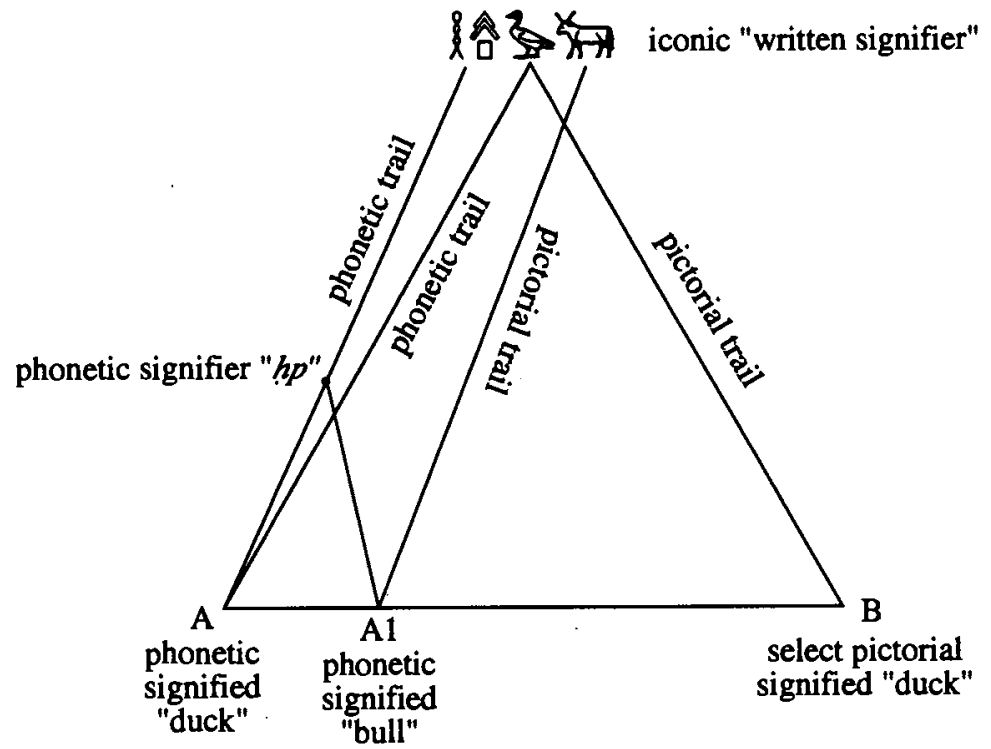

meaning $=\mathrm{A} 1$

In the $H p$ example, it seems that the bull determinative is strong enough to overcome the "false" duck signifier, and a $H p$-duck combination (like the goose lion) is not attested. Nevertheless, Brovarski (1984a:879) suggests that the duck is retained due to the exceedingly common occurrence of the goose in offering lists. This again means that the phonetic goose is not completely discarded in this case either ${ }^{39}$ but retains its pictorial identity even when appearing as part of the process of the "phonetic metaphor."

\subsection{Concluding remarks}

The hieroglyphic system walks a tightrope. On the one hand, strong forces anchoring the iconic written signifier to its natural iconic signified are activated. When the iconic reading is at stake, the "select" signified coincides, completes and even invigorates the semantic message reached through the phonetic path. Still, when the phonetic metaphor process is

39. For the goose determinative in hnk, see Baines 1985:84, fig.43. 
activated, these very powers work in opposite directions, against the soughtfor unification of the signifier with its signified, creating strong deconstructive threats on the sought-for signified which should be reached through the now rival phonetic path. The discarded, presently alien, iconic signifiersignified may still pose a threat to the semantic whole.

The thought that, as a semiologic complex, hieroglyphs are unsurpassed by any other writing system has preyed on the minds of many Egyptologists. I believe that its origin may lie in the fact that hieroglyphs form a writing system that activates all six functions of communication as listed by Roman Jakobson (1987).

The referential function is stressed by the pictorial entity in cases where iconic information is not to be discarded. Most of the determinatives also contribute to the referential information.

The emotive function, the writer's attitude, can sometimes be tracked on the pictorial level. The choice of certain "value determinatives," such as "evil," "abstract" or "fallen enemy," or "Sethian" manifests the emotion and values inhabiting the word (from the writer's or the code's point of view). Still the open character of the script allows some personal variations (for an example of a personal "script-ideolect" in hieratic, see Goldwasser 1995). The word is not represented as an objective phonetic entity to be processed by the addressee.

The conative function can be found in the strong metaphorical powers of the script, which summon the reader to be an involved interpreter rather than a distant untouched reader.

The phatic function exists on the level of redundancy and finds its expression particularly through the uniliteral signs that help the reader to decipher the script and thus "keep him going."

The metalinguistic function ${ }^{40}$ is an important one. Many of the determinatives may be seen as metalinguistic explanatory devices, conveying an amount of surplus information.

Last but not least is the poetic function. ${ }^{41}$ In many cases, there is a

40. See also te Velde 1988:174.

41. "The message assumes a poetic function when it is ambiguous and selffocusing" (Eco 1976: 262). He also stresses the fact that all six functions can coexist in a single message. Tsur describes the distinctive quality of poetry where ". . . attention is directed back to the signifiant to some extent. When attention is directed to the signifiant beyond a certain (operationally undefined) extent, the focus between the signifiant and signifie is split, resulting in the witty quality that is characteristic of the various kind of Mannerism" (1992:93). 
special effort that concentrates on the message itself. Its aesthetic aspect always receives special attention through aesthetic alternations of the number of signs in a given space for a desired graphic effect, or for the purpose of reversals. Special interest is invested in colours ${ }^{42}$ and shapes. On the semantic level, joint hieroglyphs create new beings; other signs come to life, while ambiguity toys with the reader. We can easily find examples of what Derrida would have called "graphic rhetoric." Intensified interest is projected onto the tools of the message, going beyond the semantic message itself.

Indeed, very apt are Kaplony's words - "Der Ägypter ist mit seinem ganzen Wesen ein Augenmensch, ein Freund von Bildern nicht nur in der Kunst, sondern auch in Wort und Schrift" (1972:3).

42. On colours, see Staehelin 1974. 


\title{
3. THE HIEROGLYPHIC WORD AS A COMPLEX METAPHORICAL CONSTRUCT
}

\author{
What does it mean to say that the "is" in "the rose \\ is red" has a different meaning from the "is" in \\ "twice two is four." \\ Wittgenstein, Philosophische Untersuchungen, \\ 558
}

\subsection{Introduction}

As we have seen in the previous chapters, the hieroglyphic script presents its reader not only with phonetic, but also with complex iconic information, some of which is relevant to the final meaning of the word (with different degrees of relevance), and some of which should be put aside as "counterfeit information."

In the following chapter I shall try to define the processes which underlie the semiotic classification that enables the decipherment of the individual hieroglyphic sign. I shall try to scrutinize the processes which are activated by the reader in order to make the given icon into a meaningful unit of information. We should keep in mind that this process is given life, in the first place, because every sign carries an a priori independent iconic meaning, regardless of its role in the given word.

An inquiry into the nature of the hieroglyphic word and a detailed study of the relations of signifier-signified within the word, led me to the belief that the decipherment process is constucted of a complex movement, at various levels, from the iconic pole, through metonyms, synecdoches and metaphors, to the process I called the "phonetic metaphor." Another process which takes place in almost every word is that of categorization. However, the metaphoric processes and the categorization processes are bound together, and metaphor is described in semiotic studies as well as in cognitive studies as the creation of temporary categories: "Porphyrian"1

1. The Porphyrian tree is a model for definition constructed of genera, species and differentiae, elaborated from Boethius through the Middle Ages, as an interpretation of the Isagoge written by the Phoenician Porphyry in the third century A.D. The ad hoc Porphyrian tree created in cases of certain metaphors actually controls which properties of tenor and vehicle must drop away. The 
categories by the semiotic definition, and categories by the cognitive definition, but this subject will be elaborated on later. This may be the occasion to stress that semiotic processes and cognitive processes are by no means mutually exclusive. The description of a semiotic process could involve cognitive aspects as the cognitive studies relate to the mental processes involved in bestowing meaning on signs (Eco 1984).

My objective in this endeavour was to begin drawing a general schema that will make possible a systematic description - through one mechanism - of the semiotic processes involved in the reading of hieroglyphs. The basic framework has already been laid down by Champollion, in his Principes généraux. My work is in line with Schenkel's search for a systematic description of the hieroglyphic system.

\subsection{Metonymic versus Metaphorical Axis.}

The age-old notion that metonymic and metaphoric processes lie at the center of linguistic faculties was given new emphasis by Roman Jakobson. ${ }^{2}$ In his study, "Two Aspects of Language and Two Types of Aphasic Disturbances," he calls similarity and contiguity "the gravitational poles of language," as the development of discourse "may take place along two different semantic lines: one topic may lead to another through their similarity or through contiguity. The metaphoric way would be the most appropriate term for the first case and the metonymic way for the second" (109-110).

In positing his thesis, Jakobson describes the response to what he calls "the stimulus 'hut'": "The same stimulus produced the following substitutive reactions: the tautology hut; the synonyms cabin and hovel; the antonym palace; and the metaphors den and borrow. The capacity of two words to replace one another is an instance of positional similarity, and, in addition, all these responses are linked to the stimulus by semantic similarity (or contrast). Metonymical responses to the same stimulus, such as thatch, litter or poverty, combine and contrast the positional similarity with semantic

metaphor "tooth of the mountain," would be represented as :

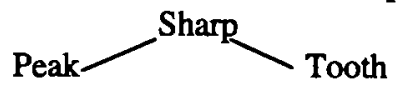

The genus "sharpness" will cause the white quality of the tooth or its sensitivity to cavities to be disregarded (Eco 1984: 46-94).

2. See Pignatari 1978. 
contiguity" (110). Metonymy and metaphor have long been recognized as the building blocks of the semantic extension of vocabulary (Ullman 1967:211-227; Lakoff 1987:19-20).

After lengthy consideration of the hieroglyphic signs, I am persuaded that the most illuminating way to study the mechanism which turns icons into units of meanings must begin with Jakobsonian terms.

\subsection{A Description of the System - From Icon to Metaphor ${ }^{3}$}

The examples below represent some of the possible varieties of interpretative movements within the script from an iconic reading, in which the image stands in iconic relationship with the signified, to what we have called a metaphoric reading, namely transposed reading, where the image stands in a relationship other than iconic with the signified.

\subsubsection{The Iconic Reading ${ }^{4}$}

An iconic reading is one in which the relations between the hieroglyphic signifier and its linguistic signified may be defined as "iconic" ("A sign is said to be iconic when there is a topological similarity between a signifier and its denotata," Sebeok, 128$)^{5}$. In these cases, the reader should not address himself to metaphoric movements. This is the most immediately visual level of hieroglyphic reading, yet, as I have explained in chapter 1 , it is not the same as picture-reading, since the script system, aiming at the representation of linguistic items, is mainly addressed to chaining the written signifier and its linguistic counterpart. Of great interest

3. We use the term "metaphor" to indicate all kinds of tropes, metaphor being the prototypical "figure of speech" (Hawkes 1972:2-5). In his Semiotics and the Philosophy of Language, Umberto Eco writes: "The term metaphor for many authors - and this is true for Aristotle and Emanuele Tesauro - has served to indicate every rhetorical figure in general; the metaphor, as the Venerable Bede put it, is 'a genus of which all the other tropes are species.' . .. It is very difficult indeed to consider the metaphor without seeing it in a framework that necessarily includes both synecdoche and metonymy. . ." (Eco 1984:87).

4. Champollion's "charactères 'mimiques' ou 'figuratifs'."

5. On the problematics of the term "iconic," see Eco 1972,1976; White 1976:81-2. 
in this context is Rolands Barthes' discussion in the "Rhetoric of the Image,"6 in which he readdresses the timeless questions: "How does meaning get into the image? Where does it end? And if it ends, what is there beyond?" Barthes concentrates on the advertising image, and states that in advertisement, as opposed to art, "the signification of the image is undoubtedly intentional: the signifieds of the advertising message are formed a priori by certain attributes of the product, and these signifieds have to be transmitted as clearly as possible. If the image contains signs, we can be sure that in advertising these signs are full, formed with a view to the optimum reading: the advertising image is frank, or at least emphatic" (Barthes 1977:33). If we replace the term "product" in Barthes' discussion with the term "referent" or "signified," we will find this is also a reasonably accurate definition of "hieroglyphic communication." One difference between ad and icon, which we should nevertheless bear in mind, is that they are subjective in different ways. Since the aim of advertisement is to attract its audience by glorifying the product, certain qualities of the advertised icon regarded as its more attractive ones, will be stressed, while others are conspicuously neglected. It seems the hieroglyphic sign is basically free of this type of pictorial molding, and we find in the script what is probably the pictorial representation of the prototypical member of the category (represented by the word) in the sphere of the Egyptian cultural code. Even animals which the culture regarded as threatening or dangerous (crocodile, lion, the Sethian animal) are represented in a "neutral" pictorial way which does not attempt to denote (at least not literally) the additional signified "fearsome." In such cases, the iconic representations in the script are strongly codified, thus limiting the freedom of the image (advertisement is also codified but under different and much less restrictive rules). The script enables variations or changes only through the indoctrination of the system (e.g., pylon, obelisk, chariot, horse, scribe's outfit [ Fischer 1976; Davies 1987:10-11; Hornung 1992:26]; a captivating example is in the word stwt "rays" during the Amarna period [Wb 4:331]), or in periods in which the central canon became less rigid (e.g., First Intermediate Period hieroglyphs). In Egyptian, the general effort is to render the pictorial innocent, to divest it of any possible multiple connotational signifieds; yet the persistent attachment to the iconic form, however codified, will always be counteracted by an opposing force. Sensual connotations aside, other latent signifieds may lurk in the folds of the iconic. Let us consider the following examples:

6. Barthes 1977. 
"human being," 过 "scribe-outfit."

If we follow Barthes' reading of Italian advertisements, we may discern a fine differentiation running through the icons in this group; while the signs for "eye," "nose," and "ear" have no particular Egyptian content, "man" (represented as a seated Egyptian male), "dog" (the typical Egyptian dog) and "scribe-outfit" (scribal materials which are specifically Egyptian) carry along with their linguistic signifieds an additional somewhat abstract signified which may be defined as "Egyptianicity." "Egyptianicity" is an additional latent signified accompanying many Egyptian hieroglyphs.? What it pertains to is not a distinctly Egyptian angle of vision, but an inherently Egyptian content. In other cases, the Egyptians have all but neutralized the icon through schematic representations. Had this road been taken further, hieroglyphs would have been found on equal terms with Chinese or cuneiform signs. However, one should remember that even in the most schematic cases one is always in the realm of the iconic (see Pierce's triadic subdivision of the iconic sign into "images, diagrams and metaphors" [Sebeok 1976:128]).

\subsubsection{The Animation of Dead Metaphors}

The vitality of any picture language is apt to contest a reactionary process, which has been known in literature as the "death of the metaphor" (Kittay 1987). Metaphors that are used to describe the king, like $9 \mathrm{~A}_{\mathrm{M}} \mathrm{mi}$ "lion," Grapow 1924: passim), retain their vitality since the iconic signifier directly evokes the pictorial signified of the concrete animal. When the enemy is

7. However, we should be very careful not to confuse the notion of 'Egyptian'-ness, which actually comes forward whenever certain typically Egyptian artistic rules are employed (Schäfer 1986:10), with the signified "Egyptianicity" contained in certain hieroglyphic signs. We are not referring here to style but to content. Compare the term "Egyptianicity" (suggested to me by Prof. A. Loprieno) to Barthes's Italianicity "the condensed essence of everything that could be Italian" (1977:47-48). This trait can also be described as the seme "Italianicity" or "Egyptianicity."

8. These metaphors are "replacement" metaphors, see Brooke-Rose 1958. 
called snhm "the locust," the viewer is confronted with the concrete presence of the insect with all its associations and connotations. In other words, the vehicle of the metaphor is conjured up. While the process known as the "dying" of metaphor probably involves some kind of distancing of the signified from its pictorial realization, by retaining the pictorial it imparts to the metaphor a constant sensual and cognitive attraction (which is why it remains one of the commonest devices used in modern advertising [see Eco below]).

The same phenomenon can be traced in verbs that have undergone a metaphorical movement; $h p r$, which has an underlying literal meaning of "to be reborn as a scarab" (see above chapter 2), or the verb a htp "to be satisfied" (see Gardiner's discussion, EG:25 and Grapow 1924:5) where a certain lucidity of the vehicle is withheld. Writing the word A $s i b$ "jackal" with the iconic signifier maintains, on the surface, the supposed metaphorical movement which motivates the connection between the dignitary and the animal. ${ }^{9}$ A most interesting example is that of $s_{7 \gamma} s^{\prime} h$. If we accept the reconstruction mentioned above in chapter 1 , the dignitaries were referred to metaphorically as "the goats that are allowed to pasture freely," or "the privileged goats." The pictorial signifier obviously preserves this metaphor. It may be of interest at this point to compare the situation in Hebrew, which is also a root language. Hebrew contains verbs and adjectives constructed of roots of animal names. The verb 1 bzz "to loot" is related semantically to the $b z$ "falcon," the result of which is something like "hawking"; the verb ע ' $t$ "to fall on, to attack" is related to the גמלני gmlny "gawky" is rooted in "eagle". The adjective גמל " גמל " $g m l$ "camel" (camel-like). The process of extending the semantic lexicon through root exploitation is still alive and kicking in Hebrew, as is shown by the relatively new colloquial word להשתפן lhštpn, which finds its origin

9. "There is little or nothing in a phonetic word to exhibit the embryonic stages of its growth. It does not bear its metaphor on its face . . . In this Chinese shows its advantage. Its etymology is constantly visible. It retains the creative impulse and process, visible at work. After thousands of years the lines of metaphoric advance are still shown, and in many cases actually retained in the meaning. Thus a word, instead of growing poorer and poorer as with us, becomes richer and still more rich from age to age, almost consciously luminous." Fenollosa (1936) said these words about Chinese. Yet we can easily replace Chinese with Egyptian, and the text will retain its full meaning and even more. 
in the word שפןpn, and means "to become a rabbit," a metaphoric expression for "cowardice." 10 Nonetheless, very few Hebrew speakers (or readers) actually keep in mind the vehicles of those metaphors - the hawk, the eagle, the camel and the rabbit - while speaking or reading them. They are all practically "dead" in the language. One may also wonder about the degree of vitality retained for English speakers by the dog in the expression "they dogged him," or the chicken in "chickened out" or the various animals in "catty," "sheepish," "fishy,"11 etc. It is easy to imagine how all these metaphors would have been "kept alive" by an iconic script, as Umberto Eco says: "In shifting from one semiotic system to another, a dead metaphor becomes an inventive one anew. . Investigations of the visual metaphor . .. have shown how worn-out expressions such as flexible can reclaim a certain freshness when, instead of being uttered verbally, it is translated visually through the representation of a flexible object" (1984:127; also Gombrich 1963:128).

\subsubsection{Visual Poetics - The Case of the Animalistic Metaphors (see fig. 14)}

Lines 13 - 23 in what is called today the "Poetical Stela" of Thutmosis III (CGC 34010) are obviously a poetic endeavour. It is probably due to these lines that this stela acquired its modern name. Besides its linguistic and literary merits, special attention has been given to the space division and the arrangement of the hieroglyphs within this space. Each stanza contains a line which describes the king metaphorically, through animalistic metaphors: ${ }^{12}$

Third stanza, line 15:

di.i m3.sn hm.k mi sšd

st bsw.f $m$ s $\underline{d}$ t di.f idt.f

"I cause them to see thy majesty as a shooting star, sowing its fire in a flame, as it gives off its steam."

10. Compare the English verb "to hare," which may be very close to the Egyptian wn "to hurry." See Ray, forthcoming.

11. Compare hns "stink" with the fish determinative (Wb 3, 301).

12. The translation is based on ANET: 374-375. 
Fourth stanza, line 16: di.i mi.sn hm.k $m$ k3 hn.tw.f

"I cause them to see thy majesty as a young bull, firm of heart, sharp of horns who cannot be felled." Fifth stanza, lines 17: di.i m3.sn hm.k m.dpy $n b$ snd $m m i(w) n$ tkn.n.tw.f

"I cause them to see thy majesty as a crocodile, the lord of fear in the water, who cannot be approached."

Sixth stanza, lines 18: $\quad$ di.i m3.sn hm.k $m$ ndtty $h^{\prime} w$ hr $p s d w$ n sm3.f 20

"I cause them to see thy majesty as a protector appearing on the back of his wild bull."

The $s m^{3}$ bull appears at the end of the line, on the far left side of the stela. However, the $s m$; bull is not a metaphor for the king but for Seth, and it would not be acceptable within the "visual rhyming" of the kingly metaphors.

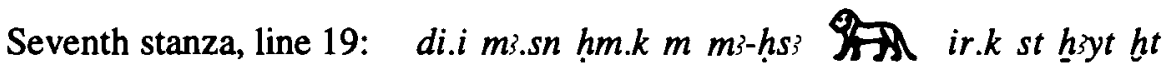
int.sn

"I cause them to see thy majesty as a fierce lion, as thou makest them corpses throughout their valley."

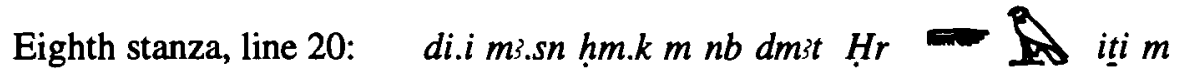
dgg.t.f $r$ mrr.f

"I cause them to see thy majesty as the 'Lord of 
the Wing' taking possession of what he sees as he wishes."

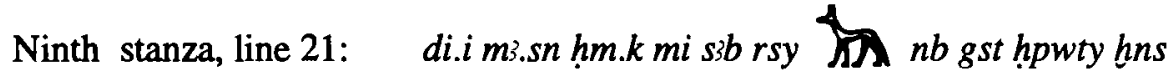
$t$ twy

"I cause them to see thy majesty like a jackal of the Southland. The lord of speed, the runner coursing the Two Lands."

Line 23 :

Although not a part of the ii.n.i - di.i formula, the Horus hieroglyph and the $k$; nht appears in a vertical line underneath the $s 3 b$.

The repetitive opening line of every stanza, manifested in exactly the same hieroglyphs (and of course wording), acts as a visual foregrounding tool for the hieroglyphic sentence that follows. Here grammar and perceptual devices intertwine while underlining the manifestations of the king. The vehicles of the metaphor - bull, crocodile, lion, and jackal - run into three other pictorial entities belonging to the animal realm: the $d m s t ~ H r$ (Horus' wing) and $H r k 3 n h t$. The stela also provides an insight into the mapping process of the metaphors; the glitter and swiftness of the $s \check{s} d$, the fierce attack of the young bull, the crocodile as the "king of fear" in the watery sphere, the ferocious aggression of the lion, the sharp eyesight and swift attack of the falcon (the king of the sky), and the speedy traversing of the Two Lands by the jackal/king.

It is very evident that visual poetics were taken into account in the creation of this stela. The scribe has actually created a kind of visual rhyming ${ }^{13}$ running almost vertically through the lines, a device well known in Chinese poetic writing, which relies heavily on "visual poetic" meanings (see Fenollosa 1936).

13. For visual poetic variations in Ptolemaic, see Derchain 1993:65-69. 


\subsection{Metonymic ${ }^{14}$ Relationship}

In his "charactères 'tropiques' ou 'symboliques'," Champollion included "métonymie," which he describes as "on peignait la cause pour l'effet, l'effet pour la cause, ou l'instrument pour l'ouvrage produit" $(1836: 23){ }^{15}$ In some cases, we find contiguity relations between the central icon conveying the phonetic information and the final meaning of the word. Several tools appear as icons in words in which the signified refers to the user or owner of the tool, and locations appear as icons in words in which the signifieds are people of those locations. A body-part, responsible for a sense, appears as an icon in words relating to that sense (Champollion gives the example of the eyes - "l'action de voir, par l'image de deux yeux humains"[1836:24]).

Metonymy plays the role of foregrounding a certain aspect, and it usually provides a more abstract word with some concrete signified. These phenomena, described by Bréal as "thickening of meaning," ${ }^{16}$ are well attested in the pictorial script.

\subsubsection{On the Pictorial Representation of the Root}

It should be of interest to compare the "hieroglyphic situation" of the root to the situation created in root-languages that are written alphabetically. ${ }^{17}$ Unlike Egyptian, the lexical root in such scripts (e.g., old Hebrew, modern Hebrew) appears in the script in a "neutral" format usually of three consonants, creating a written abstract morpheme that may be embedded in pre-existing morphological tiers to form specific words. ${ }^{18}$ It

14. I use the term "metonymic" in the broad sense of contiguity relations. Some of the "metonymies" are synecdoches according to classical definitions.

15. Schenkel has incorporated Champollion's term in his latest discussion about the semogram (1991:37).

16. "Épaississement de sens," cited in Ullman 1967:220.

17. On differences in reading processes between unpointed root languages and European alphabetic scrip, see Barr 1976.

18. On roots in the hieroglyphic script, see Schenkel 1981; Loprieno describes the root in Egyptian as "an abstract phonological entity consisting of a sequence of consonants or semiconsonants varying in number from one to four" (the italics are mine; see Loprieno 1995,4.2). On the differences between root languages and Indo-European languages in the variety of possible combination 
actually carries with it an "open" meaning, materialized differently in each of the manifestations of the root. For example, the abstract root .ר.9.ס SPR in Hebrew has a basic open meaning which is realized differently in spr "scribe"; in ספר spr "book"; in ספר spr "recounted"; in ספריה spryh "library"; and מספרת msprh - "barber-shop." 19 "Returning to the hieroglyphic case, we immediately perceive that in many instances (if not written with monoconsonants or a biliteral + consonant), one of the manifestations of the root, probably the most iconic, will be chosen to represent the phonetic value of the "open" root. ${ }^{20}$ Though probably making the root more salient, this phenomenon also chains the a priori rather "free" abstract root to one of its possible variations, via which all other meaning must pass (e.g., all

patterns see, Hodge1975: 337-378.

19. In a recent study, "Reading Consonants and Guessing Vowels: Visual Word Recognition in Hebrew Orthography," Frost and Bentin (1992) deal with the complex morphology of the Hebrew language and its possible effects on reading strategies. "Hebrew orthography was designed to provide the reader with the abstract root information, regardless of the possible words that the letter string might represent. Thus the unpointed orthography served the purpose of denoting in print the optimal amount of phonological information. The gain in omitting the vowels from the print was multiple. First, the set of letters in the alphabet was smaller - Hebrew has only 22 letters - and the written words were shorter. Second, the presentation of consonants alone made the abstract root more salient (my italics). Indeed, the original Hebrew writing system was unpointed. It remained unpointed as long as Hebrew was a living language, that is, until the second century."

When studying lexical decisions in unpointed Hebrew texts, they state that "lexical decisions are based on a fast familiarity judgement of the consonantal cluster and do not require a detailed phonological analysis of the printed word."

20. An intriguing example comes from a modern Hebrew advertisement for a computer company (see fig. 15). The advertiser tries to play up the notion of "connectivity" which is inherent in the abstract root ר.ש.p $Q S S_{R}$ that stands at the base of the modern Hebrew neologism תקשרת tqšrt "communication." In order to intensify the affinity to the notion of "connecting," he takes two paths. In one - the textual - he gives the dictionary entry which describes linguistically the relationship of תקשת $t q$ šrt to its root. In the second, he offers a pictorial representation of the basic meaning of the abstract root, that of $q$ p $q r$-"knot" which immediately enlivens the probably already forgotten relationship to the old root; thus creating a fascinating "Egyptian-like"

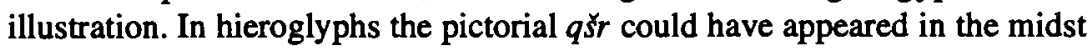
of $t q 5$ r 
Egyptian words which are built of the root $d \check{s} r$ should pass through the pictorial flamingo; all words built of the root $s n$ have to pass through the ideogram of the two-barbed arrow-head $\downarrow$, which represents iconically the notion of duality [EG, T22; Wb 4:148). ${ }^{21}$ In most cases, the reader will have to extract the abstract phonological entity from a particular icon, which will then stand in contiguity relations or sometimes in arbitrary relations (e.g. all words containing the root hnm [EG,W9; FCD:202] should pass through the jug icon) with the final meaning.

Under all circumstances, the Egyptians were highly sensitive to root structure. In the suffix conjugation, the verb is always represented with a morphology that keeps the root separated from the suffixes. The suffixes are never joined to root-letters to create biliterals or triliterals, although this possibility theoretically always existed. The phenomenon is most striking in the case of the first person suffix $i$. It is also requently understood as the carrier of the subject iconic identity. The result of this process is the surfacing of the complex nature of the signified suffix 1 st person (EG:39), in addition to its active dissociation from the root.

21. This sign should be contrasted with the one-barbed harpoon which stands for the notion of one (EG:514) 


\subsubsection{The Tool Stands as Signifier for the Owner of the Tool ${ }^{22}$}

A. 过 sš "scribe" (FCD:246)

If we pass this word through the semiotic examination we will probably achieve the following results:

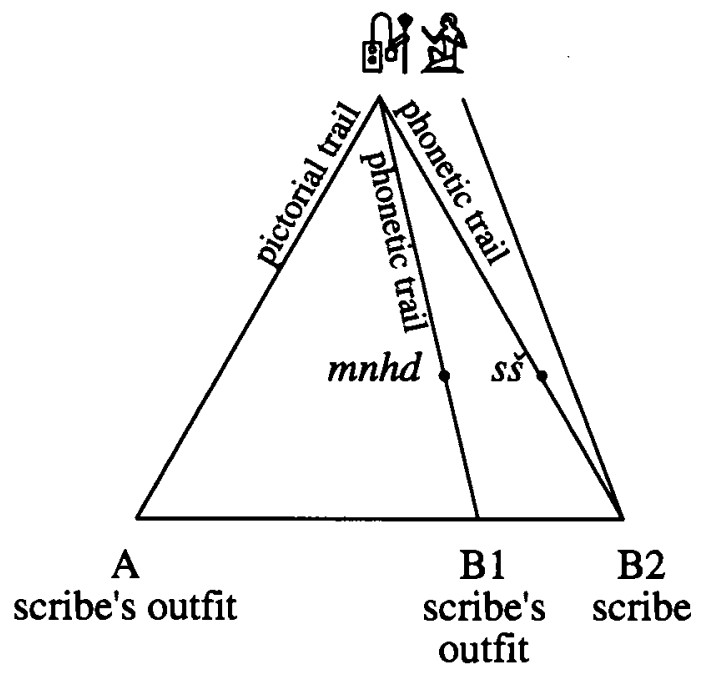

At least two different phonetic paths may be activated in this case. The iconic works as an iconic signifier, classifier, and as dispeller of ambiguity (see above chapter 2). The relations of signifieds A and B2 are metonymic. A is not completely discarded; the scribe's outfit stands in metonymic relations with the scribe, thus "thickening" the meaning by producing in the pictorial the tool which is central to his existence. The following examples exhibit more of the same characteristics.

B.

šmsw "Follower" (EG,T18; FCD:267) -

22. See Schott 1951:97. Schenkel calls this kind of sign "symbol" - "ein Symbol, dessen Gestalt im allgemeinen auf einen wichtigeren (semantischen) Aspekt des sprachlich Bezeichneten hinweist; z. B. das Schreibgerät fif für $z$ hisw 'Schreiber"' (Schenkel 1984:715). 
This sign probably depicts the equipment of an early chieftain attendant.

C. IIIIII shty (?) "Netman" (see above chapter 1) In the Old Kingdom inscription of Wernu the net sign नIIII stands for the "netman." (Or is he simply "the net"?)

D. †这 $h m w$ "Craftsman", hmmt "Craftsmanship" (EG, U24) -

The stone worker's drill again stands in metonymic relationship to "craft" or "craftsman."

E. 요 mdh "Hewer of stone" (FCD:124) The hewing tool stands for the worker.

\subsubsection{A Location Is Part of a Signifier for Someone Associated} with that Location
A. Ant 0 M

shty "Peasant" (EG, M20, p.591) -

The iconic sign of the marshland stands in metonymic relationship to the peasant.
B. 告)

histyw "the ones of the foreign land" (EG,N25) The iconic sign of the "foreign land" stands in metonymic relationship to the "dwellers of the foreign land." 


\title{
c. 애메네
}

\author{
shtyw "the horizon-dwellers" (FCD:5) -
}

The iconic sign of the horizon stands in metonymic relationship to the alleged dwellers of this region. (See the discussion of this word in Schenkel 1974). ${ }^{23}$

\subsubsection{The Part of the Body Responsible for a Certain Sense Is Part of the Signifier of the Sense}

A. $s d m$ "hear"

In this example (typical Middle Kingdom), the ear icon acquires the phonetic value $s d m$, as it is followed by the "phonetic complement" $m$, which takes the reader onto the phonetic trail. Yet the ear icon stands in conspicuous contiguity relations to the verb "to hear." However, its seems that the early choice made by the inventors of the script, to make the animal ear the iconic representative of the verb $s d m$ did presuppose certain constraints on its iconic powers. The New Kingdom phenomenon, which is known in Egyptological literature as "votive ears" or "ear stelae," presents large-size iconic human ears, either accompanied by an inscription or not, in votive contexts (Sadek 1988:245-267). However, as the "ear" of the god is what is looked for, the icon that metonymically represents the abstract quality is $\&$ the icon of the human ear, usually representing the noun $m s d r$ "ear" (EG, D18); nevertheless, the noun $m s d r$ can also be written iconically by the animal ear $\mathscr{Q}$ (EG, F21). The $\mathscr{O}$ icon was probably regarded as too much of a cliché, a "dead metaphor." The approach to the god with the human icon may also represent a prototypical choice pointing to a conceptual personification of the deities in the sphere of personal piety during the New Kingdom, surmounting their incarnations in different

23. Schenkel's description of the writing of "the entire town came to meet the king" probably also belongs here (1976). 
animalistic forms. If this is the case, a representation of an animal ear as the prototypical hearing organ of the god would be cognitively very intrusive. The parallel textual material, i.e., the "personal piety" texts, represent the same request linguistically as Imm imi msdr.k (LEM:17, 1.11), ${ }^{24}$ which is also a metonymic expression. In another prayer of the same sort Amon is called pi-sdm n 'š $n . f$ - "the hearer of the one who calls for him" (LEM:18,5).

The ear represents metonymically the god's attention, as does the English idiom "I am all ears."

\section{B. $001 \mathrm{~g}$ idnw (EG, F21)}

This title probably originally represented something like "the one who belongs to the ear" (see EG:62). Later, it is probably understood as a title. In a way, it is a secondary metonymy which stands in contiguity relation to the act performed by the ear and not to the ear itself (see below the discussion on the sail).

\subsubsection{A Coloured Entity Represents the Colour}

$$
\text { 11 ďr "red"25 }
$$

This is a prominent example of part-whole relations, where the part is represented by the whole. The part in this case is the colour "red" which should be extracted from the bird possibly denoted as "The Red." The

24. In the "personal prayer" to Amon we find the god metaphorically personified into the administrative realm, being called pi-tzty $n$ pi-nmh, "the vizier of the poor" (LEM:2,1.12-13). See also Shupak 1993:277-278.

25. The variation $\rightleftharpoons$ gave the reader enough phonetic information to lead him directly to the signified, based on the sentential and contextual information surrounding the word (this is the situation in old and modern Hebrew); however, the flamingo determinative adds information about the kind of redness. In the word $\rightleftharpoons$ C $M$ s'rt "desert" the phonetic signified is enhanced by an iconic signifier-signified which represents the "hill country," clustered along with "desert" around the same metaphoric axis (see discussion of the determinatives below). The $d \check{s} r$ bird retains its metonymic qualities relating to desert colours. For the writing of $d s ̌ r$ with the single hieroglyph of the flamingo, see Ritner 1993:147. 
abstract notion "red" belonging to the root $d \check{r}$ is materialized in writing by one of the root's variants, the flamingo. The reader has to activate a metonymical process, and take only the "red quality" as signified, out of the signifier "flamingo." The movement from the signifier "flamingo" to the signified "red" requires a metonymic process. ${ }^{26}$

An analogy of interest here is another type of red which is described by the word strictly in metonymic relation (no phonetic relation) to the signified. In this case, the quality "redness" should be extracted from the palette, and may be translated as "palette-red." Is that a different red? Are we confronted here with two types of red, "flamingo's red" (see Schott 1951:108) and "palette's red"? ?7 (on the colour "red," see Griffiths 1972; on the problematics of colour terminology, Weeks 1979: 66-68; Baines 1985a).

The "acquisition of meaning," through the signifiers, of other colourwords, like km "black" (Schott 1951:110) and wid "green," involves similar metonymic procedures.

26. Schenkel (1974:96) describes this procedure somewhat differently: "Das Derivatogramm stellt eine Assoziation mit einem Deszendenten (Derivat) dar; zum Beispiel (das eine Ableitung von $d \breve{s} r$ "rot sein" ist). Das Familiogramm stellt eine Assoziation innerhalb der Wortfamilie dar, wobei die assoziierten Elemente nicht durch Aszendenz oder Deszendenz verbunden sind; zum Beispiel

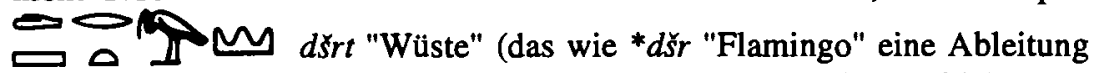
von $d s \zeta r$ "rot sein" ist). Für die Beispiele mit $d \check{r} r$ und seinen Ableitungen ergibt sich folgendes Schema (durchgezogene Pfeile geben die Richtung der Ableitung an, gestrichelte Pfeile die Ausbreitungsrichtung der Grapheme):

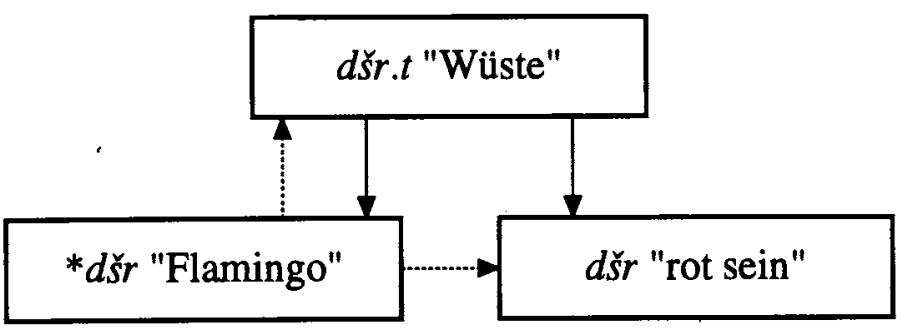

Here compare Hebrew's אדם 'dm which is the Biblical name of the Transjordanian desert.

27. Lefebvre (1949:74-75) writes about $\underline{t} m s$ - "Le déterminatif se réfère manifestement à la pastille d'ocre rouge de la palette des scribes." 


\subsection{The "Phonetic Metaphor"}

Many names have been assigned to the phenomenon I have called the "phonetic metaphor." Elsewhere known as rebus and in Egyptological studies usually as phonogram, it was the discovery of its crucial role in the script which paved the way for Champollion's decipherment of the hieroglyphs. In a sense, such a classification goes against the grain of the Champollionean tradition; to many it would seem almost a desecration to drag this phenomenon back into the pit of metaphor. For after all, was it not the notorious Greek "wholly metaphorical" approach to the script which blinkered all scholars attempting its decipherment before Champollion? Champollion himself, however, never underestimated the strong metaphorical powers of the script (Champollion 1836). I believe, therefore, that to seek an insight into the phonogram phenomenon achieved through the passageways of metaphor would be but the completion of a systematic description. As I have already said in chapter 1 , I propose to regard this phenomenon as merely another type of meta-pherein, "whereby aspects of one object are carried over or transferred to another object" (Hawkes 1972:1). Although not classified as a variation of metaphor per se by the Greeks, the phenomenon of Paronomasia is very close in its mechanism to metaphor. Metaphor is built on the discovery of similarities, or on the creation and revelation of such between two signifieds. When the enemy is called "the locust," the signifier snhm actually acquires an additional signified, besides that of the insect, taken from the word "enemy" (Kittay 1987:4). The new signified (the metaphoric one) is a combination of the two signifieds containing the characteristics of the enemy mixed with those of the locust. ${ }^{28}$ It should be stressed, however, that the locust is not incorporated as a whole into the "enemy signified"; some of its characteristics are disregarded or overlooked during this procedure. In other words, it is treated metonymically. The question of how this choice is made, or in the jargon of metaphor studies, how domains are mapped into one another, has long captured the attention of scholars. Recently it has been suggested that during the processing of the metaphor, a conceptual domain is created and the enemy is transferred at least temporarily from the domain of "human beings" into the new, temporary domain of "dangerous insects," of which the locust is a prototypical member. For a certain period, the enemy and the

28. For a discussion stressing the complexity of this procedure, see Eco 1984:87129. From the perspective of cognitive studies, see Tsur 1992:207-234; Shen 1991. 
locust become members of this category, which ipso facto defines what characteristics would be mapped. (This subject will be elaborated on in my discussion of determinatives). Of course, an ideology may sometimes have an interest in perpetuating certain categories. ${ }^{27} \mathrm{We}$ should remind ourselves here that pictorial representation per se (that is, in art) and pictorial representations in hieroglyphic script were often interchangeable in form, so that a similarity of prototypes offered itself to the viewers' attention, despite the different formal context. The locust in the script easily refers the reader to a pictorial representation of the same creature, thus retaining at least some of its attached sensuous information.

In using the example of the locust, I have chosen a rather rare metaphor, but all other more conventional metaphors of the culture appearing in the script can be analyzed in the same way.

If the basic phenomenon of metaphor - in this case a vehicle metaphor - is that a certain signifier takes a signified other than its own ("Metaphor is the application to one thing of a name belonging to another thing" Aristotle, Poetics, Chap. 21 [Hawkes 1972:7]), then in the rebus process, a certain signifier also takes another signified, but for different reasons. In examples like the $s\}$ - son, written with the icon of the duck, the signifier "duck" takes the signified "son." Yet this transposition is based not on any similarity of signifieds but on similarity between signifiers. Yet, unlike the poetic uses of puns and paronomasia, where the writer desires the signifiers to evoke two signifieds simultaneously, ${ }^{28}$ the "phonetic metaphor" procedure usually demands that the original signified be discarded, and the similarity between the signifieds is not necessarily evoked. The new sign is made of one signifier (e.g., duck icon) referring to one signified (son). However, as the rebus process is a kind of "restricted paronomasia," the ever-present option of completing the cognitive process is a tempting one, and in some cases leads further, to a search for some relationship between signifieds as well as signifiers, as in "real" metaphors. ${ }^{29}$ An important difference, however,

27. E. g., the Nazi propaganda movie Der ewige Jude which attempted to perpetuate through visual juxtaposition the metaphor "Jews are rats."

28. E.g., Shakespeare's "Ask for me tomorrow and and you shall find me a grave man" (Culler 1988:7).

29. For this subject see below. In his chapter on "The Nature of Semantic Change," Ullman classifies semantic changes under four categories: Metaphor, Metonymy, Similarity of Names, and Contiguity of Names. Thus phonetic similarity stands in one line with metaphor and metonymy in the cognitive process of "extension of meaning" (1967:211-227). 
between metaphor and paronomasia is that, as we have seen above, when metaphor combines two signifieds, a complex process of choice (or mapping) takes place, where only certain qualities of the vehicle are transferred to the target. When the king is called the $k 3$ nht (strong bull), that, of course, does not imply that he has four legs and a thick hide, but that he is strong, fertile, powerful and so on, a selection of characteristics firmly rooted in cultural indoctrinations. ${ }^{30}$ There may be situations where different cultures will map different qualities, or partially different qualities, from the same vehicle into the target. (This may even be the situation with the falcon, where the question is raised whether his hunting qualities played a part in his identification with the king). Such choices necessarily involve a concomitant process since only a part of every vehicle can be carried into the target. One notable difference therefore arises between this and the rebus principle. When the resemblance is based on signifiers, a metonymical process also takes place whereby a certain part of the sign - its name - is extracted. Yet, unlike in metaphor, the transposition process in the rebus is a constant, given a priori, by definition of the process itself - always addressing itself to the phonetic qualities of the sign. Thus the phonetic metaphor is a strictly language-contingent process and hence untranslatable.

When alluded to in most publications, ${ }^{31}$ the "phonetic metaphor" is called a rebus. Yet, it shares with paronomasia the quality of being "a figure in which, by mode of modification of sound, or change of letters, a close resemblance to a given verb or noun is produced, so that similar words express dissimilar things" (Culler 1988:5). ${ }^{32}$ The Egyptian rebus system is probably built on similarities of roots, and not only on homonymous puns like pear and pair (e.g., Hodge 1975; Schenkel 1984).

30. Compare Keel's discussion of this subject in his book The Song of Songs (1994:25-30). The ad hoc Porphyrian tree created here would be "strong dangerous creatures" or the like.

31. Rebus is mostly used in non-Egyptological publications, whereas in Egyptology the term "phonogram" prevails, although Schenkel (1984:716), differentiates between "rebus" and "phonogramm." See also Kaplony's "übertragenes Ideogramm" (1966:63). Gardiner defines the rebus as "using the pictures of things ... to indicate certain other entirely different things ... the names of which chanced to have a similar sound" (EG:7).

32. The Latin example is "Hic quos homines alea vincit, eos ferro statim vinciit" - "Those men who he beats at dice, he straightaway binds in chains." Culler regards verses like Verlaine's "Il pleure dans mon coeur/ Comme il pleut sur la ville," "live" and "love" "amor" and "mors" as cases of paronomasia. 
In his article, "The Contiguity Illusion," the semiotician Décio Pignatari (1978), discusses Roman Jakobson's distinction between the two fundamental operations of speech - the selection of certain linguistic units to substitute for another (metaphor), and the combination of selected linguistic units into units of higher complexity (metonymy); Pignatari proposes adding to the Jakobsonian examples for the metaphoric cluster around the axis of "hut" (cabin, hovel, palace), the variations "hat," "hit," or "hot," regarding them as instances of the "iconization of the verbal." Later, in his final table, he places paronomasia and metaphor along with "similarity, analogic, icon, art, poetry, signifier and the right lobe of the brain" opposite "contiguity, logic, symbol, verbal science, prose, metonymy, signified, and the left lobe of the brain. ${ }^{.33}$

For years, "punning" was regarded as almost beyond the intellectual pale (Tsur 1992:93). Lately, paronomasia, puns and their variations have regained the interest and respect of scholars. In a comprehensive essay, "The Call of the Phoneme," constituting the introduction to his collection of essays on puns, Jonathan Culler stresses the importance of paronomasia and puns in the history of thought, literature, and psychoanalysis. ${ }^{34}$ Reinstating the pun within the Jakobsonian "poetic functions" of language, Culler follows Derrida in suggesting it be viewed as a pregnant cluster suggesting a structural relationship. Culler and his associates believe that one should regard this kind of reasoning, so highly favoured by ancient cultures, as well as by poets of all ages, with respect; its subterranean activity in many texts being the place par excellence where the text assumes a life of its own.

33. The relations of scripts and brain activity are the subject of an intriguing book that was recently published. The Alphabet and the Brain searches for the roots of Greek philosophy and mathematics in the Greek writing system, which in the opinion of some authors activates the left part of the brain, while "ideographic" scripts, like Chinese, activate the right side. Undoubtedly, hieroglyphs belong to the "Chinese group" without being identical. However, there are basic differences between the Chinese and the Egyptian languages and script systems.

34. Vernus in his article in Littoral, established for the first time the relations between the Egyptian phonograms and the psychological analysis processes described by Freud. However, it was Lacan who proposed paronomasia as a central method for dream analysis and the understanding of the basic mechanisms of language. See also Abraham and Torok's (1986) elaborate study on the "Wolf Man." 


\subsubsection{New "Puncepts" of the Script?}

Can the "puncepts" ${ }^{35}$ of the script ${ }^{36}$ assume a life of their own? Are those combinations of signifiers-signified, (the ad hoc category is probably a phonetic one here) - duck-son, bird-soul, plough-love - possibly also related on the basis of their signifieds?

Addressing himself to the "duck-son" example, Horapollo suggested that the duck stands for "son" because ". . this bird is very philoprogenitive. If it should ever be pursued in order to be taken with its young, the father and the mother give themselves voluntarily to the dogs, so that the young may be saved" (p.66; also van de Walle and Vergote 1943:81). Horapollo's mistake was that he tackled the problem with the tools of "classical" metaphor, searching for the a priori connection between the signifieds, whereas in actual fact, the connection probably originated in the signifiers. Yet, during the 12th dynasty (EG, H8), in the hieratic texts of Illahun, we find a new "figure of script." Instead of the duck, an egg suddenly plays the role of the iconic signified to the signified "son" (Luft 1993:293). ${ }^{37}$ Unless there is some unknown phonetic reason, it seems the replacement of the duck was initiated when the scribes pondered the possible relations between the signifier/signified "duck"38 and the signified "son." Hence, a new relationship was materialized between the son and the duck. The duck may represent the son by virtue of its metonymic element "the egg" which is the "source

35. This term was coined by Ulmer 1988. He suggests that puncepts work for organizing thought as well as concepts (sets formed on the basis of similar signifiers rather than similar signifieds).

36. Within the sphere of Egyptian literature and religion, the pun constituted a basic phenomenon for contemplation. The importance of the pun for the development of Egyptian writing system (with examples from the Pyramid Texts) was strongly emphasized by Hodge 1975.

37. The examples come from pLondon UC XL.1 and pBerol 10002. Luft writes: "The parent's name follows an egg for $s$ clearly distinguished from the element of personal names si like Simonthu (si-mntw)."

38. The fact that the duck signified was never completely discarded is well attested in a fascinating example cited by Pascal Vernus, in his article "L'ambivalence du signe graphique dans l'écriture hiéroglyphique" (1987,fig.5). In a relief of Ramesses II , the $s 3$ duck, which makes part of a $s 3-R^{\prime}$ combination (i.e., has to be read phonetically), is offered by a seated Osiris in a neighboring column, an ' $n h$ sign directed to its beak. This unique gesture is accompanied by a small hieroglyphic explanation, reading "to your nose." 
of all sons." It seems that this metaphor surfaces later also in the sphere of language, when the king is alluded to (through a replacement metaphor) as the swht "egg" (Grapow 1924:86-87). ${ }^{39}$ However, one can not exclude the possibility that some kind of "Horopollian" reasoning stood behind the a priori choice of the duck for the pictorial representation of the phonetic si-son.

Another possible occurrence of this kind of "graphic rhetoric" (see above chapter 2) is the sign $b_{3}$. The abstract notion of the $b_{3}$ in Egyptian culture is notated in the script with the signifiers of a bird or a ram, probably on the grounds of paronomasia. In the Pyramid Texts as well as in the Coffin Texts the notion $b_{3}$ is preferably written with the bird. ${ }^{40}$ At a certain stage (Zabkar 1968:83), a new hieroglyph appears; the signifier is no longer a simple bird, but a human-headed bird signifier now refers simultaneously to two signifieds: bird (original iconic signifier) and the originally phonetic signified "soul,"41 represented now also in the pictorial signifier (metonymically or synecdochically) by the human head. The iconic signified of the bird is not discarded, but new relations are being woven between the original signified of the bird and its acquired phonetic signified - "soul." The $b$; is visualized in the form of a "human-bird," dramatizing the ability of this part of man's free-moving being to come and go from the grave.

We should, however, exercise caution when attempting such reconstructions, for metaphorical concepts like "soul birds" may theoretically have already existed as a conceptual metaphor outside the realm of the script. ${ }^{42}$ In that case, the script should be seen as a pictorial representation

39. E.g., Hatshepsut calls herself swht w3bt - "the pure egg" (Urk. IV:361,14). In one of the versions of Merikare (pMoskau Nr. 4658) we find a close metaphor, egg=womb - ir.n.fn.sn hlksw $m$ swht - "He made for them rulers in the egg" (Helck 1988:86). The papyrus dates from the second part of the 18th Dynasty. The two other versions give the word sty instead of swht. It is of course impossible to know which word appeared in the putative Urtext. This variation of the metaphor appears also later, e.g., rdi.n.k. (w)i $r$ nsw iw.i m swht "While I was (still) in the egg he appointed me as king" (or "while I [still] was as an egg"; KRI V:239,5).

40. See Ward 1978. On the ambiguity of the $b 3$ sign, see Schenkel 1974:93.

41. I use the word "soul" for lack of a better translation in English. On the complexity of the $b_{3}$ notion, see Žabkar 1975; Assmann 1983.

42. Compare Lakoff's note on the classification of birds and women in the same 
of a conceptual metaphor (as in the image of the tree-goddess, see Appendix $\mathrm{B}$ below); however, this representation comprises a signifier that refers to the combined entity of two signifieds. ${ }^{43}$

\subsubsection{The Case Of Monoconsonantal Signs.}

The monoconsonantal group is a well-defined group within the script. The members of the group share, in addition to their common reference to a one-consonant unit, the ability to play the role of the "phonetic complement." As I have shown above in chapter 2, when appearing in this role, monoconsonants actually lead the reader onto the "phonetic trail," directing him to leave behind the iconic options. This characteristic of the group was also accentuated (although somewhat differently) by Kaplony, who regards them as "phonetic determinatives." Though built from the same "rebus materials" as the other signs, they tend to be more limited by the code. In most cases they do not acquire an iconic signified, but only retain a phonetic signified. It is this quality which enables them to become the "heralds" of phonetic readings. If we take, for example, the sign $m$

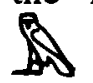

(which possesses a strong iconic identity), we may observe how rarely it retains its iconic sense. ${ }^{44}$ Its iconic signified is nearly always discarded (unlike biliterals and triliterals), indicating a rather constant shift to the phonetic trail. Unlike the former example of the $s$-son, the monoconsonant usually does not acquire a new signified by itself, but

category in Dyirbal language, as birds are believed to be the spirits of dead human females (1986:16). The appearance of the "soul-bird" in the Meroitic culture (on different levels of interaction ([Žabkar 1968:84-85], compare the metaphor "tree-goddess" below, Appendix B), and its long life within this culture, may suggest the power of this conceptual metaphor; see also Frankfort 1948. The metaphor also surfaces in Talmudic Hebrew as "צנפור הנפש" "soul bird" - referring to the most intimate, precious part of the human identity.

43. The in $\$$ discussed below in chapter 1 is, of course, also a "puncept." I shall devote a special discussion to the semiotic status of the "legged" group of signs in a future publication.

44. However, its iconic identity was probably never completely discarded, as we can learn from mutilated $m$ signs on the coffin of Princess Nubheteptikhered (Spencer 1982:157 fig.55). For signs-mutilation in funerary contexts, see below 3.5. See also the nini example p.44 above. 
completes (in cases of writing in monoconsonants) or repeats (in the case of the so-called phonetic complement) some phonetic information. Their alienation from their iconic meaning, and the submissive acceptance of a "phonetic signifier" identity without a reference to a new signified, place the monoconsonants of the hieroglyphic script on the direct route to the alphabetic system, except that they still sedulously guard their iconicity. However, having lost their iconic sense, they are the likeliest of all hieroglyphs to become "dead metaphors," as they rarely any longer initiate the movement between the concrete and the abstract as other signs do.

It seems, therefore, that the hieroglyphic system had actually contained from its earliest age (Kaplony 1972; Fischer 1989) an embedded system of "alphabet." At the latest, from the time of the Pyramid Texts era, we have abundant examples of spellings with monoconsonants only (usually plus determinatives) which are very similar to spellings in other root languages like Old Hebrew (excluding, of course, the determinative phenomenon).

What then prevented the learned scribes of the Pyramid Texts from changing the whole system into a uniliteral one? Beyond reasons of decorum, it was probably the rich cognitive and semiotic scope which the pictorial script in its full iconic scale offers its user; a richness, which would have inevitably been utterly lost in an alphabetic script.

A skeptic would be wise to ponder Gunn's response to the experiment of a scribe of the Saite period, probably under Greek influence, in writing parts of an inscription in uniliterals : ". . the complexity of normal Egyptian writing, with its determinatives and word-signs, its traditional differences in orthography for different words having the same consonants ( single consonants in an unbroken succession (for the Greeks, from whom on the hypothesis the alphabetic idea came to the Egyptians, did not yet divide their words) - witness the difficulties in reading the Naukratis stela! Perhaps it is now time to stop chiding the Egyptians for not 'taking the step which seems to us so obvious', and discarding all but their uniliteral signs, availing themselves, as it is often expressed, of the alphabet which they had all ready to hand" (Gunn 1943:56). ${ }^{45}$

45. Te Velde remarks on the same inscription: "The readability of the text was however not improved but on the contrary hampered by the unusual writing with uniliteral signs as Gunn rightly remarks" (1988:174). See also Lacau's opinion when he writes "Réduit à ses éléments purement phonétiques, le système graphique serait beaucoup moins clair: son aboutissement aurait été 


\subsection{On the Border of the Illusionary}

Icons are uncanny creatures. In funerary contexts, ${ }^{46}$ where fear conquers reality, we find them mutilated. Icons such as lion, snake, crocodile or even duck, are legless or cut. Even though the icon should have been voided of its straightforward iconic meaning through its status as representative of a word as well as by its phonetic function, on certain occasions it seems the scribes found it worthwhile to dismember or mutilate it, as though it still had the threatening potential of the "real" (see Lacau 1914,1926; Yoyotte 1963:103; te Velde 1986; Ritner 1993:157). Such examples provide strong evidence of the extraordinary resilience of iconic signifiers. It seems that the iconic sign (signifier/signified) remains the most potent device for evoking other related connoted signifieds.

While the alphabetically written word "lion" does not automatically evoke all its possible connoted signifieds, a pictorial representation of the lion may. Indeed, modern advertisement is constantly cashing in on pictorial potential (subjected to cultural code), and introduces the lion - in illustration or photography - to convey "kingship" or "power," where words are bound to fall flat.

The primal additional signified carried by a scorpion, for example, in the Egyptian cultural code was probably "dangerous" or "fearsome." Although hampered by the definite effort to liberate the scorpion-icon signifier from any obstrusive signifieds, "danger" was still alive in the hieroglyphic scorpion. Many icons convey different additional signifieds, not only "fearsome" or "dangerous." Ducks or owls carry the additional signified "ability to fly away." It is possible that this ability is the underlying cause of their mutilation, so that they should not run away (from the

l'alphabet des sémites. Et même quand les mots sont séparés par des points, par exemple dans les plus anciens textes, le squelette consonantique des racines laisse encore place à bien des hésitations. Il nous suffit d'ailleurs tout simplement de lire une phrase égyptienne transposée dans notre système actuel de transcription, même en prenant soin de séparer les mots, pour comprendre qu'une pareille simplification eût été obtenue aux dépens de la clarté" (1912:217).

46. The context in which this conjuring up takes place seems to be one in which the deepest fears, reality and magic commingle. In the realm of the dead, man is more susceptible to the awakening of the signified. In a way, this may be compared to today's film experience (in contrast to television) which puts the addressee in the dark, in a transition state between dream and reality, where the pictorial signifieds acquire dimensions beyond their reality. 
inscription, i.e., the tomb) or regroup themselves into dangerous words (Kaplony 1972; te Velde 1986; also the iw [bubal] Pyr.1188).

However prototypical, due to its iconicity, the hieroglyphic sign is kept oscillating between the word and the world; the pictorial prototype has the power to move back, in certain contexts, from the status of "signified," in the abstract linguistic realm, to the representation of a referent in the real world.

Moreover, in Egyptian belief, the icon may be "brought to life" with the help of magic. Hence, any "cracking" of iconic existence is necessarily also the "cracking" of the prototypical signified (here compare the ritual of the Execration Texts [Borghouts 1980:1143]), which may awaken into a referent, and then into a real existence.

A never-locked passageway leads from the icon to the garden of metaphor, and from thence beyond the wall, to the experience of the real. One may say that the icon is a sign which "uses its user" by arousing meanings that are extraneous to those intended at its conception. In Saussurean terms, when activated as a signifier in a strict sign system, the icon which retains its iconic meaning will always be a multi-signified signifier, rarely to be flattened or narrowed into a single restricted signified (Barthes 1977). Still, it is important to remember that even these extraneous meanings are confined within the cultural environment of their day; though possessing a certain measure of freedom, the icon is yet far from suggesting "wilde Semiose."

\subsection{The Determinatives}

\subsubsection{A Few Introductory Words on Categorization and Conceptual Domains}

Linguistic categorization has been the object of study since the days of Aristotle, via Wittgenstein, Austin, Rosch, Lakoff and many others (Taylor 1989). In this work, I have chosen to remain within the framework of Rosch's school of categorization, a framework usually defined as "the theory of prototypes and basic-level categories" (Lakoff 1987:39 and passim) which seems the most suitable for a description of the Egyptian system.

Elinor Rosch and her followers stress the notion that the world mirrored in the human categorization system is a perceived world, in which anything may be categorized by infinite methods under infinite headings. Yet people make choices, and these choices seem to be governed by certain 
rules. For example, they do not assemble things in the world by categories of colours or shapes. (There is no natural category of "red things" or "round things"). Rosch defines the principle of a categorization system as

having to do with the structure of the information so provided and asserts that the perceived world comes as structured information rather than as arbitrary or unpredictable attributes. Thus maximum information with least cognitive effort is achieved if categories map the perceived world structure as closely as possible... as an organism, what one wishes to gain from one's categories is a great deal of information about the environment . . To categorize a stimulus means to consider it, for purposes of that categorization, not only equivalent to other stimuli in the same category but also different from stimuli not in that category (1978:28).

It would be of the utmost interest to follow the "dissections" of worldknowledge represented by the determinatives of the Egyptian script system. As Rosch has shown, there is no one-to-one correlation between knowledge and language. Language may "lag behind" knowledge, just as it may shape knowledge on other occasions. Baines' (1985a) findings concerning colour terminology versus colour classification in Egypt confirm this approach. The determinative system, being meta-linguistic, ultimately reveals certain aspects of the conceptual system which have not been materialized in the lexicon.

According to the classical view of categorization, no member of a category would have any special status; the properties defining the category are shared by all members. It is "a theory about things as they are in the world" (Lakoff 1986:45). It was Wittgenstein and his theory of "Family Resemblance" that caused the first major rift in the classical theory. However, the significant breakthrough towards an innovative conception of categorization theory was accomplished through the studies of Roger Brown and Brent Berlin, followed by Elinor Rosch and her collaborators. The main difference between Rosch's point of view and the previous point of view is that Rosch defines some members of the category as having priority over other members of the same category. These members would be defined as "best examples" or "prototypes" or "cognitive reference points" and are shown to be more prominent than others.

Every categorical taxonomy consists of vertical and horizontal dimensions. Taking the example of the natural category "animal," we find the word "animal" itself classified as a superordinate term. Beneath this level, we find the basic-level (folk-generic) terms such as,"dog," "cat," 
"mouse" and so on. Each of these terms has a subordinate set of members, such as Retriever, Pekinese, Saluki.

The vertical dimension of the latter taxonomic cluster would be animal - dog - Saluki. The horizontal dimension on the basic level would be - dog - cat - mouse - giraffe, etc. On the subordinate level - Retriever, Pekinese, Saluki, German Shepherd, etc. ${ }^{47}$

A few central aspects of the "prototype theory" are of key importance to our discussion, especially the ones discussed by George Lakoff in Women, Fire and Dangerous Things.

\section{a. Basic Level Effects}

1. The basic level dimension is the highest level of a category at which category members have similarly perceived overall shapes (e.g., dog versus animal)

2. The basic level is the highest level at which a single mental image can reflect the entire category (basic level objects appear to be the most abstract categories in which an image can be reasonably representative of the class as a whole).

3. Most attributes of category members are stored at this level. Lakoff goes on to define basic level as "distinguished from other levels on the basis of the types of attributes people associate with a category at that level, in particular, attributes concerned with parts. Our knowledge at the basic level is mainly organized around part-whole divisions. The reason is that the way an object is divided into parts determines many things. First, parts are usually correlated with functions, and hence our knowledge about functions is usually associated with knowledge about parts. Second, parts determine shape, and hence the way that an object will be perceived and imaged. Third, we usually interact with things via their parts, and hence part-whole divisions play a major role in determining what motor programs we can use to interact with an object. Thus, a handle is not just long and thin, but it can be grasped by the human hand" (Lakoff 1987:46-47 and passim). This is of course a description of metonymic relationships.

47. This theory bears a basic resemblance to the theories of Dictionary and Encyclopedia. Eco (1984) summarizes the complex views on these matters. Yet these theories do not postulate the existence of the prototype. On its bearing on the Jakobsonian "two poles of language," see below. 


\section{b. Prototype Effects}

According to the classical theory, no member of the category has any special status; the properties defining the category are shared by all members.

Rosch's studies have shown that certain members of the category are perceived as prototypes or cognitive reference points; in other words, they are "best examples." A chair is a prototype of the superordinate category "furniture" (and not a lamp or a mirror). An armchair is the prototype of the basic-level "chair" (and not a bar chair). Prototypes are usually considered to be the most representative members of the category, and the most prominent ones.

\subsubsection{Ad Hoc Categories}

Ad hoc categories are not conventional or fixed categories but "rather made up on the fly for some immediate purpose" (Lakoff 1987:45). Yet, ad hoc categories obey the same rules as natural categories. They also present prototype structure, are based on common relational structures and make possible inferences from one member of the class to the other. The common example is "things one takes from one's home during a fire" (Barsalou 1983; Shen 1994). It has recently been argued that metaphors are ad hoc categorizations (Glucksberg and Keysar 1990). As Shen recently put it "metaphors consist of concepts which belong to different common taxonomic categories, whose interpretation consists of the creation of an alternative, ad hoc, grouping of the conceptual world. . . in the metaphor 'rage is a volcano,' instead of the common stable categorization of 'rage' together with other types of emotions. . . the procedure. . . is suggesting an alternative grouping of 'rage' - this time with 'volcano' as members of an alternative ad hoc category which is typically represented by the 'vehicle' (i.e., 'volcano'). This category can roughly be described as 'things that erupt violently and unexpectedly,' although we should take into consideration that this is merely a label for certain semantic/conceptual content which represents the ad hoc category in question" (Shen 1994). Thus, this theory suggests that all metaphors are class inclusion statements, and explicitly links categorizing processes to metaphor understanding (Gibbs 1994:246247; compare here Gombrich's discussion on Impresa [1972:160-170]). 
This cognitive perspective strongly resembles the semiotic views of the "ad hoc Porphyrian tree" as presented by Eco (1984:93-94 and chapter 3 above, note 1). However, I have given preference to the cognitive approach, since the semiotic approach overlooks the fact that the vehicle in the ad hoc category (for that matter the ad hoc Porphyrian tree) is mostly a prototypical member of the newly formed category, of which the tenor is usually a less prototypical member (volcano is more prototypical for "things that erupt violently"; locust is more typical to a category like "frightening, appearing in thousands, causing ultimate destruction" than the simple "enemy").

\subsubsection{Domain}

The definition of "domain" is somewhat vague. I shall use it in this work to define networks of taxonomic and schematic relations; these are in fact organized knowledge, which form correlational structures (see Shen 1991), and a cluster of information composed of dictionary and encyclopedic knowledge. This knowledge is culture-bound (Eco's "code") and emerges from world knowledge. A word gets its meaning not only from paradigmatic and syntagmatic differences à la Saussure, but is embedded in knowlege and beliefs (Taylor 1989:83). Domains are probably built of series of categorical classifications and attributed properties (Lakoff 1986:31). They may have fuzzy borders and may well overlap partially.

If we remind ourselves at this point of the two Jakobsonian dimensions presented at the beginning of this chapter - the metaphorical and metonymic axis - we may easily perceive that the metaphoric axis is parallel to the categorical relations, whereas the metonymic axis is parallel to the schematic one. Yet, metaphor per se will be created in cases when two concepts are not simply placed on the metaphoric axis (within the same category), but belong a priori to different categories.

\subsubsection{A Glimpse into the Landscape of the Egyptian Mind - The Status of the Determinatives}

Determinatives are related to the word preceding them in two main ways: metaphoric or metonymic, i.e., categorical or schematic. Together they form part of a domain. Sometimes the word carries two determinatives representing both axes. Any arbitrary look at the determinative in the 
dictionary will reveal the kind of movement we are already familiar with from the iconic to metaphoric or metonymic relations. The determinative may have an iconic relationship with the preceding word, or may relate to it in metaphoric or metonymic ways.

\subsubsection{The Metaphoric Axis}

\section{a. Iconic Determinatives - The Horizontal Dimension}

These are repetitive pictorial representations of "the whole," and are close to linguistic synonyms; therefore they belong to the metaphoric axis (Jakobson 1956). Being "pictorial tautologies," and by the rules of the script repetitive, they probably represent in the pictorial the Egyptian prototype of the word which makes the category ("Most of our words and concepts designates categories" Lakoff 1987:XIII, in his discussion of the objectivist view). This group is self-limiting due to its iconic nature. Here are some randomly selected examples:

'rrwt "gate" $\sum_{0} 0 \sqrt{1}$ (FCD:45); 'nht "goat" f 'rt "jaw" (FCD:38); iw "dog" (FCD:12); tbwty "sandals"

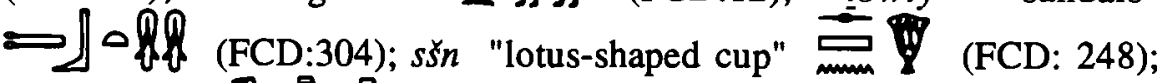
imm "seize" can be determined with the prototypical action: nini "greeting" " (FCD:126); ${ }^{48} \mathrm{~ms}$ "bear, give birth" $\|$ 月; in the last example the pictorial prototype refers to the human procedure, although the verb can refer to animals (e.g., Appendix A below and st $m s$ "egg laying duck" [FCD:206]). A sociological prototype is concealed in the choice of $s d r$. (EG: 593) "spend the night" (FCD:259), as I already mentioned in the first chapter. Another prototypical human choice appears with the verb $m t$ "die" (FCD:120), whereas the verb hism "to catch fish" accepts as its determinative a bird (egret) picking on a

48. For a recent contribution on nini, see Westendorf 1991 , and p.66 above. 
fish, i.e., an animalistic prototype (FCD:163). The last examples may possibly also be regarded as superordinate categories which are classified, by a lower-order example, probably the prototypical basic level ones. ${ }^{49}$

\section{b. Superordinate Determinatives - The Vertical Dimension}

This is the most common type of categorical relationship presented by the script. The superordinate categories referred to in the following examples are not identical with modern natural classifications, but present somewhat different conceptual domains, which are yet to be studied in detail. The few examples I have suggested only bear witness to the existence of the phenomenon.

The most obvious examples occur in places where specific gods are determined by the "general god" $\rightarrow$, त (EG:32) determinatives. The falcon determinative seems to be a basic-level member whose position as a prototype grants it the power to become a representative of the more abstract superordinate level (Lakoff 1987:79 and passim). ${ }^{50}$ The same phenomenon is attested to in the case of various trees. Most basic-level members of the

49. E.g., 'swt $\triangle 0 \rrbracket \& 8$ Pyr. 1957b. This kind of "reversed classification" is typical of the Old Kingdom, e. g., 'wt hsst "desert cattle" in Fischer 1977:74. In this relief a "visual reference game" is played with the beholder. The cattle determinative in the inscription appears in line with the large-scale pictorial representation of the cattle; the desert game also appears in line with their large-scale representation, and the four kinds of ducks in the pictorial representation are connected to the ducks in the inscription. See also iws with four kinds of cattle, in Munro 1993, pl.19.

50. This process is described by Schenkel as "Die einzelnen Semogramme sind entweder gemäss a) bzw. b) nur spezielle Semogramme oder gemäss c) allgemeine Semogramme; oder aber sie können beides sein: Ein Semogramm, das als allgemeines Semogramm auftritt, kann zugleich einen besonderen Bezug zu einem ganz bestimmten in seine Bedeutungssphäre fallenden Wort (und den etymologisch mit diesem verwandten) haben, einem Wort, dem par excellence die betreffende Bedeutung zukommt. Z.B. steht $\square]$ als allgemeines Semogramm gemäss c) bei Bezeichnungen von Gebäuden wie $\square[$ 'wt 'Kammer' . . . oder $\stackrel{\text { S }}{\square}$ sht 'Horizont' . . . Das typische Gebäude aber, das das Shc.-Zeichen im übrigen darstellt, ist prw 'Haus'; dementsprechend steht [] als Notation gemäss a) in der Schreibung $\left.{ }_{1}\right]_{p r w}$ 'Haus'"' (1984:721). 
"tree category" accept what has become the general "tree determinative" (EG, M1). This is generally viewed as a schematization of what was probably determined by the cultural code as the "tree prototype" - the sycamore (Baum 1988). Here again the more general notion is represented by the prototype.

Another superordinate category represented by the prototype is what might be regarded as the "human (male) category." It classifies what may be regarded as various basic-level and subordinate terms, describing different social statuses and occupations, e.g., idhy "march-man' $4=844$ i⿱乛龰 (FCD:36); 'nh "person" $f^{m} \in$ (FCD:44); 'prw "sailors" (FCD:42); wt "embalmer" (FCD:71); sdmi "judge" 104 (FCD:259) or itw "thief"

This superordinate sign carries a strong additional signified "Egyptian" (see above chapter 2).

Another form of a pictorial representation of an abstract superordinate classification can be discerned through the Egyptian sign which follows most basic-level words classified in English under the superordinate term "animal." Most animals take an a priori iconic determinative, but many of them may additionally take a sign that seems to represent "animal skin + tail." Thus the possible literal definition of the superordinate term is "having skin and tail" (EG, F27). Otherwise the same sign was used in the script to define the notion of "made of leather," meaning iconically "animal hide." The tail was probably the only pictorial device which could ensure an understanding of the sign - a shared metonymic characteristic which in the pictorial came to represent the abstract whole. It may be argued that in this case no prototypical member would provide a "gestalt" general enough to stand for the whole category. Indeed, since animal icons carry strong iconic power, it is probable that no prototypical member could be generalized to the extent of representing the whole category. If compared to the god determinative case $\rightarrow$, the signified is not "a falcon" but "the falcon-god on the standard," the iconic identity of the bird itself is not as compelling.

Some very conspicuous examples of superordinate terms are the determinatives usually described in Egyptology as "bad" ,abstract" $\longrightarrow$, "aggression" Hand "movement" $\triangle$ (EG,Chap 24; Schenkel 1984). These superordinate terms and their possible evolvement are outside the scope of this work and are the subject of a separate study. Nevertheless, 
one may remark that the "aggression" determinatives ( prototypical representations (once again expressed in human terms; the "shortened" representation is a pictorial synecdoche, emphasizing the limb responsible for the aggression). It seems they also represent prototype selections that stand for a superordinate abstract.

In the case of the "bad bird," one must keep in mind that categories are an outcome of a perceived world, and are, as a result, bound by cultural codes. It appears that in a certain period, in the agricultural society, the crop-eating sparrow was considered as the "best example" of bad events. Less straightforward is the category of the papyrus, which originally meant "written" or "belonging to writings" (Wiesmann 1922). It may over time have acquired an extended meaning like "what is on papyrus" or "in written words, but not in reality," or "in words, but not in reality," to the modern mind an ultimate definition of "the abstract" (see also chapter 1 above, n.68). The mechanism operating here was probably that of a metonymic extension or ad hoc categorization. If "conceptual metonymy" was involved, it means that a certain category or domain was extended by a metonymic process which involved the transition from "central cases" which contained concrete, basic-level objects (in our case materials connected with writing), and was then probably extended by metonymy to "things that exist only in writing and language." This process is exemplified by Lakoff on the Japanese classifier Hon (Lakoff 1986). However, in the case of these superordinate categories or domains, the fundamental question that arises, and the most important one to my mind, is what were the cognitive and cultural reasons which made this particular dissection-scheme of the world worthwhile for the ancient Egyptian? This question is especially intriguing in the case of the so-called "abstract" category. Why was the "abstract" category differentiated in the first place? Did it have anything to do with some kind of "Domain of Experience Principle" ${ }^{51}$ The assembling of the "evil" "harmful" things in the world in a separate overriding category is easier to understand. Lakoff describes this phenomenon by what he calls the "important property principle." One of the most prominent qualities that can separate an element from its natural category is "harmfulness" (Lakoff 1986:16). This quality appears in the Egyptian script mainly as a secondary superordinate classification. Yet the "bad" category, as every other category, presents basic central members like bin 40 "bad" or šw "empty."

51. See Lakoff 1986:20. 


\section{c. Parallel Determinatives - On the Horizontal Dimension}

Words that take determinatives which do not seem to be activated as superordinates, but remain on the horizontal dimension, are rather rare. Yet the phenomenon indubitably exists. A clear case is the word idyt -"girl" $4=490$ (FCD:34); in this case what was probably the prototypical member "boy," categorizes the girl, where we might have expected a superordinate "woman" determinative. The same phenomenon appears in the word hwnt "maiden" provides a double categorization $1+0$ m horizontal and on the vertical dimension at once, and again in one of the variations of the writing of isyt "old woman" 1 A 1 A The first determinative is the prototype of "the elderly," the old man, which stands on the horizontal dimension, the second determinative is the superordinate "woman," evidently the vertical dimension. In the case of the $i$ w "old man" 1 (FCD:8) the situation is simplified, as the first determinative is iconic and the second is the superordinate term "man." 53 Another possible example of horizontal categorization is the $\breve{w t}$ feather $\beta O$, which may accept the "hair" $\beta \beta$ III determinative (FCD:262) (is the feather understood as "consisting of hair"? In this case it would be transferred to the metonymic axis). The word inm which is translated by Faulkner as "skin of man," appears with the animal skin determinative which is the prototypical pictorial representation (see above). When the word denotes "animal skin" it may take the hair determinative $4 \pi$

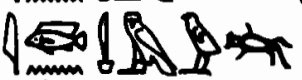
(metonymic), or a rare iconic determinative (Urk. IV:329,10) of rug-like panther skin (FCD:23).

52. One version (BH2C) of spell 162 of the Coffin Texts provides a variation with the child determinative followed by the superordinates "man" and "woman", i.e., "mankind".

53. "Folgen mehrere Determinative direkt aufeinander, so geht die Abfolge vom

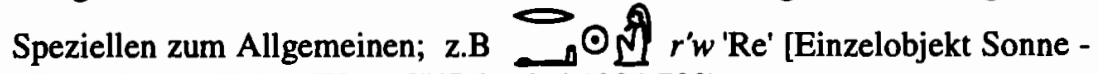
Klasse der göttlichen Wesen]"(Schenkel 1984:722). 


\subsubsection{The Metonymic Axis ${ }^{54}$}

The metonymic axis is an extremely complicated one, as it preserves a variety of contiguity relationships, ${ }^{55}$ some of which are meronymic relations, while others reveal different options. I shall here attempt only to briefly outline a few possible ways in which determinatives can relate metonymically to their determined word.

To return to the first example in this chapter, the 'rrwt "gate," this word is found eligible for other determinatives, even when referring to the same signified, e.g., in the variation $\$ 4$ is the whole of which the gate is a part. Another possible determinative is "the town corner"? $\sqrt{ }(\mathrm{EG}, \mathrm{O} 38)$ which also stands in contiguity relations with the gate, as two parts of a whole. Metonymy is also a powerful tool of focussing. ${ }^{56}$ When the same word is determined by the material $\approx$ H $\triangle$, it is made of ("consisting of" relationship), it is translated as "leaf of double door" (FCD:45). The word $\xi w t$ "feather," mentioned above, may take a wing determinative $P$, of which the feather is a part (FCD:262).

The "consisting of" relationship is a very basic one within the

54. See Eco's discussion on the problematic relations of metonymy and synecdoche, 1984:114-117. We follow Lakoff and Johnson by defining as "metonymic" all contiguity relations.

55. Umberto Eco writes "As far as synecdoche is concerned, it is spoken of as a 'substitution of two terms for each other according to a relation of greater or lesser extension' [part for the whole, whole for the part, species for genus, singular for plural, or vice versa], whereas metonymy is spoken of as a 'substitution of two terms for each other according to a relation of contiguity' [where contiguity is a rather fuzzy concept insofar as it covers the relations of cause/effect, container/content, instrument for operation, place of origin for original object, emblem for object emblematized, and so on]. And when it is specified that the synecdoche carries out a substitution within the conceptual content of a term, while metonymy acts outside of that content, it is hard to see why the part for the whole is a synecdoche and the material for the object is a metonymy - as though it were 'conceptually' essential for an object to have constituent parts and not to be made of some material" (1984:90).

56. See Lakoff and Johnson 1980:35-40. 
framework of the determinative system. A prominent example is the 't "limb" which takes the "flesh" determinative 0 (EG, F51), leading to the 'nh "mirror" $+\mathcal{O}$ (FCD:44) that takes the "metal" determinative, and the 'wnt "stave" which takes the "wood" determinative (FCD:40); the smi "whip" $\| \&\left\lfloor\uparrow^{\prime}\right.$ takes the "leather" determinative (FCD:227), and the kingly $3 n d w t$ skirt 1 can accept an iconic determinative, or be defined by the "cloth" determinative $\ell_{\text {min }}=410$ "

In a different sort of metonymic relationship, the determinative stands in a "direct object" relationship with the word. The verb i'r "to mount" hm "to demolish" (FCD:191) and its synonym shnn

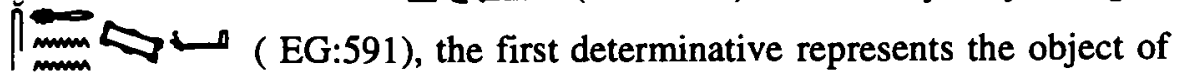
the demolition (a wall); the second is the superordinate classification icon for "aggression." In the word snb "overleap" $1 / \Omega$ (EG, O36), the wall represents the object which was overleapt. $h b$ "to catch" 80 (FCD:167) specifies the objects of the catch - fowl and fish - both represented by the prototypical members chosen by the code to represent their categories. ${ }^{57}$ The word $w h^{\prime}$ "fisherman" the metonymic determinative of the fish (schematic axis) as well as a superordinate human being. In certain cases, the word receives both the bird and fish determinatives "fowler" (FCD:66). In these cases, the metonymic choice clearly serves the purpose outlined above by Lakoff of directing the addressee's attention to a certain aspect of a word.

Many words comprise, with their determinatives, a contiguity relationship that can be described somewhat loosely as "central object relations." The words are usually more abstract than the entities which

57. See also rsf (FCD:153). 
make up their determinatives. The Canaanite word i-b-r (Hebrew אביר) (EG, E6) takes the horse as a determinative. The $n w$ "hunter" attached to the root) and the superordinate determinative "male human being." Nevertheless, we may find examples where the determinative is a $\operatorname{dog}$ m. 15127 = Couyat and Montet 1912:86), referring to the central role played by this animal in hunting. The ship following the verb $n^{\prime} i$ "to travel" activity. $i 3 k b$ "mourning" A determinative of the woman's hair which played a substantial role in the mourning rituals. Sometimes an additional superordinate determinative is added, that of the superordinate "emotions." $i j k b y t$, the female mourner,

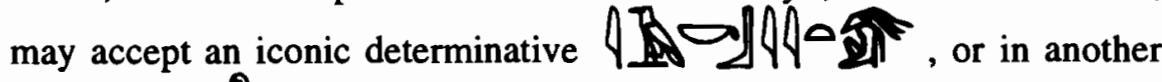
version 11 (FCD:9), the metonymic determinative will be followed by the categorical determinative of the metaphorical axis. Here we again encounter a very common phenomenon of the hieroglyphic script, as we are given a part of the "landscape" surrounding the word in a kind of a multidimensional view (metonymic + categorical).

Very interesting metonymic relations constantly appear in words defining some kind of deficiency or imperfection. In cases of handicap $̌ p$ "blind" quality" is regarded, like positive qualities, as part of the domain of the "eye" and the "ear"58 (both are basic-level terms). The same phenomenon can be traced in examples describing other deficiencies like $w \breve{s}$ and $n k m$ "bald"

58. Lacau (1912:211) writes about the eye and ear determinatives that they may stand for "l'object, l'action, ou les actions que l'on peut accomplir avec cet objet." 
(FCD:161), or iwi "be boatless" (FCD:12). It is always the "missing element" that classifies the word, rather than what exists - in the case of the bald man, for example, we may well ask why he is not determined simply by the head; this method underscores the absence by using an icon which represents the missing quality iconically (hair, cloth) or metonymically (eye, ear). The absence becomes all the more alive in the presence of the presence. On the other hand, when the word acquires a metaphoric extension (in cases such as $w \varsigma^{\Varangle}$ "destroyed"), and the writing preserves the original determinative, the determinative works against the "death process" of the metaphor. ${ }^{59}$

An interesting complex metonymic movement is exhibited by the icon of the sail. Besides its obvious iconic meaning, it constantly appears with all words connected with "wind," ${ }^{100}$ either with $n f t$ "wind" or with more specific definitions of winds, iibt "east wind" of imnty "west wind" " 11 (FCD:21); or swt "the force of wind"

(FCD:215). Thus a metonymically related icon, owing its existence to wind, and its power to the potency of wind, defines what would otherwise be pictorially indescribable. A less obvious connection

59. The opposite situation also occurs, in transposed meanings like sty "stare" It Plos - originally "shoot," hence "shoot a look" (FCD:252); prt "offsprings"

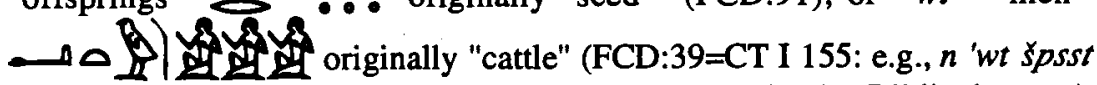
in pWestcar, 17), or $r h$ "to 'know' a woman" (in the Biblical sense) $\rightarrow$ (FCD:152). In these cases, the determinative represents the metaphorical meaning, which is already inherent on the verbal level.

60. "Ainsi, un signe ne vaut pas toujours par ce qu'il représente exactement; un glissement de pensée, une métaphore, une métonymie, une synecdoque, une antonomase peuvent affecter sa valeur: soit le signe représentant une voile gonflée par le vent; il vaut comme idéogramme pour les termes signifiant

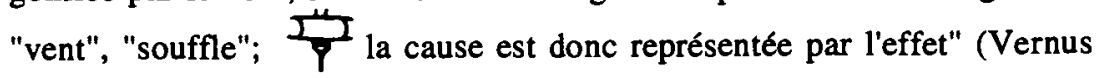
1983:27). 
appears when other abstract or difficult words assume the sail as a determinative, for example: $\mathrm{hm}$ " to be dry" be cold" $\quad \ell \rrbracket \mid \frac{\text { Y }}{\text { (FCD:177); }}$; hmw "dust"

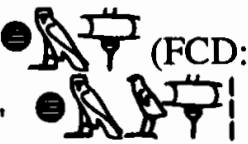

(FCD:190); the first two situations, caused by the wind, the third, a substance carried by the wind. But while in the first "sail" cases, the relationship between the sail and the wind is immediately understandable, there exists only a secondary connection between the latter examples and the sail; these refer to the sail only in order to ultimately reach the concept of "wind."

\subsubsection{Ad Hoc Categories}

The most fascinating kind of relationship between word and determinative appears in a limited number of words in the script. On our uninterrupted journey on the categorical-metonymic path, we are suddenly confronted with a somewhat confusing set of determinatives, which, when related to the determined word, seem to be located neither on the categorical axis of the word, nor exactly on the metonymic scheme.

We find the words srwt "prophecies" and sr "foretell" defined by the giraffe (EG:E27); the word $n$ " "smooth" takes the "scribe outfit" as its determinative. knd DW respectively describe different types of anger (EG:439). The crocodile plays the role of determinative in sšd "flash" (FCD:249); ${ }^{62}$ id "be aggressive" (Suys 1935=Ani:10); ${ }^{64}$ skn "be greedy" $\left.\right|_{\text {mm }} ^{0}$ (FCD:251 also snk FCD:234; see Shupak 1993:109), and is an optional determinative

61. hs may also take an iconic determinative $\$ 1 \$$

62. See Faulkner 1968:41, and Griffiths 1970:194-195.

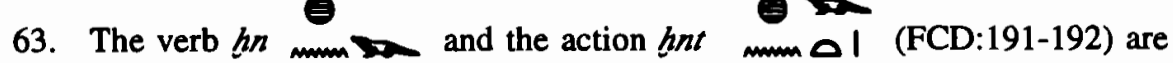
somewhat obscure aggressive actions that may be mapped into the "crocodile categorization." $s n$ is another negative word connected to crocodiles; Gardiner suggests "infested with crocodiles" (FCD:268).

64. ' $f i<i^{\prime} f, f^{\prime}=3 f^{\prime}$ (Osing 1978:188); see also "fft Osiris" CT VII 197,b. 
also in hnt "greed" and in hnty "be covetous, greedy" may alternate with the superordinate determinative for aggression (FCD:173). In the Coffin Texts the crocodile determines the word ksy $=44$ so "powerful" or "vigorous" (Meeks $A L$ II:399).

From an utterly different sphere of behavior comes the word $3 m s$ "to show solicitude" the cow suckling its calf. The verb pihd "to be turned upside down" usually determined by a man standing upside down, 21 may take the overturned boat determinative hns "move in two directions" (Gardiner 1955:13) is determined by the two-headed mammal. ${ }^{65} \mathrm{~A}$ different set of ideas is reflected in the spelling of š̌d "window" (FCD:249) with the eye and house determinatives. Strangely enough, the sht "horizon" constantly defined by the "house determinative."

All the above words probably represent crystallized ad hoc categories, and provide an excellent case for the theory which defines metaphor as the creation of a new category. Here metaphor par excellence is an apparent extension of the methodical system of classification, the only difference being that in these examples, the Jakobsonian metaphoric axis is activated between categories, and the classifier represents another category. I will examine these examples one by one; however, in order to differentiate between the metaphoric movement in the Jakobsonian sense and metaphor as a cross-category phenomenon, I have chosen to describe the metaphors below as similes. In any case metaphor and simile are not distinguishable in the field of the pictorial (Gombrich 1963:12).

In the case of $s r \mid \longrightarrow \hat{A}$ " foretell," ${ }^{66}$ instead of it being classified with the anticipated superordinate classifier of "senses and emotions" (of

65. In Pyr. 416a metaphoric determinative is followed by an iconic one. Pyr. 1266c projects the spelling 1306a has a different determinative, see Gardiner 1955:13 n.5.

66. For a recent discussion, see Shirun-Grumach 1993:54-58. 
which indeed we have an example hoc category, which represents an alternative conceptual grouping of the world, is created. This surrogate grouping suggests something roughly like "those who see before anyone else," of which the giraffe certainly is a prototypical member, since its most prototypical characteristic - height - is taken into account .

In the case of $n$ " "smooth" "smooth things" is probably constructed. From this metaphor we may conclude that the surface of the scribe-palette seems to be an eminent example of the "smoothness" notion within the Egyptian code.

The neighboring words $\underline{d n d}$ and $k n d^{67}$ comprise an ad hoc category of "raging creatures." When the attacking bull is chosen as the prototypical member, the metaphoric categorization implies "angry like a bull," which probably means quiescent yet potentially lethal anger. When the monkey is the prototype, it implies "angry like a monkey," which describes a noisy but not essentially dangerous kind of anger (see EG:439).

Unlike the other animals, the crocodile appears as a simile determinative ${ }^{68}$ in more than one word. It seems to be a salient prototype

67. Vycichl (1990) suggests that knd and dnd are probably the same word, and that the Egyptian word is connected to the Semitic qird - "monkey" (Arabic). Even if this suggestion is to be accepted, the Egyptian speaker probably did not retain in memory the connection to the Semitic word, and the determinative still had its metaphorical effect.

68. For the crocodile as simile, see Goldwasser and Laor 1991. Assmann also regards the crocodile determinatives as metaphoric - "Es gibt aber einen wichtigen Unterschied im Signifikationsmodus der Dinge, d. h. in der Art, wie Dinge Bedeutung annehmen können, sobald sie in den Rahmen der Hieroglyphenschrift eingeführt werden. Den ersten, normalen Modus möchte ich den "direkten", den zweiten und ungewöhnlicheren den "metaphorischen" nennen. Im direkten Modus bedeutet das Bild eines Dinges entweder (als Ideogramm) das Ding selbst, oder (als Phonogramm) dessen Namen in seinem (konsonantischen) Lautwert. Im metaphorischen Modus bezeichnet das Bild eines Dinges nicht das Ding selbst, sondern eine Eigenschaft, die dieses Ding in paradigmatischer bzw. "emblematischer" Weise verkörpert. . . das Ding, hier: das Krokodil, bezeichnet nicht einfach das Wort oder den Begriff "Krokodil", sondern einen Begriff von "Krokodilhaftigkeit" als Inbegriff der (auf den Menschen übertragenen) Verhaltenseigenschaften des Krokodils. Es handelt sich um das Verfahren der Metapher, angewandt auf die Funktionen der Schrift"(1991:92) 
in an ad hoc category of "voracious, greedy beings" due to its exorbitant eating habits. ${ }^{69}$ It was also considered as an accurate demonstration of a specific kind of aggressiveness of which it might serve as the prototype, ${ }^{70}$ in the ad hoc category "aggressive beings." sšd - "flash" - may reflect the feasible ad hoc categories "swift motions" or "bright entities" of which, for the Egyptian mind, the crocodile made the "best example" due to its notorious swift and sudden attacks, or due to the glitter of its scales. A collection of all words classified by the crocodile (including the ones in which it appears in an iconic role) would give a picture of the contemporary mental "crocodile domain" as reflected in the script (to be distinguished from literary material on this subject).

In the $s m s$ determinative, we find an ad hoc categorization of "caregiving" taken from the animal domain. It seems that the Egyptians were sensitive to the cow's care for her offspring, as can be seen in several examples of tomb reliefs. ${ }^{71}$ The ad hoc category is probably "taking care of" or the like. In this case the mother-cow becomes the prototype for the ad hoc category "taking care of" instead of the human mother.

When the king says to the snake in the Pyramid texts (685): $h r h r . k$

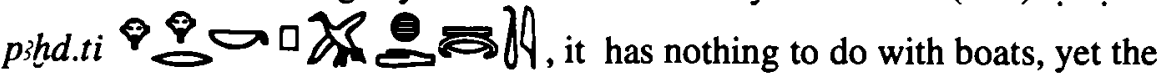
word pihd accepts the "turned over boat" determinative, the boat being a most prototypical member in an ad hoc category of "upside down." When the boat keels over, the process in which it is involved (in the metaphor of sailing) is sharply interrupted, and the vehicle actually falls into disuse. This vehicle offers all its richness to the target "upside down" (also g33? [Pyr.662]). The prototypical nature of the boat in relation to the notion of "overturn," in all its metaphoric extensions, is further enhanced by the existence of the verb $p n^{\prime}$ which probably originally described a literally "upside-down boat" and was then extended into wider metaphorical use, in cases where no actual boats were concerned (Grapow 1924). This clarifies the prototypicality of the ship and its sphere to the cultural consciousness of the Egyptian. Egypt's unique geographical conditions also highlight the

69. See van de Walle and Vergote 1943:89.

70. It may be that id was an a priori designation of a "crocodile quality" (see $\mathrm{Wb} 1: 24,12$ ). In this case the metaphor already exists on the linguistic level, and not on the "scriptural" one. As the use of the word in the human domain is the prevailing one, the determinative should be very active in preventing or slowing down the "death" of the metaphor.

71. E.g., Boessneck 1988, pl.94; also Assmann above. 
central conceptual metaphor $^{72}$ - LIFE IS A JOURNEY ON THE NILE which governs many linguistic, ${ }^{73}$ religious (the solar-boat journey) and metalinguistic expressions within the Egyptian culture.

The surrealist bovid presents a pictorial simile for hns "moving as a double-dead animal, each pulling in another direction."

The eye determinative accompanying the word š̌d "window" is somewhat surprising. If it is not based on metonymy ("one looks through the window," or "one is seen through the window" [Gardiner 1947 I:212*$\left.213^{*}\right]$ ), it seems that the window is metaphorically conceptualized here as "the 'eye' of the house." The ad hoc category is constructed of something like "parts through which one can see" and is formed by an interlacing process of conceiving parallel part-whole relations between the window and the house, the eye and the entire body. In Aristotelian terms, this is a complex metaphor, based on four elements, so that B's relationship with A is analogous to D's relationship with C (Hawkes 1972:7-8). It should be noted that "the house" (term $\mathrm{A}$ ) is also provided by the script, while acting as an additional metonymic determinative describing the whole of which the window makes a part.

In this context one may mention another part of a building. The word $w b$; "front court" determinative (Wb $1: 291$, Meeks $A L$ I:85). Aside from root reasons ( $w b_{3}$ ) "open" also takes the eye determinative), another stimulus for this combination seem to be the ad hoc category "parts through which one may see" (it is interesting that the word is spelled with the sky determinative which, through contiguity relations, denotes something like "through which

72. On the conceptual metaphor, see Appendix B below, note 1 .

73. See, for example,"mni" "to moor" = "to die" (FCD: 107); "iwi" "boatless" = "helpless" (Goldwasser 1981 and bibliography there); hdi "travel downstream" = "northwards" (FCD:199); hnty- "sail upstream" ="travel southward" (FCD:195); see Grapow 1924:151-152. Another possible metaphor is msti 'pr.t "loaded boat": dif hpr.i m dnht nrt mi msti 'pr.t "May he cause that I shall become as a vulture's wing, like a loaded boat." This poetic metaphor appears in a "personal piety" style hymn to Amon; (pAnastasi IV,1.10,4=LEM:45, 10-11). In many cultures a prevailing conceptual metaphor is LIFE IS A JOURNEY (see Lakoff and Turner 1989). Since English is a language of a seafaring people who governed a large empire, the deep structure metaphor LIFE IS A JOURNEY ON SEA proliferates in English in metaphors like "sail through," "plain sailing," "sail into," "trim one's sails," "sail against the wind" and "nervous wreck," see Gulland and Hinds-Howell 1986:179-182. 
the sky can be seen" "front-court" does not surrender itself to the comparison with the "eye-body" image, since the latter conveys different relations in space.

The deep-structure conceptual metaphor - THE HORIZON IS THE ETERNAL ABODE - is so profoundly rooted in Egyptian culture - especially in royal and religious contexts ${ }^{74}$ - that the definition of the sht "horizon" by the house determinative would scarcely attract the notice of an Egyptologist. The ad hoc category created here is "places in which one resides" of which the house makes the prototypical member (compare here $d w s t$ "netherworld" and $d$ wityw "dwellers in the netherworld" [FCD: 310],often with the house determinative; see also Hornung 1982:227-228).

\subsubsection{Rage, Sickness, and Dangerous Behaviour - The "Myth and Belief Principle":}

In a recent contribution, Classifiers as a Reflection of the Mind, George Lakoff attempts to analyze the Dyirbal's "classification of objects in the universe." This native Australian language presents a system of linguistic categorization markers embedded in the spoken language. The Dyirbal language projects four categories:

(1) bayi - under which one can find men, kangaroos, possums, bats, most snakes and most fish, some birds, most insects, the moon, storms, rainbows, boomerangs, some spears, etc.

(2) balan - women, bandicoots, dogs, platypuses, echidnas, some snakes, some fishes, most birds, fireflies, scorpions, crickets, the hairy mary grub, anything connected with water or fire, sun and stars, shields, some spears, some trees, etc.

(3) balam - all edible fruit and the plants that bear them, tubers, ferns, honey, cigarettes, wine, cake.

(4) bala - parts of the body, meat, bees, wind, yamsticks, some spears, most trees, grass, mud, stones, noises, language, etc.

Lakoff and Dixon (who was the first to study Dyirbal classification; his works form the basis for Lakoff's studies on the Dyirbal) believed that the explanation for what might seem to' a Westerner's eye a fantastic grouping

74. E.g. , ' $r$ ntr $r$ iht.f - "The king (lit. god) has ascended his horizon" (Blackman 1972:3= Sinuhe, R6 ). 
"à la Borges," should be sought for in various processes that carried the system from a representation of "natural" categorizations into a system of categorization which is very difficult to account for, and is probably strongly culture-bound. One of Lakoff's central suggestions for a re-classification impetus is what he describes as the "Myth and Belief Principle." Part of the Dyirbal's ostensibly strange "divisioning" of the world could be explained through the fact that "myth and beliefs are domains of experience that are relevant for categorization." This means that mythological reasons may be the basis for categorical classifications. In Dyirbal, as already mentioned above, birds are believed to be the spirits of dead human females, and so would be classified in the same class (balan) with females.

It would be of the utmost interest to clarify to what extent, if at all, this principle affected the Egyptian categorization system (as represented in the script). If this principle were found to be inactivated within the frame of the script, that would indicate a complete resistance of the system to the principle, in which case hardly any conclusion could be reached. On the other hand, if it were found to be activated, the range of the activation would allow us to ponder to what extent religious conceptualization processes overrode the secular ones in the Egyptian mind. ${ }^{75}$

Modern scholarly tradition considers the Egyptians a deeply pious, myth-oriented people. Religious beliefs and magical practices are assumed to be their basic means of interaction with the world, and religion seems to form the centre of their Weltanschauung.

In light of this view, one would have expected that such a conceptualization of the world would serve as a moulding-frame for the Egyptian categorization system, as we have seen in the case of the Dyirbal. If we take but a few examples, one would expect the sky to accept a female determinative or cow determinative. Yet the $p t$ "sky" usually exhibits a secular determinative in all the examples offered by the dictionaries (Wb $1: 490,491$; FCD:87). It is Nut, the godly manifestation of the sky, that takes the superordinate deity determinative (FCD:127). The various words

75. The term "Egyptian mind" should be taken very advisedly. What is represented in the script is probably the elite conceptualization system. On the definition of the extent to which textual and material information represents anything other than the elite culture, compare:"Was wir hier fassen können, sind natïrlich nur die Anschauungen der jeweils die Denkhöhe ihrer Zeit repräsentierenden Sprecher. Darunter wird die Menge derer, die sich eben doch überall und jederzeit an die Fassbarkeit des gegenwärtigen Bildes gehalten haben werden, nicht gering gewesen sein" (Otto 1963:258). 
for "bull" are clearly separated from the $H p$ (Apis), and are classified under the superordinates "cattle" or "fertility" (FCD:283). The msh "crocodile" does not take a deity determinative, and is carefully differentiated from Sobk. The itrw "river," even when referring to the Nile, takes secular determinatives of "waterways." The i'n "baboon" usually takes an iconic or superordinate determinative (WB 1:41; unless it refers to Thoth, e.g., Lesko Dic. I:3). The dung beetle hprr from the young sun god Hprr "cat" take an iconic \& 8 or superordinate determinative 8485 (Wb 2:42; and many examples in Malek 1993) but are not classified in the deities category.

I would like to suggest, as a working hypothesis, that based on the determinative system, in many cases, the Egyptian maintained a separation between the "things in the world" and divine beings that had the ability to be incarnated or manifested in those worldly beings (Otto:1963; Hornung:1982:68). ${ }^{76}$ The divine incarnations usually had separate names, like $N w t, S b k$, and $H p$, that were different entities than their secular counterparts. Yet, the picture is rather complex. It is rather surprising to find that according to the dictionary selections, $H p$ (Apis bull) rather frequently does not take a deity determinative, but only the bull determinative. Sobk usually presents a different iconic identity than the animalistic crocodile - (a statue?) - yet it is still a crocodile (EG, I 5*).

A somewhat different picture emerges from an examination of the celestial bodies, "sun" and "moon." Here the least religious names of the sun and the moon, itn and $i$, project a mixed approach of categorization. When $i$ 'h appears in the Pyramid texts, it may receive an iconic (non-divine) determinative $4 \ldots$ (Pyr. 1001, see also Wb 1:42). However, in the 18th-dynasty inscription of King Amosis we find the king described metaphorically as $i^{\prime} h m h r-i b d w s w$-"the moon amongst the stars." The $i$ 'h "moon" is determined there by a clear determinative of Thoth i.e., an anthropomorphic bird-headed being (Urk.IV:18,10), which obviously transfers the moon from the category of "celestial being" into the category "gods." Although the itn was originally classified by the iconic determinative "sun disk" $\int_{\text {mm }}^{0} \odot$ (FCD:33;Wb 1:145), it seems that the Amama revolution

76. Evidently, every case should be studied separately with regard to different periods and different genres of texts. 
did not leave the categorization system untouched. The Late-Egyptian dictionary examples of the post-Amama period show a clear tendency towards a constant, additional classification of the itn sun disk $\oint_{\text {mem }}^{0} \odot$ गी (Lesko, Dic. I:59-60). ${ }^{n 7}$ Nevertheless, further examination which I hope to conduct in the near future may corroborate or refute this theory.

However, the locus par excellence of the religious reformation of the categorization system is the Sethian case. In his book Seth, God of Confusion, Hermann te Velde presents a list of words that take the Sethian determinative. $^{78}$ This assemblage represents an ad hoc category which includes a few superordinate categories which comprise sickness and suffering, behaviour disturbances, weather disturbances, and even dream disturbances (Simpson 1966:44-45). In the "suffering and sickness" words we sometimes find the Seth signifier accompanying the "bad bird" determinative (e.g., $m r$ "be sick" In the behaviour disturbances we find it in a complementary relationship with the "aggression" determinative or the superordinate "feelings" determinative, e.g., $\mathrm{nm}^{\prime}$ "to be one-sided" I the words describing weather disturbances it stands with the determinative of wind, water, and rain e.g. kri phph "storm"

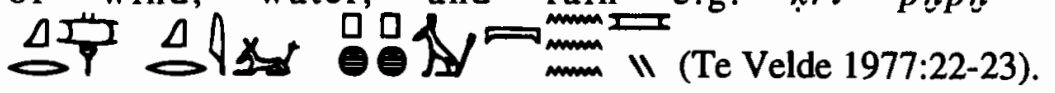

Those words were taken out of their natural categories and placed under one roof in the "Sethian category," which makes an ad hoc category of something like "abnormal disturbances," of which the Sethian animal is the religious prototype. Some words in the category (from te Velde's collection) seem to constitute central members. (On the ad hoc category projecting central and non-central members such as natural categories, see above and Shen 1994). In nšni "rage, storm, disaster"

77. "It is striking that the names of the "cosmic" deities of Egypt, unlike those of Greece, are not the same as the words for the elements in the cosmos which they embody. The earth is $t 3$ but the earth god is Geb, and the sky is pt but the sky goddess is Nut; the sun god Re stands besides itm, the term for the sun disk, and the moon is called $i^{\prime} h$, while the two early moon gods are Thoth ... and Khons. ... This distinction between names and phenomena should warn us against hastily dubbing a deity a "moon god" or an "earth god" - the nature of Egyptian cosmic deities is much richer and more multifarious" (Hornung 1982:68).

78. To the list add shnw -"destruction," Groll 1982:86. 
and $n k m$ "to suffer" $\triangle \triangle$ (FCD:141), the Seth determinative appears to be almost obligatory. At the end of the categorical scale stand words like ih (3hw) "misery" "illness" 4 四 (FCD:3; most frequently determined by the "bad bird" determinative), "wn "to be dispossessed" OP (Wb 2:209), this last usually determined by the superordinate "aggression" and only optionally adopting the Sethian determinative (at a rather late date, too). Moreover, standing on the murky fringes of the category, it can also accept the rival categorization - that of the Horus icon.

\section{The Case of sik "to collect"}

Almost all words determined by the crocodile (except perhaps š̌d) have strong negative connotations. They belong to the categories of greed, wild eating habits, wild power, and aggressiveness. ${ }^{79}$ However, on the whole, the crocodile determinative presents a strong case of non-mythological classification, which does not mirror the religious representation of the crocodile, as the beneficent god Sobk. In a "mimetic" ${ }^{80}$ representation, the script reflects the real qualities of the reptile as experienced by human beings. However, the tension between the religious pole and the secularrealistic pole is evident even in the religious sphere as early as the MiddleKingdom. The realistic qualities of the crocodile invade even the early "topical" representations of Sobk, the beneficent crocodile god; in the "Hymn to Sobk" it is described as iti.f " $n h m$ ' $w 3$ "as he seizes life as a thief," or spd ibhw "sharp of teeth" (Gardiner 1957, pl.2,4; pl.3,73; compare also CT spell 424; recent discussion in Supak 1993). During the Late Period, the mimetic legacy of the crocodile in a way overcame the religious indoctrination, and the crocodile role as a Typhonic animal is very much stressed (Brunner-Traut 1980; for the crocodile's Typhonic names see Hopfner 1940-1941:222).

However, in contrast to the prevailing appearance of the crocodile determinative in words pertaining to negative signifieds, there is one

79. For ' $h m$ - "voracious spirit" the word, see Gardiner 1957:51,n.8. On the possible existence of a Dynasty 0 king named "The Aggressive Crocodile," see Dreyer 1992.

80. For the definition of Topos and Mimesis, see Loprieno 1988:11-12. 
conspicuous example. The word sik "to collect" exhibits a completely positive line of connotations. It appears in the Pyramid Texts in passages pertaining to the collection of limbs and bones. In some examples the word appears with the determinative of the "hugging hands" $\triangle \Pi$ (Pyr. $654 c, 735,739 b, 1684 c, 2182 c$ ), which can be taken as a kind of iconic determinative, once with a kind of basket I $\triangle 480$ [see Vycichl 1983:186 on the relations of this word with the Semitic sakkw] the same determinative appears in ink "collect" FCD:24), which is a metonymic determinative, and several times without any determinative (e.g., Pyr.645c, 1801c, 1981b). In the Coffin Texts the subject of "collection of the limbs" becomes rather dominant. Almost all the examples that use the verb sik suddenly present a new determinative, a tail-folded crocodile (EG, I5). In spell 1029 (CT VII,255) in the sentence ip.k ksw.k sik.k'wt.k, seven versions of the word appear with the tail-folded crocodile, three versions with the "abstract" determinative, and three examples without any determinative. Through the whole corpus of the Coffin Text, the root $s ; k$ takes one of these three options as a determinative. ${ }^{81}$ The iconic representation of the tail-folded crocodile, is almost always sharply differentiated from the "regular" straight-tail crocodile. This differentiation is also carried into the hieratic script, e.g., nos.241,243) ${ }^{82}$ From now on the spelling of sik with the crocodile determinative becomes very common, and appears along with the word in various contexts that have nothing to do with bones or limbs.

Where did this crocodile come from? In the Old Kingdom, Kaplony traces the rare mention of a crocodile deity, which is called $S 3 k$. and indeed Kaplony attributes to it the role of "Sammler der Osirisglieder" (Kaplony 1981:103, n.181; Meeks $A L$ I:305). The reason for this somewhat absurd role acquired by the crocodile can be found in the sphere of the religious description of the animal. The canonical religious tradition represents Sobk, conceptualized as "the ruler of the river," in a positive role, despite (or because of) its cruel animalistic qualities. Playing this role, the crocodile is actually represented as the helper of Osiris, assuming the role of "assembling the bones" (Brunner-Traut 1980:796). In the important hymn to Sobk (Gardiner 1957, line 50), it is said: hns.k wid-wr shn:k it.k

81. E.g., CT I 163,380; III 295, 309, 326; V 123,153; VI 217.

82. Brovarski (1984b:1018) accepts the suggestion (rejected by Loprieno [personal communication]), that $S b k$ and $s 3 k$ are actually the same word . 
Osiris gm.n.k sw s'nh.n.k sw - "You fare over the Great-green, you assembled your father Osiris, after you had found him.You have revived him." The word shn $\cap$ is translated by Gardiner in the publication as "to look for" ; Meeks, however, (following Westendorf) translates it as "unir, embrasser" (Meeks AL I:341, see also Gardiner 1947 II:254* and FCD:241).

It seems the action of "collecting the bones" had a strong mythological connotation that governed the signified of the word sik. When a crocodile was venerated in the positive role of the "Assembler of the Osiris bones" the root sik was chosen to be the base for its name (probably a participle). The appearance of the $s 3 k$ from the early Middle Kingdom onwards as a determinative, even if initially based on a possible rebus between the crocodile god (probably derived from the verb) and the verb, enhances and perpetuates its positive role. Because of its unique iconic identity, so different from the non-mythological qualities of the crocodile, the s3k crocodile could have acquired a signified of a "good" crocodile, to be differentiated from the regular one. Thus in the spelling "to collect," the iconic crocodile signified is not discarded and is activated as a simile "as the crocodile who collected the Osiris bones, ${ }^{183}$ which is carried along with the phonetic signified. The folded tail seems to be the only way a theoretical collection by a crocodile can be envisioned, unless it uses its jaws. However, the crocodile jaws can hardly sustain any positive reference; the mythological crocodile may "collect" limbs in the water with the movement of his huge tail. In the most common spelling cultural-religious dependent prototype in an ad hoc category "actions of collecting," of which the crocodile makes the prototype. Yet, being a rebus writing in origin, or even carrying a rebus association, the $s 3 k$ hieroglyph resists a movement into other words which are synonymous, describing the act of collection.

If indeed the determinative system represents conceptual organization - like the Sethian category discussed above - the sik

83. A rare example from the Coffin Texts probably belongs here. In Spell 158, where the subject is "fishing Horus' hands," one version (B.M. 38041) writes the name Sbk with the hieroglyph. The same phenomenon occurs again in the parallel version of the Book of the Dead (spell 113, see Sethe 1922:24*-26*). Is it not an iconic representation of the crocodile in his particular role of "collector of bones"? If this is the case, it means that the tail-folded crocodile carries a full iconic meaning that can be disconnected from the phonetic ski. 
determinative may be regarded as another intrusion of the "Myth and Belief Principle" into the secular categorization system. This process will culminate during the Ptolemaic period.

\subsection{A Few Concluding Words}

Hopefully, my reader has been able to perceive, even through this very narrow keyhole, the elaborate metaphoric processes that are involved in the decipherment and reading of every hieroglyphic inscription. The script makes use of variegated metaphoric abilities, phonetic, iconic and semantic, all activated together to orchestrate a rich and very charged, culture-bound meaning. On the one hand, its strong mnemonic power, acquired through the extensive use of the concrete icon, works forcefully against the cognitive process which we describe today as the "death" of metaphor. On the other hand, the script strongly interferes with our cognitive selection processes, choosing our categorical prototype members for us, as well as reducing the mental-space between signifier and signified. Each determinative reflects a complex metaphorical and metonymical relationship with its word, which creates "central meaning components" in almost every item in the lexicon. The determinative system is a rule-governed, constrained system which paints a colourful picture of the mental organization of the Egyptian cosmos.

Now that we have passed the magic "wand of metaphor" over the hieroglyphs, their redundancies and surfeit have indeed unveiled for us qualities of richness, opulence, and a multiplicity of options at every stratum of the linguistic system; and moreover, a licence, indeed an invitation to the individual - be it reader or writer - to play a highly active role in the creation and interpretation of all those strata.

Is it not the road to be taken as Jonathan Culler (1987:183) states when he writes about "The linguistic of writing":

A linguistics of writing . . . would seek to invert the usual relation between discrete, already codified signs and the material usually deemed irrelevant except as a means of manifestation. It would treat discrete signs as special cases of a generalized echoing, and explore whether a linguistics could be constructed on such a model, and how far it could go. Above all it would need to attend to what lies outside an ordinary linguistics but furnishes much matter for literary criticism: the tantalizing prospect that caused Saussure so 
much anguish in his work on anagrams, of perceiving patterns, hearing echoes, and yet being uncertain, in principle as well as in practice, about their status. The task of linguistics has been to divide the signifying from the non-signifying excluding the latter from linguistics, but if this boundary region is central to language and its functioning . . . then this geography must be revised, and the uncertainty of echoes, the problematic materiality of language which may or may not carry meaning and produce effects, must lie in the center of our concerns. A linguistics of writing must address a textuality linked to the materiality of language, which necessarily gets misread when transformed into signs, as it might be by our semiotic drive.

If we believe that language shapes reality, that its every expression has more than one simple meaning; that it not only teems with, but thrives on its ambiguities, that high-spirited and strong-minded, when asked to sit for a portrait, it instantly springs up, displaying every feature but the one sought for, resisting - simply by its liveliness - its portrait maker's plea to catch and form it into a perfect piece; if we believe all that, we begin to respect it, perhaps even to side with it against the portrait maker; and the liveliest, most intractable coltish signs and expressions of language then become dearest to our hearts. To my mind, some of the finest of such expressions ever to have been produced are pictorial hieroglyphs. 


\section{Appendix A}

\section{ANOTHER FORM OF FOCUSSING}

\section{A. Positing the Question}

Does the pictorial script have any effect whatsoever on the syntactic or pragmatic organization of the hieroglyphic sentence?

Does it make any difference from the grammatical point of view if we write a sentence by iconic pictures or by letters? Would that have any effect on the reader's cognitive attention and on cognitive events occurring during the processing?

I believe that the answer is positive. It is hard to evaluate the impact of the pictorial icon in every hieroglyphic inscription. There are probably many inscriptions where the conventionalized icons do not cause any shift in attention. Nevertheless, I would like to present a few cases where to my mind, the pictorial representation should make at least some grammatical difference.

\section{B. Focus in Egyptian Grammar}

In a recent elaborate book, Friedrich Junge (1989), through his discussion of "emphasis," summarized the prevailing views in Egyptology on focussing. In his definition, "focus" in a sentence is an additional level of cognitive attention. Focus is optional, unlike "subject" and "predicate." Every sentence has a subject and predicate, but some sentences may have focussing constructions or focussing intonation. focussing construction will be visible and detectable within the written text; intonation is of course invisible and undetectable.

Junge presents some examples in English (1989:19 citing Leo Depuydt):
a. John saw a play yesterday.
b. John saw a p l a y yesterday.
c. J o h n saw a play yesterday.

In examples $b$ and $c$, the words play and John, respectively, are marked by intonation. They are selected items in the sentences making a contrastive selection from a limited set of candidates. 
Thus, "'focussing' is a device to mark out a single member of a declarative statement for specification or contrast; the focal stress overrides the 'normal' intonation structure of the utterance in terms of 'given' and 'new' and rearranges it" (Junge 1989:20).

In Egyptian, intonation focussing is of course concealed from us today. Yet overt grammatical devices can be detected, for example in cleft sentences and some of the so-called "emphatic" constructions. (All emphatic constructions become overt in Late Egyptian; see Černy and Groll 1984).

I would like to suggest another level of focussing in hieroglyphic inscriptions, which may be called "visual focussing." If knowledge is regarded today as being built of "cognitive units" (Junge 1989:43), the creation of any deliberate or even undeliberate new attention center may have an impact on the addressee's attention, evaluation and understanding of the sentence or the text. Since hieroglyphs are pictures, they may present a sophisticated "attention game." Its range runs from the possibility of inserting an iconically rare or frightening sign in the midst of an hieroglyphic inscription to altering a hieroglyphic word by a large-scale iconic sign. These manipulations exercise the "power of the image" on the addressee. Possible examples of this phenomenon are of course innumerable, variegated, and exist on different levels and scales of visual attention. My purpose here is by no means to initiate any kind of collection of available examples, but to point out this unique phenomenon of the hieroglyphs, which owes its existence to the pictorial nature of the script.

The first example that I present is a complex "marked" focussing construction. Nevertheless, the focussing is not achieved only through syntactic terms, but also through "visual focussing." Although visually overt, these cases may be compared to intonation, which is an added level of focussing. Nevertheless, one should keep in mind here that unlike the case of intonation, the intentions of the writer remain hidden. The question of whether the new focussing is an intentional or unintentional event must remain unanswered.

Figure 16, my first example, comes from the tomb of $M r y-i b$ in Giza (JG II, 128), from its north Türleibung. On the lower register, facing $M r y-i b$ and his son $M r y-i b-s r i$, a man, probably a scribe, stands holding a list. The inscription above runs: dit 'š̌ in -.-. . What is missing is of course the logical subject of the utterance, the agent, the giver of the list.

1. For the infinitive as dit, see Edel 1955: 348-349. in is a focus marker, which is used to introduce the logical subject of a passive construction, see Loprieno 1995,4.4.1. 
It seems that in this case the author of the inscription exercised the "open path" back to the icon, and returned the subject of the sentence to what we called in the first chapter the "rough iconic phase." This minimal sentence is made up of hieroglyphs together with iconic representation. The iconic part is an essential part of the sentence, its subject, and not a determinative. in is a focus marker, which is used to introduce the logical subject of a passive construction (see Loprieno 1995,4.4.1;1988:51). The additional "visual focussing" of the scribe (who is indeed carrying the list, i.e., the grammatical object) creates a somewhat different topic-focus constellation, as the sentence structure is "overridden" by another focussing device. This has the effect of making the subject more focalized, conveying much more "new" information. The pictorial here strongly overrides the syntactical focus device, carrying it to a much higher level of cognitive attention.

The question that remains open to some extent, is what kind of cognitive impact is created by the introduction of the pictorial icon into the hieroglyphic sentence. Does its "newness" lie in its straightforward processing, almost without any metaphorical or other cognitive "transpositions"? Does it create a strong "attention center" that competes with the "attention centers" of the syntactic and pragmatic levels? Does the fact that the scribe actually carries the written tablet in his hands reduce the impact of the visual focussing ${ }^{2}$ since the tablet makes up part of the grammatical predicate?

A comparison of interest here are some examples brought by Henri Fischer in his Orientation of Hieroglyphs. The first is a scene of singing and dancing (fig. 17=Fischer 1977, fig. 81). Usually this scene is accompanied with the phrase $h s t n i b 3$ (see Fischer ibid, fig. 80). The word $i b_{3}$ is missing, and its role is played by the full-fledged iconic representation of the dancers.

Another example of a different sort of visual attention shifting comes from the Unas Causeway reliefs (fig.18=Fischer 1977, fig. 85). Here we find the sentence $m s(t) s 3 p n w(i) n p n w$; the first $p n w$ is written phonetically, while the second $p n w$ is written by the pictograph of the mouse. It attracts strong cognitive attention due to the appearance of the rather rare pnw hieroglyph as giving birth to its new-born. The hieroglyph is carried again to the full pictorial essence, being disconnected from the usual signified of $p n w$ into a different signifier of a female pnw giving birth. The other parts of the sentence are written by "transposed" icons (see above, chapter 1)

2. On the problematics of the semiotic description of Old Kingdom tomb scenes, see Shirun-Grumach 1987. 
with weakened iconic force due to phonetic transpositions; yet, as we have shown above, the $m s$ may still carry additional metaphoric connotations ${ }^{3}$ (the presence of the duck is even somewhat "disturbing," bringing forward a strong bird signifier/signified that should be completely discarded by the reader). It seems that the "cognitive attention" of the reader is directed towards the end of the sentence, to the focalized grammatical subject slot, creating a sort of additive focussing by the full iconic representation of the birth-giving female mouse, which seems to coincide perfectly with Junge's description of the attitude of the writer towards the syntactic "marked subject" as "making sure what discourse will be about by elaborately marking and characterizing it" (1989:44). Yet, as in the above example of Mry ib, some of the "added knowledge" of the predicate is embedded in the subject icon.

Another kind of "focussing game" between the visual attention and the syntactical information is played to a great extent through the "enlarging" phenomenon, whereby one of the hieroglyphic signs within the inscription is given priority through its size. This act has the effect of carrying the icon back to its former phase of iconicity, again creating a strong direct address to the reader's attention. A somewhat elaborate example comes from the tomb of Ptahotep (fig.19=Fischer 1977, fig.77). The text, using reversals, reads ir n.f mnit-šs siht.f hr ir-ht in hry-hbt "That there be made for him [the ceremonies of] crossing the lake and his transfiguration in performing the rituals by the lector priest" (Fischer 1977:77). This caption is built again of passive construction + in + agent, which is a grammatically focussed form, the marking placed on the infinitive.

However, two "visual focussing" centers may carry cognitive attention elsewhere. The first is the deliberate enlargement of the $\underline{h r y-h b t}$ determinative to more than a double-size hieroglyph. Moving toward the pictorial representation, this hieroglyph easily catches the addressee's attention, creating a powerful visual focussing center in the sentence, which completes the syntactical pattern, not threatened by the mass of smaller hieroglyphic signs in the midst of the inscription. Nevertheless, the situation may be even more complex. Intentionally or unintentionally, the scribe has created an elegant feature on the opposite side of the inscription, headed by an elegant $h r$ face, resting upon the $i r-h t$ as some kind of schematic human body. It seems that another visual attention center may have been created here, bringing into play a new iconic association that stands outside

3. See above chapter 1 . 
the strict semantic value of the sentence. ${ }^{4}$

Visual focussing did not cease to exist after the Old Kingdom. As Henri Fischer shows in his book (1977) and as Vernus has recently pointed out (1986), elaborate variations continue to play a part in the hieroglyphic inscriptions of the Middle and the New Kingdoms. ${ }^{5}$ However, I would like to present a rather rare example, which appears in an unexpected location, i.e., in a non-literary hieratic letter from the end of the New Kingdom. Butehamun, the writer of the letter, was a famous scribe, belonging to the elite group of scribes of Deir el Medineh at the end of the 20th dynasty. In a newly published letter of his (fig. 20, B.M. 10411, Janssen 1991, pls. 3,4), a striking pictogram appears in the midst of the cursive hieratic text. The sentence runs:

$r-n t y h n^{\prime}(d d ?)$ iw $t 3-m d t n p^{3}$

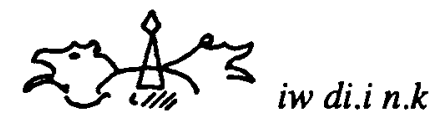

" And further: as for the matter of the

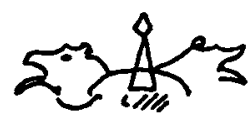

which I have given to you."

A unique pictograph probably describing an amulet appears in the midst of the first phrase, which is a syntactically focussed phrase, being built of an extra-position $+i w$ sdm. $f$ (Sarah Groll suggests the possibility of alternative substitutions of $r, i w$ and the prothetic yod in this period; see also Winand 1992:38). The appearance of the unique pictorial entity in the midst of the hieratic script creates a strong additional visual focussing which doubles the syntactical stress. This device is repeated again by the scribe in the next sentence in a similar syntactical position. Two enlarged iconic red crowns again catch the addressee's attention, doubling the focus of the syntactical level.

Visual focussing can be compared to intonation. It is sure to be there, but its impact cannot always be measured by scientific tools. Visual focussing can also be exercised in non-iconic systems through methods of enlargement, bold face, or through literary devices like "enjambement."

4. Here see also the tomb of $I h 3$ where the goddess $m 3^{\prime} t$ appears in an enlarged form in his titularity, JG VI p.75 abb. 18.

5. Here I did not go into the question of whether reversals have any effect on visual focussing. This should be left for a later study. 
Yet being arbitrary phonetic signs they could never make use of the full "power of the image" that is available to the hieroglyphic system.

The methods used in the hieroglyphic script for visual focussing should be compared to modern advertisement methods. In their search for the fastest and strongest hold on the addressee, advertisements make bold use of visual focussing, using pictures of a certain referent in the midst of an alphabetic message, exploiting to its fullest the power of the pictorial to seduce its audience. 


\section{Appendix B}

\section{INTERACTION PROCESSES AND IMAGE SCHEMA OF THE "TREE-GODDESS" METAPHOR IN THE NEW KINGDOM.}

In this chapter I present a case study of one prevalent visual metaphor, the "tree-goddess," and its variants, in order to demonstrate the striking similarity between the processes of metaphor exhibited by these ancient examples, and the sober results of carefully controlled modern experiments in cognitive psychology. One unique advantage of such an experiment over modern ones may be that the subjects under examination (the makers of the metaphor in all its variants) are free of the experimenter's gaze, his assumptions or expectations; to the best of our knowledge, the ancient Egyptians who drew pictorial representations of conceptual metaphors ${ }^{1}$

1. Metaphor resides in thought, not just in words. Conceptual metaphor structures the understanding of one domain in terms of another (if a concept is understood and structured on its own terms - without making use of structure imported from a different conceptual domain - it is not metaphorical [Lakoff and Turner 1989:57]). ARGUMENT IS A WAR is a conceptual metaphor that is reflected in language by a wide variety of expressions, e.g., "Your claims are indefensible"; "His criticisms were right on target"; "I demolished his argument" (Lakoff and Johnson 1980:4; Gibbs 1994). Conceptual metaphor embraces every day use of language as well as poetics. If we take the deep-structure metaphor DEATH IS DEPARTURE, we can find it materialized in expressions like "He passed away" "He's gone to the great beyond" etc. It is splendidly realized in a poem by Emily Dickinson:

Because I could not stop for Death-

He kindly stopped for me-

The Carriage held but Ourselves-

And Immortality

A neighboring metaphor - DEATH IS A JOURNEY - governs the following parts of the poem: We slowly drove- He knew no haste

And I put away

My labor and my leisure too

For his Civility-

(Lakoff and Turner 1989:1-5,10-12 and passim)

The conceptual metaphor DEATH IS A JOURNEY is most dominant in the Egyptian world view. Compare here the discussion of LIFE IS A JOURNEY ON THE NILE , chapter 3 above, p.98. 
were unaware of what became Greek and post-Greek definitions of metaphor. On the other hand, the "tree-goddess" case is both repetitive enough and diverse enough to satisfy the demands of empirical investigation for a variety of material; ${ }^{2}$ while repetition enables us to isolate "convention" and estimate the enduring power of one particular metaphor, the wide range of variation within the metaphor reveals the measure of artistic freedom which preserved the vitality of the concept.

Since some have called into question the validity of the term "metaphor" when applied to representations of Egyptian deities, one may as well begin with a justification of the obvious. Surely Herman te Velde (1990) applied no more than common sense when he wrote about the personification of natural objects in Egyptian religion: "The personifications are little more than metaphors. . . When poets of Egyptian love-songs let trees speak in their poems, this really does not mean that people, even when in love, have I-Thou relations with trees. Egyptian gods and goddesses could indeed reveal themselves in trees, but one cannot deduce from this that Egyptians had I-Thou relationships with trees as such." In Fecundity Figures, John Baines also has convincingly identified personifications in the pictorial as belonging to the realm of metaphor $\left(1985, \mathrm{Ch}\right.$. 1.3.1.1.). ${ }^{3}$ Similarly, Othmar Keel, in his recent elaborate discussion of the "treegoddess," states:"Natürlich wussten die ÄgypterInnen, dass es keine solchen Bäume oder Frauen gibt. Sie brachten damit zum Ausdruck, dass sie an Bäume glaubten, die sie als Manifestation einer analog zu menschlichen Personen vorgestellten Macht verstanden (der Einfachheit halber manchmal als 'personifizierte Bäume' bezeichnet)" (Keel 1992:63-64). ${ }^{4}$ Waltraud Guglielmi in her article, "Personifikation" in the Lexikon der Ägyptologie, differentiates between personifications which belong to the sphere of literature and art, which she understands as metaphors "ohne dass der Dichter oder Leser glaubt oder glauben könnte, die Dinge oder Vorgänge seien wirkliche Personen," and personifications in the religious sphere which are understood differently - "eine Erlebnisweise, in der Dinge oder Vorgänge zugleich als Person und als Sache erlebt werden."

In the field of the general study of metaphor, Lakoff and Johnson

2. For comprehensive studies of the subject, see Baum 1988:36-87,277-284 and Keel 1992:61-138.

3. See also Silverman 1991.

4. See also his bibliographical list on the subject of the tree-goddess; to the bibliography add Baines 1985:61-63 and Wilson 1990. 
have placed the process of personification within the metaphorical processes by saying that "perhaps the most obvious ontological metaphors are those where the physical object is further specified as being a person. This allows us to comprehend a wide variety of experiences with nonhuman entities in terms of human motivations, characteristics, and activities" (1980:33). ${ }^{5}$ In the pictorial realm, the psychologist John Kennedy (1982), discussing metaphors in pictures versus figures of speech, presents, as his first example of a modem pictorial metaphor, a personification of a tree, or more accurately a female personification of an arbor (fig.21).

Probably popular religion was attracted to the wonder of the fruit tree very early in Egypt's history. Somewhere around the beginning of the 18 th dynasty, this natural blessing which bestows on man both nourishment and protection (within its shade), found a primal analogy in the first and most beneficent power, the female or mother-goddess (herself an age-old personification). The phenomenon of the tree was thus propitiously illuminated by the most basic experience of the mother, a result of the deep-structure conceptual metaphor THE FRUIT TREE IS A MOTHER GODDESS. ${ }^{6}$ On the other hand, the goddess, and her rather obscure relation to man, are conceived via the readily available mother-son and man-tree relations. ${ }^{?}$

5. In his recent book on metaphor MacCormac writes "... it certainly seems that all personifications are metaphors. One might object that primitive peoples [certainly an unbefitting attribute for the ancient Egyptians, O. G.] who believe that rocks and trees are inhabited literally by animistic spirits presume personifications that are not metaphors. In applying human attributes to these non-human objects, primitive peoples do not think that they are crossing semantic categories. Or do they when these rocks and trees take on an aura of mystery?" (1985:37).

6. The identification of tenor versus vehicle in pictorial metaphors, where grammar and syntax can not come to our aid, is problematic. This problem was recently discussed in detail by Forceville 1994.

7. Keel sees these relations somewhat differently, not including the "mother domain" - "Die entschlossene Darstellung der Isis oder der Nut als Sykomore entspringt wohl dem Bedürfnis, diese grossen Göttinnen in dem, was wir "Natur" nennen, präsent und erfahrbar zu machen bzw. die Erfahrung dieses Baumes zu einer Erfahrung des Göttlichen zu verklären, kurzum aus der Verbindung von Himmel und Erde, aus der "Inkarnation" des Göttlichen im Augenblick der Begegnung mit dem Tod Kraft zu gewinnen. Für die AuftraggeberInnen dürfte letzteres das Entscheidende gewesen sein" (Keel:1992:92-93). 
The categories, or the slots of the conceptual metaphor are necessarily inclusive rather than particular (that is, they may include several members of the same group - in this case TREES), and so are also widely serviceable, or perhaps widely originated. In the FRUIT TREE slot one encounters mainly the sycamore, but also the palm tree, and rarely also a shrub. ${ }^{8}$ In two known examples, the tree appears as a double entity - sycamore-palm. Here two members of the FRUIT TREE category are represented together, enhancing the surrealistic impression. (fig.37, and Keel 1992:120 fig.72) . Likewise, in the category of the MOTHER GODDESS one recognizes Isis, Nut, Hathor, Maat, Imentet and Nephthys and even Taweret (Baum 1988:6162; Keel 1992 passim). Identification may sometimes prove ambiguous, so that it may look like one goddess, (i.e., Isis, by the headdress) and be named as another by the inscription (Hathor, see Keel 1992:128, fig.83).

Surfacing quite late in the canonical corpus, the tree-goddess reflects a concept which apparently existed for some time on the margins of the repertoire of religious images before its admission into the pictorial canon sometime during the 18th dynasty. It is not certain whether its marginality afforded its creators a greater freedom, or possibly forced them to adopt versatility as a way of applying pressure on the canon to absorb the concept. In any case, this versatility evinces the relative newness of the concept as an accomplished metaphorical being in the pictorial aggregate of the repertoire. And, whatever their cause, the concept's popularity and changeability are what allow us to examine, in this case, the metaphorical lifeline of religion. Metaphorical beings of the religious sphere would have taken shape through institutional indoctrination by priests (this was probably the case with many "mixed" deities, for example Sobk-Re), or via popular metaphorical conceptualizing. As a non-institutional being, "the sacred tree" had no known priests or temples from the pharaonic period. It seems to have been, so to speak, "naturally created," and therein lies its importance to $\mathrm{us}^{9}$ (this does not exclude the possibility that in certain cases the

8. On the possible appearance of the "arbre carbonise," see Baum 1988:45 and Keel 1992:87.

9. "The identification of the sycamore with the Mother of God continued into Christian times. In the apocryphal gospels the story is told that, on their flight into Egypt, the Holy Family sheltered beneath a huge sycamore at Matarieh near Cairo where they drank from a clear spring in its shade. When Herod's agents came close to discovering them there, the tree's trunk opened up and enveloped them, keeping them safe and nourishing them with its fruit until the danger was past" (Wilson 1990, 81; also Baum 1988:86-87). 
metaphor was made concrete, and reverence accorded to certain actual trees, e.g., Keel 1992:87); as we have seen in relation to the script, a dynamic movement between the concrete and the abstract remained the hallmark of Egyptian culture. ${ }^{10}$

Conceptual metaphors do not always appear as such in the linguistic arena, but their existence may be deduced from their numerous other manifestations in literature and art. ${ }^{11}$ Although the texts accompanying the pictures are outside the purview of my present study, it is worthwhile mentioning Othmar Keel's conclusion, after he reviewed his collection of pictorial examples, that generally no separate term or name occurs in language referring to the new combined entity of tree-goddess, but only trees and goddesses apart. ${ }^{12}$ Yet he mentions that the goddess is in fact called Nht-Nut at least once (closely following her introduction to the canon). Her subsequent description is indeed a combination of characteristics of the sycamore and the goddess Nut. The dead man hopes to bask in the shade of her boughs and eat of her fruits, to suck nourishment from her breasts as he is being lifted to the sky to join the ihmw-wrd (fig.23=Keel 1992:97, fig.42 [Kenamun]). In this manner, the pictorial concept seeped into the religious imagination. In the equivocal tongue of the Ramesside tomb of Paser (Keel 1992:121, fig.73) we are left to ponder: "The great Nut, splendid in her name of Nht."

Normally, if the metaphor is included in the accompanying texts, it

10. See also Baines 1985:72.

11. Lakoff and Turner 1989. These manifestations are called by Levin "satellite metaphors" (Levin 1988:5). Compare also Gombrich's term "cultural common knowledge" which he describes as the "sources of metaphor," saying that "religion provides most cultures with a central area of metaphor" (Gombrich 1979:13). Hornung and Baines use the term "meta-language,"see Hornung 1982:124; Baines 1985:22.

12, "Die literarische (und ikonographische) Überlieferung kennt Göttinnen wie Isis und Nut, die für die Toten wichtig sind, die ikonographische Bäume wie Sykomoren und Palmen, mit denen sie die (gemalten) Gärten im Grab ausstattet. Die Ikonographie verbindet ab Thutmosis III. beide in einer Weise, wie das die literarische nicht gemacht hat. Sie bezeichnet diese Mischwesen weiterhin schlicht als Isis, Nut usw. oder als Sykomore. Der Terminus 'Baum-Göttin' ('tree goddess') existiert im Ägyptischen nicht. . . Aber die modernen Begriffe bezeichnen ganz genau den ikonographischen Sachverhalt, der in der ägyptischen Sprache kein prägnantes Äquivalent gefunden hat. Am nächsten kommt ihm etwa 'Nut in ihrem Namen Sykomore'"( Keel 1992: 95). 
usually appears as a replacement ${ }^{13}$ metaphor; that is, the text represents only the source domain (vehicle), ${ }^{14}$ of the metaphor. When, for instance a king is referred to in a verbal metaphor as the "strong bull," the new term "bull," initially summoned to enhance "king," now replaces the whole kingbull combination. In our own case, Isis, Nut or Hathor replace the tree altogether on the textual level. In a few cases, the metaphorical being is referred to as Nht, that is, only to the tenor. This phenomenon is well attested in modern examples of pictorial metaphors (Forceville 1994). Nevertheless, it is the joint pictorial information of both goddess and tree which provides the text with a metaphorical connotation.

The fascinating range of pictorial examples of the tree-goddess seems to enhance in particular those theories posited by I.A. Richards, which maintain that metaphor is not just a set of comparisons or an understanding confined to the pragmatic level but a creation of a new being (Gibbs 1992:586-588), contingent on interaction processes. As Umberto Eco puts it "In other words, two images are conflated, two things become different from themselves, and yet remain recognizable, and there is born a visual (as well as conceptual) hybrid" (1984:96). In the case of the treegoddess, we may easily perceive that during the process both target (tenor) and source (vehicle) are not only affected, but are, in effect, constantly "on the move"; a metaphoric process which endorses the somewhat out of vogue term "vehicle" coined by Richards as opposed to the more currently popular "source." As witnessed before in the $b 3$ bird example, a free-flowing movement between the two poles of tenor and vehicle enlivens the conceptual field.

Among the various representations of the tree-goddess several basic categories of representation may be discerned, according to the degree of interaction. Most of the examples are variations on those primal themes. I have regarded as pictorial representation of the concept "tree-goddess" only those representations which included the tree and the goddess respectively. Depictions of the two "celestial sycamores" have been excluded, as have the problematic "garden personifications" (though it may well be that the

\section{See Brooke-Rose 1958:1-25.}

14. "The target conceptual domain is the domain to be understood metaphorically. The source conceptual domain is the domain in terms of which the target is to be understood metaphorically. A conceptual metaphor consists of a target, a source, and a mapping between them." (Turner 1992:268 n.4). "Target" in the modern literature of metaphor is parallel to "tenor," whereas "source" is parallel to "vehicle." 
ancient belief in celestial sycamores and the concept of the "garden personification" later paved the way for the conceptualization of the treegoddess, as it related the sycamores at a very early date to the divine). ${ }^{15}$

Category $\mathbf{I}^{16}$ - The goddess and the tree are represented separately. No actual metaphorical movement is as yet achieved pictorially. Inscription plays an important identifying role. This representation is not very common. (One must not take "as yet" to mean this was necessarily a chronologically earlier stage in the development of the metaphor (figs. 22,23,24 [Keel 1992 figs. $\left.\left.55,{ }^{17} 42,96\right]\right)$.

Category II - The peeping goddess. In some instances, the representation of the goddess gives the impression that she is hiding in female guise amongst the boughs. In these cases, it seems that the metaphor is represented more concretely, and what Baines calls the "reality status" of the figures remains doubtful. The tree and the female goddess do not actually generate together an Aristotelian "something else," but remain apart, as two entities, "a goddess who hides in the tree." Textual material will evince comparable

15. Personifications of the sycamore and the garden would reflect the understanding of the tree's characteristics in human, rather than divine terms, see Baines 1985:55. On the problem of the two sycamores and the garden personifications see, Keel 1992:69-74,92-93 (including bibliography).

16. Category Ia - The hairdress category (Keel 1992:75-76, figs. 47a,55;103) The tree becomes a part of the goddess' hairdress. It is questionable whether the tree goddess is at all represented in this category, (Baines 1985:55). This method of identifying a deity by an overhead symbol is a convention of many cultures, especially popular in Mesopotamia (Hornung 1982). This type of pictorial representation is perhaps a reduction of identity relations to genitive relations if compared to the linguistic sphere. In the case of the "tree hairdress," there is an avoidance of obvious available "image-schema" (see below) similarities between the two parts of the supposed identity metaphor. However, in examples like that of the scorpion goddess Selket or Khepri, it is the image-schema which resists the creation of the pictorial interaction that is possible on the linguistic level; in this context one should mention Baines' suggestion that the Maat feather is left unpersonified because "the sign resists being 'read' as a body" (1985:66).

17. The example of fig. 22 can also be considered as an example of the hairdress category, see the above note. Yet the goddess stands in front of a splendid tree. 
expressions such as $N h t n N w t$ (figs.25,26=Keel 1992 figs. 78,43; see also Keel 1992,fig. 63 [a superimposition?]).

Category III - Superimposition. A salient variation: the goddess-vehicle appears as superimposed on the tree, but without interaction. This situation may in some cases at least produce a foregrounding of the goddess at the expense of the tree, so that a metaphorical "new being" is not yet fully accomplished. ${ }^{18}$ This may explain the phenomenon of writing the name of the goddess on the trunk of the tree. (figs. $27,28,29=$ Keel 1992, figs. 88 , $89,95)$.

Category IV - Interaction. This is a very common representation. The metaphor has good image-schematic ${ }^{19}$ potential as the arms of the goddess naturally intertwine with the branches, her body emerges as a congenital extension of the trunk, and her face easily interchanges with the fruit (compare fig. 21 above).$^{20}$

This category can be divided into at least two sub-categories:

Category IVa - The tree grows human limbs, hands and sometimes also a breast. The hand and breast version is the oldest (known to us) and the most canonical one, as it originates in the tomb of Tuthmosis III. It seems that during the reign of this king the pictorial metaphor was incorporated into the canon (figs.30,31,32=Keel 1992,figs. 40, 66, 69).

Category IVb - The female goddess grows from the trunk of the tree. This version is the most successful on the image-schematic level, as the elongated female body blends seamlessly with the

18, On this version Von Bissing writes "Baum und Frauenfigur stehen da gewissermassen aufeinander, um nicht zu sagen hintereinander, jede organische Verbindung, welche die älteren Bilder zum Teil prachtvoll erreicht hatten, fehlt" (cited by Keel 1992:88)

19. Mark Turner, following Mark Johnson, defines "image-schema" as "extremely skeletal images that we use in cognitive operations. . . when we map one image metaphorically onto another, we are constrained not to violate the schematic structure of the target image"(1991:57-58).

20. From the modern version of the tree personification we can see that on the image-schematic level the curvaceous tree lends itself more easily to an allusion of a female body than that of a male body. 
trunk, while the hand completes the interaction with the branches; indeed, a most popular version. (In some examples it is rather difficult to decide whether this is an interaction case or the "peeping goddess" version) (figs. 33,34=Keel 1992, figs. 77, 79).

Category V - The cow version. As some female goddesses are also manifested in cows, one would have expected to see many examples of cow-tree variations. Keel's collection, however, contains only one version with the cow, and it seems that this kind of representation is rather rare (Baum 1988:69). I believe that the cow version is rejected consciously or unconsciously on image-schematic grounds. The cow has no imagery domains interchangeable with the tree, although on the conceptual level the cow's milk may well interchange with the tree's sebum. The final entity creates a strong surrealistic impression (fig.35=Keel 1992, fig. 85).

Category VI - The palm tree. In some examples the palm tree stands for the category "FRUIT-TREE." On the domain interaction level, the palm tree is less successful than the sycamore, as it contains no sebum, and its trunk has no cavities. On the image-schematic level, interaction is problematic. The palm's branches are too markedly separate from one another for the arm to blend successfully into them, and their shape runs contrary to its natural bend. The palm fruit, too, can hardly be portrayed as a human face peeping amidst the leafage. Indeed, the interaction examples of the palm tree are much fewer in number than those of the sycamore (fig. $36^{21}$ =Keel 1992,fig. 70).

Category VII - The combined tree sycamore-palm. This combination is known from at least two examples (Keimer 1929). In the only complete version known to date, the tree which is a combination of a sycamore and palm, constitutes the goddess's body. Her four arms are extended holding a tray of food (fig. $37=$ Keel 1992, fig.71). Baum suggests that we are facing here an actual natural phenomenon which may have existed in a certain area of Egypt (1988:277-284). Even so, metaphorical meanings cannot be

21. Keimer (1929:83) and Keel (1992:80) regard this example as a palm-goddess. Baum (1988:280) sees it as a combination sycamore-palm because the petioles of the palm-trunk are not represented. It seems to us that the palm's trunk is simply schematized here, and is not necessarily combined with the sycamore. Moreover, the sycamore goddess appears separately in the same tomb (Keimer, ibid). 
dismissed. In this elaborate case, the deep structure metaphor THE FRUIT TREE IS A MOTHER GODDESS, is woven out of four strands, the tree represented by two interlacing tenors, and the target by two female personifications. If so, this rare example reveals the sophisticated possibilities of the pictorial force, too vibrant to restrain itself to one tenor-one target, as in verbal satellite metaphors. (For another example see fig. 38=Keel 1992, fig.72).

It has recently been suggested that the processes of superimposition and interaction play an important role in the processing of metaphor (see Harris et al. [1980] and Albert Rothenberg [1988]). ${ }^{22}$

In an experiment designed to probe the nature of the mental image evoked by a metaphorical sentence, Harris and his associates asked thirty-six subjects to describe the images they constructed for eight metaphorical sentences, eight dead metaphors, and eight nonmetaphors. One important question was whether the images produced would only refer to the semantic domain of the topic or to the semantic domain of the vehicle as well. The results have shown that metaphors and dead metaphors did not evoke different results. $30.2 \%$ of the total responses involved either the topic+vehicle or some less appropriate but also metaphorical response. In looking over the topic+vehicle images, the experimenters report that "one cannot help but be struck by their creativity and complexity. . . Not only are both the topic and vehicle semantic domains present, but they are intertwined in some complex ways. . . many other examples also involved metonymy, a type of figurative language where a part of the whole or a symbol for it is used to stand for the whole. Not a single topic+vehicle response merely pictured the two semantic domains juxtaposed but rather had them intricately fused" (p.177). In their conclusive discussion they repeat that "While such images [of metaphorical sentences] may sometimes be simple literal icons representing particular objects or events, they are frequently highly creative, constructed, literally anomalous 'surrealistic' images" (p.178).

In his studies of experimental psychology, Albert Rothenberg attempted to evaluate the role of mental imagery during the metaphorical process in language and in the visual arts. In his empirical study he tried to define the context for the mental quality which he calls "homospatial process" - an act of "actively conceiving two or more discrete entities occupying the same space, a conception leading to the articulation of new identities" (e.g.,

22. I thank Rina Dudai for this reference. 
metaphorical beings) ${ }^{23}$ - which in his opinion is involved in the development of new conceptions in science as well as in art. ${ }^{24}$

In the first experiment, the first group of subjects was shown two slides of different naturalistic scenes, projected on a screen and superimposed upon one another. Subjects in a second control group were exposed to the same pictorial images, but instead of being superimposed, the slides were projected side by side on the screen. The experimental task consisted of creating a metaphor stimulated by the various pairs of slides (10 pairs were used). The results were conclusive. Metaphors produced by the experimental group exposed to the superimposed stimuli were rated significantly higher than those produced by the group exposed to the same stimuli separately.

In the third experiment, Rothenberg turned to metaphor in the visual arts. Using gifted art students as subjects, he assigned them to either superimposed or separate viewing of the slides; they were then asked to construct a sketch evoked by the stimulus. Rothenberg underlines the fact that "the superimposed stimuli used displayed a complex bringing together of the two component slide photographs. They were, therefore, also somewhat hazy" (1988:451). However, in the highly creative works stimulated by the superimposed images, a clear factor of interaction and integration of the elements appeared.

Rothenberg's results were unequivocal. The complex bringing together of visual elements, rather than side-by-side naturalistic image display, or additive combinations in figure-ground configuration, leads to the most artistically and verbally creative products. Thus it appears that the canonized visual metaphor of the "tree-goddess" provides us with a peephole into the processes involved not only in metaphorical conceptualizing in ancient Egypt, but also into what seems to be an omnipresent behaviour of the human mind. The most interesting result is that superimposition and interaction played a dominant role in the processing and demonstration of the full-fledged metaphors in both cases. The Egyptian representations additionally point to the fact that the mental imagery of metaphor may involve a bilateral move of the two parties until they are superimposed and

23. "The resulting conception, because it corresponds to nothing in the physical reality and because discrete elements conflict and overlap, is necessarily both transitory and hazy. It is a way station in the formulation of new and effective forms and structures" (Rothenberg 1988:444).

24. He accepts Aldrich's definition of the visual metaphor as "a transcendence of ordinary visual field perception and an interactive relationship among visual elements" (1988:445). 
interact. Yet, without the superimposition and interaction processes, the "new-born" idea hardly comes to life.

To conclude, I would like to suggest that the "tree-goddess" was not created only by iconography, ${ }^{25}$ but that iconography further indicates a deep-structure conceptual metaphor, set on the edge of the repertoire somewhere at the beginning of the 18 th dynasty, probably with much earlier roots. Possibly, the concept owes its popularity to the multiple mapping processes between the target (tenor) and source domain (vehicle), and to the very successful image-schematic potential of the metaphor. Many characteristics of the two domains map into each other. The godly mother, as well as the fruit tree, cares and shades, provides milk (white sebum) and water (water sources connected to the tree), supplies food and shelter; in the big cavities of the huge sycamore, the dead may attain refuge (or, some may say, satisfy an urge to return to the mother's womb). Yet, what led to its pictorial popularity is probably its multiple pictorial mapping - the trunk and the body, the hands and the branches, the fruit and the face. ${ }^{26}$

The enchanted "new being" created by the conceptual metaphor THE FRUIT TREE IS A MOTHER GODDESS, can be placed on the horizon of poetics.

25. It seems that Baines also believes that "the text or the concept must be prior to the picture, even if the picture cannot be turned back into text" (1985:73). On the complexity of relations (in general) between text and picture see Keel 1992; Keel deals with this subject extensively in his various publications.

26. "Il reste à trouver ce qui a pu précisément motiver l'établissement de rapports aussi étroits entre F. sycomorus et les divinités maternelles, et ce problème parait pratiquement insoluble" (Baum 1988:37). 
Appendix B 


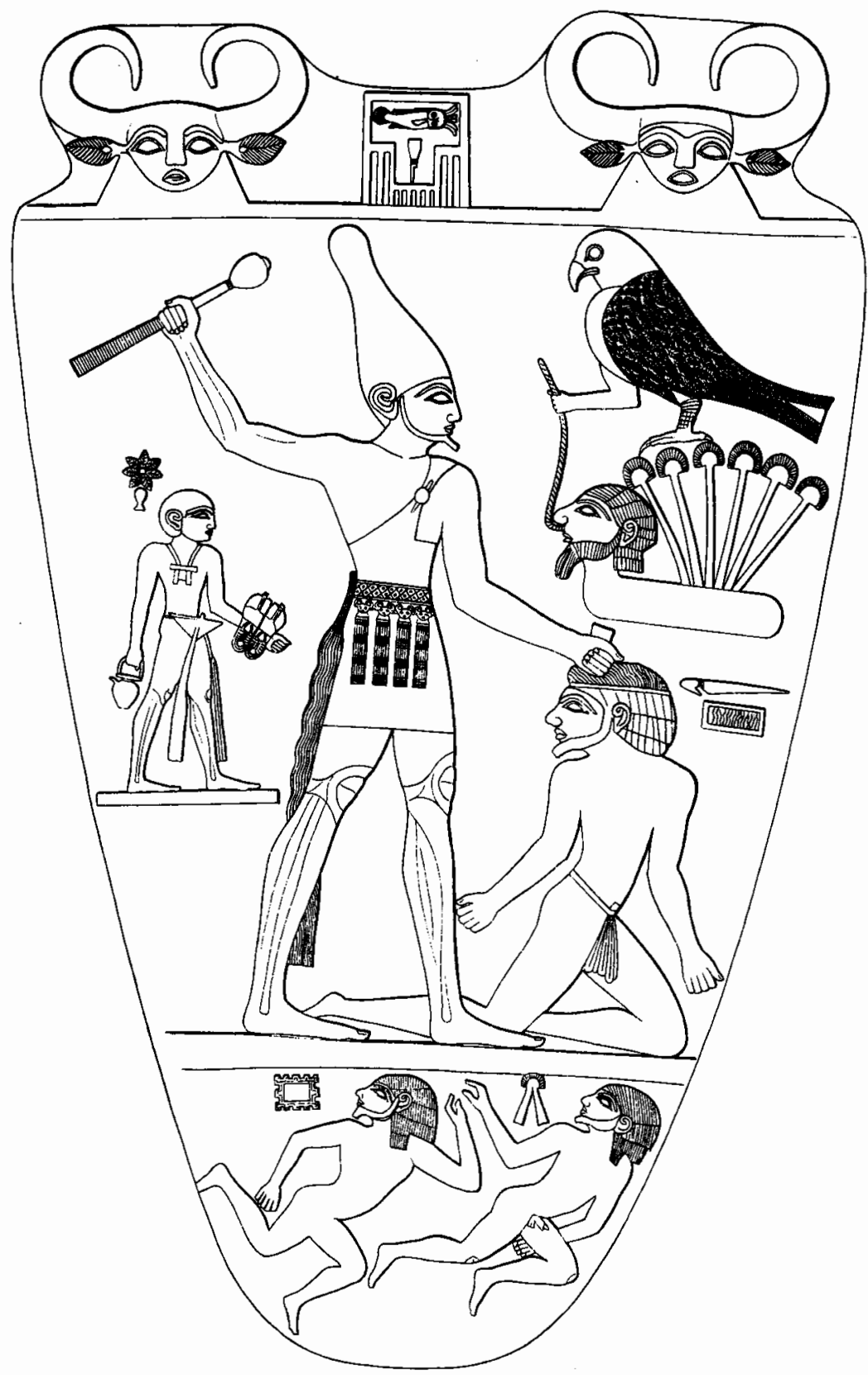

Fig. 1. The Narmer palette, recto (after Quibell 1898, pl. XII, fig.1) 


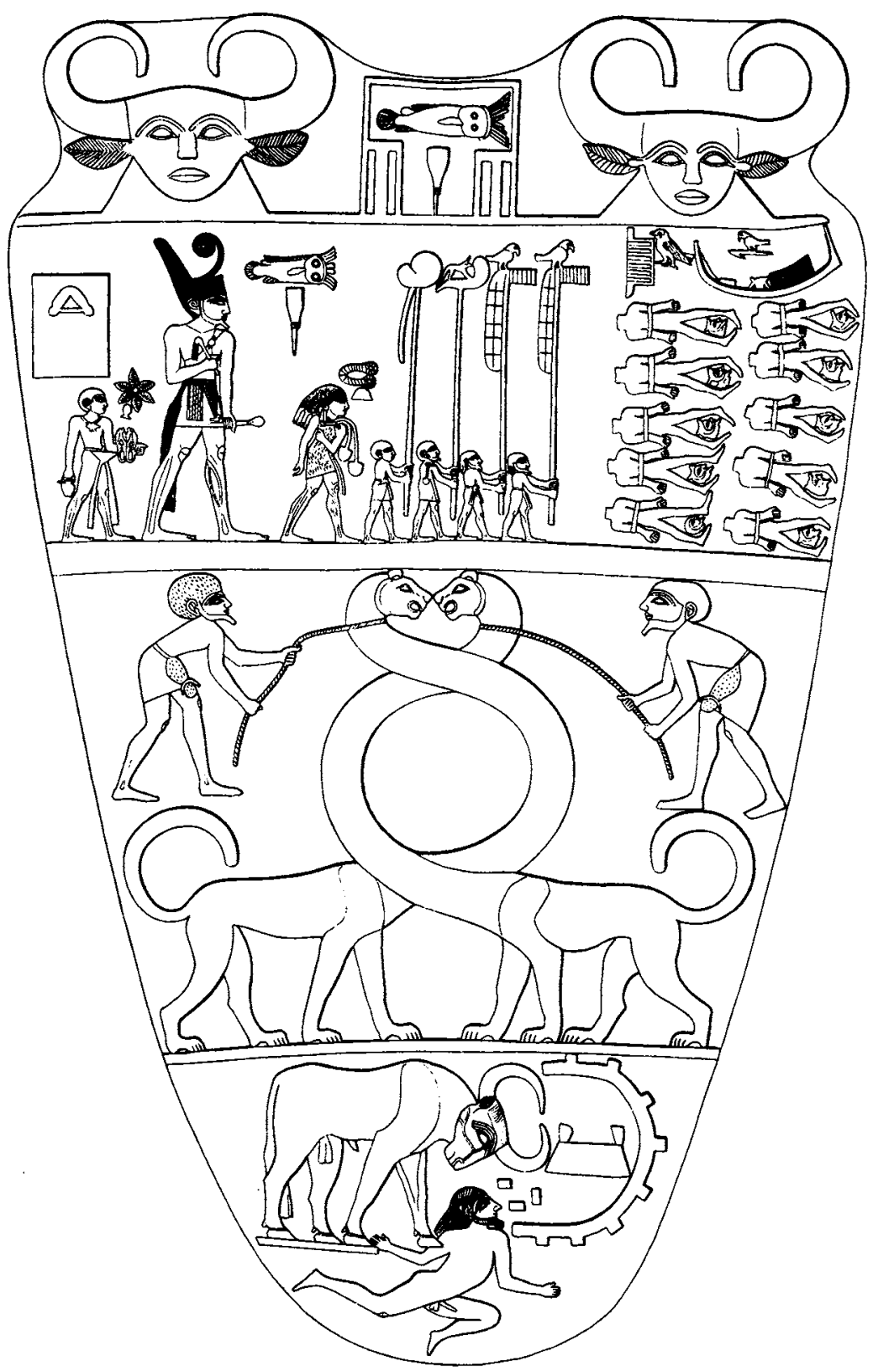

Fig. 2. The Narmer palette, verso (after Quibell 1898, pl. XIII, fig.2) 


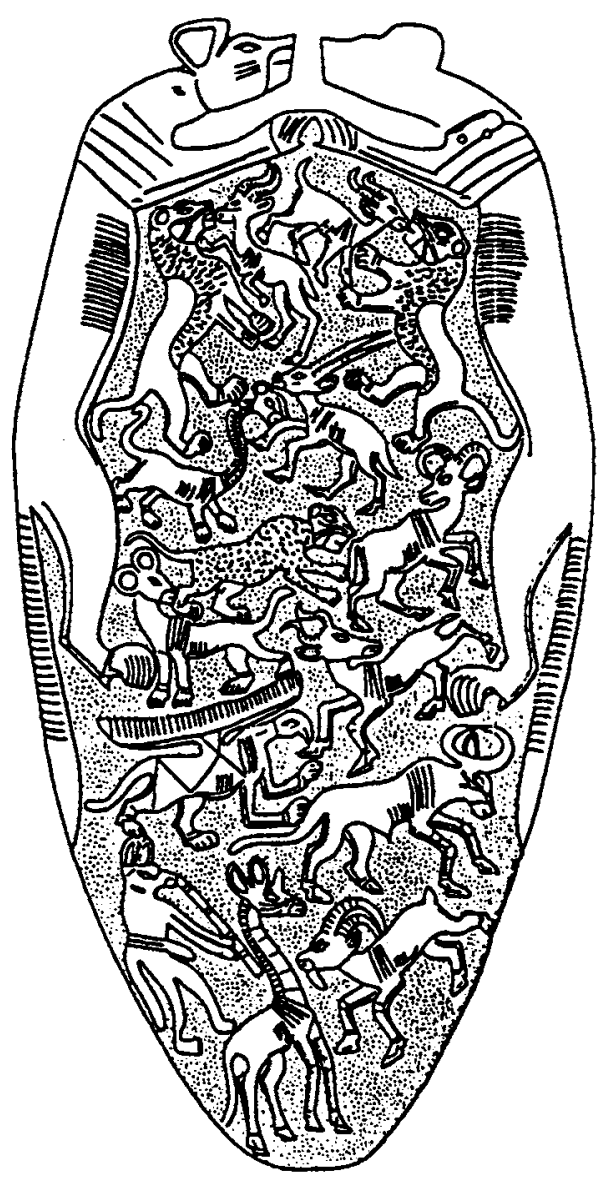

Fig. 3. The Two-dog palette (after Kemp 1989, fig.14) 


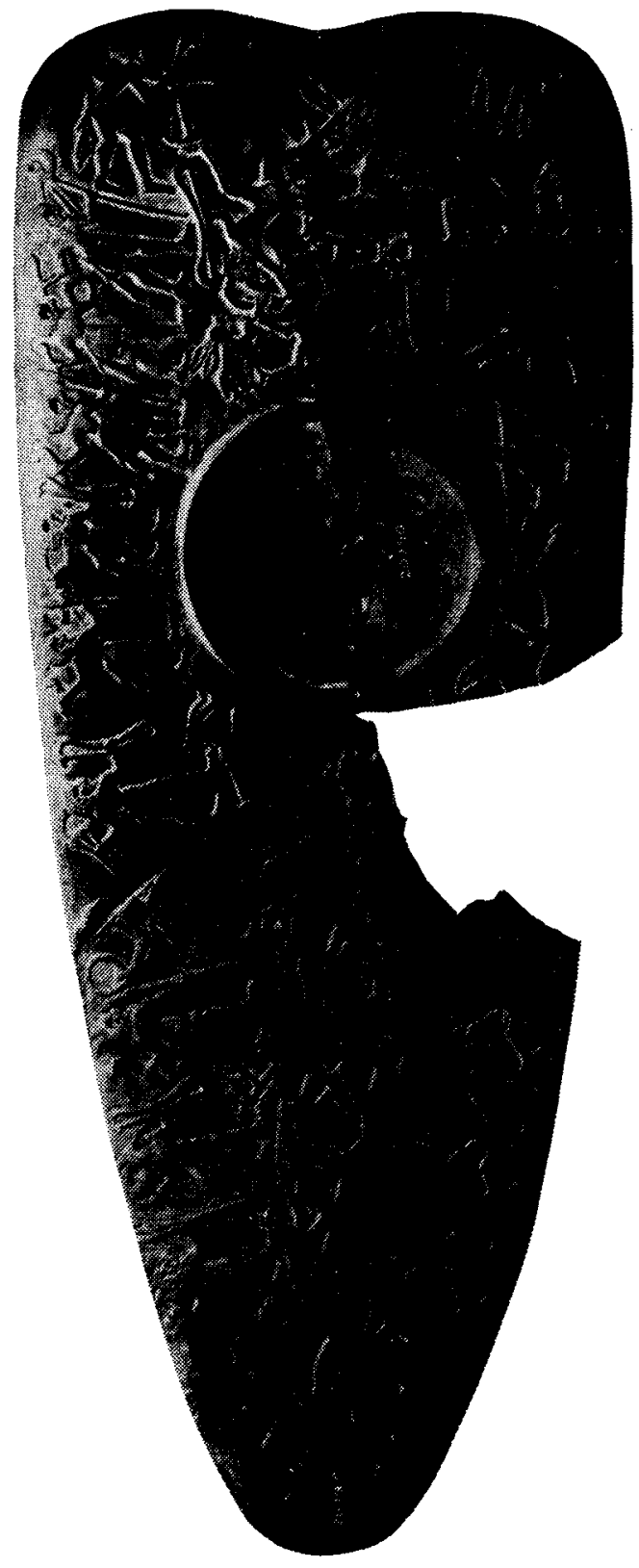

Fig. 4. The Hunter's palette (after Petrie 1953, pl. A, 3) 


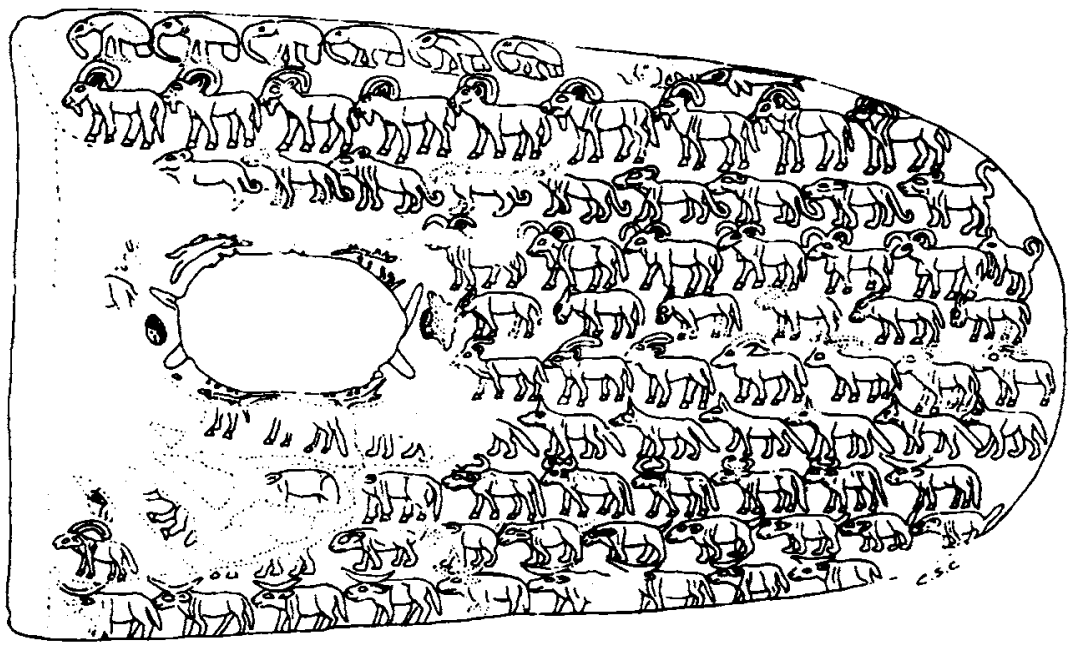

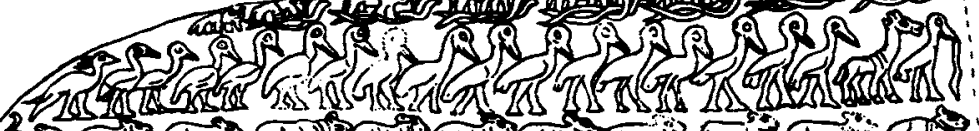

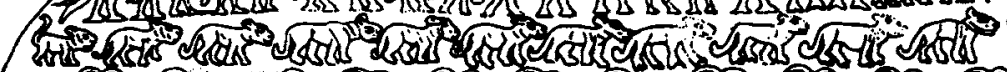

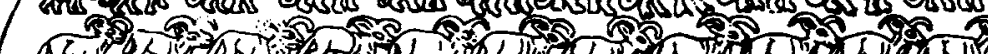

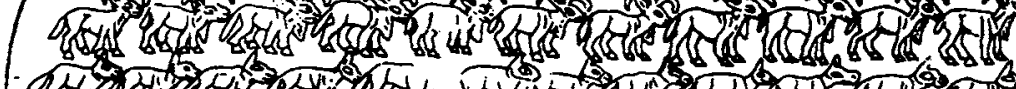

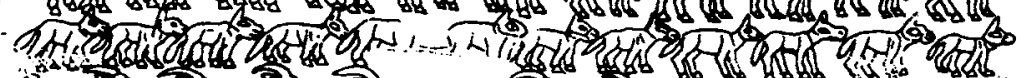

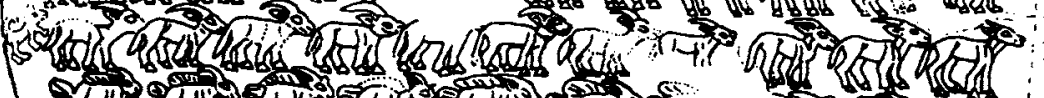
out of

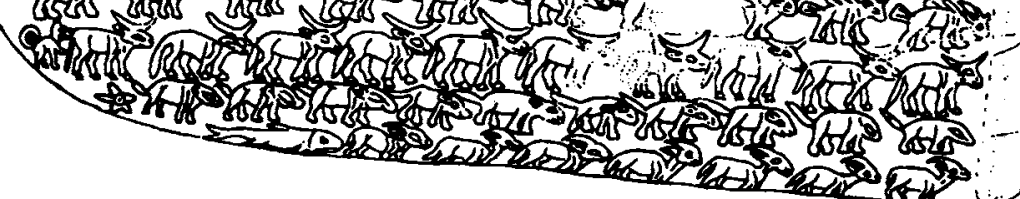

Fig. 5. Brooklyn handle: carved ivory knife. (after Davis 1992, fig. 8) 


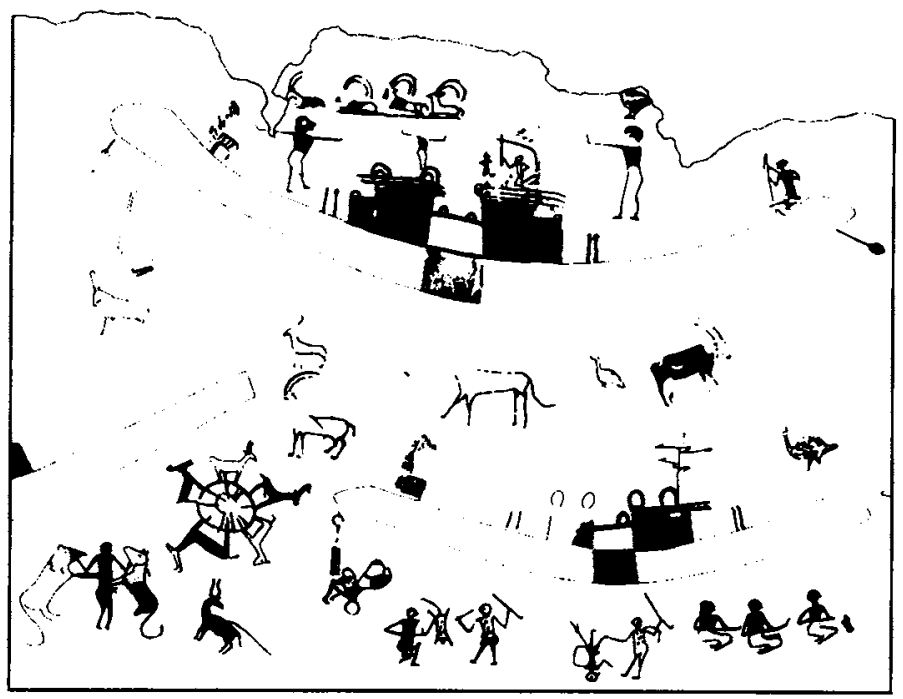

Fig. 6. Hierakonpolis tomb 100 (after Kemp 1989, fig.11)

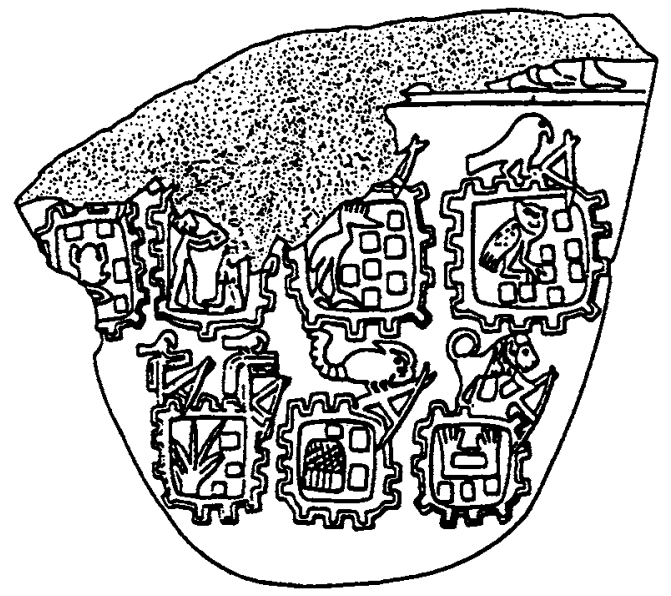

Fig. 7. The Libyan palette (after Kemp 1989, fig.16) 


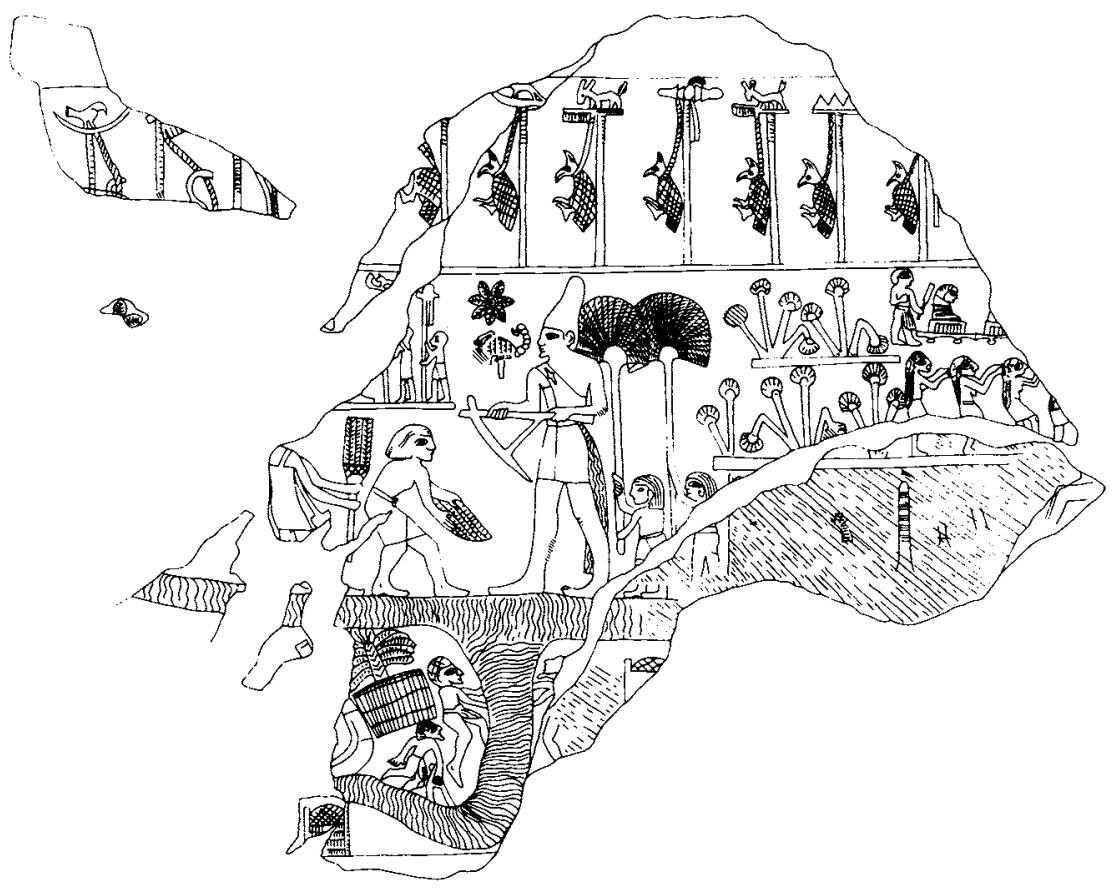

Fig. 8. The macehead of king "Scorpion" (after Millet 1990, fig.2) 


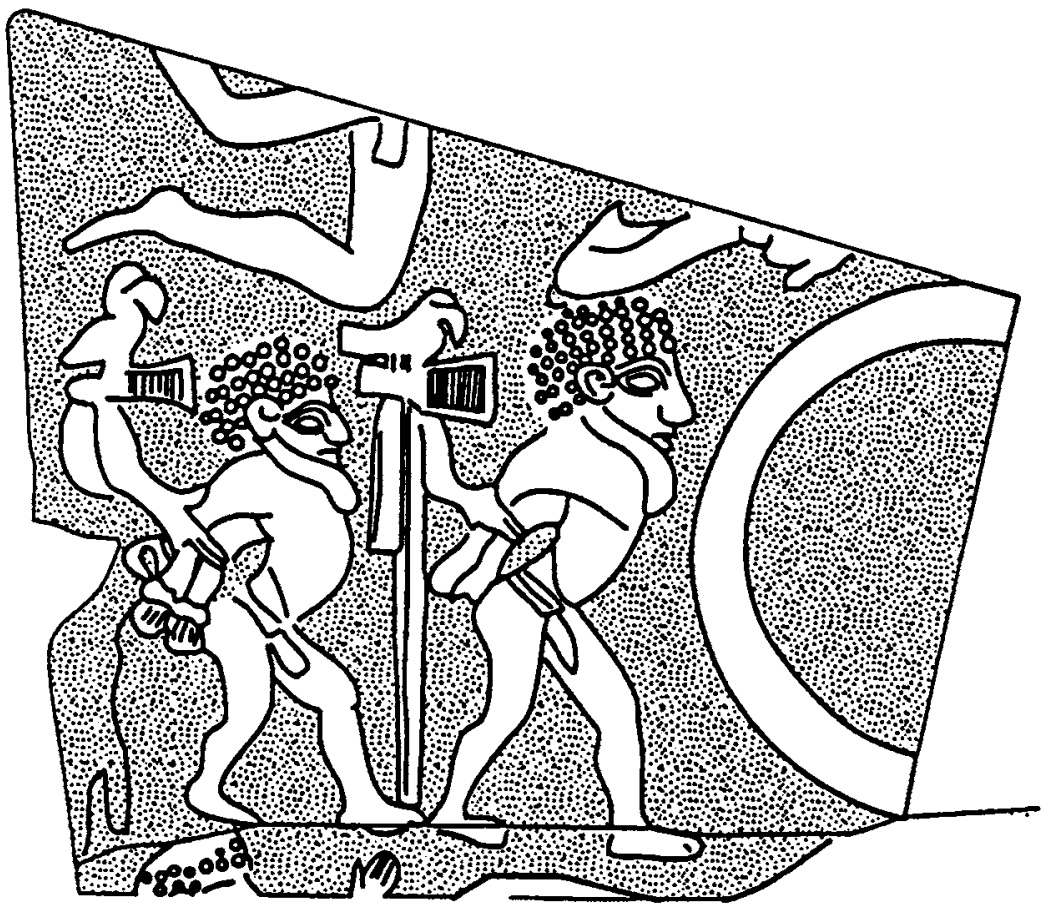

Fig.9. The Battle field palette (after Davis 1989, fig.6.11)

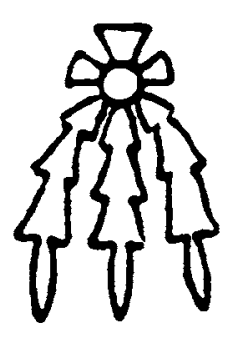

Fig. 10. ms sign

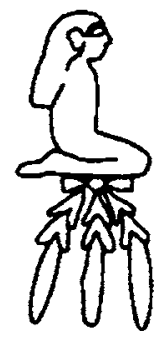

Fig. 11. $m s$ sign after Fischer 1980b:9, fig.4d 


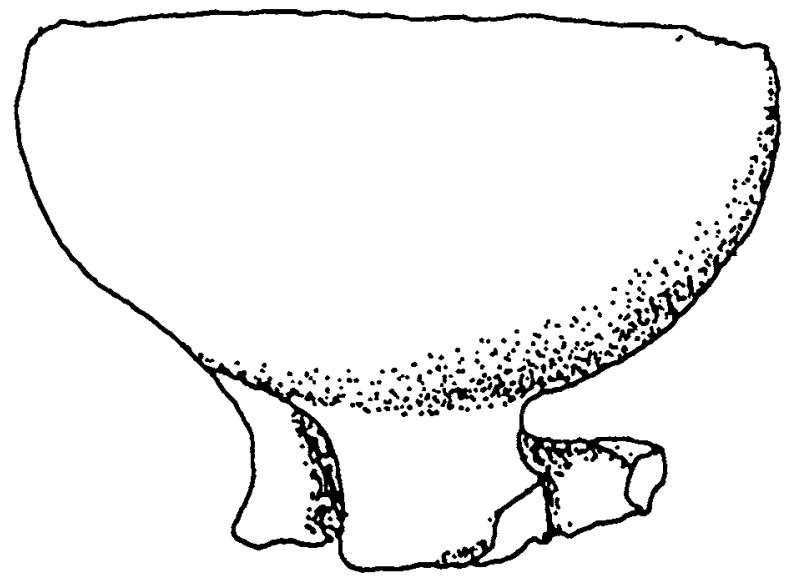

Fig. 12. A predynastic "legged bowl" (after Fischer 1986, fig. 12) 


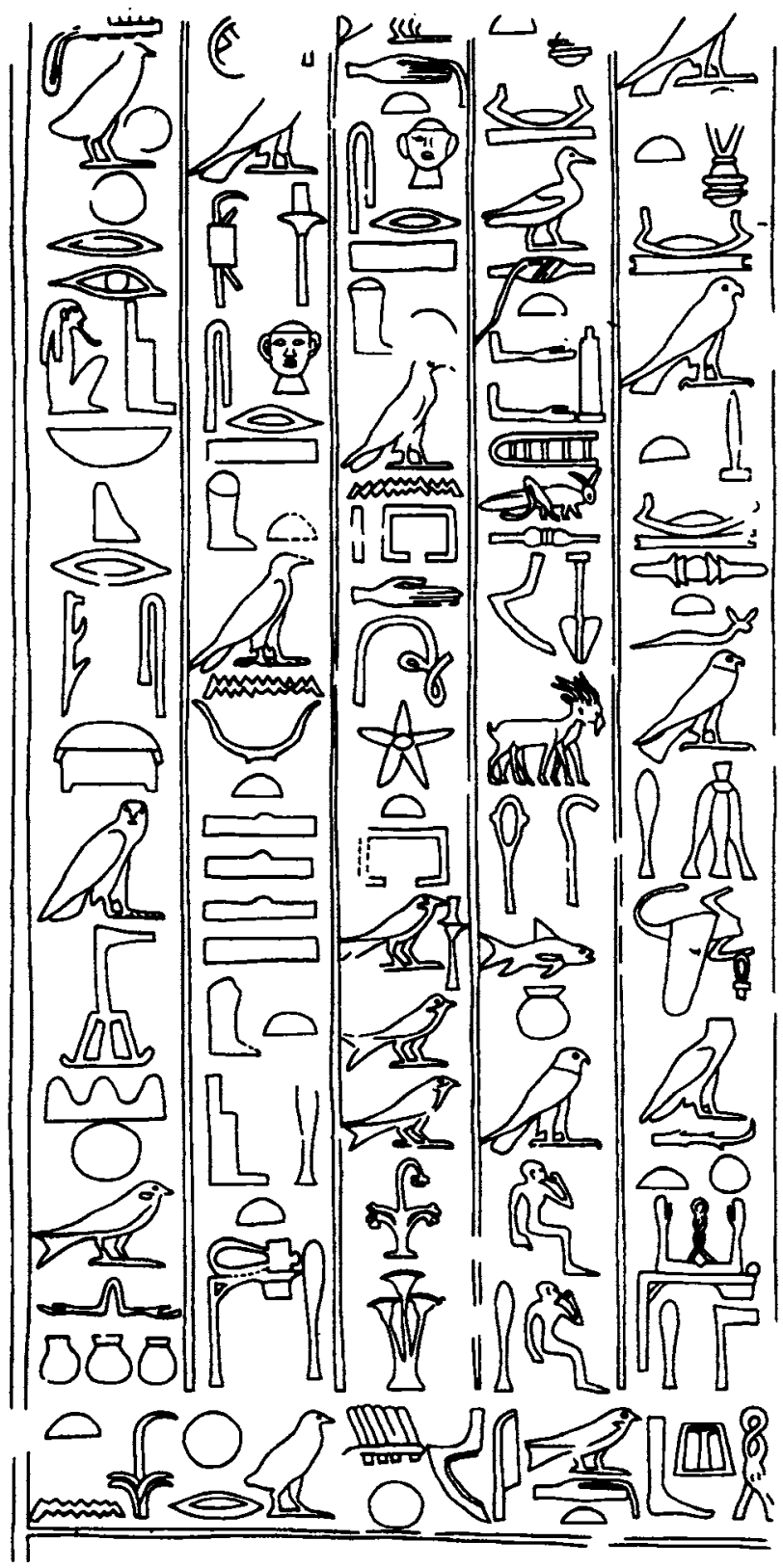

Fig. 13. From the tomb of Wernu (after Davies et al. 1984, pl.28) 


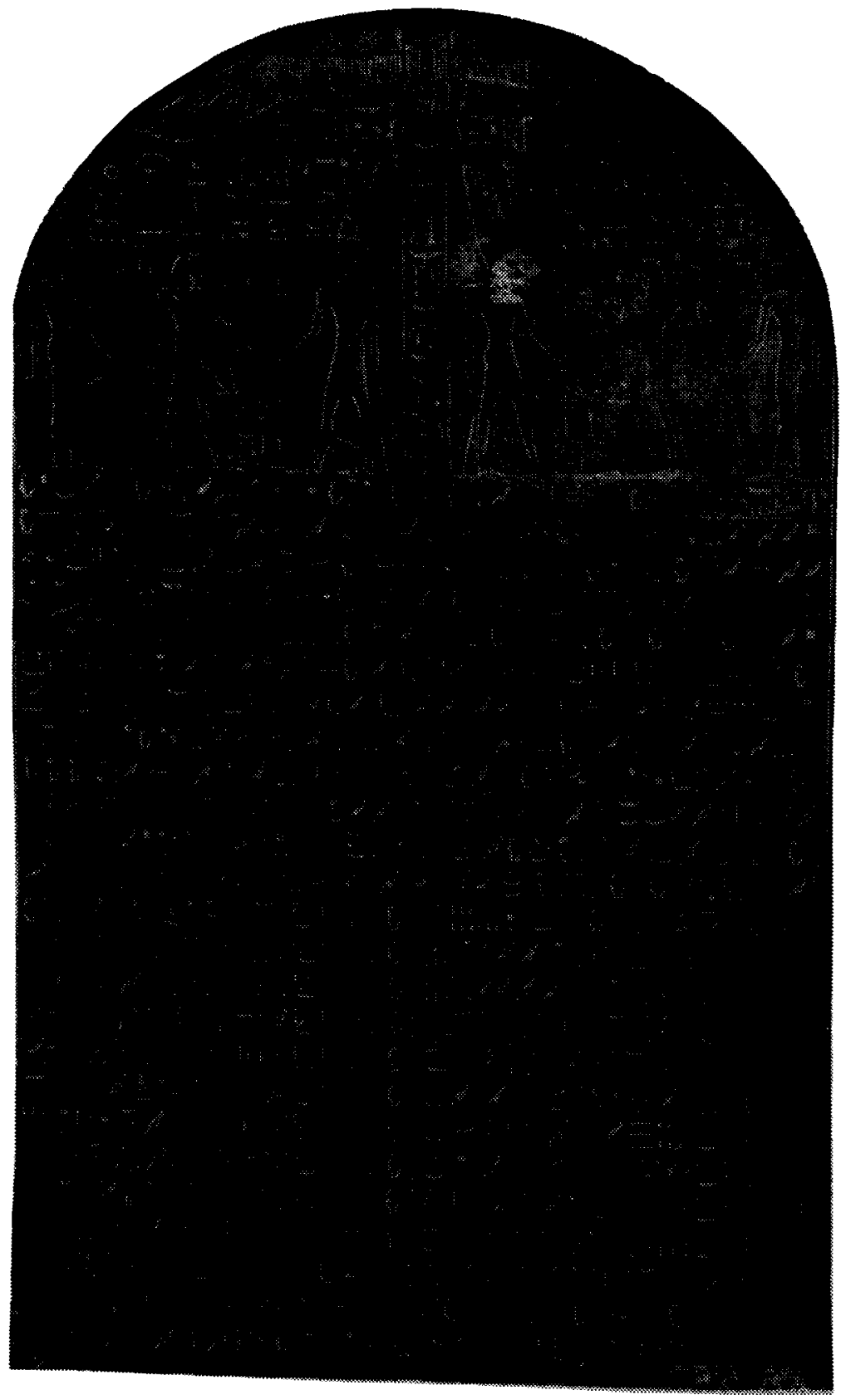

Fig. 14. The "Poetical Stela" (after CGC No.34010) 

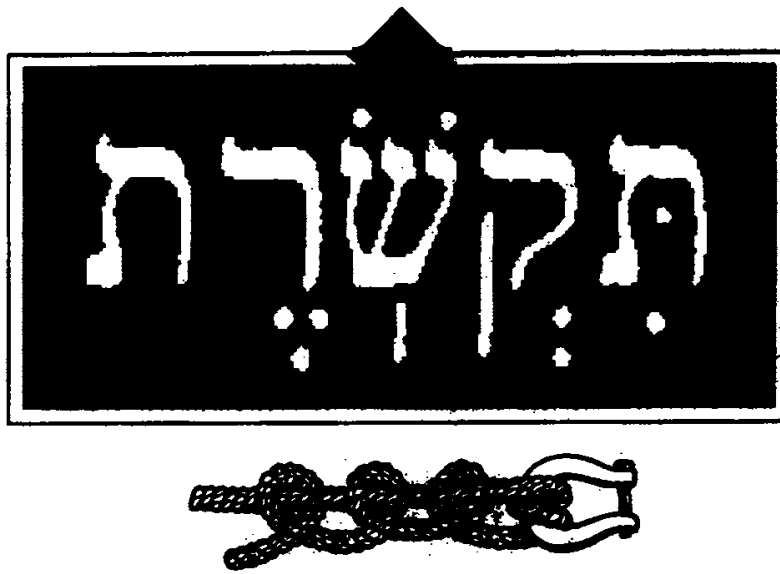

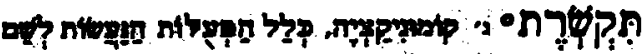

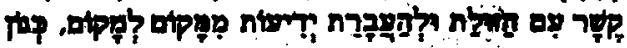
- - -

- EnTp?

Fig. 15. The advertisment for "תקשרת" 


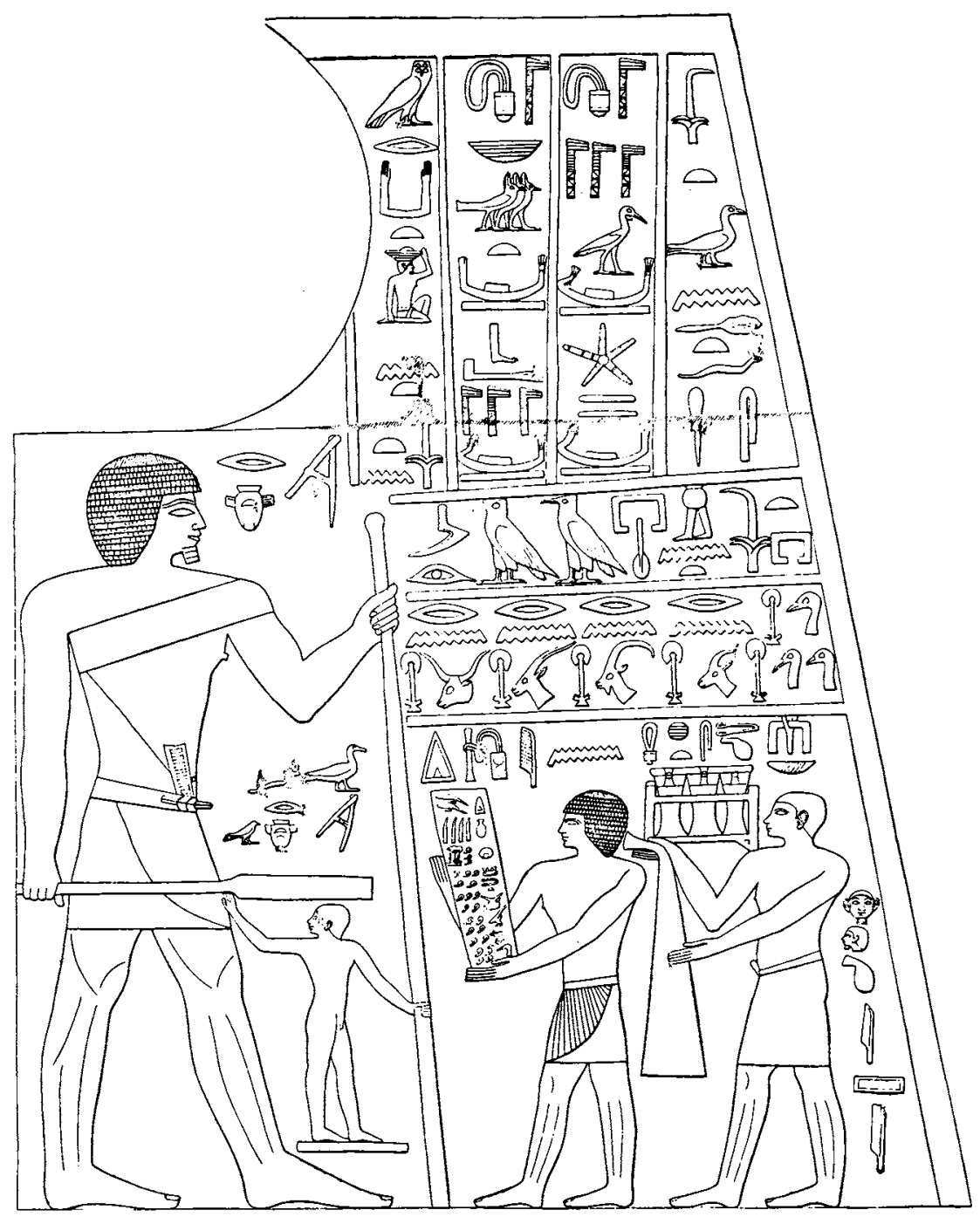

Fig. 16. The inscription of $M r y-i b$ (after JG II, 128) 


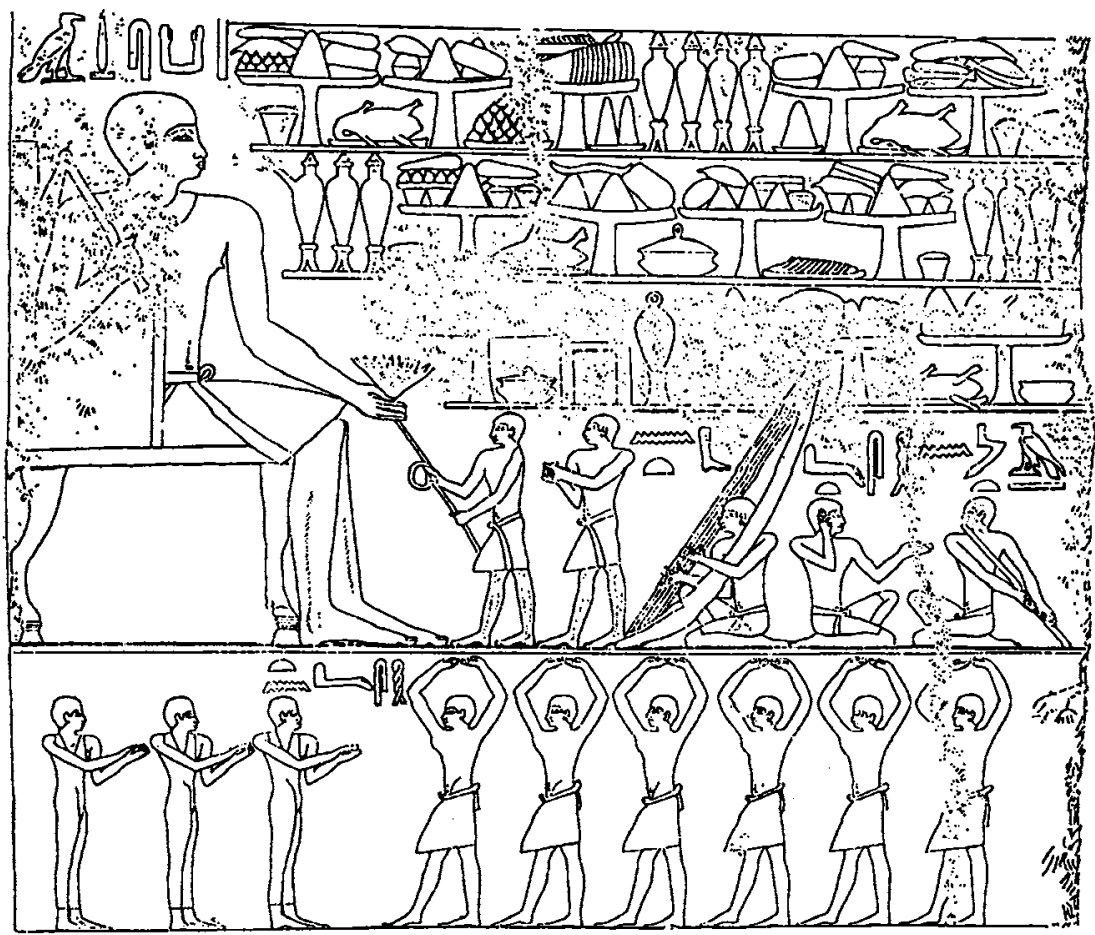

Fig. 17. Dancing scene (after Fischer 1977, fig. 81) 


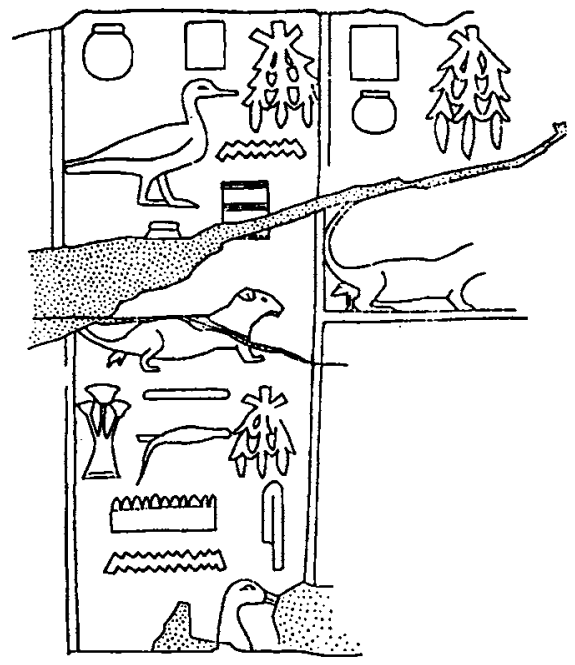

Fig. 18. The Mouse (after Fischer 1977, fig.85)

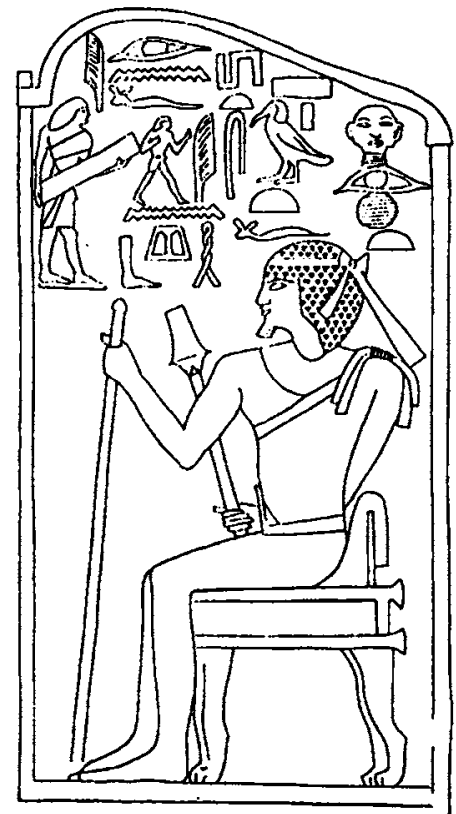

Fig. 19. Inscription from the tomb of Ptahotep (after Fischer 1977, fig.77) 


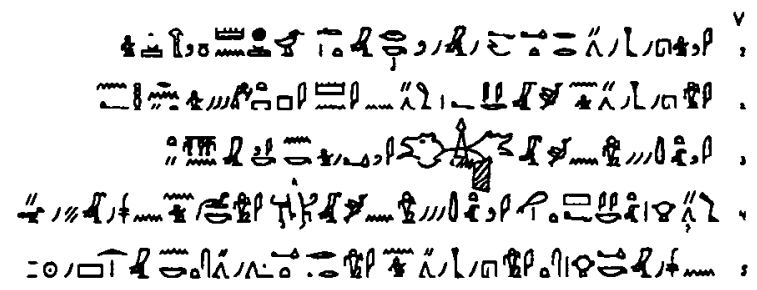

YIII/H, 品, I

Fig. 20. pBM 10411, transcription to the Verso (after Janssen 1991, pl.3)
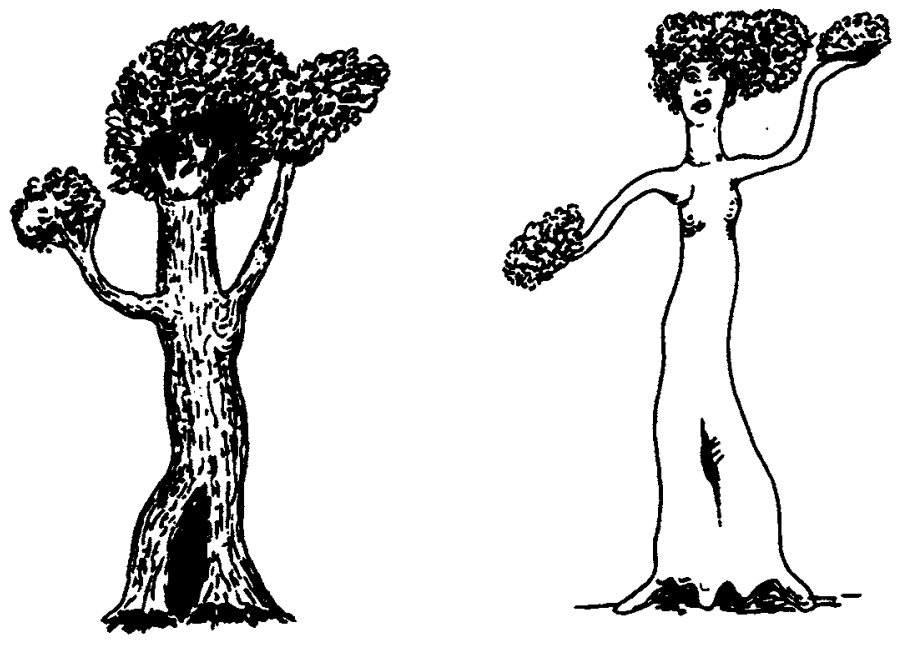

Fig. 21. Tree personification (after Kennedy 1982, fig.1) 


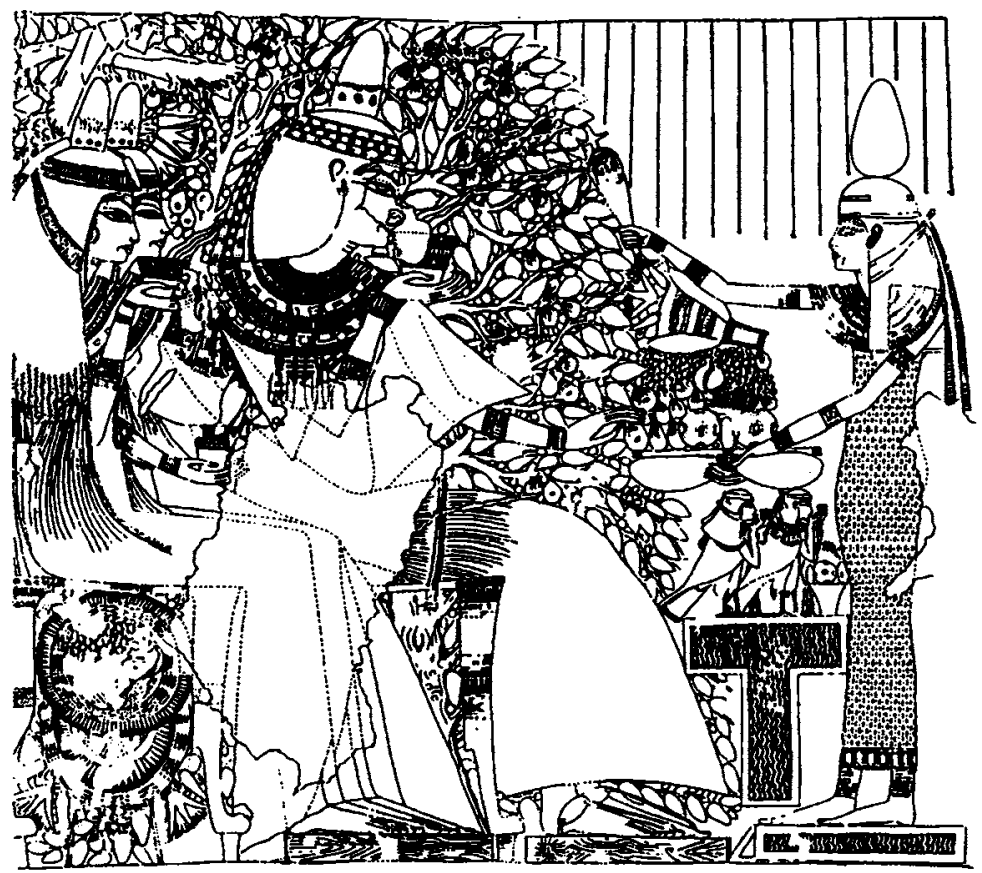

Fig. 22. Tree and Goddess (after Keel 1992, fig.55) 

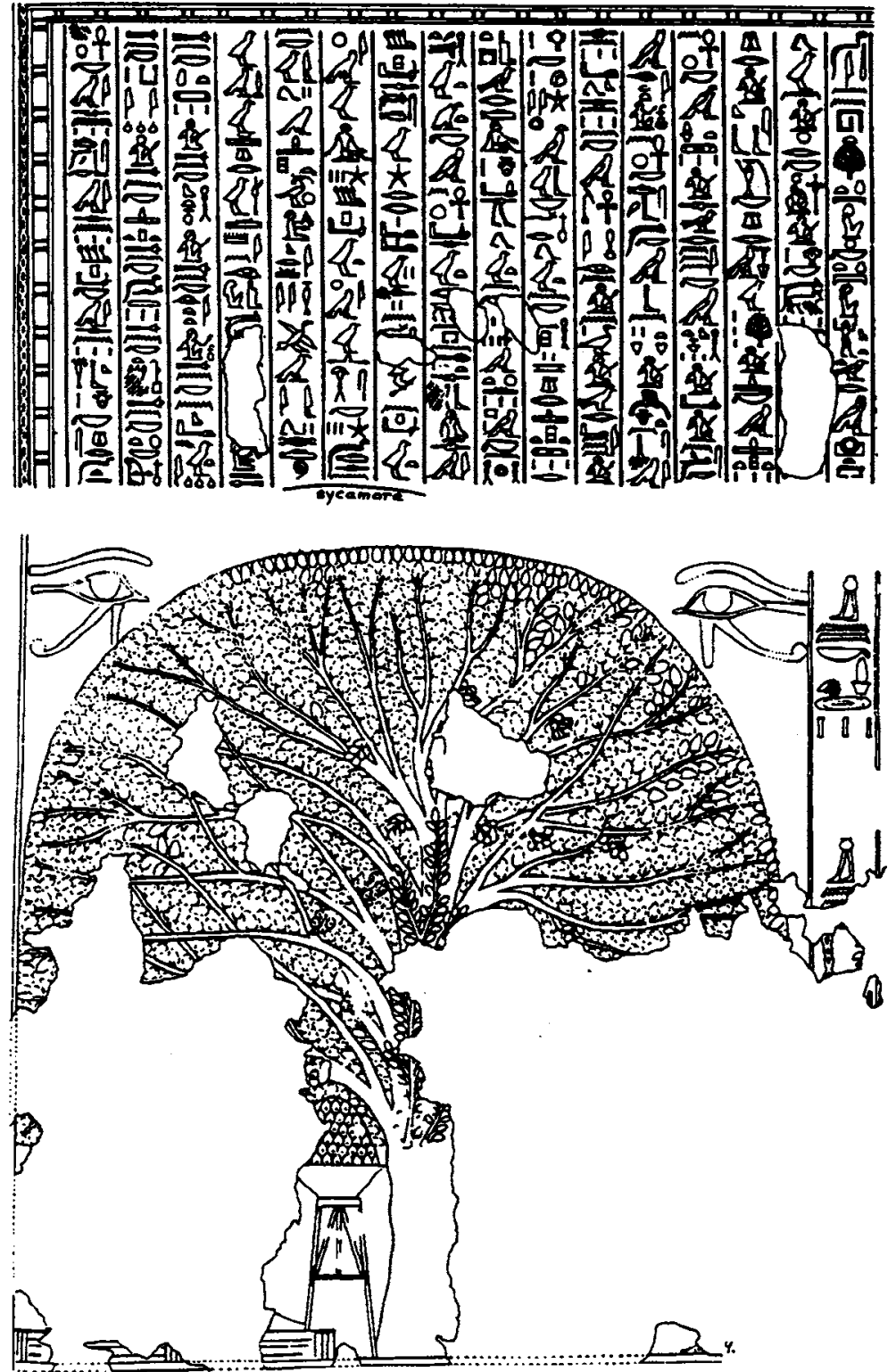

Fig. 23. Tree and Goddess (after Keel 1992, fig.42) 


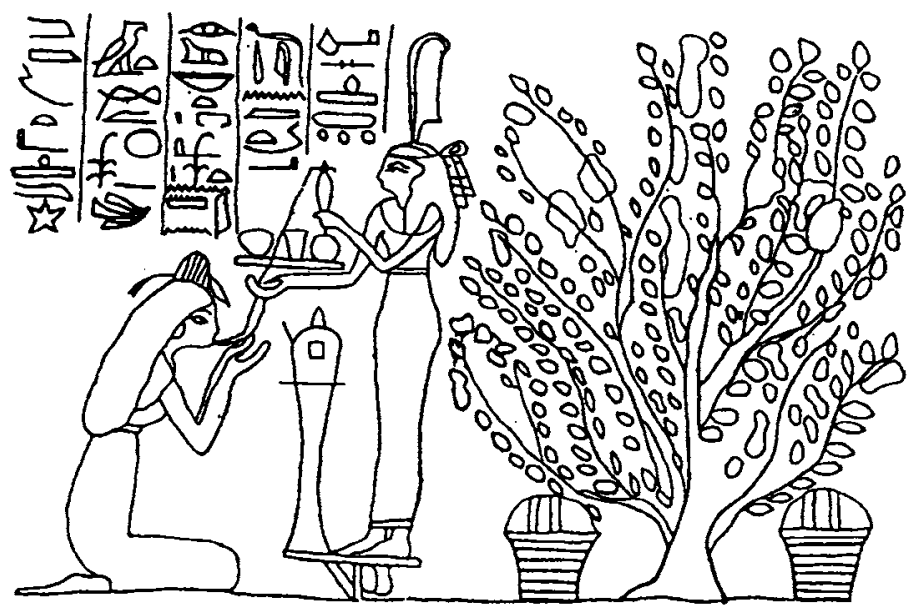

Fig. 24. Tree and Goddess (after Keel 1992, fig.96)

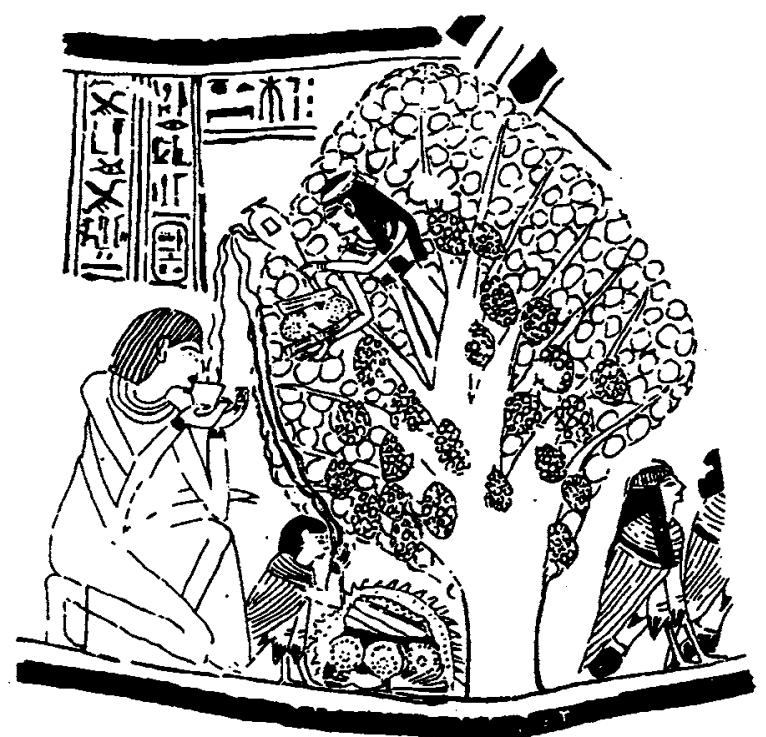

Fig. 25. The peeping goddess (after Keel 1992, fig.78) 


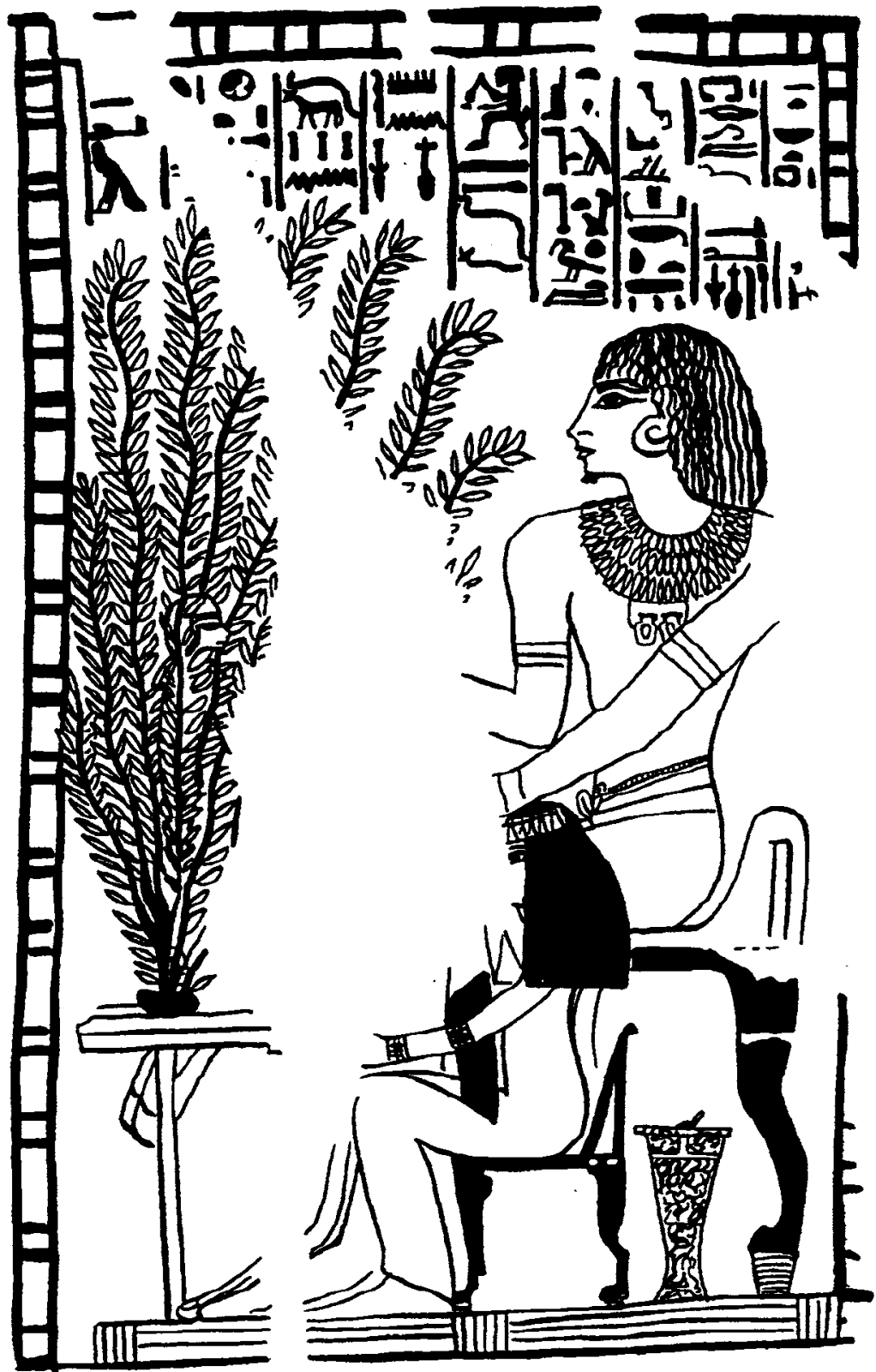

Fig. 26. The peeping goddess (after Keel 1992, fig.43) 


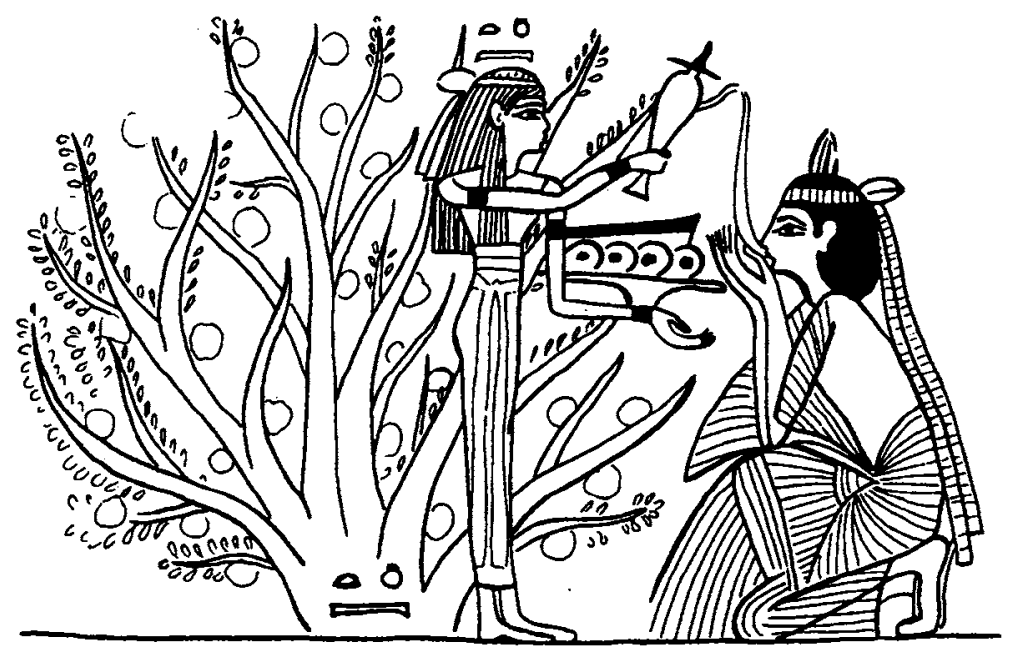

Fig. 27. Superimposition (after Keel 1992, fig.88) 


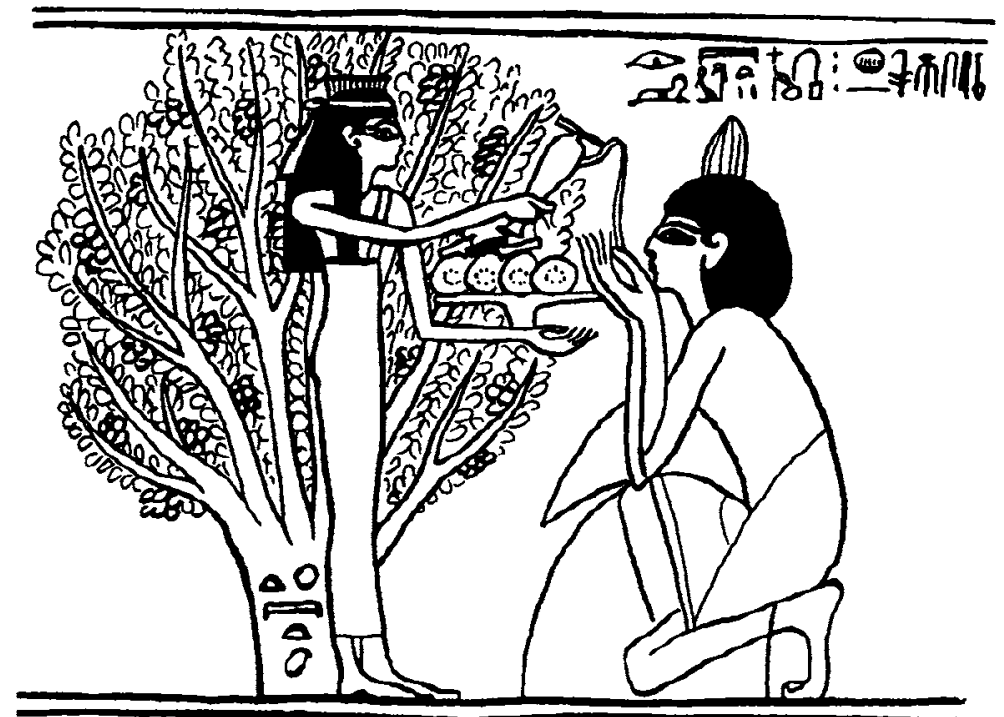

Fig. 28. Superimposition (after Keel 1992, fig.89)

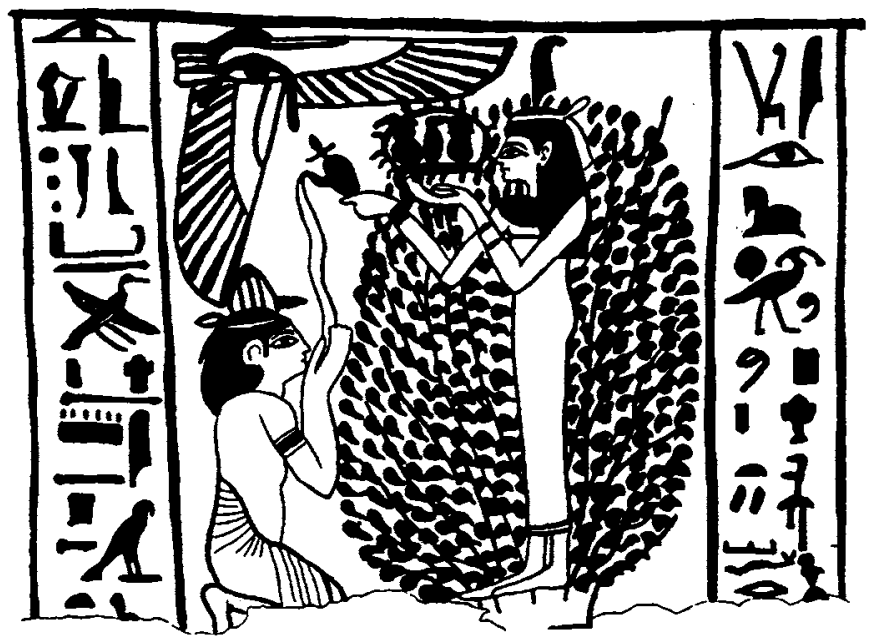

Fig. 29. Superimposition (after Keel 1992, fig.95) 


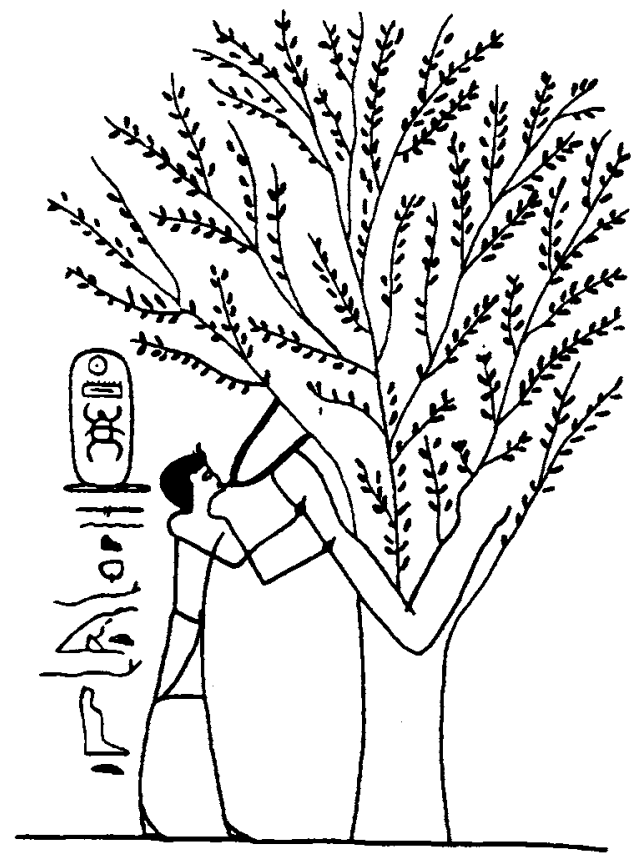

Fig. 30. The tree grows human limbs (after Keel 1992, fig.40)

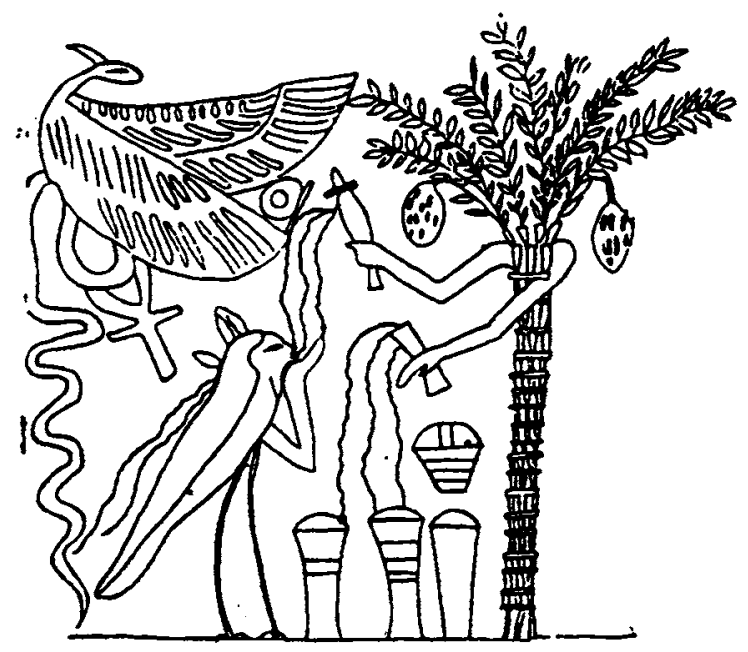

Fig. 31. The tree grows human limbs (after Keel 1992, fig.66) 


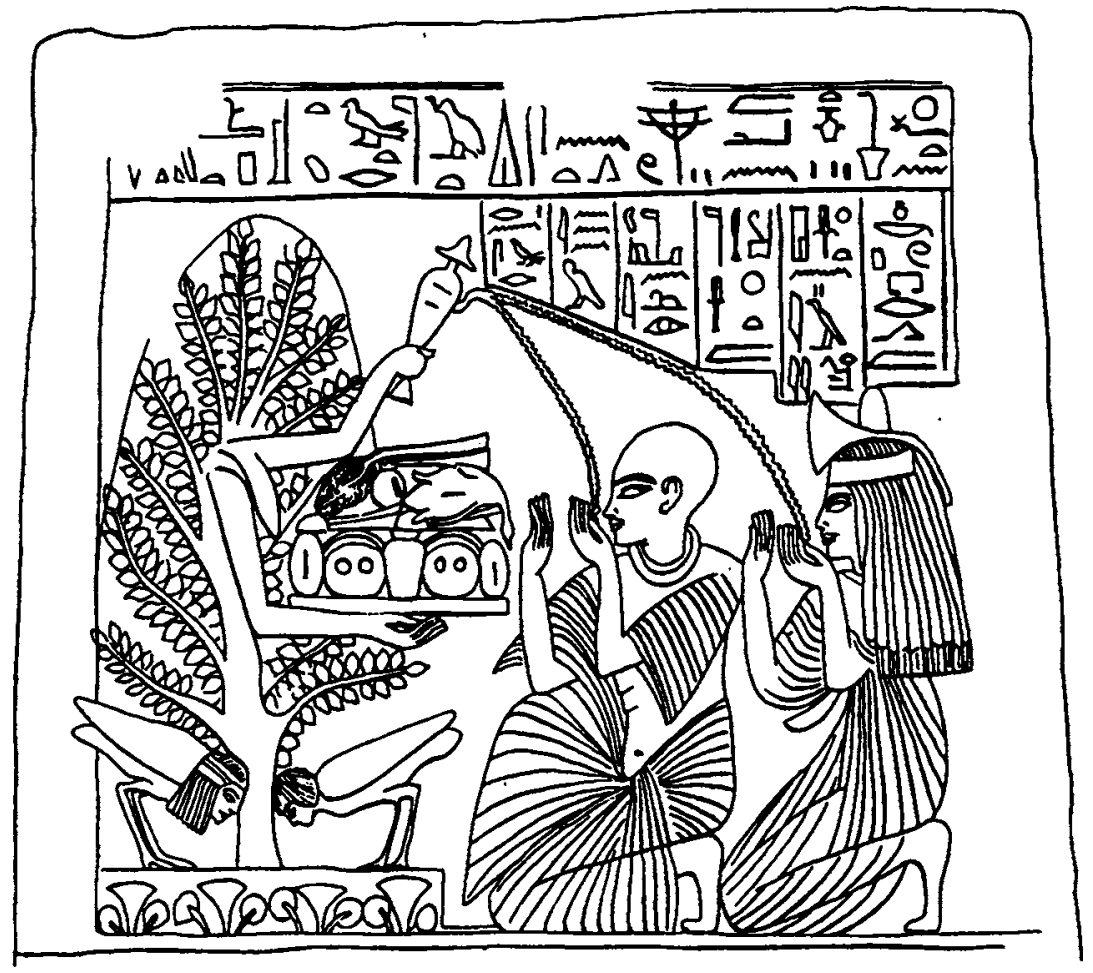

Fig. 32. The tree grows human limbs (after Keel 1992, fig.69) 


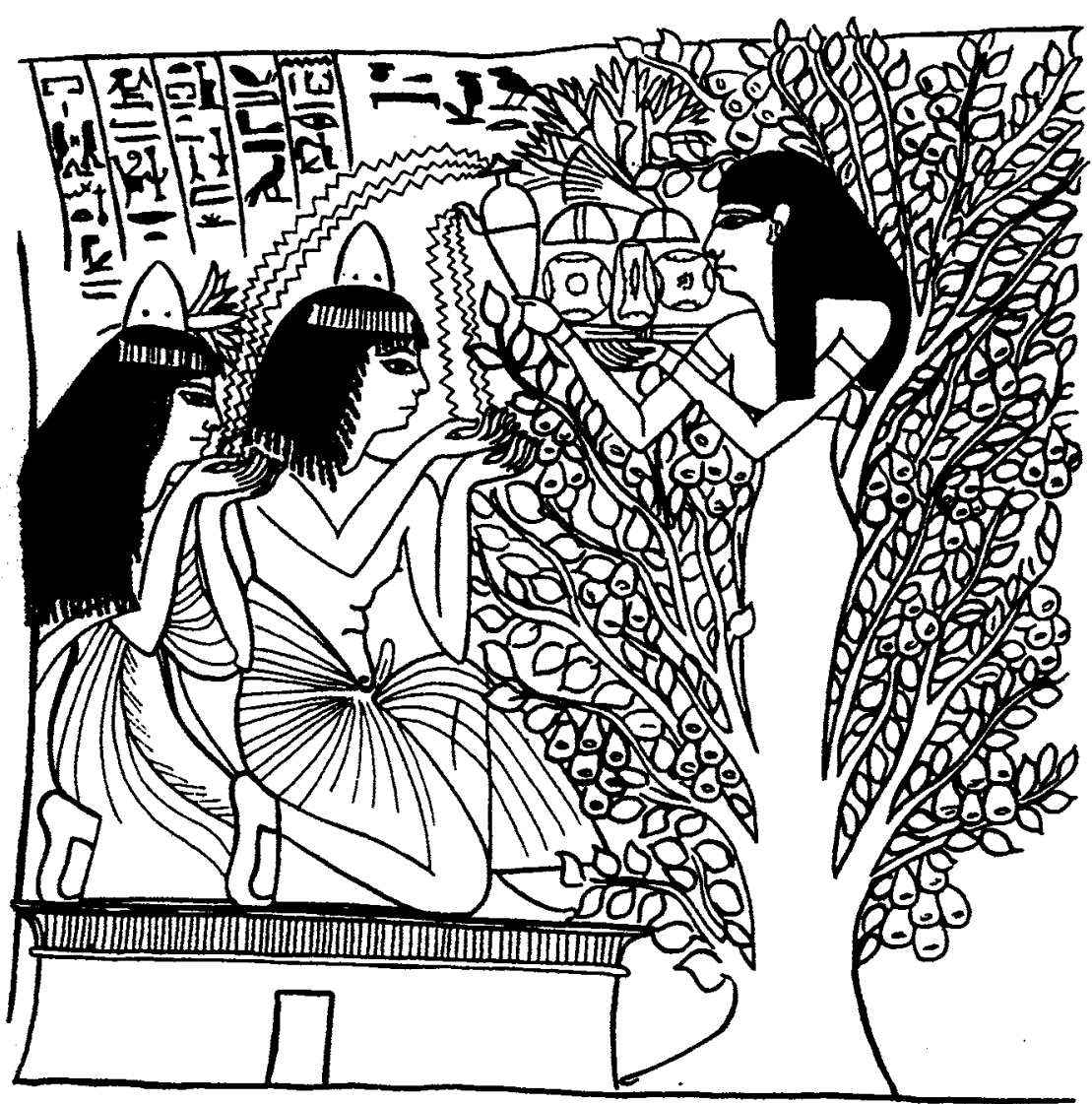

Fig. 33. The female goddess grows from the trunk (after Keel 1992, fig.77) 


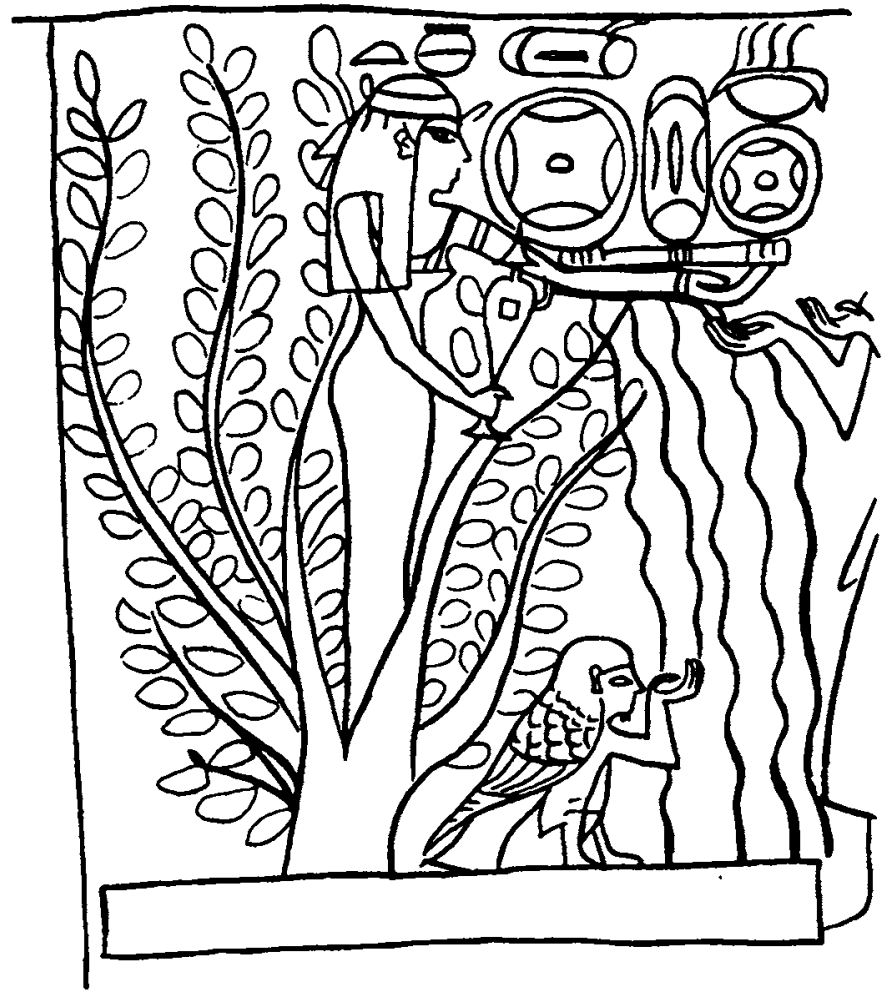

Fig. 34. The female goddess grows from the trunk (after Keel 1992, fig.79)

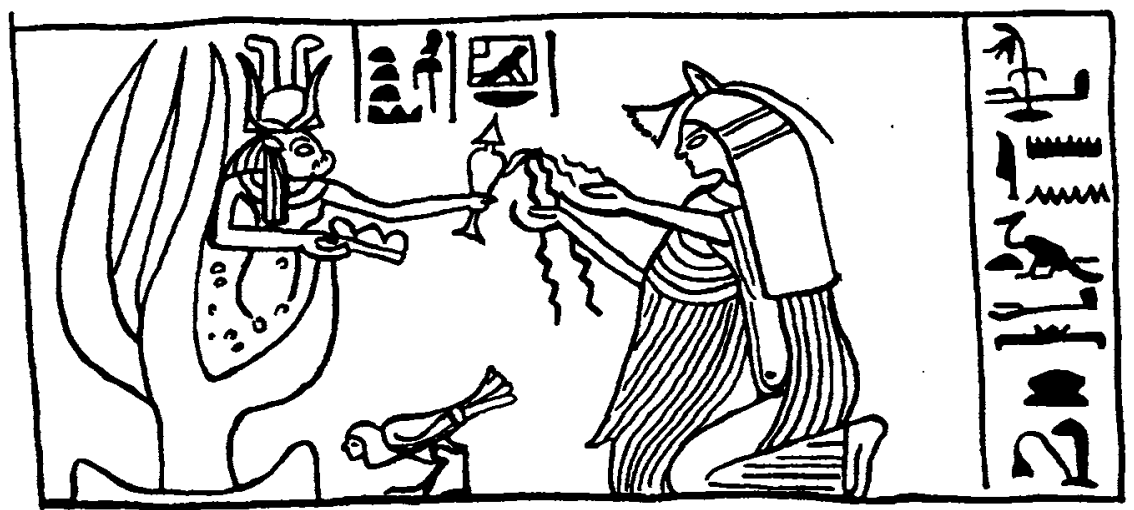

Fig. 35. The cow version (after Keel 1992, fig.85) 


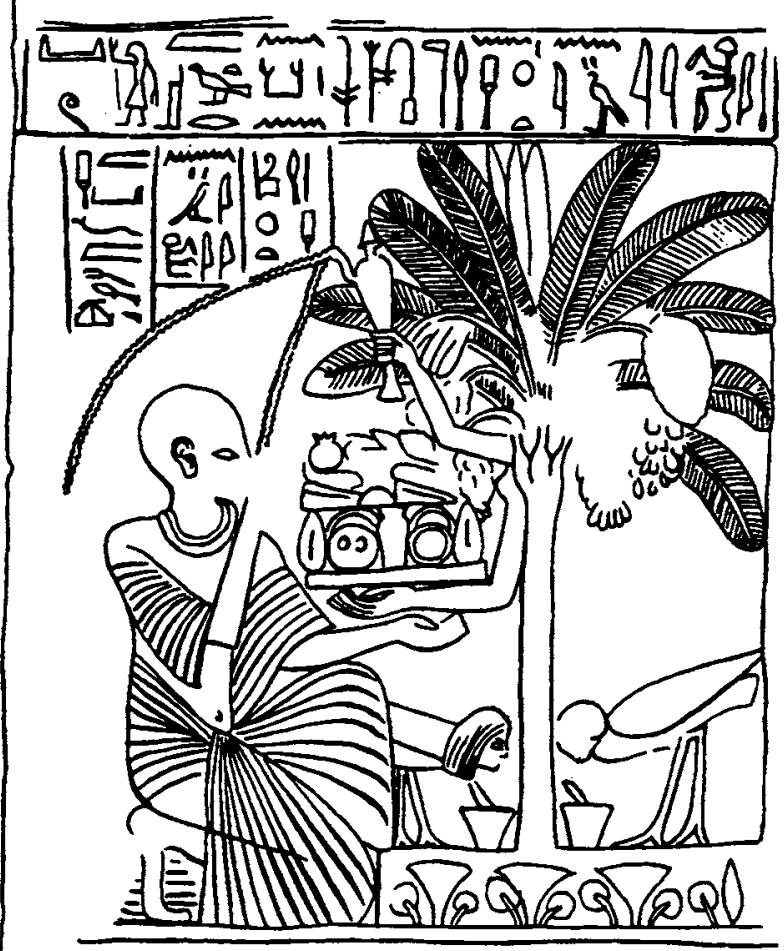

Fig. 36. The palm tree (after Keel 1992, fig.70) 


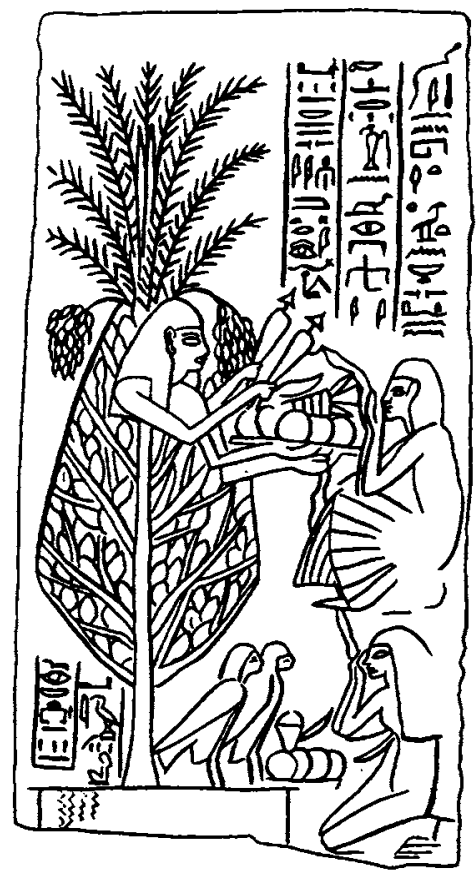

Fig. 37. The palm-sycamore combination (after Keel 1992, fig.71)

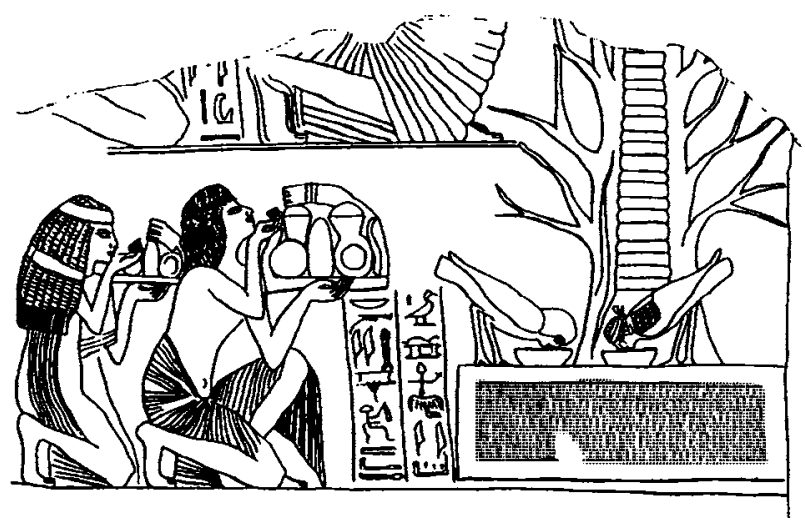

Fig. 38. The palm-sycamore combination (after Keel 1992, fig.72) 


\section{LIST OF FIGURES}

1. The Narmer palette, recto (after Quibell 1898, pl. XII, fig. 1)

2. The Narmer palette, verso (after Quibell 1898, pl. XIII, fig. 2)

3. The Two-dog palette (after Kemp 1989, fig. 14)

4. The Hunter's palette (after Petrie 1953, pl. A,3)

5. Brooklyn handle: carved ivory knife (after Davis 1992, fig. 8)

6. Hierakonpolis tomb 100 (after Kemp 1989, fig. 11)

7. The Libyan palette (after Kemp 1989, fig. 16)

8. The macehead of king "Scorpion" (after Millet 1990, fig. 2)

9. The Battlefield palette (after Davis, 1989, fig. 6.11)

10. $m s$ sign

11. $m s$ sign (after Fischer 1980b:9, fig. 4d)

12. A predynastic "legged bowl" (after Fischer 1986, fig. 12)

13. From the tomb of Wernu (after Davies et al. 1984, pl. 28)

14. The "Poetical Stela" (after CGC No. 34010)

15. The advertisement for "תקטרת"

16. The inscription of $M r y-i b$ (after JG II, 128)

17. Dancing scene (after Fischer 1977, fig. 81)

18. The Mouse (after Fischer 1977, fig. 85)

19. Inscription from the tomb of Ptahotep (after Fischer 1977, fig. 77)

20. pBM 10411, transcription to the Verso (after Janssen 1991, pl.3)

21. Tree personification (after Kennedy 1982, fig. 1)

22. Tree and Goddess (after Keel 1992, fig. 55)

23. Tree and Goddess (after Keel 1992, fig. 42)

24. Tree and Goddess (after Keel 1992, fig. 96)

25. The peeping goddess (after Keel 1992, fig. 78)

26. The peeping goddess (after Keel 1992, fig. 43)

27. Superimposition (after Keel 1992, fig. 88) 
28. Superimposition (after Keel 1992, fig. 89)

29. Superimposition (after Keel 1992, fig. 95)

30. The tree grows human limbs (after Keel 1992, fig. 40)

31. The tree grows human limbs (after Keel 1992, fig. 66)

32. The tree grows human limbs (after Keel 1992, fig. 69)

33. The female goddess grows from the trunk (after Keel 1992, fig. 77)

34. The female goddess grows from the trunk (after Keel 1992, fig. 79)

35. The cow version (after Keel 1992, fig. 85)

36. The palm tree (after Keel 1992, fig. 70)

37. The palm-sycamore combination (after Keel 1992, fig. 71)

38. The palm-sycamore combination (after Keel 1992, fig. 72) 


\section{LIST OF ABBREVIATIONS}

ÄAT

ANET

AnOr

$A S A E$

BAe

BdE

$B E S$

$C d E$

CGC

CT

EG

FCD

$G M$

$\mathrm{HÄB}$

IOS

JARCE

$J E A$

JG

JNES

KRI
Ägypten und Altes Testament

Ancient Near Eastern Texts Relating to the Old

Testament, ed. James B. Pritchard. 2nd ed.1969

Analecta Orientalia, Rome

Annales du Service des Antiquités de l'Egypte, Cairo

Bibliotheca Aegyptiaca, Brussels

Bibliothèque d'Etude, Cairo

Bulletin of the Egyptological Seminar, New York

Chronique d'Egypte, Brussels

Catalogue Général des Antiquités Egyptiennes du Museé du Caire, Cairo

Coffin Texts (spell)

A. H. Gardiner. Egyptian Grammar. 3rd ed. (rev.) Oxford, 1957

R. O. Faulkner. A Concise Dictionary of Middle Egyptian. Oxford, 1962

Göttinger Miszellen, Göttingen

Hildesheimer ägyptologische Beiträge, Hildesheim Israel Oriental Studies, Tel Aviv

Journal of the American Research Center in Egypt, Boston

Journal of Egyptian Archaeology, London

H. Junker, Giza, 12 vols. Vienna and Leipzig, 1922-55

Journal of Near Eastern Studies, Chicago

K.A. Kitchen, Ramesside Inscriptions. 7 vols. Oxford, $1968 \mathrm{ff}$. 
$L \ddot{A}$

LEM

Lesko, Dic.

LingAeg

LRL

MDAIK

Meeks, $A L$

OBO

$\mathrm{p}$

Pyr.

rt.

$R T$

$R d E$

$S A K$

Urk.

vs.

$\mathrm{Wb}$

$Z \ddot{A} S$

W. Helck and E. Otto, eds., Lexikon der Ägyptologie, 7 vols. Wiesbaden, 1975-89
A.H. Gardiner, Late-Egyptian Miscellanies. Brussels, 1937

L. Lesko, A Dictionary of Late Egyptian, Vols. I-IV. Berkeley, 1982-1989

Lingua Aegyptia. Journal of Egyptian Language Studies, Göttingen

J. Č erný, Late Ranesside Letters, Brussels, 1939

Mitteilungen des Deutschen Archäologischen Instituts, Abteilung Kairo, Berlin, Wiesbaden and Mainz

D. Meeks, Année lexicographique, Vol. I-III. Paris, 1980-1982

Orbis Biblicus et Orientalis, Freiburg, Switzerland and Göttingen

papyrus

Pyramid Texts (spell)

recto

Recueil de travaux rélatifs à la philologie et à l'archéologie égyptiennes et assyriennes, Paris Revue d'Egyptologie, Cairo, Paris and Louvain Studien zur Altägyptischen Kultur, Hamburg Urkunden des ägyptischen Altertums, founded by Georg Steindorff

versus

A. Erman and H. Grapow, eds., Wörterbuch der ägyptischen Sprache. 6 vols. Berlin and Leipzig, 1st ed. 1926-31, 2nd ed. 1957

Zeitschrift für Ägyptische Sprache und Altertumskunde, Leipzig and Berlin 


\section{BIBLIOGRAPHY}

Abraham, N. and M. Torok. 1986. The wolf man's magic word: A cryptonymy. Minneapolis: University of Minnesota Press.

Arnett, W. S. 1982. The predynastic origin of Egyptian hieroglyphs: evidence for the development of rudimentary forms of hieroglyphs in Upper Egypt in the Fourth Millennium B.C. Washington: University Press of America.

Assmann, A. 1988. Die Sprache der Dinge. In Materialität der Kommunikation, edited by H. U. Gumbrecht and K. L. Pfeiffer, 237-251. Frankfurt: Suhrkamp.

Assmann, J. 1983. Re und Amun. Die Krise des polytheistischen Weltbilds im Ägypten der 18.-20. Dynastie. OBO 51. Freiburg: Universitätsverlag.

---. 1989. HIEROTAXIS. Textkonstitution und Bildkomposition in der altăgyptischen Kunst und Literatur. In Beiträge zur Literatur, Sprache und Kunst des alten Ägypten. Festschrift für Gerhard Fecht, edited by J. Osing and G. Dreyer. ÄAT 12, 18-42. Wiesbaden: Otto Harrassowitz.

.... 1990. Die Macht der Bilder. Rahmenbedingungen ikonischen Handelns im alten Ägypten. In Genres in Visual Representations, edited by H.G. Kippenberg, L.P. van den Bosch, L. Leertouwer and H.A. Witte. Visible Religion VII, 1-20. Leiden: E.J. Brill.

---. 1991. Stein und Zeit. München: Wilhelm Fink.

Baines, J. 1985. Fecundity Figures. Warminster: Aris \& Phillips.

-.-. 1985a. Color terminology and color classification: Ancient Egyptian color terminology and polychromy. American Anthropologist 87:282-297.

---. 1988. Literacy, social organization, and the archaeological record: The case of early Egypt. In State and society, The emergence and development of social hierarchy and political centralization, edited by J. Gledhill, B. Bender, M. T. Larsen, 193-214. London: Unwinhyman.

--- 1989. Communication and display: The integration of early Egyptian art and writing. Antiquity 63:471-482.

---. 1990. Aspect du symbolisme royal et divin des temps archaïques. Bulletin de la société française d'Egyptologie 118:5-37. 
---. 1991. On the symbolic context of the principal hieroglyph for "god." In Religion und Philosophie im alten Ägypten: Festgabe für Philippe Derchain zu seinem 65. Geburtstag, edited by U. Verhoeven and E. Graefe, 29-46. Leuven: Peters.

---. 1993. Symbolic roles of canine figures on early monuments. Archéo-nil 3:57-63.

Bard, K.A. 1992. Origins of Egyptian writing. In The followers of Horus. Studies dedicated to Michael Allen Hoffman 1944-1990, edited by R. Friedman and B. Adams, 297-306. Oxford: Oxbow Books.

Barr, J. 1976. Reading a script without vowels. In Writing without letters, edited by W. Haas. Mont Follick series 4, 71-100. Manchester: Manchester University Press.

Barsalou, L.W. 1983. Ad hoc categories. Memory and Cognition 11(3):211-227.

Barthes, R. 1977. The rhetoric of the image. In Image, Music Text. Translated by $\mathrm{S}$. Heath, 32-51. London: Fontana Press.

Baum, N. 1988. Arbres et arbustes de l'Egypte ancienne. Orientalia Lovaniensia Analecta 31. Leuven: Departement Oriëntalistiek.

Beckerath, J. von. 1984. Handbuch der ägyptischen Königsnamen. München: Deutscher Kunstverlag.

Bennington, G. 1992. Mosaic fragment: If Derrida were an Egyptian... In Derrida; A critical reader, edited by D. Wood, 97-199. Oxford: Blackwell.

Black, M. 1962. Metaphor. In Models and metaphors, edited by M. Black, 25-47. Ithaca: Cornell University Press.

Blackman, A.M. 1972. Middle-Egyptian Stories. BAe II. Bruxelles: Edition de la Fondation Egyptologique Reine Elisabeth.

Blackman, W.S. 1968. The fellahin of Upper Egypt. London: Frank Cass \& Co. Boessneck, J. 1988. Die Tierwelt des alten Ägypten. München: C.H. Beck. Borghouts, J.F. 1980. Magie. In $L \ddot{A}$ III:1137-1151.

Brooke-Rose, C. 1958. A Grammar of metaphor. London: Secker \& Warburg. --- 1971. An ABC of Ezra Pound. Berkeley and Los Angeles: University of California Press.

Brovarski, E. 1984a. Seret. In $L \ddot{A}$ V:879-880. 
---. 1984b. Sobek. In $L \ddot{A}$ V:995-1030.

Brown, G., and G. Yule 1983. Discourse analysis. Cambridge Textbooks in Linguistics. Cambridge: Cambridge University Press.

Brunner, H. 1977. Herz. In $L \ddot{A}$ II:1 158-1168.

Brunner-Traut, E. 1980. Krokodil. In $L \ddot{A}$ III: 791-801.

de Buck, A. 1935-1961. The Egyptian Coffin Texts, Vol. 1-7. Chicago: University of Chicago Press.

Cannuyer, C. 1990. Brelan de "pharaons" Ramesès XI, Thoutmosis III, et Hatshepsout. In Studies in Egyptology Presented to Miriam Lichtheim, edited by S. I. Groll, 98-115. Jerusalem: The Magnes Press.

Černý, J., and S.I. Groll. 1984. A Late Egyptian grammar. Rome: Biblical Institut Press.

Champollion, J.F., 1836. Principes généraux de l'écriture sacrée égyptienne. Reprint. Paris: Institut d'Orient/Michel Sidhom, 1984.

Cooper, A. 1987. Chinese evidence on the evolution of language. In The Oxford companion to the mind, edited by R. L. Gregory, 142-146. Oxford and New York: Oxford University Press.

Couyat, J., and P. Montet 1912. Les inscriptions hiéroglyphiques et hiératiques du Ouâdi Hammâmât. Le Caire: Institut français d'archéologie orientale du Caire.

Culler, J. 1982. On deconstruction. Theory and criticism after structuralism. Ithaca: Cornell University Press.

--- 1986. Saussure. Fontana Modern Masters. Rev. ed. Cornell: Fontana Press.

---. 1987. Towards a linguistics of writing. In The linguistics of writing. Arguments between language and literature, edited by N. Fabb, D. Attridge, A. Durant, C. MacCabe, 173-184. Manchester: Manchester University Press.

--- 1988. The call of the phoneme: Introduction. In On puns. The foundation of letters, edited by J. Culler, 1-16. Oxford: Basil Blackwell.

David, M.V. 1865. Le débat sur les écritures et l'hiéroglyphe aux XVII et $X V I I I^{e}$ siècles. Paris: S.E.V.P.E.N.

Davidson, D. 1978. What metaphors mean. In On metaphoring, edited by S. Sacks, 29-45. Chicago: The University of Chicago Press. 
Davies, W.V. 1987. Egyptian hieroglyphs. Reading the past. London: British Museum Press.

Davies, W.V., A. El-Khouli, A. B. Lloyd, and A. J. Spencer. 1984. Saqqara tombs. 1. The mastabas of Mereri and Wernu. Archaeological Survey of Egypt 26. London: Egypt Exploration Society.

Davis, W. 1989. The canonical tradition in Ancient Egyptian art. Cambridge: Cambridge University Press.

-.-. 1992. Masking the blow. The scene of representation in late prehistoric

Egyptian art. Berkeley: University of California Press.

Depuydt, L. 1994. On the nature of the hieroglyphic script. Z̈̈S 121:1-92.

Derchain, P. 1993. Sur les pensers antiques. CdE LXVIII:65-69.

Derrida, J. 1974. Glas. Paris: Editions Galileé.

--. 1976. Of grammatology. Translated by G. Chakravorty Spivak. Baltimore and London: The Johns Hopkins University Press.

---. 1982. Margins of philosophy. Translated by A. Bass. New York: Harvester Wheatsheaf.

Dreyer, G. 1992. Horus Krokodil, ein Gegenkönig der Dynastie O. In The followers of Horus. Studies dedicated to Michael Allen Hoffman 19441900, edited by R. Friedman and B. Adams, 259-263. Oxford: Oxbow Books.

Eco, U. 1971. A semiotic approach to semantics. Versus 1:21-61.

--- 1972. Introduction to a semiotics of iconic signs. Versus 2:1-15.

-.-. 1976. A theory of semiotics. Bloomington: Indiana University Press.

--.. 1984. Semiotics and the philosophy of language. Bloomington: Indiana University Press.

Edel, E. 1955-1964. Altägyptische Grammatik. 2 Vols. AnOr 34 and 39. Rome: Pontificium Institutum Biblicum.

Endesfelder, E. 1994. Götter, Herrscher, König - zur Rolle der Ideologie bei der Formierung des Ägyptischen Königtums. In Ägyptische Tempel Struktur, Funktion und Programm, edited by R. Gundlach and M. Rochholz. HÄB 37, 47-54. Hildesheim: N.p.

Endrödi, J. 1991. "Figurative discourse" and "communication" in the emerging state of Egypt. GM 125:21-36.

Even-Zohar, I. 1990. Polysystem studies. Poetics Today, vol. 11, no.l. 
Fairservis Jr., W. A. 1991. A revised view of the Na'rmr Palette. JARCE XXVIII: $1-20$.

Faulkner, R. O. 1968. The pregnancy of Isis. JEA 54:40-44.

--.. 1973-1978. The ancient Egyptian Coffin Text. Vol. 1-3. Warminister: Aris \& Phillips Ltd.

Fenollosa, E. 1936. The Chinese written character as a medium for poetry. London: Stanley Nott.

Fischer, H. G. 1963. A stela of the Heracleopolitan Period at Saqqara: The Osiris "Iti." ZÄS 90, 35-41.

---. 1976. Archaeological aspects of epigraphy and palaeography. In Ancient Egyptian epigraphy and palaeography, 29-51. New York: The Metroploitan Museum of Art.

--. 1977. The orientation of hieroglyphs. Part I, Reversals. New York: The Metropolitan Museum of Art.

-.-. 1980. Hunde. In $L \ddot{A}$ III:77-82.

-.-. 1980b. The evolution of composite hieroglyphs in Ancient Egypt. In Ancient Egypt in the Metropolitan Museum Journal, Supplement: Volumes 12-13 (1977-1978), 5-19. New York: The Metropolitan Museum of Art.

---. 1986. L'écriture et l'art de l'Egypte ancienne. Paris: PUF (Press universitaires de France).

--. 1989. The origin of the Egyptian hieroglyphs. In The origins of writing, edited by W. M. Senner, 59-76. Lincoln and London: The University of Nebraska Press.

Forceville, C. 1994. Pictorial metaphor in advertisements. Metaphor and Symbolic Activity 9:1-29.

Frank, M. 1989. What is neostructuralism? Translated by S. Wilke and R. Gray. Theory and History of Literature 45. Minneapolis: University of Minnesota Press.

Frankfort, H. 1948. Kingship and the gods. 2d ed. Chicago: The University of Chicago Press.

---. 1948a. Ancient Egyptian religion. An interpretation. New York: Columbia University Press.

---. 1956. The birth of civilization in the Near East. New York: Doubleday Anchor Books. 
Frost, R., and Bentin, S. 1992. Reading consonants and guessing vowels: Visual word recognition in Hebrew orthography. In Orthography, phonology, morphology, and meaning, edited by R. Frost and L. Katz, 27-44. Amsterdam: North-Holland.

Gardiner, A. H. 1909. The admonitions of an Egyptian sage. Leipzig: J.C. Hinrichs'sche Buchhandlung.

.... 1915. The nature and development of the Egyptian hieroglyphic writing. $J E A$ 2:61-75.

--- 1947. Ancient Egyptian onomastica. London: Oxford University Press.

---. 1955. A unique funerary liturgy. JEA 41:9-17.

--- 1957. Hymns to Sobk in a Ramesseum papyrus. RdE 11: 43-56.

-... 1961. Egypt of the Pharaohs. Oxford: Clarendon Press.

Germon-Riley, M. 1985. Paléographie des signes hiéroglyphiques sous les deux premières dynasties. Doctorat de Thèse de IIIe cycle. Sorbonne, Paris.

Gibbs, R. W. 1992. When is metaphor: The idea of understanding in theories of metaphor. Poetics Today 13, no. 4: 575-606.

-... 1994. The poetics of mind. Figurative thought, language, and understanding. Cambridge: Cambridge University Press.

Glucksberg, S., and B. Keysar. 1990. Understanding metaphorical comparisons: Beyond similarity. Psychological Review 97:3-18.

Goedicke, H. 1988. Zum Königskonzept der Thinitenzeit. SAK 15:123-141.

Goldwasser, O. 1981. Hekanakhte and the "boat metaphor." GM 40:20-21.

-.-. 1995. The conception of the poetic form - A love letter to a departed wife.

Ostracon Louvre 698. IOS (forthcoming).

Goldwasser, O., and N. Laor. 1991. The allure of the Holy Glyphs: A psycholinguistic perspective on the Egyptian script. GM 123:37-51.

Gombrich, E. H. 1963. Meditations on a hobby horse. Oxford: Phaidon.

--.. 1979. The sense of order. Oxford: Phaidon.

.... 1979a. Ideals and idols. Oxford: Phaidon.

Grapow, H. 1924. Die bildlichen Ausdrücke des Ägyptischen. Leipzig: N.p.

Griffiths, J.G. 1970. The pregnancy of Isis: a comment. JEA 56:194-195. 
--- 1972. The symbolism of red in Egyptian religion. In Ex Orbe Religionum. Studio Geo Widengren XXIV Mense Apr. MCMLXXII Quo Die Lustra Tredecem Feliciter Explevit Oblata Ab Collegis, Discipulis, Amicis, Collegae Magistro Amico Congratulantibus, Pars Prior, edited by J. Bergman, K. Drynjeff, and H. Ringgren, 81-90. Leiden: E.J. Brill.

Groenewegen-Frankfort, H. A. 1951. Arrest and movement: An essay on space and time in the representational art of the Ancient Near East. London: Faber and Faber.

Groll, S.I. 1982. Grammar as a means of dating. In Egyptological studies, edited by S. I. Groll. Scripta Hierosolymitana XXVIII, 11-104. Jerusalem: The Magnes Press.

Guglielmi, W. 1982. Personifikation. In $L A ̈$ IV: 978-987.

Gulland D. M., and D. E. Hinds-Howell. 1986. The Penguin dictionary of English idioms. London: Penguin Books.

Gunn, B. 1943. The Naukratis stela. JEA 29:55-59.

Haas, W. 1976. Writing: the basic options. In Writing without letters, edited by W. Haas, 131-208. Mont Follick series 4. Manchester: Manchester University Press.

Harris, R. 1986. The origin of writing. London: Duckworth.

Harris, R. J., M. A. Lahey, and F. Marsalek. 1980. Metaphors and images: Rating, reporting, and remembering. In Cognition and figurative language, edited by R. P. Honeck and R. R. Hoffman, 163-189. Hillsdale: Lawrence Erlbaum Associates.

Haskell, R.H. 1987. Giambattista Vico and the discovery of metaphoric cognition. In Cognition and symbolic structures: The psychology of metaphoric transformation, edited by R. E. Haskell, 67-82. Norwood: Albex Publishing Corporation.

Hawkes, T. 1972. Metaphor. The Critical Idiom 25. London: Methuen.

Hayes, W. C. 1953. The scepter of Egypt. Part 1, From the earliest times to the end of the Middle Kingdom. New York: Harper - Metropolitan Museum of Art.

Helck, W. 1985. Gedanken zum Ursprung der ägyptischen Schrift. In Mélanges Gamal eddin Mokhtar. Institut français d'archéologie orientale, edited by P. Posener Krieger. BdE 97, 395-408. Le Caire: Imprimerie de l'institut français d'archéologie orientale. 
Helck, W. 1988. Die Lehre für König Merikare. Wiesbaden: Otto Harrassowitz.

Hodge, C. T. 1975. Ritual and writing: An inquiry into the origin of Egyptian script. In Linguistics and anthropology. In honor of C. F. Voegelin, edited by M. D. Kinkade, K. L. Hale and O. Werner, 331-350. Lisse: The Peter de Ridder Press.

Hodge, R., and G. Kress. 1979. Language as ideology. London and New York: Routledge.

Hopfner, T. 1940-1941. Plutarch. Über Isis und Osiris. Monographien des Archiv Orientàlni IX. Prague: N.p.

Horapollo. The hieroglyphics of Horapollo. Translated by George Boas.

Bollingen Series XXIII. Princeton: Princeton University Press, 1950.

Hornung, E. 1982. Conceptions of god in ancient Egypt. Translated by J. R. Baines. Ithaca, N. Y: Cornell University Press.

--.. 1992. Idea into image. Essays on ancient Egyptian thought. Translated by E. Bredeck. New York: Timken Publishers.

Hornung, E., and E. Staehelin. 1976. Skarabäen und andere Siegelamulette aus Basler Sammlungen. Mainz: Philipp von Zabern.

Iversen, E. 1993. The myth of Egypt and its hieroglyphs. 2d ed. Princeton: Princeton University Press.

Jacq, C. 1988. Sur les pas de Champollion. Editions Michèle Trinckvel.

Jakobson, R. 1956. Two aspects of language and two types of aphasic disturbances. In Fundamentals of language, edited by R. Jakobson and M. Halle, 67-96. The Hague and Paris: Mouton.

--. 1987. Linguistics and poetics. In Language in literature, edited by $\mathrm{K}$. Pomorska and S. Rudy, 62- 94. Cambridge: The Belknap Press of Harvard University Press.

Janssen, J.J. 1990. On the scent of a fox. Discussion in Egyptology 16:45-50.

---. 1991. Late Ramesside letters and communications. Hieratic papyri in the British Museum VI. London: The British Museum Press.

Johnson, M. 1987. The body and the mind. Chicago: The University of Chicago Press.

Junge, F. 1989. "Emphasis" and sentential meaning in Middle Egyptian. Wiesbaden: Otto Harrasowitz. 
Kaiser, W. 1990. Zur Entstehung des gesamtägyptischen Staates. MDAIK 46: 287-299.

Kammerzell, F. 1993. Aristoteles, Derrida und ägyptische Phonologie. Zu systematischen Verschiedenheiten von geschriebener und gesprochener Sprache. In Sesto Congresso Internazionale di Egittologia. Vol II, 243-251. Torino.

Kaplony, P. 1966. Strukturprobleme der Hieroglyphenschrift. CdE XLI:60-99.

---. 1972. Die Prinzipen der Hieroglyphenschrift. In Textes et langages de l'Egypte pharaonique, 3-14. Le Caire: Institut français d'archéologie orientale du Caire.

--- 1981. Die Rollsiegel des Alten Reiches. Monumenta Aegyptiaca 3 ${ }^{B}$. Bruxelles: Fondation égyptologique reine Elisabeth.

Keel, O. 1992. Das Recht der Bilder gesehen zu werden. OBO 122. Freiburg: Universitătsverlag.

---. 1994. The Song of Songs. A continental commentary. Translated by F. J. Gaiser. Minneapolis: Fortress Press.

Keimer, M. L. 1929. Sur un bas-relief en calcaire représentant la déesse dans le sycomore et la déesse dans le dattier. $A S A E$ 29: 81-88.

Kemp, B. 1989. Ancient Egypt. Anatomy of a civilization. London: Routledge.

Kennedy, J. M. 1982. Metaphor in picture. Perception 11:589-605.

de Kerckove, D. and C. J. Lumsden, eds. 1988. The alphabet and the brain. Berlin: Springer-Verlag.

Kittay, E. F. 1987. Metaphor. lts cognitive force and linguistic structure. Oxford: Clarendon Press.

Lacau, P. 1912. A propos de la grammaire égyptienne de M. Erman. $R T$ 34:206-218.

---. 1914. Suppressions et modifications de signes dans les textes funéraires. ZÄS 51:1-64.

---. 1926. Suppression des noms divins dans les textes de la chambre funéraire. $A S A E$ 26:69-81.

---. 1954. Sur le système hiéroglyphique. Le Caire: Imprimerie de l'institut français d'archéologie orientale. 
Lakoff, G. 1986. Classifiers as reflections of the mind. In Noun classes and categorization, edited by C. Craig, 13-51. Amsterdam and Philadelphia: John Benjamins Publishing Company.

---. 1987. Women, fire, and dangerous things. Chicago: The University of Chicago Press.

Lakoff, G., and M. Johnson. 1980. Metaphors we live by. Chicago: The University of Chicago Press.

Lakoff, G., and M. Turner. 1989. More than cool reason. Chicago and London: The University of Chicago Press.

Lefebvre, G. 1949. Rouge et nuances voisines. JEA 35:72-76.

Levin, S. R. 1988. Metaphoric worlds. Conceptions of a romantic nature. New Haven and London: Yale University Press.

Lévi-Strauss, C. 1966. The savage mind. Chicago: The University of Chicago Press.

Lichtheim, M. 1973. Ancient Egyptian literature. Vol.1. Berkeley: The University of California Press.

Loprieno, A. 1988. Topos und Mimesis. Wiesbaden: Otto Harrassowitz.

---. 1991. On the typological order of constituents in Egyptian. Journal of Afroasiatic Languages 1:201-26.

--- 1995. Ancient Egyptian. A linguistic introduction. Cambridge: Cambridge University Press.

Luft, U. 1993. Asiatics in Illahun: A preliminary report. In Sesto Congresso Internazionale di Egittologia. Vol. II, 291-298. Torino.

Lyons, J. 1977. Semantics. Cambridge: Cambridge University Press.

MacCormac, E. R. 1985. A cognitive theory of metaphor. Cambridge: MIT Press.

Malek, J. 1993. The cat in ancient Egypt. London: British Museum Press.

Matlin, M. W. 1994. Cognition. Fort Worth: Harcourt Brace Publishers.

McLuhan, M. 1964. Understanding media. The extensions of man. London: Sphere Books.

Meltzer, E. S. 1980. Remarks on Ancient Egyptian writing with an emphasis on the mnemonic aspects. In Processing of visible language. 2nd. ed. New York: P. A. Kelers. 
Meyer, K. H. 1974. Kanon, Komposition und "Metrik" der Narmer Palette. $S A K$ 1:247-265.

Miall, D. S. 1987. Metaphor and affect: The problem of creative thought. Metaphor and Symbolic Activity 22:81-96.

Millet, N. B. 1990. The Narmer macehead and related objects. JARCE XXV11:53-60.

Möller, G. 1965. Hieratische Paläographie. Rev. ed. Osnabrück: Otto Zeller.

Mrsich, T. Q. 1978. Ein Beitrag zum "hieroglyphischen Denken" $S A K$ 6: 108-129.

---. 1979. Ein Beitrag zum "hieroglyphischen Denken" (2. Teil). SAK 7:164-225.

Munro, P. 1993. Der Unas Friedhof Nord-West I. Mainz am Rhein: von Zabern.

Neisser, U. 1976. Cognition and reality. New York: W.H. Freeman and Company.

Norris, C. 1987. Derrida. Fontana Modern Masters. London: Fontana Press.

O'Connor, D. 1989. New funerary enclosures (Talbezirke) of the Early Dynastic period at Abydos. JARCE XXVI:51-86.

Oren, E. D. 1989. Early Bronze Age settlement in northern Sinai: A model for Egypto-Canaanite interconnections. In British Archaeological Reports. International Series 527(i):389-405.

Osing, J. 1978. Review of Coptic Etymological Dictionary, compiled by J. Cerny. JEA 64:186-189.

Otto, E. 1963. Altägyptischer Polytheismus. Eine Beschreibung. Saeculum $14: 249-285$.

Paivio, A. 1991. Images in mind: The evolution of a theory. New York: Harvester-Wheatsheaf.

Petrie, W. M. F. 1953. Ceremonial slate palettes and corpus of protodynastic pottery. Edited by H. F. Petrie and M. A. Murray. London: Egypt Research Account.

Pignatari, D. 1978. The contiguity illusion. In Sight, sound, and sense, edited by T. A. Sebeok, 84-97. Bloomington and London: Indiana University Press. 
Podemann Sørensen, J. 1987. Ancient Egyptian religious thought and the XVIth Hermetic Tractate. In The religion of the Ancient Egyptians. Cognitive structures and popular expressions, edited by G. Englund, 41-58. Uppsala: Acta Universitatis Upsaliensis.

Polotsky, H. J. 1976. Les transpositions du verbe en égyptien classique. IOS $6: 1-50$.

Posener, G. 1968. Aménémope 22,9-10 et l'infirmité du crocodile. In Festschrift für Siegfried Schott, edited by W. Helck. Wiesbaden: Otto Harrassowitz.

Pulgram, E. 1976. The typologies of writing-systems. In Writing without letters, edited by W. Haas, 1-28. Mont Follick series 4. Manchester: Manchester University Press.

Quibell, J. E. 1898. Slate palette from Hierakonpolis. Z $\ddot{A S} 36:$ 81-84.

Ray, J. 1986. The emergence of writing in Egypt. World Archaeology 17 no.3:307-316.

-.-. Forthcoming. Thoth Spd-wn, the moon and the hare. JEA.

Richards, I. A. 1936. The philosophy of rhetoric. Oxford: Oxford University Press.

Ritner, R. K. 1993. The mechanics of ancient Egyptian magical practice. Studies in Ancient Oriental Civilization No. 54. Chicago: The Oriental Institute of the University of Chicago.

Rosch, E. 1978. Principles of categorization. In Cognition and categorization, edited by E. Rosch and B. Lloyd, 28-49. Hillsdale, N. J.: Erlbaum.

Rothenberg, A. 1988. Creativity and the homospatial process. Psychiatric Clinics of North America 11 no.3:443-459.

Sadek, A. I. 1988. Popular religion in Egypt during the New Kingdom. HÄB 27. Hildesheim: Gerstenberg Verlag.

Saussure, F. de. 1966. Course in general linguistics. Translated by W. Baskin. New York: McGraw-Hill.

Schäfer, H. 1986. Principles of Egyptian art. Rev. ed., edited by E. Brunner-Traut and translated by J. R. Baines. Oxford: Oxford University Press.

Schenkel, W. 1974. Zur Struktur der Hieroglyphenschrift. MDAIK 27:85-98.

--. 1976. The structure of the hieroglyphic script. Royal Anthropological Institute News 15:4-7. 
--. 1980. Horus. In $L \ddot{A}$ III:14-25.

--- 1981. Rebus-, Buchstabiersilben- und Konsonantenschrift. GM 52:83-93.

---. 1983. Wozu die Ägypter eine Schrift brauchten. In Schrift und

Gedächtnis. Beiträge zur Archäologie der literarischen

Kommunikation, edited by A. and J. Assmann, 45-63. München:

Wilhelm Fink Verlag.

---. 1984. Schrift. In $L \ddot{A}$ V:714-735.

--. 1991. Tübinger Einführung in die klassische-ägyptische Sprache und

Schrift. Tübingen: N.p.

Schott, S. 1951. Hieroglyphen: Untersuchungen zum Ursprung der Schrift. Wiesbaden: N.p.

Schulman, A. R. 1991-2. Narmer and the unification: A revisionist view. BES 11:79-106.

Sebeok, T.A. 1976. Contributions to the doctrine of signs. Bloomington: Indiana University Press.

Sethe, K. 1922. Die Sprüche für das Kennen der Seelen der heiligen Orte (Totb. Kap. 107-109. 111-116). Z̈̈S 57:1-24; 57-78.

---. 1935. Das hieroglyphische Schriftsystem. Glückstadt und Hamburg: J.J. Augustin.

---. 1964. Vom Bilde zum Buchstaben. In Untersuchungen zur Geschichte und Altertumskunde Ägyptens. Vol.12. Hildesheim: Georg Olms Verlagsbuchhandlung.

Shen, Y. 1991. Schemata, categories, and metaphor comprehension. Poetics Today 12 no. 1:111-124.

---. 1992. Metaphors and categories. Poetics Today 13, no. 4:771-794.

-.-. 1994. Metaphors, ad hoc categories, and principles of natural categorization. Forthcoming.

Shirun-Grumach, I. 1987. Zur strukturalen Semantik in der Kunst. In Form und Mass, Festschrift für Gerhard Fecht, edited by J. Osing and G. Dreyer. ÄAT 12, 429-435. Wiesbaden: Otto Harrassowitz.

-... 1993. Offenbarung, Orakel und Königsnovelle. ÄAT 24. Wiesbaden: Harrassowitz Verlag.

Shupak, N. 1993. Where can Wisdom be found? OBO 130. Freiburg: Universitätsverlag. 
Silverman, D.P. 1991. Divinity and deities in ancient Egypt. In Religion in ancient Egypt, edited by B. E. Shafer, 7-87. Ithaca and London: Cornell University Press.

Simpson, W. K. 1966. Letter to the dead from the tomb of Meru. JEA 52:39-52.

Sinha, C. 1988. Language and representation. New York: New York University Press.

Spencer, A. J. 1982. Death in ancient Egypt. London: Penguin Books.

Staehelin, E. 1974. Zu den Farben der Hieroglyphen. GM 14:49-53.

Störk, L. 1977. Fuchs. In $L \ddot{A}$ II:348.

Suys, E. 1935. La sagesse d'Ani. AnOr. 11. Rome: Pontifical Biblical Institute.

Taylor, J. R, 1989. Linguistic categorization. Prototypes in linguistic theory. Oxford: Clarendon Press.

Tefnin, R. 1979. lmage et histoire. Reflexions sur l'usage documentaire de l'image égyptienne. CdE 54:218-244.

--- 1984. Discours et iconicité dans l'art égyptien. GM 79:55-69.

Tsur, R. 1992. Toward a theory of cognitive poetics. Amsterdam: NorthHolland.

Turner, M. 1987. Death is the mother of beauty. Chicago: The University of Chicago Press.

---. 1991. Reading minds. Princeton: Princeton University Press.

Ullman, S. 1967. Semantics. An introduction to the science of meaning. Oxford: Basil Blackwell.

Ulmer, G. 1988. The puncept in grammatology. In On puns. The foundation of letters, edited by J. Culler, 164-189. Oxford: Basil Blackwell.

Vandier, J. 1962. Le Papyrus Jumilhac. Paris: Centre National de la Recherche Scientifique.

te Velde, H. 1977. Seth, god of confusion. Leiden: E. J. Brill.

-.-. 1986. Egyptian hieroglyphs as signs, symbols and gods. Visible Religion IV-V: 63-72.

---. 1988. Egyptian hieroglyphs as linguistic signs and metalinguistic informants. Visible Religion VI:169-179. 
--- 1990. Some remarks on the concept "person" in the ancient Egyptian culture. In Concepts of person in religion and thought, edited by H.G. Kippenberg et al. Berlin and New York: N.p.

Vercoutter, J. 1991. La prédynastie égyptienne. Anciens et nouveaux concepts. In Mélanges Jacques Jean Clère. Cahiers de recherches de l'institut de papyrologie et d'égyptologie No. 13, 137-146. Lille: Université Charles de Gaulle-Lille III.

Vernus, P. 1982. Espace et idéologie dans l'écriture égyptienne. In Ecritures. Systèmes idéographiques et pratiques expressives. Actes du colloque international de l'Université de Paris VII, 22, 23 et 24 avril 1980, 101116. Paris: Le Sycomore.

--- 1983. Ecriture du rêve et écriture hiéroglyphique. Littoral 7/8, 27-32.

--- 1985. Des relations entre textes et représentations dans l'Egypte pharaonique. In Ecritures II, edited by A. M. Christin, 45-66. Paris: Le Sycomore.

---. 1986. L'écriture hiéroglyphique: une écriture duplice? Confrontation. Cahiers 16:59-66.

---. 1987. L'ambivalence du signe graphique dans l'écriture hiéroglyphique. In L'espace et la lettre. Ecritures III, edited by A. M. Christin, 61-65. Paris: Editions RETZ.

---. 1993. La naissance de l'écriture dans l'Egypte ancienne. Archéo-nil 3:75-108.

Vycichl, W. 1983. Dictionnaire étymologique de la langue copte. Leuven: Peeters.

-.-. 1990. La vocalisation de la langue égyptienne, Tome I. Le Caire:

L'institut français d'archéologie orientale de Caire.

van de Walle, B. and Vergote, J. 1943. Traduction des Hieroglyphica d'Horapollon. CdE 35: 39-89;199-247.

Ward, W. A. 1963. Egypt and the East Mediterranean from predynastic times to the end of the Middle Kingdom. Journal of the Economic and Social History of the Orient 6:1-57.

---. 1978. The four Egyptian homographic roots B-3. Rome: Biblical Institut Press.

Weeks, K. 1979. Egyptology language and art. In Egyptology and the Social Sciences, edited by K. Weeks, 57-81. Cairo: The American University in Cairo Press. 
Westendorf, W. 1975. Anatomie. In $L \ddot{A}$ I: 879-880.

---. 1991. Die Nini-Begrüssung. In Religion und Philosophie im alten Ägypten, Festgabe für Philippe Derchain, edited by U. Verhoeven and E. Graefe. Orientalia Lovaniensia Analecta 39, 351-362. Leuven: Uitgeverij Peeterers.

White, J. J. 1976. The argument for a semiotic approach to shaped writing: The case of Italian futurist typography. Visible Language X: 53-86.

Wiesmann, H. 1922. Die Determinative des sprechenden Mannes und der Buchrolle in den Pyramidentexten. ZÄS 57: 73-78.

Williams, B. and T. J. Logan. 1987. The Metropolitan Museum knife handle and aspects of Pharaonic imagery before Narmer. JNES 46:245-285.

Wilson, H. 1990. Sycamore and fig. Discussions in Egyptology 18:72-82.

Winand, J. 1992. Etudes de néo-égyptien, 1. La morphologie verbale. Ægyptiaca Leodiensia 2. Liège. N.p.

Yadin, Y. 1955. The earliest record of Egypt's military penetration into Asia? Israel Exploration Journal 5:1-16.

Yoyotte, J. 1963. Etudes géographiques II. RdE 15:87-119.

Žabkar, L. V. 1968. A study of the Ba concept in ancient Egyptian texts. Studies in Ancient Oriental Civilization 34. Chicago: The University of Chicago Press.

--.. 1975. Ba. In $L \ddot{A}$ I: 588-590.

Zeidel, D. W. and A. Kasher. 1989. Hemispheric memory for surrealistic versus realistic paintings. Cortex 25:617-641. 


\section{GENERAL INDEX}

Admonitions, writer of, 31

Advertisements, aims of, 57;

Hebrew, modern, example of representation of "open root" in, $64 \mathrm{n}$; processes of selection in, 38

Aldrich, 124n

Amarna, 57

Anubis, 44

Apis bull, 101

Aporias, 36

Archaic period, see Neithotep

Aristotle, 72. See also Metaphor. Aristotelian "something else", 120

Assmann, Aleida, 34-5

Assmann, Jan, 6n, 10n, 29n, 34n, 96n

"Attention center", 110

Avenues, information, in pictographic process, $40 \mathrm{Axis}$, metaphoric, 85-6

Axis, metonymic, 90-4

Axis, metonymic vs. metaphorical, 55-6

Baines, John, 14, 14n, 15, 15n, 81, $115,120,120 \mathrm{n}, 125 \mathrm{n}$. See also Libyan palette.

Barthes, Roland, 9, 57, 58n

"Battlefield palette", metonymic essence of, $15 \mathrm{n}$; pictorial metaphor in, 14; standards on, 15. See also Metaphor.

Baum, N., 122

Bed, Egyptian, as pictograph, 32

Bennington, Geoffrey, 37

Berlin, Brent, 81

Bissing, von, $121 \mathrm{n}$

Blackman, A.M., 20

Blackman, Winifred, 20
Body, part of, responsible for certain sense, as part of signifier for the sense, 68-9

Boethius, 54n

Bones, collecting, mythological connotation of, 105

Borghouts, J.F., 37n

Bowl, legged, 21, 21n

"Break from within", 37, 45

Brovarski, J.F., on incongruity of the goose, 50; on occurrence of goose in offering lists, 51

Brown, Roger, 81

Brunner, Helmut, 32

Brunner-Traut, Emma, 4, 4n

Bull palette, 14n

Butehamun, 112

Categorization, 80-106; classical view of, 81; system of, 80-1

Category, ad hoc, 83-4; basic level of, 82; "Porphyrian", 54, 54n; "prototypical members" of, 33

Champollion, 56n, 63, 71

Civilization, Egyptian, emergence of, 3; "form" of, 3; "roots" of, 3

Classification, semiotic, enabling decipherment of hieroglyphic word, 54

Cognition, and size, 24

"Cognitive attention", reader, of, 111

Combinations, advanced metaphoric, absence of, 13

Communication, hieroglyphic, definition of, 57

Concept, 27-8; relationships with signifieds, signifiers, image and context, 39; select, 9

Conceptual metaphor, definition of, $114 n$

Connotations, metaphoric, 111 
Construct, hieroglyphic script, 21, system as complex metaphorical, 22-4

Context, relationships with signifieds, signifiers, image and concept, 39

Crocodile, as "Assembler of the Osiris bones", 105; as Typhonic animal, 105; mention of deity of, 104; mimetic legacy of, 103; real qualities of in "mimetic" representation, 103; realistic qualities of, in "topical" representations of Sobk, 103; represented as helper of Osiris, 104; words determined by, 103-5

Culler, J., 37, 73, 73n, 74, 106-7

Culture, Egyptian, linguistic and metalinguistic expressions in, 97

Davidson, D., 13n

Davis, Whitney, 6, 6n, 10

Deconstruction, 36

Definitions, categoric, cognitive role of, 33

Deir el Medineh, 112

Derrida, Jacques, 10, $11 \mathrm{n}, 35$, $35 \mathrm{n}, 35-39,37 \mathrm{n}, 38 \mathrm{n}, 40-2,53$

Determinative, abstract, $24 \mathrm{n}, 89$; as "ambiguity dispeller", 41;80; confusing set of, $94-5$; deliberate enlargement of, double-size hieroglyph to, 111; iconic, 85-6; parallel, 89; reflecting complex metaphorical and metonymical relationship with its word, 106; Sethian, 102, 105; status of, 84; superordinate, 86-9

Device, syntactical focus, overridden by pictorial, 110

Differentiations, categoric, cognitive role of, 33

Domain, conceptual, creation of, $71 ; 80-106$; definition of, 84
Dyirbal, language, classification in, $77 \mathrm{n}, 99-100$

Eco, Umberto, 18n, 27n, 28, 28n, 52n, 56n, 60, 90n, 119

Effect, "non-deconstructive", 40; prototype, 83

Egypt, geographical conditions of, highlight central concepual metaphor, 97-8

Egyptian, ancient, images as written signifiers in, 29

Egyptian, Late, 109

"Egyptianicity", Egyptian hieroglyphs of, compared to Barthes' "Italianicity", 58n

Egyptians, intellectual progress of, 29; as pious, myth-oriented people, 100

Emblem, 6. See also Support, triadic

Enjambement, 112

Entity, coloured, represents the colour, 69-70

Even-Zohar, Itamar, 8

Examination, semiotic, 66

Falcon-King, 12, 15-6

Fenollosa, E., 59n

Fischer, Henri, 11, 110, 112

Focus, Egyptian grammar, in, 10813; optional, 108

Focussing, another form of, 108-13; as complex "marked" construction, 109; centers, "visual", 111; construction, with in written text, visible and detectable, 109; "game", between visual attention and syntactical information, 111 ; intonation, comparison to, 109,112 ; marking out single member of declarative statement, device for, 108; "visual", 198, 199; visual in hieroglyphic script, 
methods used, comparison with modern advertisement methods, 113

Forceville, C., 116n

Foxes, fennec, in Egyptian script, 20. See also Blackman, Winifred

Frank, M., 11n, 19n

Frankfort, Henry, 3, 8n

"Freedom of difference", reduction of, 38

Freud, Sigmund, 36

Frost \& Bentin, 64n

Fruit tree, as double entity, 117; as

Mother Goddess, 122; palm tree as category of, 122

Function, conative, 52; emotive, 52; metalinguistic, 52; poetic, 52 ; phatic, 52 ; referential, 52

Gardiner, A.H., 12n, 73n, 105 Gebel el-'arak, knife-handle of, 10n Gestalt, of decorum, 9; "summarized", 46

Giza, 26; tomb in, 109

Goldwasser, O. and Laor, N., 43n

Greyhound, Saluki, as pictograph, 33

Groenewegen-Frankfort, H.A., $7-8,11$

Groll, Sarah, 112

Guglielmi, Waltraud, 115

Gunn, B., 78

Haas, 39n

Harris, Roy, 3n. See also Writing

Hathor, 117, 119

Hatshepsut, 76n

Hebrew, verbs and adjectives constructed of roots of animal names in, 59-60

Helck, W., 13n

Hermetic tractate, XVIth, 27

Hierakonpolis, tomb $100,10 \mathrm{n}$

Hieroglyphics, reference to two or more signifieds, 38-9; system of alphabet in, 78

Hieroglyphs, 7; as sophisticated "attention game", 109; importance to the history of ideas and semiotics of, 35; oneness of, 26

Horapollo, 32n, 75

Horning, $10 \mathrm{ln}$

Horus, $12 n$

Horus falcon, 12n, 32

Horus icon, 103

Horus-King, 13

Hunter's palette, 6

Icons, as "children of the mind", 24; as tools of thought, 25; vs. word, classification system of, 8; concrete, as pictorial metaphors, 24; phonetic resemblance of two, 17 ; "open path" back to, 110; shift from concrete to abstract, by the Egyptians, 21; "transposed", 17, 110

Iconic picture, fixing to signifier, 16 Ideo-phonogram, Derrida's, 39 Ideo-phonograph, Derrida's, 38, 40 Illahun, hieratic texts of, 75 Image, advertising, 57

Image, as semiotic text, $6 \mathrm{n}$; as visual option, 8; difficulty in positive identification of, 10 ; "intrusion" of, 18n; mental, definition of, $8 \mathrm{n}$; motivated, as "built-in" property of script, 29; "power of", on addressee, 109; surrealistic, as pictorial equivalents of metaphors, 12 ; visual representation of, 9

"Image-schema", 120n

Imentet, 117

Information, extra-semantic, 47; phonetic and iconic, harmony 
between, 49; "redundant"

phonetic, 47

Inscriptions, hieroglyphic, understandable to the illiterate, $33 \mathrm{n}$; metaphoric processes in decipherment and reading of, 106; variations of visual focussing in, 112

Intellectual order, new, 3, 4; in emergence of Egyptian civilization, 3

Interpretant, 27

Isis, 117,119

Jakobson, Roman, 52, 55

Johnson, M., 9n, 115, $121 \mathrm{n}$

Johnson, Samuel, 13

Jumilhac, papyrus, 44

Junge, Friedrich, 108, 111

Kaplony, P., 53, 77, 104

Keel, Othmar, 115, 116n, 118, 122

Kennedy, John, 116

Khepri, 120n

King Amosis, 101

King-Falcon, $12 \mathrm{n}$

King-Horus, $13 n$

King Narmer, 5, 13n, 14, 18

King Scorpion, 7, 14

King Senwosret I, 16n

Kittay, E.F., 16n

Lacau, P., 49n, 78n

Lakoff, George, 8n, 33, 82, 99, 115

Lefebvre, G., 70n

Level, metaphoric, 11-17

"Libyan palette", as early form of complex metaphorical thought, 14; pictorial metaphor in, 13, 14. See also Metaphor.

Limbs, collection of, in Coffin

Texts, 104

Location, as part of signifier for someone associated with it, 67-8
Loprieno, A., 63n

Luft, U., 75n

Maat, 117; feather of, 120n

MacCormac, E.R., 116n

McLuhan, Marshall, 9n, 34n

Metaphor, animalistic, 60-2; Aristotle, definition of, 72; as conceptual, 118; as conceptual and cognitive tool, 12n; conceptual, categories of, 116-17; conceptual, Egyptian pictorial representations of, 114-15; concrete icons as pictorial, 24; concretization of, 21 ; dead, animation of, 58-60; "dead", as uniliteral pictographs, 43; deep structure of, 12-3; deep-structure conceptual, in Egyptian culture, 99; definitions of, 12; iconic representation of, 24; Greek and post-Greek definitions of, 115; in pictures, vs. figures of speech, 116; mapping process of, 62, 73; "phonetic", 17, 18, 23, 42, 50, 71-4; phonetic, for representation of proper names, 18 ; pictorial, first appearance of, 134. See also "Libyan palette" and "Battlefield palette". Pictorial representation of, 76-7; pictorial, as tools of thought, 25; processing of, role of superimposition and interaction in, 123; replacement, 118; second level of pictorial representation of, 12 ; suggestive combination of, 13; symbols and emblems expanded into, through personification, 14; taming of, 3 ; initiatory taming of, 4 ; as tools of thought, 25; validity of, when applied to representations of Egyptian deities, 115; vehicle 
of, iconic reflection on, 23

Metaphorical beings, religious sphere of, taking shape by popular metaphorical conceptualizing, 117

Metaphorical sentence, nature of mental image evoked by, 123

Metonymy, role of, 63

Mind, Egyptian, 100n

Monoconsonants, becoming dead metaphors, 78

Mother goddess, category of, 117; primal analogy with fruit tree, 116

Move, new metaphoric, 16-7

Movement, interpretive, possible varieties of, 56-60; metaphorical, of verbs, 59

"Myth and Belief Principle", 106

Narmer mace-head, 5

Narmer palette, 5; coincidence and contiguity barred from, 8; as different linguistic components, 6; Early Dynastic finds, among, 5; iconic principal scene in, 10; image, sensual power of, in, 18; indicating turning point from pre-state to state, 5; as linguistic construct, 6 ; linkage between sound image and restricted concept, 9; as metaphor, 12; as new codification system, 7 ; as new image, 6; new pictorial entity of, 16; as normative text, 5 ; as poetic accomplishment, 25 ; recto and verso of, 5,18 ; representing birth of a semiotic system, 6; ripening of personification process in, 15 ; verbal act in, 11

Neit-hotep, inscription of, example of sought-for signified, phonetically and visually, $44 \mathrm{n}$
Nht, 118

Nht-Nut, description of, as combination of the characteristics of the sycamore and the goddess Nut, 118

Nephthys, 117

Nut, 100, 117, 118, 119

Object, as arbitrary sign, 27 ; concrete, location of outside the word-sign, 30; Egyptian attachment to, 4 ; new status of, 4

Orthography, Hebrew, 64n

Otto, E. 100n

Paivio, Allan, 24n

Palettes, ceremonial slate, 4

Papyri-Man, 12

Paronomasia, 71, 73n, 74, 76; and metaphor, difference between, $72-3$; as method for dream analysis, $74 \mathrm{n}$; poetic use of, 72 ; "restricted", 72; shared quality of, with metaphor, 73

Paser, Ramesside tomb of, 118

Personification, $12 n$; process of, as kernel of a whole thought system, 15; of sycamore and garden, $120 \mathrm{n}$

Pictogram, materialization of, 21

Pictograph, of human parts, 32; uniliteral, 43

Pictorial phrase, metaphorical, 16

Picture, 6. See also Support, triadic. Processing of into linguistic information, 18

Pignatari, D., 74

Plato, 38

Poetics, visual, 60-2

Poetry, processes of selection in, 38; activation of, 51-2

Process, "transposition", 16, 16n

Processes, cognitive, reconstruction of, 4 
Processes, metaphorical, operation of, 38

Processes, semiotic, possibility of systematic description of, 55

Processing, metaphoric, 17

Prototype, as "best example" of category, 31

Ptahotep, tomb of, 111

Ptolemaic period, 106

"Puncepts", 21-2n, 75, 75n, 77n

Puns, and variations, 74; within

Egyptian literature and religion, $75 n$

Reader, as involved interpreter, 52

Reading, iconic, 56-8

Rebus, $13 \mathrm{n}, 17 \mathrm{n}, 37 \mathrm{n}, 71,72,73$, $73 \mathrm{n}, 77,105$

"Rébus à transfert", 35, 42

Relationship, triadic, 27-53. See also Signification, triangle of.

Relations, contiguity, arbitrary, with final meaning, 65, 68; between central icon and final meaning of word, 63 ; with final meaning, 65

Religion, animalistic-emblematic realm of, 14

Representation, iconic, codification of, 57; large-scale iconic, $11 \mathrm{n}$; schematic, neutralization of icon through, 58; synecdochical, 48

Rhyming, visual, 62

Richards, I.A., 119

Riverboat, Nile, as pictograph, 32

Root, pictorial representation of, 63-5

Rorty, Richard, 37

Rosch, Elinor, 80-1, 83

Rothenberg, Albert, 123-4

Saussure, Ferdinand de, 28, 37, 38

Scene, as semiotic text, $6 \mathrm{n}$

Schemata, of decorum, 9
Scheme, notion of, $8 \mathbf{n}$

Schenkel, W., 55, 63n, 66n, 68n, 70n, 73n, 86n, 89

Scorpion mace-head, 5, 10n

Script, as part of "official culture", 33

Script, alphabetic, 39

Script, hieratic, as abstractization of hieroglyphic script, $24 \mathrm{n}$

Script, hieroglyphic, birth of, 4; differs from every other known script because of its iconicity, $41 \mathrm{n}$; in the light of twentieth century theory, 26-53; interference with cognitive processes of, 106; mechanisms of, 37. See also Culler.

Script, non-iconic, 33

Scripts, relations with brain activity, 74n

Sebeok, T. A., 56

Selket, 120n

Sethe, K., 30

Sethian animal, as cultural prototype, 102

Sethian category, 102

Shen, Y., 83

Sign, as abode of two main powers, 37; creation of a new, 17; concept and processing of in Egyptian thinking, 26; definition of by Egyptians, 26; dynamic aggregate of, 33; hieroglyphic, double role of, 30 ; hieroglyphic, coupling of theory of with Derrida's deconstructive approaches, 36; hieroglyphic, sharing with modern semiotics the concept "word" as the abode of signifier and signified, 39; hieroglyphic, oscillation of between word and world, 80; iconic, triadic sub-division of, 58; mono-consonantal, 77-8; 
motivated hieroglyphic, 21; phonetic, 6. See also support, triadic. Represented hieroglyphic, image of a "select concept" of, 30; Saussurean, 30; Saussure's different graphic representation of, 28; theories of, 27-53

Signification, triangle of, 27-53

Significatum, 27-8

Signified, abstract, 58; arbitrary bond between certain and signifier, phonetic, 18; bond with signifier, 17 ; classification system of, 8; as concept, 9; as part of double role in hieroglyphic signs, 30; floating, 10; iconic, 51; iconic, unsuccessful "banishment" of, 42; latent, 58; linguistic, 56, 58; phonetic, 40-3, 45-8, 50-1; pictorial, 58; pictorial, discarded, deconstructive powers in, 47 ; preferred, 10, 47; primal additional, carried by scorpion, 79; relationships with signifiers, image, concept, and context, 39; Saussurean, 30; Saussure's graphic representation of, 28; select, 40 ; select pictorial, 40-3, 45-7, 50-1; semantic, 47; vs. signifier, phonetic and pictorial, 8; sought-for, $35,44,47,52$; two or more in hieroglyphic words, 39

Signified-elect, 31-5

Signifier, arbitrary bond between phonetic and signified, certain, 18; bond with signified, 17; composite, 76; "covert" phonetic, 44; "double", hosts two different components, 39; "double written", 44; fixing of iconic picture to, 16-7; hieroglyphic, 56; iconic, unsuccessful "banishment" of, 42; linkage with select concept, 9; phonetic, 40-3, 45-8, 50-1; phonetic and pictorial, 8; pictorial, choice of, 31 ; pictorial, preservation of metaphor by, 59; relationships with signifieds, image, concept, and context, 39; resilience of, 79 ; Saussure's graphic representation of, 28; vs. signified, classification system of, 8 ; as "sound image", 9; two different in hieroglyphic words, 39; visible, written, within the hieroglyphic system, 18; "written", referring to "phonetic", 29; written, of ancient Egyptian, as images in, 29; written, as part of double role in hieroglyphic signs, 30; written iconic, 40-43, 45-8, 50-51, 66; written, "non-motivated", 43

Signifier-signified, within word, relations of, 54

Signs, hieroglyphic, "iconization" of, $11 \mathrm{n}$

Sinuhe Tale, 16n

Size, and cognition, 24

Sobk, 101, 103-4; "ruler of the river", conceptualized as, 104; hymn to, 104

Sobk-Re, 117

"Sound image", Saussurean, 39

Space, conceptual, institutional shaping of, 31

Speech, abstract units of, search for possible representations of, 17

State, Egyptian, formation period of, 10

Stimulus, metonymical responses to, 55-6

Structure, root, Egyptian sensitivity to, 65

Structuring, semiotic, efforts in, 4 
Superimposition, 121

Support, triadic, 6-7. See also picture; emblem; phonetic sign.

System, codification, 7-11

System, hieroglyphic, written signifier within, 18

System, hieroglyphic script,

19-22; as complex metaphorical construct, 22-4

System, hieroglyphic sign, operation of, 38

System, hieroglyphic thought, 42

System, iconic hieroglyphic script, $4 \ln$

System, semiotic, as polysystem, 7

Taweret, 117

Tefnin, R., 6n

Terminology, Saussurean, 8, 8n, 80

Texts, Egyptian, translation into

Greek, 27. See also Hermetic tractate. Coffin, 76, 89n, 104,

105n; Execration, 80; funerary, 49;

Pyramid, 75n, 76, 78, 97, 101, 104

Thoth, 101

Thought, figure of, 30

Tool, as signifier for its owner,

66-7

Trail, phonetic, 40-3, 45-8, 50-1, 66

Trail, pictorial, 40-3, 45-8, 50-1, 66

"Transpositions", cognitive, 110

Tree-goddess, 117; iconography indicates deep-structure conceptual metaphor in, 125; peeping goddess, 120 ; pictorial examples of, 119 ; tree and goddess represented separately, 120; tree becomes part of goddess' hairdress, $120 \mathrm{n}$; various representations of, 120-3
"Tree-Goddess" metaphor, combined sycamore-palm in, 122 ; cow version of, 122 ; female goddess grows from trunk of tree, 121-2; interaction processes and image schema of, 11425; interaction in, 121-2; palm tree in, 121; superimposition in, 121 ; with human limbs, hands, and a breast, 121

Tree, Porphyrian, 54n; "ad hoc", 84

Tsur, R., 52n

Turner, Mark, 119n, 121n

Tuthmosis III, tomb of, 121

Two-dog palette, 6

Ullmann, 72n

Unas Causeway, reliefs at, 110-11

Vandier, J., 44n te Velde, H., 78n, 102, 115

Vernus, P., 19n, 74n, 75n, 112

Vycichl, W., 96n

Weeks, Kent, 10n

Wernu, inscription of, 24, 67; tomb of, example of metaphorical construct from, 22

"Wilde Semiose", 34-5

Word, double representation of, 44; hieroglyphic, contents of, 39. See also Signifiers and Signifieds. Hieroglyphic, as complex metaphorical construct, 54-70; vs. icon, classification system of, 8 Writing, "rule-free", cannot be described as, 43; transition from prewriting, $3 n$

Zeidel \& Kasher, 12 


\section{INDEX OF EGYPTIAN WORDS DISCUSSED IN THE TEXT}

$3 b$ (panther), 58

imm, 85

ims, 95,97

sht, 86n, 95, 99, 99n

3htyw, 68

$3 d, 94,97 \mathrm{n}$

iзyt, 89

isw, 89

i3bt, 93

$i, k b, 92$

i kkbyt, 92

i'n, 101

$i^{\prime} r, 91$

i'h, 101, 102n

iw, 112

iw (dog), 85

iw (bubal), 80

iw $3,86 \mathrm{n}$

iwi, 93, 98n

iwn, 23

$i b, 32$

ib, 110

$i b i, 45$

$i-b-r, 92$

Imn, 69

imnty, 93

in, $21,77 \mathrm{n}$

Inp, 44

inm, 89

ink, 104

ir-ht, 111

irt, 32n

ih (3hw), 103 ihmw-wrd, 118

itn, 101 , 102, 102n

itrw, 101

itw, 87

idi, 92

idyt, 89

idnw, 69

' $t, 86 \mathrm{n}$

't, (limb), 91

', (ass), 85

'wt, 86n

'wt, 45, 86n, 93n

'wy, 23

'wn, 103

'wnt, 91

'prw, 87

'f' (i'f), 94, 94n

'ff, 85

'nh, 75n

'nh, (person), 87

'nh, (mirror), 91

'nht, 85

'rt, 85

'rrwt, 85, 90

'h, 16n

'hm, 103n

's, 69

'k $m$ sšw, 38,39

w3d, 70

$w b ; 98$

wn, 60n

$w h^{\prime}, 91$

wš, 92 
$w t, 87$

b3, 42, 76, 76n, 119

bin, 88

bik, 16n, 58

pt, 100, 102n

pihd, 95, 97

pn', 97

pnw, 110

pr, 46, 86n

pri, 47

prt, 93n

phph, 102

$m ;, 23$

$m i-h s ;, 61$

$m 3 i, 58$

miw (mit), 101

$M n$ hpr R', 33n

$m n i, 98 \mathrm{n}$

$m r, 102$

$m s, 20,85,110$

$m s h, 101$

msti 'prt, 98

$m s d r, 32,68,69$

$m t, 85$

$m d h, 67$

nini, 44, 77n, 85, 85n

$n^{\prime} i, 92$

$n^{\prime \prime}, 94,96$

N'r $m r, 5$

$n$ 'š, 103

$N w t, 101$

$n w$ (bowl), 21, 21n

$n w$ (hunter), 92

$n f t, 93$

$n m^{\prime}, 102$
Nht $n$ Nwt, 121

$n$ ňni,102

nkm (bold), 92

nkm (suffer), 103

$R^{\prime}, 33 n, 89 n$

$r m t, 31$

$r h, 93 \mathrm{n}$

rsf, 91n

hiy, 92

him, 85

hwnt, 89

$h b, 91$

$H p, 51,101$

hmt, 67

hmww 67

hnk, $51 \mathrm{n}$

hnt, 95

hnty, 95

$H r, 62$

$h r$ (face), 111

$h s, 94 \mathrm{n}$

hst, 110

htp, 34n, 59

histyw, 67

hm (demolish), 91

hm (dry), 94

$h m w, 94$

hnms, 20n

hn, 94n

hns, 95, 95n, 98

hnš, 60n

hpr, 33n, 48, 49, 49n, 59

hprr, 101

Hprr, 101

hnty, 98n 
hdi, 98n

hri-hbbt, 111

$s$ (door bolt), 23

$s$ (man), 31

st $m s, 85$

$s$ (duck), 17,40,46

s? (son), 41, 72, 75, 75n,

$76,77,110$

$s i b, 59,62$

$s i k, 103,104,105$

$S ; k, 104$

s'h, 23, 59

swt, 93

swht, 76, 76n

Sbk, 101, 105n

$s m_{3}, 23$

sm3 (bull), 61

smi, 91

sn, 19n, 65

snb, 91

snhm, 23, 59, 71

$s r, 94,95$

Srt, 50

shn, 105

shty (netman), 67

shty (peasant), 67

shnw, 102n

skn (snk), 94

$s \check{s}, 66$

$s \check{s}$ (record), 109

$s \check{n}, 42,43,46,85$

$s \check{s} d, 60,62,94,97,103$

sšd (window), 95, 98 sty, 93n

stwt, 57

$s d m, 32,68,69$

sdmi, 87

$s d r, 32,85$

šw, 88

šwt, 89,90

sp, 92

šmsw, 16n, 66

šndwt, 91

knd, 94, 96

kri, 102

$k ;, 58$

k: nht, 19, 62

k: rnp, 61

$\mathrm{km}, 70$

ksy, 95

g33, 97

T3-Mhw, 12n

tp, 32

tbwty, 85

tms, 70, 70n

tsm, 32, 33n

dit (infinitive), 109

$d w 3 t, 99$

$d w$ styw, 99

dpy, 61

$d p t, 32$

dmst $\mathrm{Hr}, 61,62$

$d \check{r}, 69,69 \mathrm{n}, 70 \mathrm{n}$

$d s ̌ r t, 69 \mathrm{n}, 70 \mathrm{n}$

dnd, 94, 96 